3.

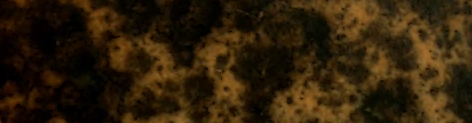

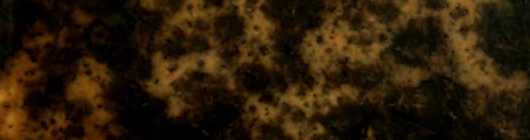

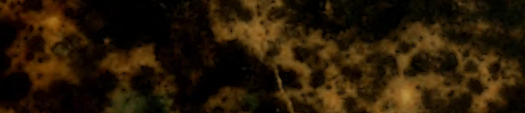
s

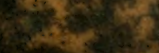

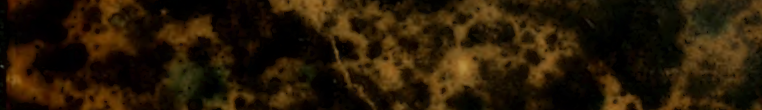

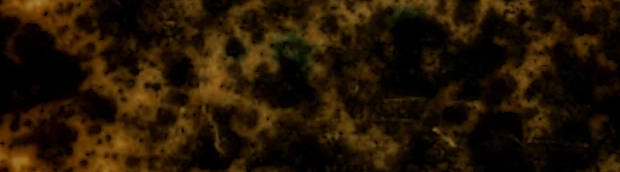

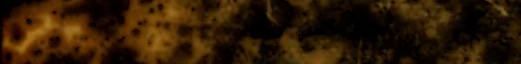
rat

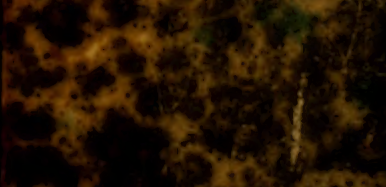

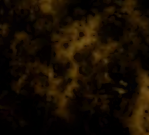








\section{BIBLIOTHĖQUE DE POCHE DU}

IATUEAIISTE

X III 

Bibliothèque de poche du;Naturaliste. - XIII.

\section{FLORE \\ coloriée de poche \\ (1) \\ LITTORAL MÉDITERRANÉEN de Gênes à Barcelone \\ Y COMPRIS LA CORSE}

139 planches coloriées et 5 planches noires représentant 144 espèces

\section{TEXTE \\ Par O. PENZIG}

Professeur à l'Université de Gênes.

DESSINS

Par $\mathbf{M}^{\text {me }}$ HÉRINCQ et MM. CUISIN et JOBIN

\section{PARIS}

LIBRAIRIE DES SGIENGES NATURELLES PAUL KLINCKSIECK 3, RUE GORNEILLE, 3

1902

Tous droils réservés. 


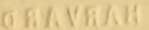

visesisvinu

YYIAFIBI.

- P4r

MAY 251904

Lerbarium. 


\section{AVANT-PROPOS}

Ce qui frappe le plus les touristes, venus pour la première fois sur le littoral de la Provence et de la Ligurie, c'est le changement de végétation qui se manifeste à leurs yeux, brusquement, lorsqu'arrivés par l'Italie septentrionale ils ont franchi les Apennins, ou peu à peu, quand après avoir parcouru la vallée du Rhòne, ils dépassent la ligne des Cévennes.

Rentrés chez eux, ces mèmes touristes, en décrivant les merveilles de la « Riviera (1) à ceux qui ne la connaissent pas, rappellent les impressions que leur ont causées les oliviers, couvrant d'un manteau vert grisàtre les pentes ensoleillées des collines et des basses montagnes; les sombres cyprès se détachant nettement sur les fonds clairs du paysage méridional; les Joois parfumés où fleurissent ef fructifient les orangers. les cédratiers et les citronniers; ils parlent avec enthousiasme des majestueux palmiers, des gigantesques agaves, des monstrueux figuiers d'Inde; et, afin de colorer leurs récils d'une nuance scientifique, ils ne manquent généralement pas d'ajouter que ces plantes sont a caractéristiques o pour ce Littoral.

Or, on étonnerait beaucoup la plupart de ces voyageurs en leur disant que cet ensemble si harmonicux el, pour ainsi

1. A l'itranger la Cóte didzur nest commur que sous le nom de Rivieru, dénomination moins repandue en France. 
dire, inséparable des vues de rettr région n'est autre qu'un mélange d’espèces régétales très hétérngènes, originaires de quatre continents différents, artificiellenent réunies par la main de l'homme, et toutes introduites à des époques historiques plus ou moins reculées.

Parmi ces plantes si souvent appelćes a caractéristiques o du Littoral, aucune n'y est vraiment indigène, sauf peutc̀tre l'olivier et le figuier, dont nous ne royons toutefois aujourd hui que des exemplaires cultivés. Ainsi les cyprès et les pins-pignons sont originaires de l'Orient; les dattiers ont été importés de l'Afriçue par les Sarrasins; les orangers et les citronniers sont venus de la zone subtropicale de l'Asie; les figuiers d'Inde et les agaves de l'Amérique centrale; les ficoïdes, dont les lourds festons lécorent les murs des jardins, proviennent du Cap de Bonne-Espéranee, etc. Qui pourrait s’imaginer l'aspect des bords de la Méditerranée dépourvus de ces superbes végétaux que nous sommes si habitués à $\mathrm{y}$ admirer maintenant?

La flore spontanée et vraiment caractéristique de la Prorence et de la Ligurie est bien différente de celle que lhomme y a introduile pour son asrriment ou pour son utilité. Mais cette végétation primilive ne s'est conscrvée intacle quà de rares endroits, loin des grandes rues ballue: par les étrangers : c'est particulièrement sur les sables de la plage, parmi les rochers près de la mer, dans les maquis, les garrigues ou fourrés d'arluustes toujours verts, dans le's bois de chènes à feuilles fersistantes, de pins maritimes el de chàlaigrniers, ver's le sommet des montagnes où apparaissent encore les caractères de la flore indigène.

D'ailleurs, en portant son attention sur les humbles plantes qui croissent le long des chemins ef des sontiers, le louriste: du Yord ne larde pas à s'aperevoir que, mème dans les régrions les plus fréquentées du Lilloral, la flore diflere très sensiblement de celle qu'il avail coulume de voil dans le's champs, les bois et les prairies de son pays. 
Le Français éprouvera moins de surprises, car un grand nombre des espèces figurées se retrouvent chez lui dans cerlaines contrées jouissanl d'un hiver clément.

Notre intention est done de faire conmaitre ou de rendre plus familières aux visiteurs de la a Riviera o les plantes qu'ils auront occasion d'y rencontrer le plus fréquemment. Nous espérons que ce petit volume sera bien accueilli du public, vu qu'il n'existe encore aucun ouvrage apte à aicler les profanes en botanique dans la connaissance des plantes du Midi.

Nous arons mentionné, pour toutes les espèces figurées, leurs noms vulgaires en diverses langues, ainsi qu'en provençal et dialecte gènois ou ligurien. D'autre part, nous avons cru bien faire en consacrant quelques pages et planches à celles des plantes cultivées, qui se rencontrent le plus souvent, ou qui attirent surtout l'attention des royageurs par leur structure et leur aspect : pour celles-ci, comme pour les espèces spontanées, nous arons indiqué leur provenance, leurs noms et leurs usages.

Gênes, février 1902.

Prof. O. PENZIG. 


\section{CLEMATIS FLAMMULA.}

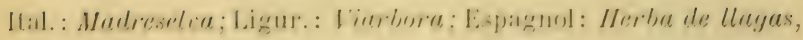
Muelmera; Allem.: Waldrebe.

Ilante vivace, grimpante, a liges samenteuses, ligneuses a la base, qui s'entrelacant comme colles d'une liane, firissent parfois par étouffer ou par ceraser sous leur poids la plante sur laquelle elles s'appuient. 'Tres souvent aussi, la Clématite recouvre les murs des vignobles, des plants d'olivier, elc. $\mathrm{Au}$ printemps, elle est ornéc de milliers de fleurs blanches, de grandeur moyenre, formant de petites étoiles a quatre divisions, mais elle est peut-che encore plus élégante a l'automne, quand chaque flemr a élé remplacée par un plumel de filaments soyeuxargentins, divariqués et entorlillés. Dans cet étal les branches sont très onnementales; et comme ses fruits résistent longtemps sans s'altérer, la plante peut tres bien servir a orner les appartements.

Celte espece est vénéneuse, comme la plupart de ses congénères; el de même que le clemalis Vilalba du Nord, elle peut être employée extérieurement, eomme remède rubifiant el mème vésicaloire. Malgré ces propriélés, dans quelques pays de la Riviera, les paysans mangent les jeunes pousses de ces planles comme légumes, aprés avoir détruit par la cuisson le principe âcre et volatile qu'elles contiennent.

Elle se distingue du c. Vitalba surtout par les feuilles toujours vertes, presque coriaces, plus découpées el a divisions plus petites. 


\section{$-1-$}

Haies, murailles. - flemit en mai al juin.

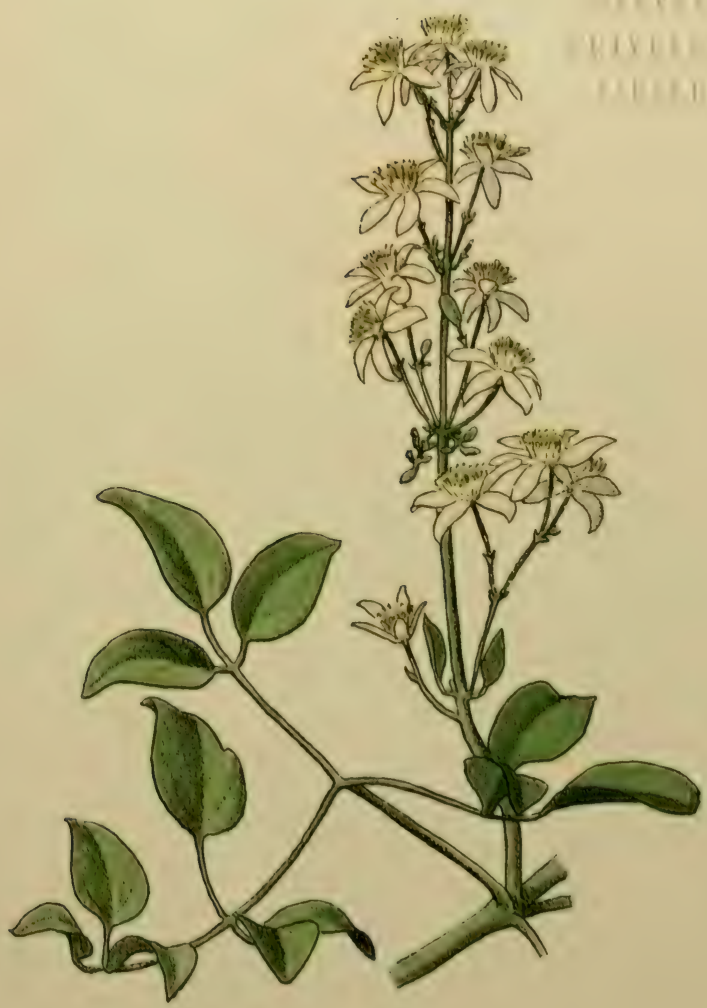

Clematis Flammula.

Frume. Clématite nammile. Prou. Entrevadis, Rivonando. 


\section{$-2-$}

Pelouses ; sous les oliviers. - Heurit de janvier en mars.

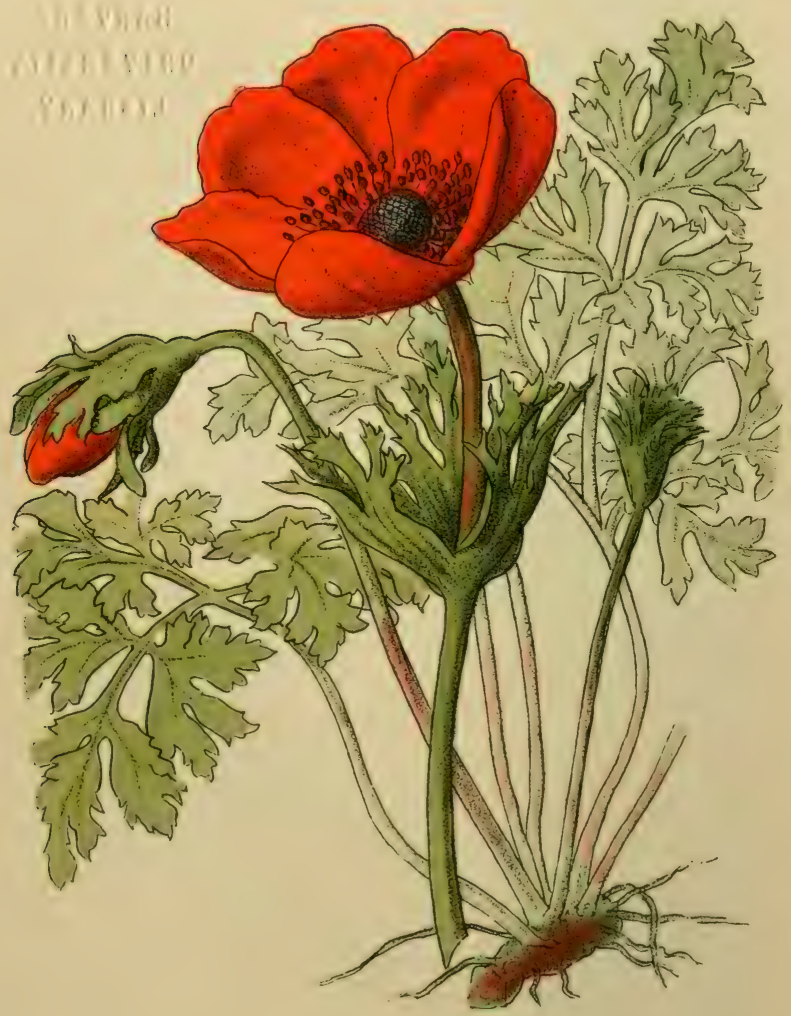

Anemone coronaria.

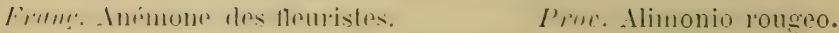




\section{ANEMONE CORONARIA.}

Ital. : Anèmone; Ligur. : Anèbolo; Espagn. : Anèmona; Allem. : Anemòne; Angl. : Anemon.

Plante vivace de 20 à 50 centimètres de hauteur, commune sous les oliviers dans toute la région littorale depuis Gênes, et dans toute la Provence. Il est pourtant difficile pour les visiteurs du littoral de pouvoir admirer cette jolie plante dans sa station originaire, car les paysans et les enfants des lieux plus visités par les étrangers arrachent sans pitié chaque matin les fleurs qui s'ouvrent à l'ombre des oliviers, et en portent de grands bouquets dans les villes. Il y en a de nombreuses variétés, à fleurs écarlates, loses, bleues, pourpres, blanches, avec ou sans tache à la base des feuilles florales; et on ne pourrait trouver pelouse plus jolie que celle formée par toutes ces variétés entremêlées, telle que l'on peut l'admirer dans la villa Hanbury, entre Menton et Vintimille.

Les fleuristes en font un grand emploi pour les bouquets d'hiver; et on commence à cultiver cette espèce même dans les régions les plus septentrionales.

Les souches tubéreuses, presque sphériques, doivent être plantées à l'automne. On en fail une grande exportation de la Riviera aux établissements d'horticulture du nord.

L'Anémone des fleuristes est âcre, vénéneuse, comme toutes les espèces congénères, mais elle n'a aucun emploi en médecine. 


\section{ANEMONE STELLATA.}

Cette jolie espèce d'Anémone compte parmi les premiers messagers du printemps dans le Midi. Souvent déjà au mois de janvier, quelquefois même au mois de décembre, on peut apercevoir ses gracieuses étoiles bleues ou lilas sur le gazon des collines; et aux mois de février et de mar's, toutes les pentes, tous les lieux herbeux en sont parsemés. Elle a la souche tubéreuse, comme l'Anemone coronaria, mais elle est beaucoup plus petite dans toutes ses parties. La couleur des fleur's varie beaucoup : plus foncée, presque pourprée au commencement de la floraison, elle devient ensuite de plus en plus pâle; et les feuilles florales des fleurs épanouies depuis longtemps sont presque entièrement blanches. 
$-3-$

Pelouses sèches des collines. - Fleurit de janvier en avril.

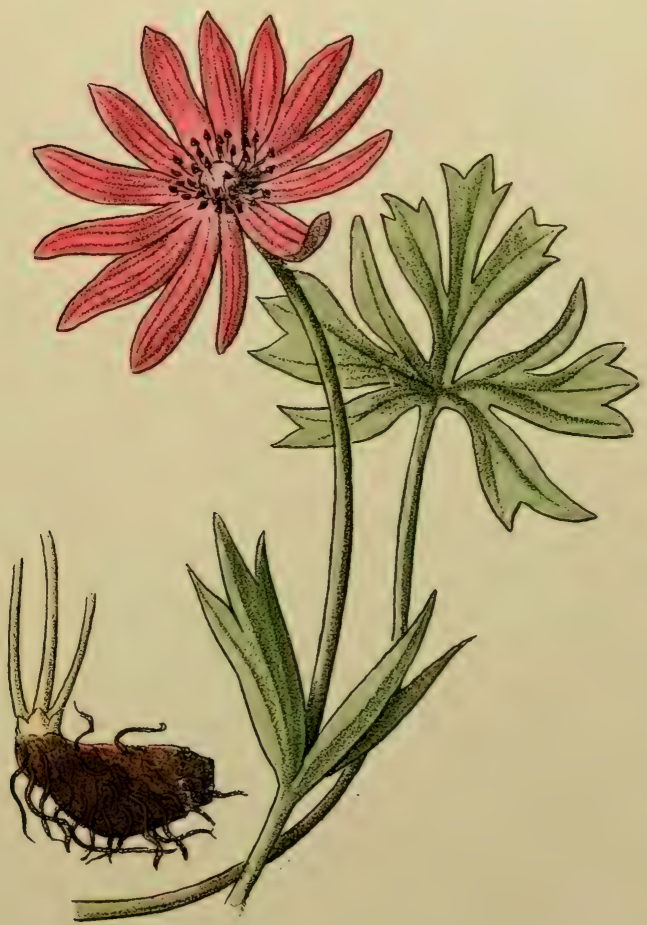

Anemone stellata.

Frans. Anémone étoilée.

Prov. Alimoino estellado.

- Renonculacées. - 
$-4-$

Lieux secs, sous les oliviers. - Flenlil dr janvin on mars.

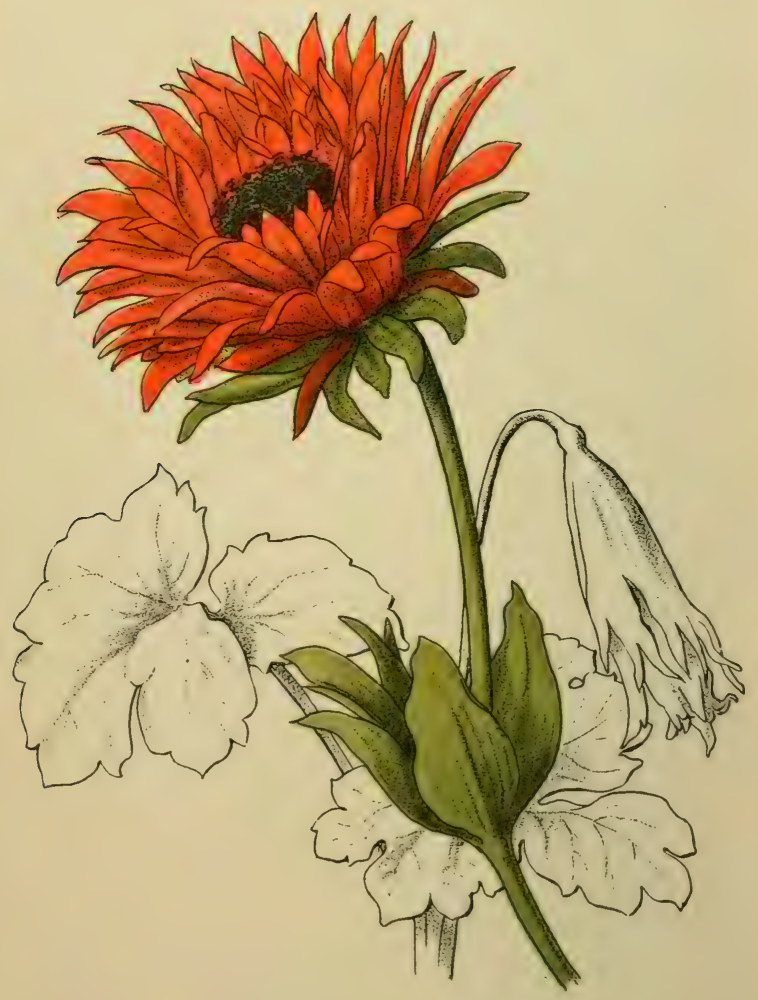

Anemone pavonina.

Frane. Anémone ail de paon.

Prox. Alimonio llammo.

- Renonculacíes. - 


\section{ANEMONE PAVONINA.}

L'Anemone paconina est considérée par quelques auteur's comme étant une rariété de l'A. stellata; mais elle se montre toujours plus robuste, plus haute (jusqu'à 60 centimètres de hauleur); en outre, les feuilles florales y sont beaucoup plus nombreuses et de coloration écarlate. A la base de chaque feuille florale, il y a sourent une tache plus pâle, blanchâtre, de telle sorte que les organes centraux de la fleur (étamines et pistil), qui sont colorés en violet noiràtre, se relèvent remarquablement dans l'auréole centrale. Plus fréquente que la forme à fleurs simples est la variété à fleurs doubles, c'est-à-dire à fleurs dont le nombre des feuilles florales (sépales) a été considérablement augmenté. En même temps, ces sépales deviennent plus étroits, plus pointus et plus pàles, de sorte qu'au point de vue esthétique les fleurs simples apparaissent beaucoup plus belles que ces fleurs monstrueuses.

Cette espèce est exploitée par les fleuristes, comme l'A. coronaria; elle devient de plus en plus rare, à cause de la persécution que lui font subir les paysans. Peut-êlre a-t-elle été seulement introduite dans le littoral des régions plus orientales; on ne la rencontre en effel que dans les terrains cultivés. 


\section{NIGELIA DAMASCENA.}

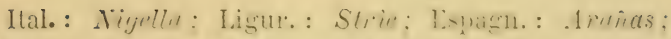

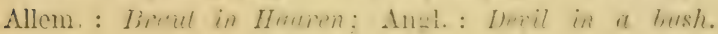

I'lante annuelle de 15 à 80 centimetres le hauteur, à racine pirotante, presque ligneuse; à lige clroite, peu ramifiée. Feuilles découpées en nombreuses dirisions linéaires, presque capillaires. Quatre ou cinq de ces feuilles sont réunies directement sous chaque fleur, à l'extrémité de la tige ou des rameaux, et forment une espèce de grille ou de réseau tout autour de la fleur ou du fruit: c'est de cctte particularité que la plante a pris dirers noms populaires comme : a le diable dans le buisson, la belle aux cheveux dénoués », etc. Ses fleurs, cn forme d'ćtoiles d'un bleu pâle, sont remarquables ainsi que ses gros fruits verts, gonflés, presque sphériques, qui renferment une grande quantilé de semenees noires. opaques, anguleuses et rugneuses. Ces graines ont un parfum particulier, semblable à celui des framboises, et clans quelques pays, surloul en Orient, on en fait usage pour aromatiscr les confiscries. I)ans la pharmacopée de l'Orient, la Nielle a aussi me cerlaine importance, comme une autre espece orientale du même genre, le rigella saliva.

'Très répandue dans les champs cullirés et surtout sous les oliviers de la région méditerranémue, la * patte d'araignée o est souvent cullivée dans les parterres de nos jardins, mème dans les régions les plus septentrionales. 
Champs, lieux cultivés. - lilmil "ll ivil ol mai.

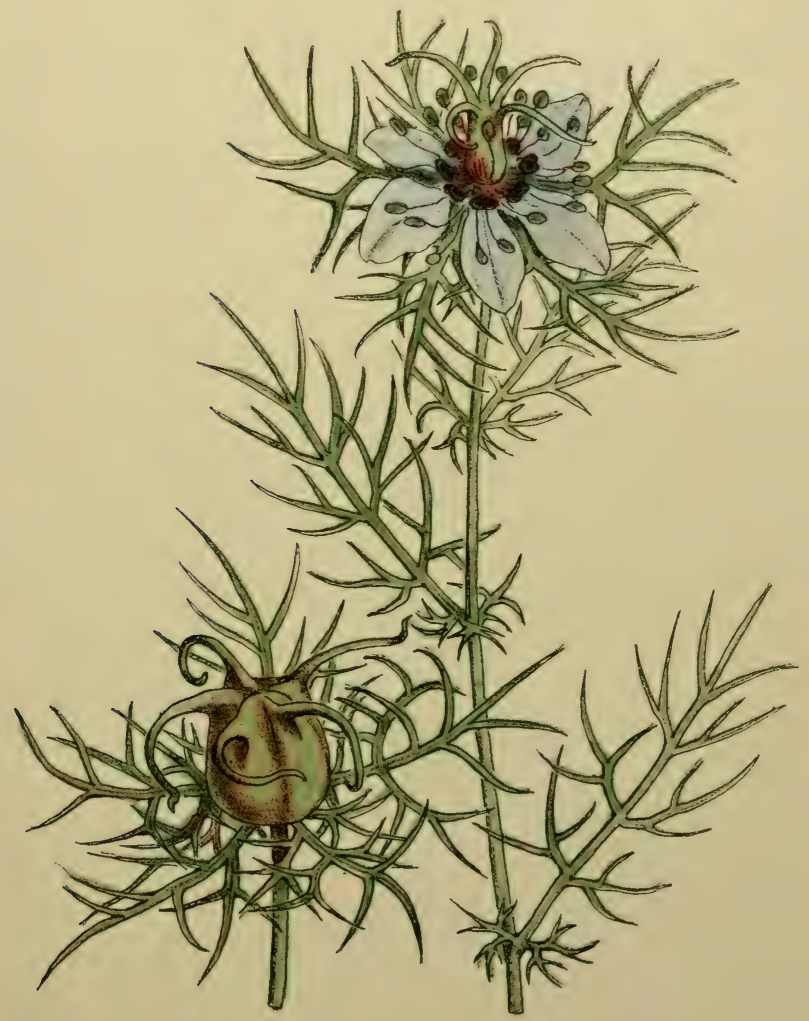

Nigella damascena.

Frune. Nigrllo de Damas. Chereux de Vénus. Prov. Nielo barburlo. 
Haies, murailles, lieux cultivés. Flmult dr firrier en arril.

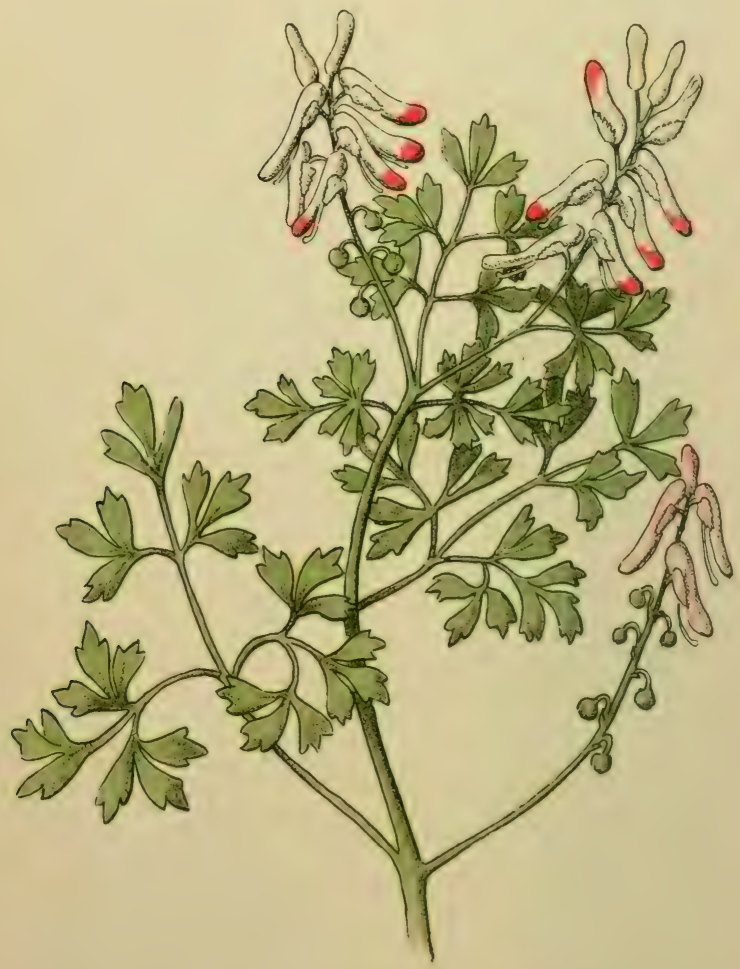

Fumaria capreolata.

firans. Fumetere grimpante. Prov. Ubriago. 


\section{FUMARIA CAPREOLATA.}

Ital. : Fumolerra: Ligur. : Gallelli; Espagn.: Giallarets; Allen. : Rankender Erdrauch; Angl. : Climbin! Fumilory.

Plante annuelle, à tiges glabres, cassantes, un peu charnues; grimpante à l'aide de ses feuilles, dont la base sensible s'enroule facilement autour des objets qu'elle touche, de même que dans la Capucine ou dans certaines espèces de Clématites.

Avec plusieur's autres espèces du même genre, la Fumeterre grimpante orne de ses fleurs les cliamps, les murs, les haies; el c'est surtout sous les oliviers ou sur la terre fertile des plantations d'orangers qu'elle se développe en pleine vigueur. Les petites fleurs, réunies en grappes serrées, varient de teinte, du blanc jaunâtre au rose foncé, avec l'extrémité tachée de noir ou de pourpre; les fruits sont petits, sphériques, très durs et ne s'ouvrent pas à la maturité.

Toutes les espèces de ce genre contiennent des substances âcres ou amères; et, en particulier, le Fumaria capreolata possède des propriétés irritantes. Si l'on frolte la plante fraîche entre ses mains, il s'en dégage une odeur pénétrante, assez forte pour faire venir les larmes aux yeux. Très probablement, l'ancien nom de fumus terrae et le mot Fumaria sont basés sur celte propriété. Très estimées jadis dans la médecine populaire, surtout contre les maladies du foie, les fumeterres n'ont aujourd'hui aucun usage en pharmacie. 


\section{LEPIDIUIM DRABA.}

Espagn. : Capellans, Babols, Pàpolas.

Plante vivace de 30 à 70 centimètres de hauteur, très commune et par troupes dans les champs, les décombres et surtout sur les terrains à peine défrichés, sur le talus des chemins de fer, etc.; dans quelques localités, elle prédomine tout à fait, en recouvrant le terrain de milliers d'exemplaires et formant de grandes taches blanches à l'époque de la floraison. Elle appartient à la catégorie de plantes que l'on appelle * migratrices »; originaire de l'Orient, elle a envahi peu à peu toute l'Europe, marchant le long des routes et des lignes de chemins de fer. Cela s'explique par la petitesse des graines qui sont transportées très facilement par le vent et par les courants d'air produits au passage des trains. Il y a un certain nombre de plantes migratrices qui profitent de ce moyen de transport moderne, comme l'Erigeron canadense, le Stenactis bellidiflora, etc.

Comme tous les Lepidium, le L. Draba contient une substance volatile, âcre, brûlante, qui lui donne un goût désagréable. Parmi ses congénères, nous rappellerons le Cresson Alénois (Lepidium sativum), souvent cultivé comme plante condimentaire, et le Lepidium latifolium, dont les graines entrent dans la composition de la moutarde. 
Décombres, le long des routes. - Fleurit d'arril en juin.

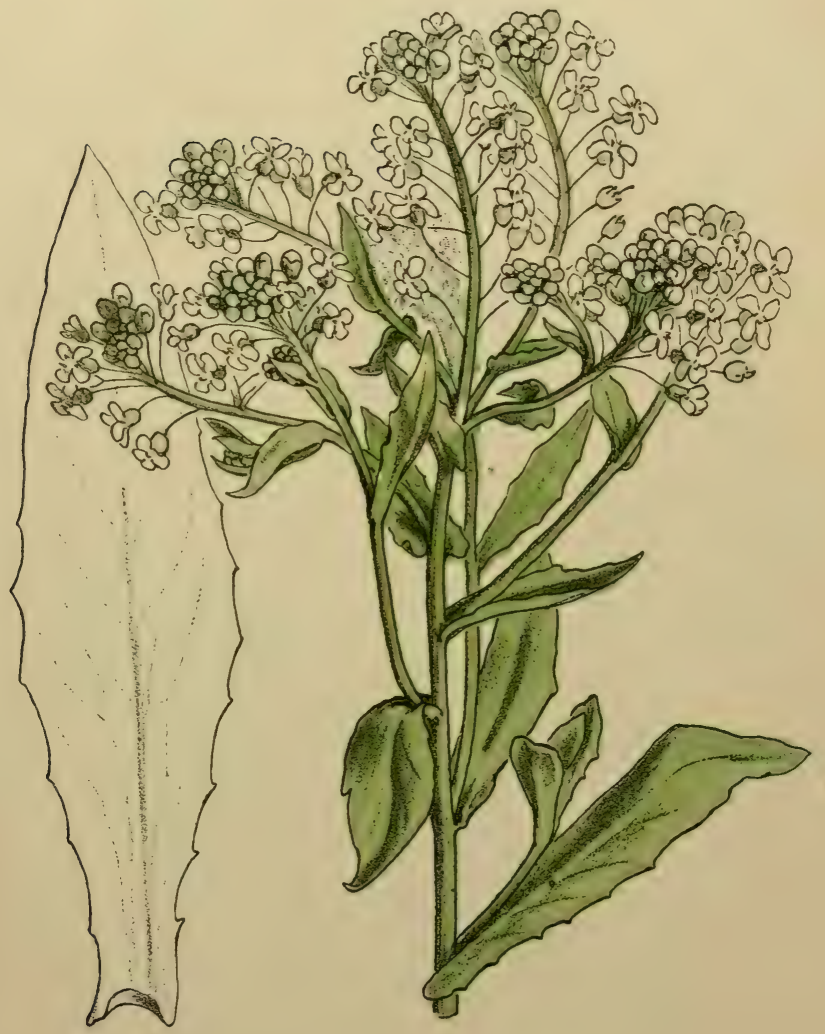

Lepidium Draba.

Frane. Passerage nrave.

Prov. Pan Jlan, Caulechoun. 
$-8-$

Rochers, murailles. - Frmil "linhle "'n mal's.

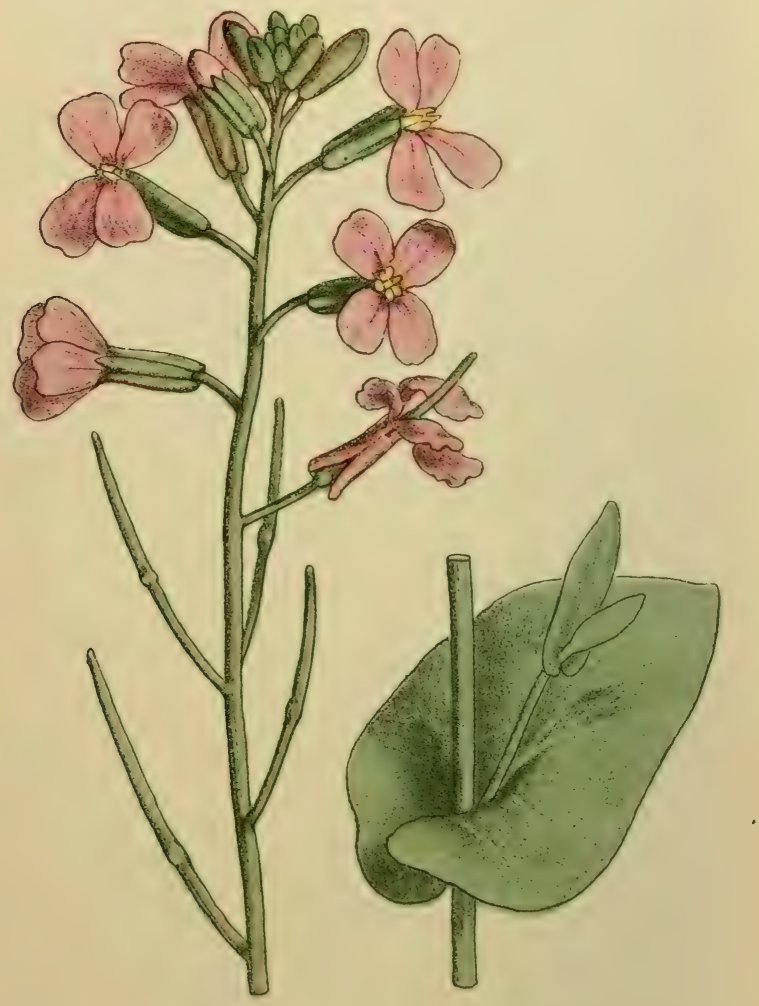

Moricandia arvensis.

Frone. Moricandie des champs. Prov. Iloustardo fèro. 


\section{MORICANDIA ARVENSIS.}

\section{Ligur.: Cavolassi; Espagn.: Collejon.}

Plante vivace, à souche presque ligneuse, très ramifiée, haute de 50 à 80 centimètres. Abondante le long de la route sur la Corniche, entre Nenton et Vintimille, mais localisée presque absolument en cet endroit. On la retrouve aussi sur les rochers de Monaco, près de Marseille, en Espagne, mais elle y est rare. Cette localisation est d'autant plus curieuse que l'on rencontre souvent, le long' de la Riviera, d'autres endroits tout à fail semblables, quant à la conforınation et à la constitution du terrain.

Grâce à l'abondance de ses fleurs, d'un beau violet, el à son feuillage glauque, charnu, le Moricandia se fait remarquer facilement, même par les profanes en matière de botanique: il est presque l'unique ornement des rocailles blanches ou jaunâtres qui bordent la route à l'ouest de Vintimille.

Les habitants en font la récolte pour la donner au bétail; et je crois même qu'ils en mangent les feuilles, cuites comme des choux. 


\section{DIPLOTAXIS ERUCOIDES.}

\section{Espagn. : Rabanisas blancas.}

Herbe annuelle, haute de $15 \mathrm{à} 40$ centimètres, très commune sous les oliviers, dans les plantations d'orangers et dans tous les lieux cultivés, surtout de la partie occidentale du littoral méditerranéen : elle ne dépasse pas, vers l'orient, San Remo, tandis qu'elle est très répandue en Corse, dans l'Italie méridionale, en Espagne et en Algérie.

Les feuilles inférieures de la tige sont étalées en rosette, d'un beau vert frais; les fleurs blanches ou veinées de lilas tournent au violet en se fanant; elles sont assez grandes pour attirer l'altention des passants.

Toute la plante a une odeur désagréable, semblablt à celle de la Rue ou de la Roquette; et selon les expériences faites récemment à Montpellier par le professeur Planchon, elle est vénéneuse pour les brebis, quand, à l'état frais, elle se troure mélangée en proportion considérable à leur pâture. 
$-9-$

Lieux cultivés, ombragés. - Fleurit de mars on mai.

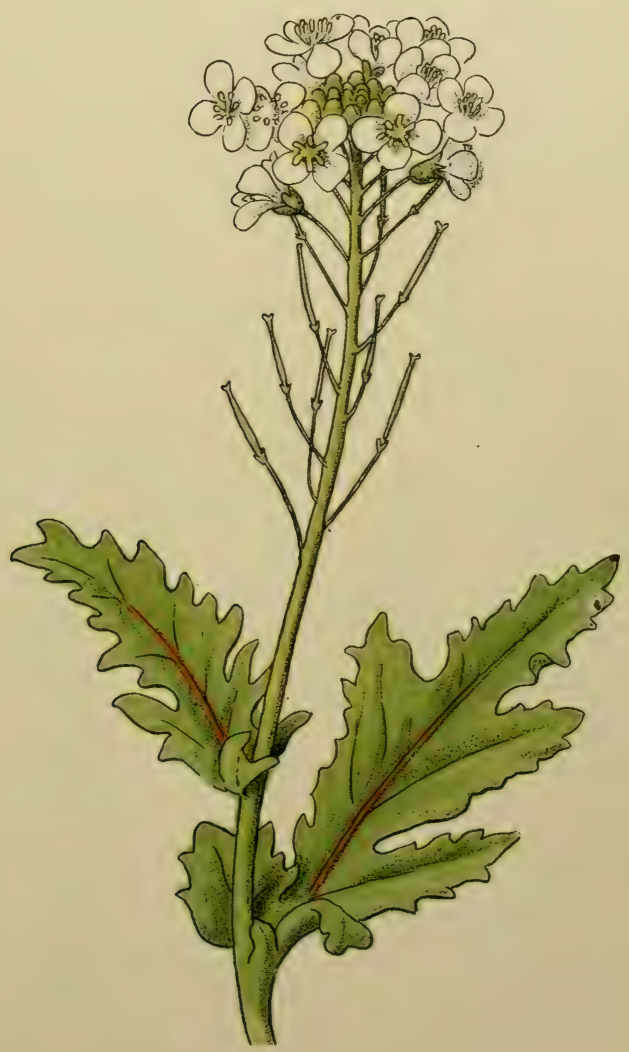

Diplotaxis erucoides.

Frane. Fausse Roquette. Prov. Rouqueto blanco. 


\section{$-10-$}

Sables maritimes. - Flemil en mai of juin.

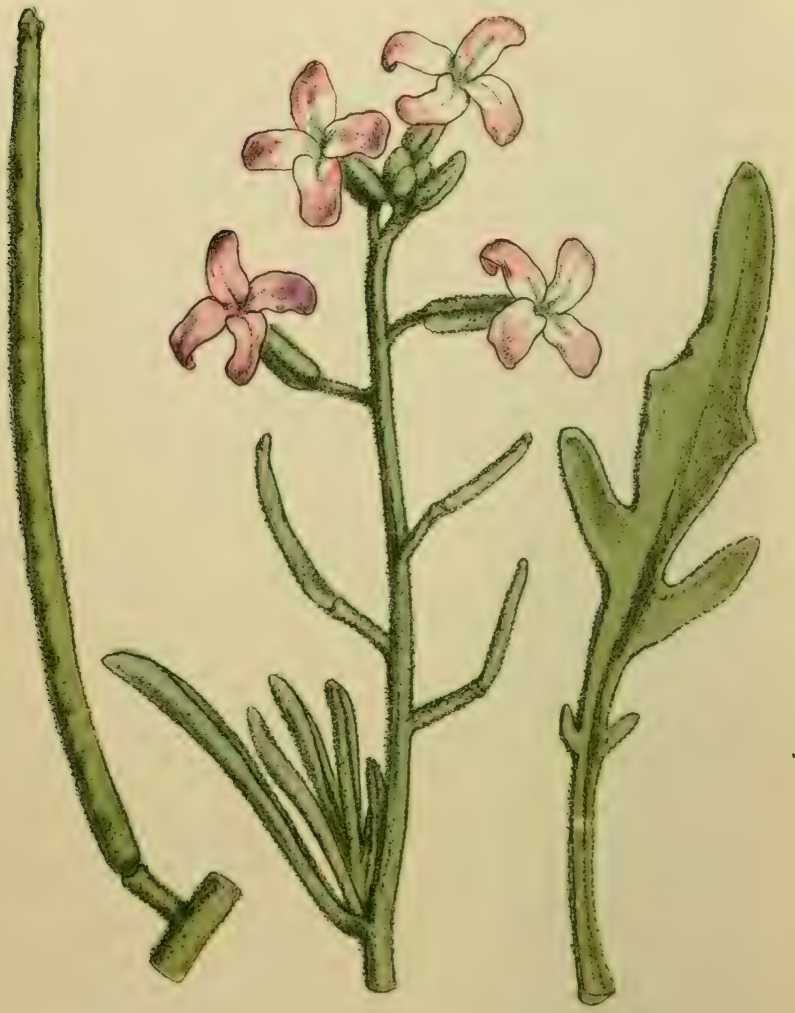

Matthiola sinuata.

Frane. Giroflice dentéc. Prov. Gouranić fer. 


\section{MATTHIOLA SINUATA.}

Ital. : Tülnciueca merinn: Allem. : Strand-Lertioje; Angl. : Sect-Gilliflower.

Plante bisannuelle à racine pirotante; abondante sur les sables marins dans certaines localités de la Riviera (Cannes, Golfe Jouan, Menton, Bordighera). Dans la première année, la plante ne produit qu'une rosette de feuilles allongées, bordées de quelques dents dirariquées. Ces feuilles restent étalées sur le sable, formant des étoiles d'un rert glauque ou blanchâtre, dù à un feutre cendré dont toute la plante est revêtue. Dans la seconde année, au centre de cette roselte, l'on roit s'élever la tige florifère, peu ramifiée, haute de 20 à 40 centimètres et portant des grappes plus ou moins allongées de fleurs purpurines. Les fleur's ressemblent beaucoup à celles de la Giroflée commune (Matthiola incana) qui croît abondamment sur les rochers maritimes escarpés à Marseille, Monaco, Menton, Gênes, et qui diffère du M. sinuatr surtout par la souche virace, ligneuse, par ses feuilles non dentées, et par le relouté de son duret non glanduleux. - La Giroflée commune est cultivée partout dans les jardins de la Riviera, comme dans le Nord; et ses fleurs, souvent dédoublées ct très variées de couleurs, y atteignent des dimensions extraordinaires. Pour l'exportation des fleurs coupées, en hiver, on cultire particulièrement, sur une grande échelle, une variété très florifère, nommée la a Giroflée blanche de Nices. 


\section{ALISSUM MARITIMUM.}

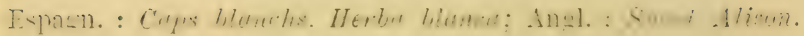

Plante rirace, gatannante, bien connue des visiteurs de la liviera en liver, parce qu'elleest cléja bien fleurie pendant les mois de norembre, décembre el janvier, quand la plupar des anlres vegélaux sont en repos. Partout sur les décombres, anx lieux pier'eux, sur les murailles, sur les rochers maritimes, on rencontre ces jolies fleurs blanches. riunies en grappes denses, exhalant un doux parfum de miel très caractéristique. Aussi les abeilles complent-elles parmi les visiteurs les plus assidus de celle espice. La floraison continue, du resle, pendant loute l'année; et il est facile die voir sur la mème souche des fleurs a peine épanouies et des truits déja mùrs. Ceux-ci sont orbiculaires, comprimes en forme de lentilles, et revêtus du même duvel cenlré, soyeux, qui recouvre toute la plante.

A l'époque de la malurilé, les loux parois convexes du fruit se dílacherit, et apres la dispersion des graines, on peut observer une mince cloisun blanche argentée, qui divisait en deux loges la cavití du fruit. Plus tard, cette cloison disparail aussi, et il ne reste qu une espice de cercau parfailement circulaire, formé par lo bord plus resistant clu fruil. 


$$
-11-
$$

Lieux secs, rochers maritimes - Flnult prespun toutr l'ammin.

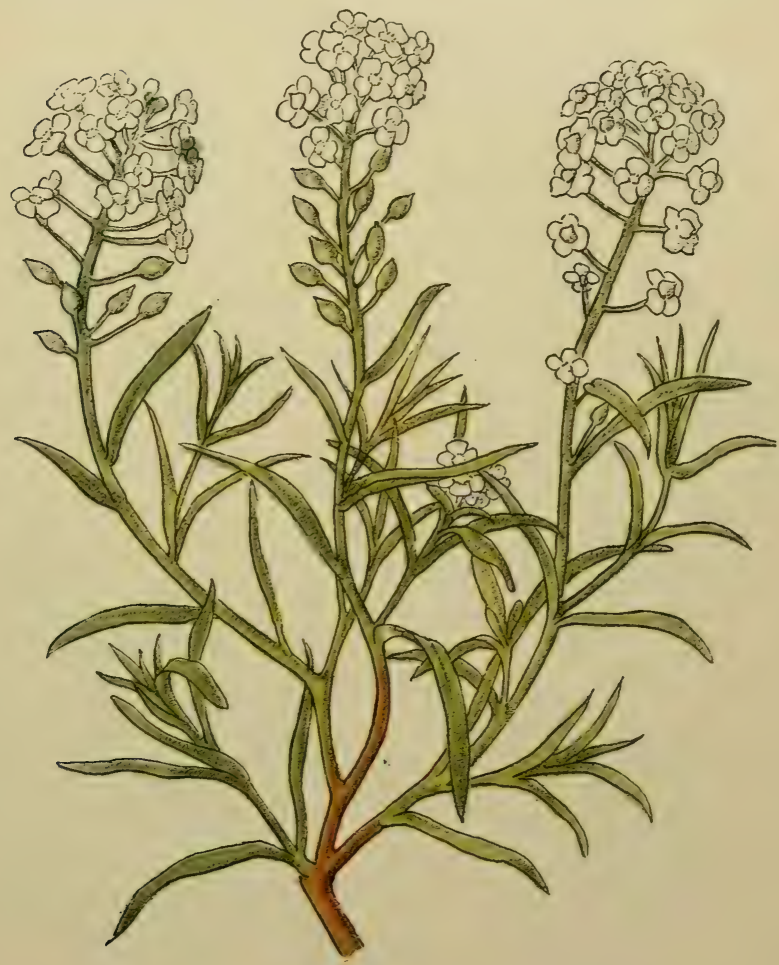

Alyssum maritimum.

Frane. Alysson maritime. Prov. Erbo blanco. 


\section{$-12-$}

Fentes des rochers et des murailies. - Flurit on juillet.

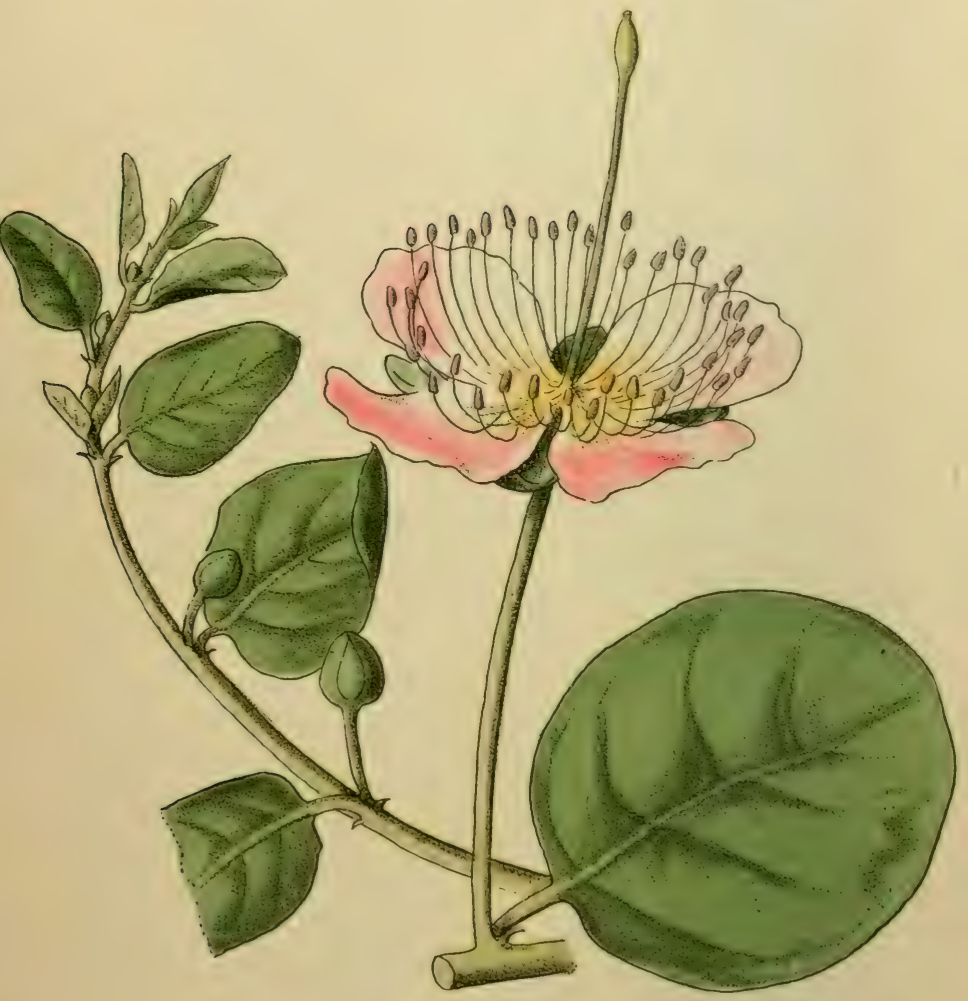

Capparis spinosa.

Frans. Câprier.

Prov. Tapénić.

- Capparidées. - 


\section{CAPPARIS SPINOSA.}

Ital.: Cupperi; Ligur. : Tàpani; Esıagn. : Taparèra ; Allem. : Kapernstrauch; Angl. : Caper.

Plante vivace, à souche touffue, ligneuse, arec de nombreuses branches sarmenteuses, croissant abondamment sur les rochers maritimes, et surtout dans les fentes des murailles. Dans la Provence on cultive le câprier en grand, sur des terrasses formées de murs en pierres sèches.

Les branches sont armées, à la base de chaque feuille, d'épines courtes, recourbées, qui manquent toutefois dans une variété; les feuilles, un peu charnues, glauques, sont souvent attaquées par un champignon parasite (Cystopus Capparidis) qui y produit des taches irrégulières, blanchâtres, un peu saillantes, et qui peut sérieusement endommager la plante. Les fleurs, très grandes avec leurs pétales blancs et leurs étamines nombreuses, teintes en violet ou lilas, complent parmi les plus belles de notre Flore.

Les câpres, condiment bien connu, sont les boutons des fleurs (et non le fruit, comme beaucoup de personnes le croient); on les cueille en été, et on les fait macérer dans le vinaigre. La quantité de câpres récoltées chaque année en Provence (d'après le docteur Sauvaigo) s'élève à plusieurs milliers de kilogrammes. Le fruit est charnu, elliptique, porté par une espèce de pédoncule spécial qui sort du centre de la fleur; il contient de nombreuses graines, qui germent facilement. On peut, du reste, multiplier aussi le câprier par boutures et par marcottes. 


\section{CISTUS ALBIDUS.}

Ligur.: Smizzighe; Espagn.: Estepu, Jarublanon; Allem. : Haidenröschen; Angl.: Cistrose.

Arbrisseau d'un mètre ou d'un mètre et demi de hauteur, à feuilles persistantes, blanchâtres, cotonneuses, avec de grandes fleurs purpurines, semblables aux roses sauvages; très répandu sur les collines pierreuses du littoral, souvent en compagnie de l'espèce suivante ou d'autres espèces du même genre (Cistus salviifolius, C. ladaniferus, C. laurifolius, C. longifolius, etc.). Comme toutes les espèces de Cistus, celle-ci est très riche en matière résineuse, aromatique et astringente; et la médecine populaire en tire profit dans beaucoup de cas. On emploie les feuilles et les fleurs, « Ilerba et Flores Cisti maris, de l'ancienne pharmacopée, contre la dysenterie, et extérieurement, pour g'uérir les blessıres et les plaies. En Grèce on en utilise les feuilles sèches pour faire une infusion aromatique, semblable au thé ou à la tisane de verveine.

En Corse, les Cistes sont très abondants et y portent le nom de Mucchio. On prétend que Napoléon $\mathrm{I}^{\mathrm{er}}$, quand il visitait son île natale, la sentait de loin, grâce à ces plantes. 


\section{$-13-$}

Collines; bruyères. - Fleurit en arril nt mai.

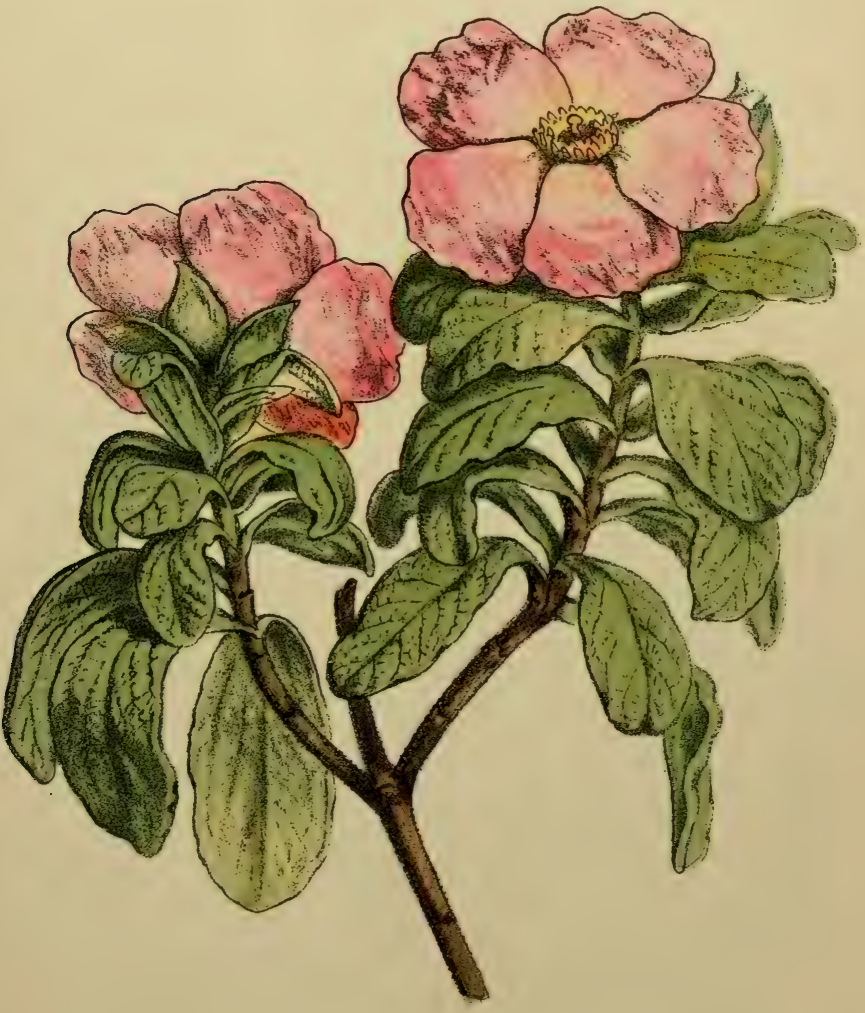

Cistus albidus.

Fiane. Ciste colomnenx.

Prov. Musan. Messugo blaneu. 
$-14-$

Maquis, bruyères. - Flewit en mai et juin.

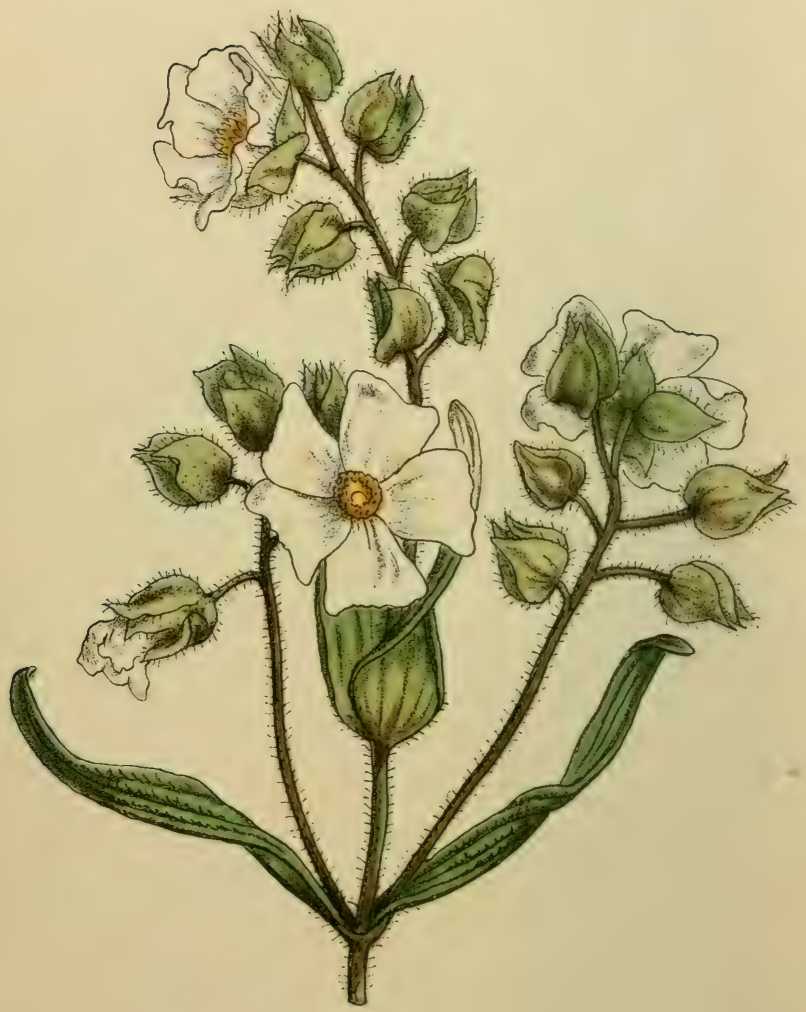

Cistus monspeliensis.

Franc. Ciste de Montpellier. Prov. Muga, Moujès. Messugo négro - Cistacées. - 


\section{CISTUS IMONSPELIENSIS.}

Ligur. : Marrin: Espragn. : Jaguar:o, Estepa negra: Angl.: White Cistrose.

Arbrisseau touffu d'un à deux mètres de hauteur, à feuilles persistantes, coriaces, lancéolées ou presque linéaires, roulées aux bords, semblables à celles du romarin; fleurs d'un blanc jaunâtre, un peu plus petites que celles de l'espèce précéden te, avec laquelle le $C$. monspeliensis se troure sourent associée. Une troisième espèce encore est très commune dans la Riviera, et même plus répandue dans la partie orientale, le $C$. salviifolius, très semblable par la constitution des fleurs au $C$. monspeliensis, mais avec des feuilles plus larges, rugueuses, semblables à celles des sauges.

Ce sont surtoul les différentes espèces de Cistes, qui avec leur parfum fort résineux, embaument l'air de la Prorence, de la Riviera, de Nice, de la Corse, on les sent à grande distance sur la mer, arant même d'aperceroir les côtes. Plusieurs espèces, comme le $C$. creticus et $C$. ladaniferus, fournissent aussi à la médecine une substance résineuse, très appréciée autrefois, et connue sous le nom de Ladanum. 


\section{SILENE ITALICA.}

Plante vivace, à tiges herbacies, droites, de 50 centimètres à un mètre de hauteur. commune dans les bois, dans les haies de la zonc littorale et sur les collines.

'Toule la plante est fortement visqueuse par la présence de certains poils glanduleux; l'inflorescence surtout en est munie abondanturent. Ainsi il est très facile de roir collées à la surlace des tiges et des pédoncules de ce silène une grande quanlité de pelites mouches, de mouchernis, de fourmis : c'est une vraie plante attrape-monche, qui est aussi utilisée, comme les autres plantes visqueuses, par exemple Inula viscosa, Drosophyllum lusitanicum par les paysans pour délivrer les appartements des mouches, pendant l'été. Notre Silène pourtant n'appartient point à la calćrorie des plantes si curieuses, dites plantes cariniores, qui tuent et dérorent les insectes et les autres animalcules dont elles ont pu s'emparer : dans nolre cas le revètement risqueux est une simple arme de défense contre les insectes nuisibles, en les empechant d'arriver; en grimpant, jusqu'aux fleurs. Il y a plusieurs autres espèces de Silènes, qui atteign-11t le même but par un moyen un peu différent, c'est-à-dire par la production d'un anneau, plus on moins large, de matière gluante, visqueuse, nvire, au-dessous de chaque noud de la lige, toul à fait comme les anneaux de goudron, que nos paysans appliquent autour des tiges des pommiers, pour les préserver des chenilles. 
Bois des collines; sous les oliviers. - Flemrit en mai.

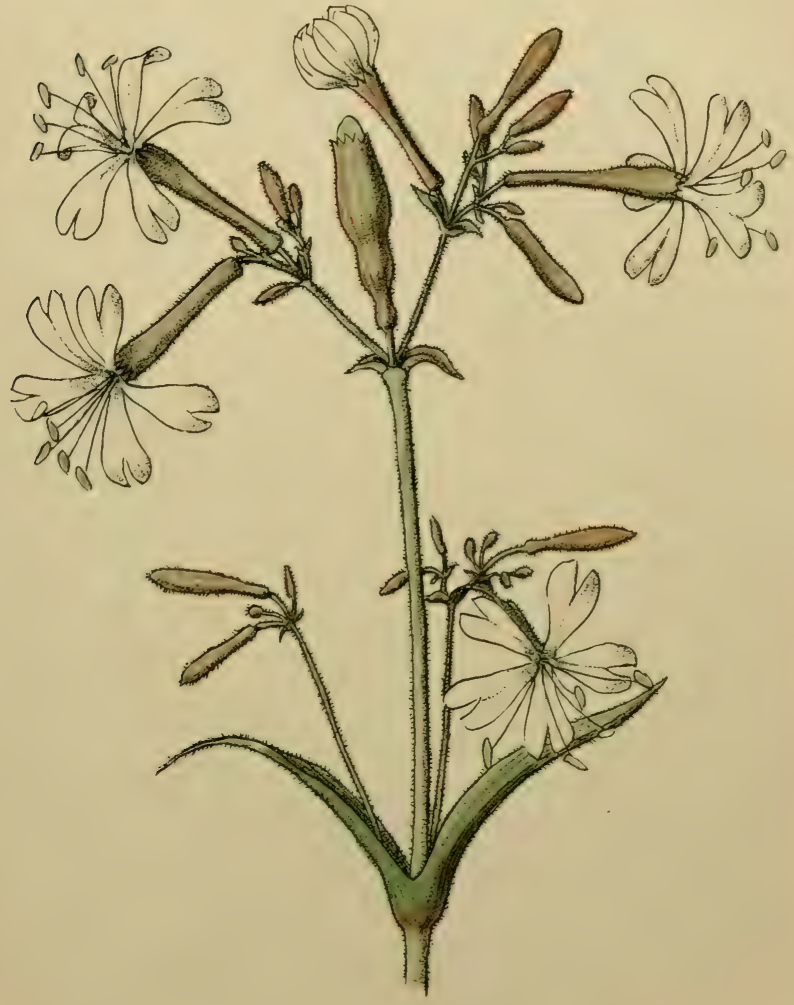

Silene italica.

Fronç. Silène d'Italie.

Prov. Crenihet ler. 


\section{$-16-$}

Sables maritimes. - linurt "n mai " juin.

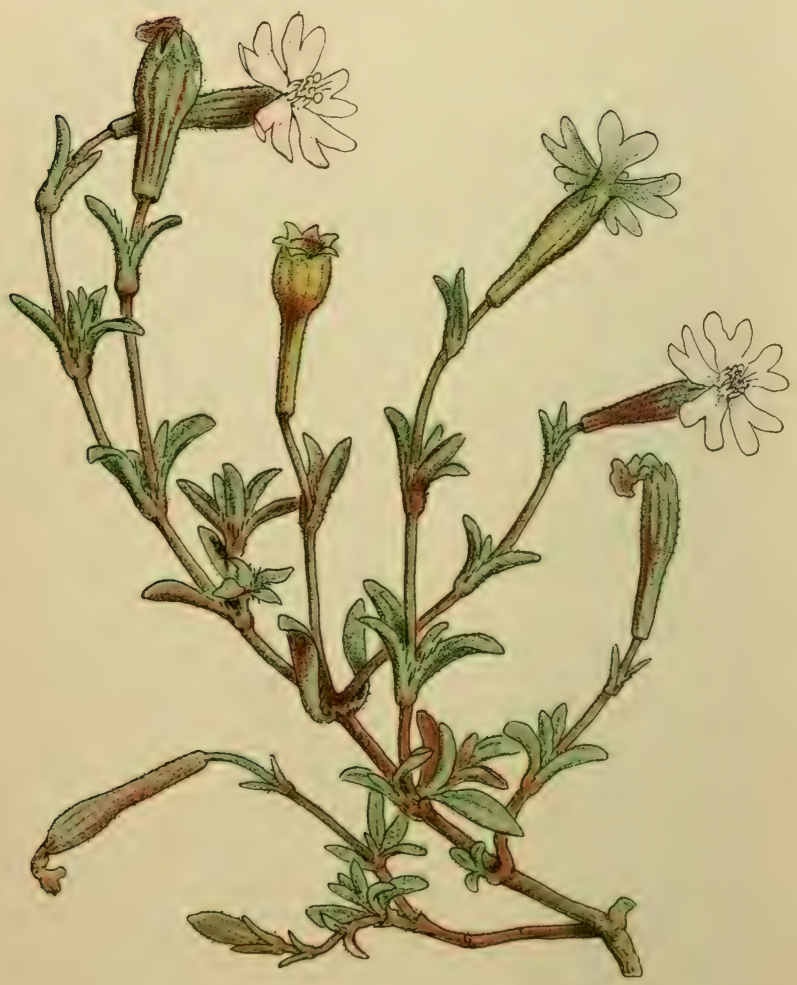

Silene sericea.

Frans. Silène soyeuse.

Prov. Cournihet fer. 


\section{SILENE SERICEA.}

Herbe annuelle, à racine pivotante, souvent très longue, à tiges étalées ou courbées, droites à l'extrémité. Çà et là, au bord de la mer, sur le sable fin de la plage. Les fleurs, d'un beau rose, sont ouvertes seulement aux heures de grand soleil - par opposition à celles de beaucoup d'autres espèces de Silènes, qui ourrent leurs fleurs uniquement pendant la nuit, le soir, ou bien quand le ciel est couvert de nuages. Le Silene italica, figuré à la planche $1 \mathrm{~b}$, est de ce nombre, comme le $S$. noctiflora, S. nocturna, etc. La raison de cette différence est à chercher dans la nature des insectes habitués à visiter les fleurs des diverses espèces de Silènes, et qui, sans le vouloir, favorisentleur fécondation, en transportant d'une fleur à l'autre le pollen des étamines aux organes femelles. En effet, pour les Silènes noctiflores, ce sont des papillons nocturnes qui viennent en chercher le nectar et aident à la fécondation, tandis que notre Silene sericea est fréquenté par les abeilles et par des papillons diurnes. 


\section{DIANTHUS LIBURNICUS.}

Ital. : Garofano a maz:elli; Ligur. : Cianuefuni de S. Piero; Espagn. : Clavell; Allen. : Buschenclke; Angl. : Clove pink.

Nous trourons fréquemment dans la Flore du littoral deux espèces d'œillets qui peurent être considèrées comme les parents les plus proches et, peut-être, comme les types sauvages des deux sortes d'œillets cultivées communément dans nos jardins.

En effet, le Dianthus liburnicus, figuré sur la planche ci-contre, et qui est très répandu sur les rochers maritimes et dans les lieux secs, pierreux de toute la région littorale de la Riviera, est très roisin de l'OEillel-des-Chartreux ou OEillet-de-poèle (D. Carthusianorum) qui se trouve partoul dans nos parterres. Quand on a soin de le cultiver dans un bon terrain, bien fourni d'engrais, il augmente de beaucoup le nombre et l'éclat de ses fleurs.

L'autre espèce (D. virgineus), qui est égralement commune sur les rochers de la zone maritime et qui differe du $D$. liburnicus par ses fleurs solitaires, beaucoup plus grandes, est probablement la forme sauvage de l'OEillet commun (D. Caryophyllus), dont la culture a pris un développement rraiment extraordinaire en Provence et dans la Ligurie occidentale. Ce sont surtout les weillets, dits remonlants, à floraison perpétuelle, dont on cullive un grand nombre de variétés dans le Jidi, en plein air ou sous des châssis, pour le commerce hivernal. La floraison commence en oclobre ou novembre : dans de bonnes conditions un hectare planté d'œillets peut donner un rendement de 2.000 à 6.000 francs. 
$-17-$

Lieux secs, herbeux - Fleurit "n mai et juin.

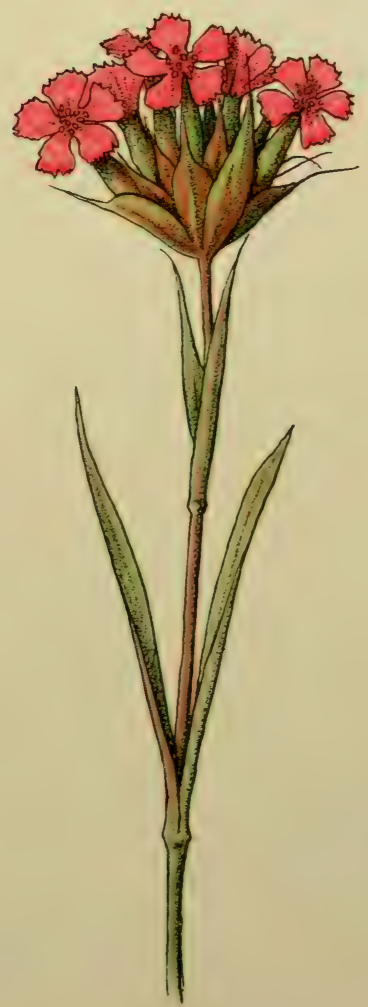

Dianthus liburnicus.

Frans. OEillet de Croatie. Prov. Gidlouflada, Ginouflie de cinq fueio. 


$$
-18-
$$

Rochers et sables maritimes. - Fomrit on jinvien ot firrier.

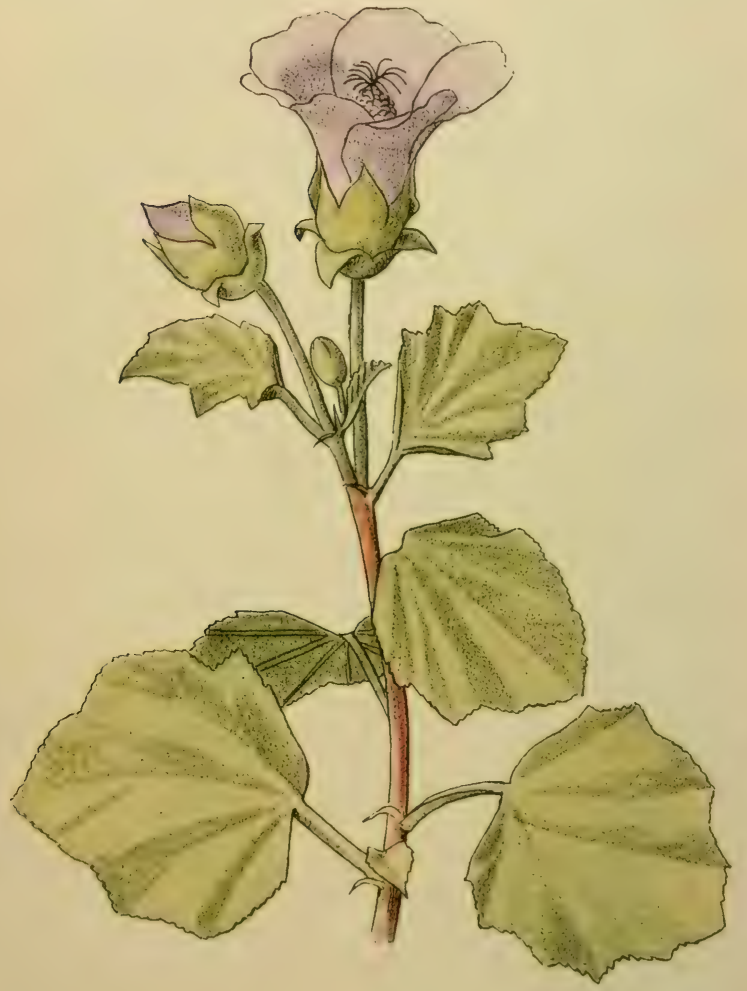

Lavatera maritima.

Frane. Lavalère maritime. Prov. Grando maongo. 


\section{LAVATERA MARITIMA.}

Plante vivace, haute d'un à deux mètres, à tiges ligneuses à la base, herbacées dans la partie supérieure, toute blanche, cotonneuse. Assez répandue sur les rochers maritimes du littoral, mais non partout.

Cette belle Nalvacée, une des plus remarquables parmi les espèces indigènes, a aussi le mérite d'être très printanière: on peut la trouver déjà fleurie vers la fin de janvier; ses fleurs sont assez résistantes et conservent même assez bien leur teinte délicate rose violacée, quand elles sont desséchées arec un peu de soin.

On peut employer les fleurs du Lavatera maritima comme celles de l'Althaea pour en faire des tisanes émollientes, pectorales.

Sous les oliviers, on rencontre çà et là deux autres espèces de Lavatera, L. trimestris et $L$. punctata : celles-ci sont annuelles, à tiges herbacées, grêles, avec des feuilles vertes, hérissées de poils; les fleurs sont assez grandes, mais moins belles que celles du L. maritima . 


\section{LINUM STRICTUM.}

Tandis que le lin des champs et presque toutes les autres espèces de lin qui croissent dans le Nord ont leurs fleurs d'un beau bleu ou rose (a l'exception du L. catharticum, qui les a blanches), il existe, dans la Flore de la région méditerranéenne, de nombreuses espèces de lin à fleurs jaunes.

Parmi celles-ci, l'espèce la plus répandue est le L. strictum : on le rencontre parlout dans la zone littorale, soit sur les sables arides de la plage, soit le long des sentiers, sous les olivier's et dans les champs cultivés, ou il atteint quelquefois une hauteur de 80 centimètres. Par sa tige droile, raide, il est facile à distinguer du $L$. gallicum, autre espèce à fleurs jaunes, petiles, plus grèle, à rameaux filiformes, étalés.

Dans les forêts de pins et dans les bruyères du littoral, on peut aussi admirer cà et là une belle espèce de lin à fleur's très grandes, remarquables par l'éclat de leur teinte d'un jaune très vif : c'est le L. campanulatum. Plus rare encore est le $L$. maritimum, dont les tiges grêles, minces, se trourent parfois entrelacées autour des joncs, dans les lieux marécageux ou sur les rochers humides du littoral. 
Lieux secs, pierreux, sablonneux. - Flurit an arril of mai.

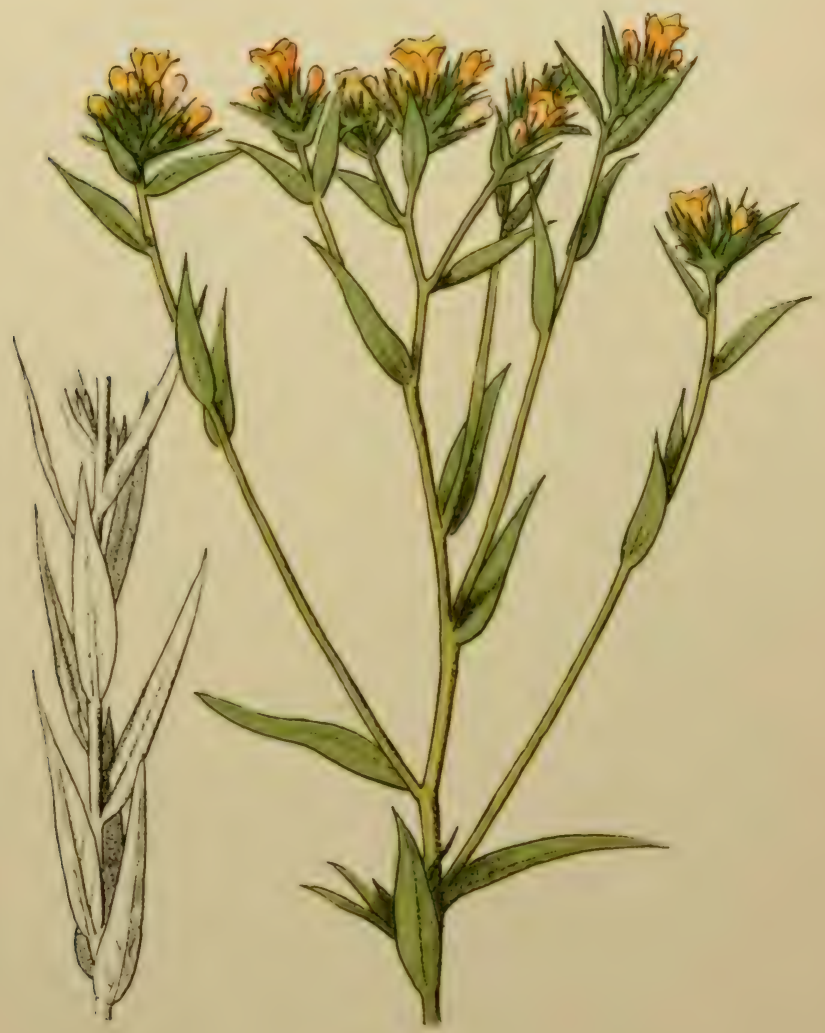

\section{Linum strictum.}

Fivens. Lin laide. Prov. Lin fer. 
Jardins, lieux cultivés. - Fleurit de janvien en mars.

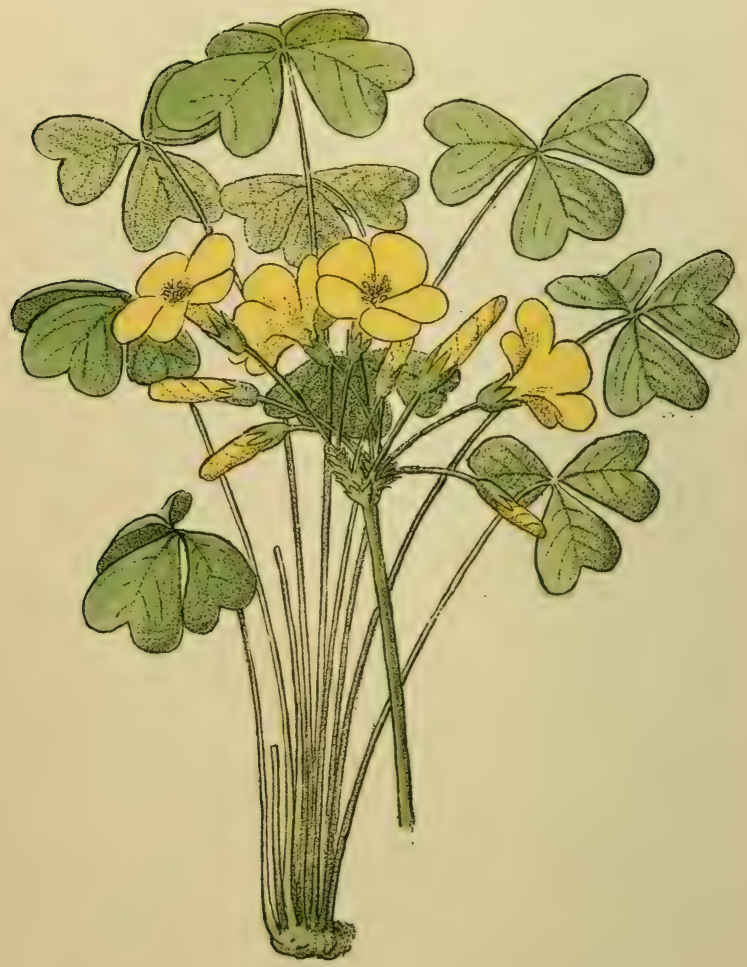

Oxalis cernua.

Franc. Oxalide penchée.

Prov. Ousèio fèro: 


\section{OXALIS CERNUA.}

Espagn. : Matapan.

Celte jolie plante vivace, à souche bulbeuse, n'es pas indigène du littoral et n'appartient même pas à la Flore d'Europe : mais depuis longtemps elle s'est introduite, par la culture, dans presque toute la zone littorale de la mer IIéditerranée. Très répandue en Algérie et en Sicile, elle commence à envahir les terrains cultivés de la Riviera, en marchant lentement de l'Ouest rers l'Est. On la retroure surtout sur le sol enrichi des cultures d'orangers et de citronniers, sous les oliviers, dans les vignes, où, par ses fleurs penchées, ouvertes seulement aux heures de grand soleil, et par ses feuilles d'un beau vert clair, elle forme un gracieux ornement.

Comme les autres espèces d'oxalis, elle contient dans tous ses organes une quantité considérable d'acide oxalique, qui donne aux feuilles un goût acide, rafraîchissant, assez agréable, très apprécié par les enfants qui les mangent volontiers. Cependant il ne faut pas en abuser, car l'acide oxalique est toxique quand il est introduit en grande quantité dans l'organisme humain.

On peut employer le suc exprimé de ses feuilles et de ses tiges pour enlever les taches d'encre noire sur le linge ou sur le papier. 


\section{POLYGALA NIC $\& E$ ENSIS.}

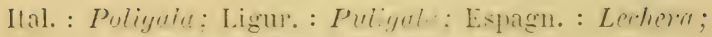
Angl. : Milli-uarl.

Plante virace, ayant plusieur's tiges herbacées, droites, simples, de 15 à 40 centimètres de hauteur. Feuilles éparses, les inférieures généralement plus courtes et plus larg'es que les supérieures; fleurs en grappes terminales, plus ou moins nombreuses, d'une teinte qui varie entre le rose, le lilas et le violet; quelquefois aussi elles sont blanches.

Très commune dans les prés des collines.

Beaucoup d'espèces de Polygala contiennent des substances amères, et d'autres, émétiques ou expectorantes : aussi toutes les espèces d'Europe sontelles emplorées clans la médecine populaire, surtout le $P$. amara (plus petit que le nôtre), qui croît dans les prés des montagnes.

La racine du $P$. Senega de l'Amérique fournit un remède très usité dans les affections des poumons et des bronches, et cette espèce est encore utilisée dans sa patrie contre le poison des serpents les plus venimeux.

Les espèces d'Europe sont presque toutes herbacées; mais, dans nos jardins et surtout sous le climat privilégié de la Riviera, on cultive plusieurs espèces de Polygala exotiques qui se présentent sous forme d'arbrisseaux touffus, toujours verts, arec de grandes fleurs brillantes, violacées ou roses. Ce sont surtout le $P$. myrtifolia et $P$. grandifolia, indigènes au Cap de Bonne-Espérance, qui sont très répandues dans les jardins du littoral et qui trouvent aussi un bon emploi dans le commerce des fleurs. 
$-21-$

Pelouses, prés des collines. - Fleurit "1l aril et mai.

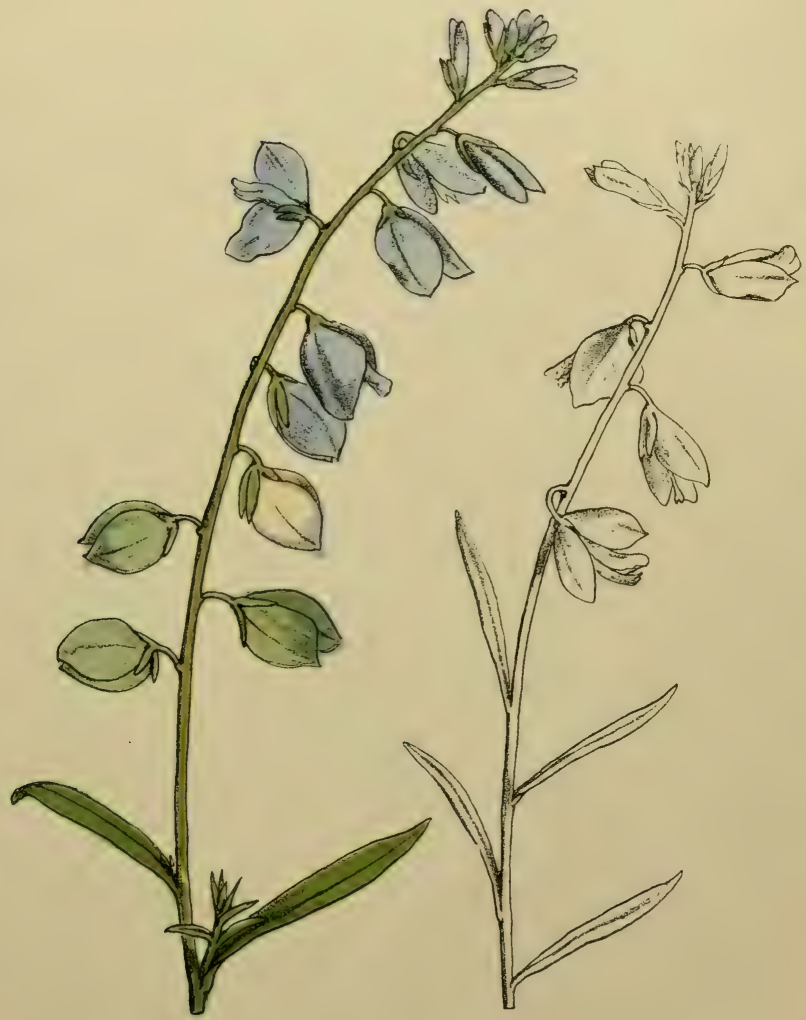

Polygala nicaeensis.

Frans. Polygala grêle. Prov. Erbo dòu la. 


$$
-22-
$$

Lieux secs, pierreux. - Flmit "n juin el juillet.

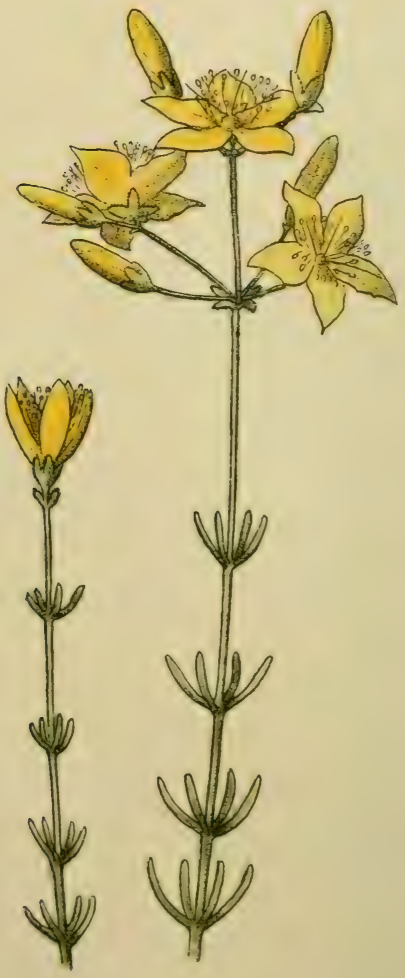

Hypericum Coris.

Frome. Millepertuis rerticilli. Prov. Té dr mountagno. 


\section{HYPERICUM CORIS.}

Plante vivace, à plusieurs tiges droites, presque ligneuses, hautes de 20 à 40 centimètres.

Assez commune le long des routes, dans les endroits pierreux de la zone littorale et sur les collines.

Un examen un peu attentif des feuilles y fait apercevoir une quantité de peliles glandes en forme de menus points noirs : ce sont les mêmes réservoirs d'huile volatile que nous retrouvons, sous forme de points transparents, dans les feuilles du Millepertuis (Hypericum perforatum) et dans celles du citronnier et de l'oranger. Outre l'huile essentielle, notre plante contient aussi des substances résineuses et tanniques; les médecins de la Grèce ancienne attribuaient au Kóp:s de nombreuses rertus, comme plante diaphorétique, diurétique et emménagogue. On en faisait une infusion dans le vin, pour renforcer l'organisme malade : mais à présent personne n'en fait plus usage.

Plusieurs autres espèces du même genre $(H . A n$ drosaenum, H. Ascyion, H. calycinum) fournissent par leurs feuilles fraîches un bon remède pour les plaies et les contusions. 


\section{TRIBULUS TERRESTRIS.}

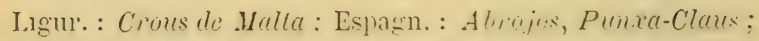
Angl. : Callrop; Allem. : Burieldorn.

Plante annuelle, à racine pivotante, arec plusieur's tiges divergentes, minces, étalées horizontalemenl sur le sol; assez commune sur les terrains sablonneux, le long des sentiers, sur la plage de la mer.

Cette petite plante est intéressante à divers points de vue : pour le botaniste, parce qu'elle est presque le seul représentant, dans notre Flore, de la famille des Zygophyllacées, et à cause de la curieuse disposition sur les tiges de ses feuilles et fleurs. Pour les profanes, c'est surtout la forme singulière de ses fruits qui attire l'attention : ils ont à peu près la forme d'une croix de Malte, à 4-כ̆ coques ligneuses, épineuses, partant d'un centre commun.

Chez les anciens auteurs, nous trouvons souvent le Tribulus mentionné comme une des planles les plus nuisibles à l'agriculture et comme une espèce très désagréable à cause de ses épines. Mais ce n'est évidemment point de notre petite Zygophyllée qu'il s'agit : très probablement Pline, Virgile et autres appelaient Tribulus la plante qui porte aujourd'hui le nom de Centaurea Calcilrapa, Centaurée dont l'involucre floral, armé de pointes, rappelle la chausse-

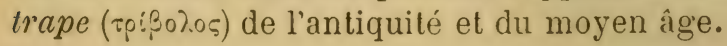


Lieux sablonneux. - Flemit tr mai 'n aotht.

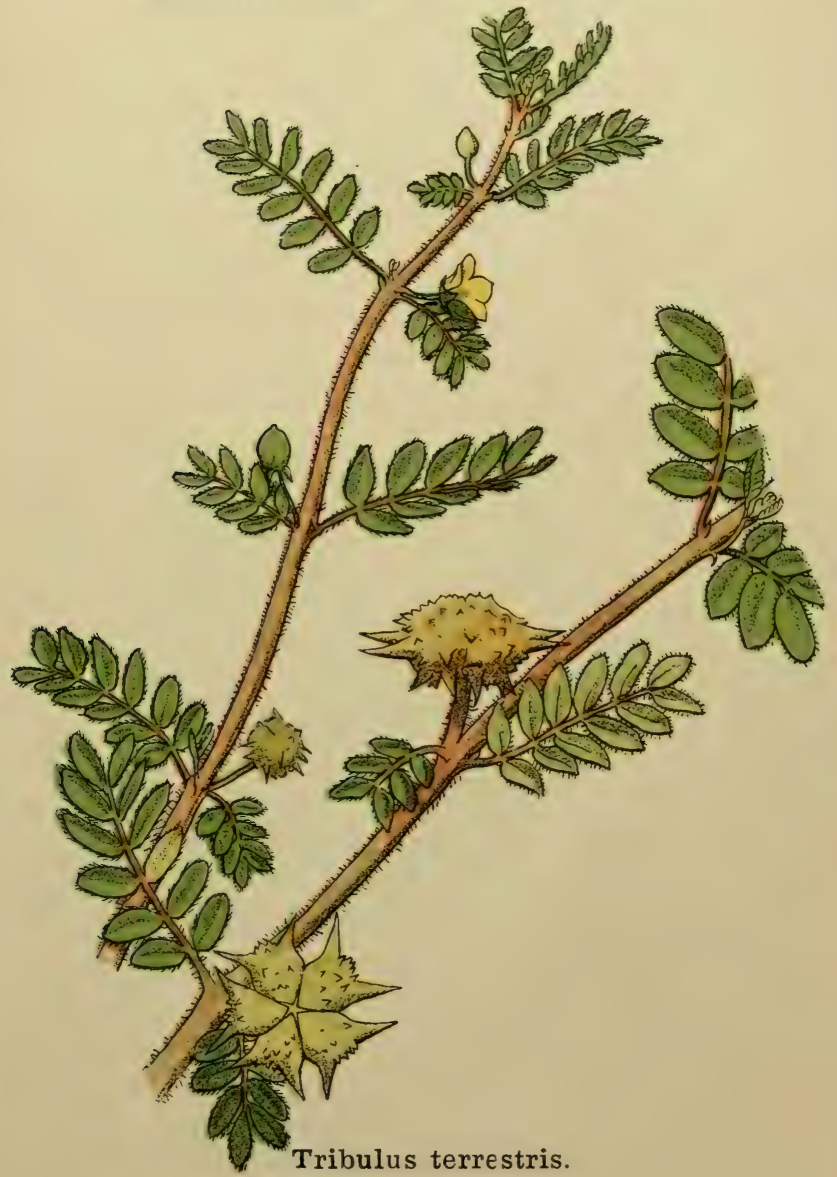

Frans. Croix de Malte. Prov. Trauco-pèiro. 


$$
\text { -.- 2'- }
$$

Prés des collines. - Hmrit "n mai w juin.

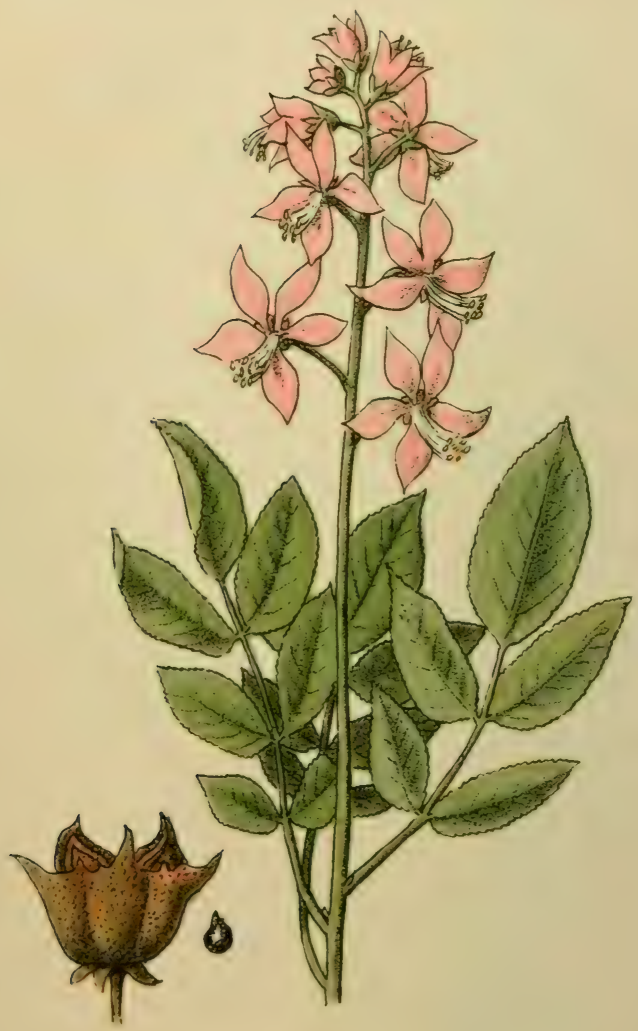

Dictamnus albus.

Frume. Fraxinelle blanche.

Prov. Dictan blanc 


\section{DICTAMNUS ALBUS.}

Ital. : Dilamo, Frassinella; Ligur.: Nurèa ; Allmn. : Diplam.

Plante vivace, de 60 centimètres à un mètre de hauteur; assez répandue dans les prés, surles pentes herbeuses de la région des collines.

C'est, par la beauté et l'éclat de ses fleurs, une des plantes les plus remarquables de notre Flore. Les feuilles sont raides, presque charnues, d'un beau vert foncé, les fleurs très grandes, roses, veinées de pourpre, en grappe allongée. Toutes les parties de la plante, excepté la racine, sont munies de nombreuses glandes, situées à l'intérieur des tissus ou un peu proéminentes, lesquelles conliennent une grande quantité d'huile essentielle, très âcre et d'une odeur pénétrante. Celte huile est très inflammable; et si, par une journée chaude, on approche de la plante la flamme d'une allumette, on peut assister à une sorte d'explosion, due a l'inflammation subite de toute l'essence volatilisée par la température ambiante.

La * Fraxinelle blanche » avait au moyen âge une grande renommée pour ses propriétés médicinales, et encore à présent la racine en est employée comme remède tonique et aromatique. 


\section{RUTA BRACTEOSA.}

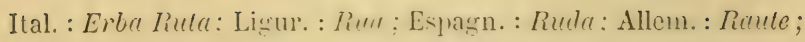
Angl.: laue.

Plante vivace, de 50 centimètres à un mètre de hauteur, à tiges droiles, ramifiées, presque ligneuses à la base : fréquente dans les décombres, dans les lieux pierreux et rocailleux, des plages jusqu'aux hautes montagnes.

L'odeur très forte, pénétrante et aromatique de la Rue est due à la présence de nombreuses glandes qui, lorsqu'on regarde les feuilles contre la lumière, se présentent comme autant de pelits points transparents. Ces glandes contiennent une huile essentielle, volatile. Outre celte essence, la liue renferme une substance très amère : et c'est à ces deux produits que la Rue doit le rôle important qu'elle a toujours joué dans la médecine.

Le peuple surtout l'emploie beaucoup pour en faire une espèce d'eau-de-vie tonique, slomachique, par simple immersion de ses feuilles dans l'espritde-rin; on lui attribue aussi une action rermifuge assez forte.

La Rue, bien connue et appréciẻe par les anciens, est une des plantes dont Charlemagne imposait la culture autour des maisons, dans son fameux édit De hortis et villis imperialibus; et la grande diffusion et popularité de celte plante, mème dans les contrées les plus septentrionales, est certainement en partie une conséquence de cet ordre impérial. 
Endroits pierreux, décombres. - Fleurit en juin et juillet.

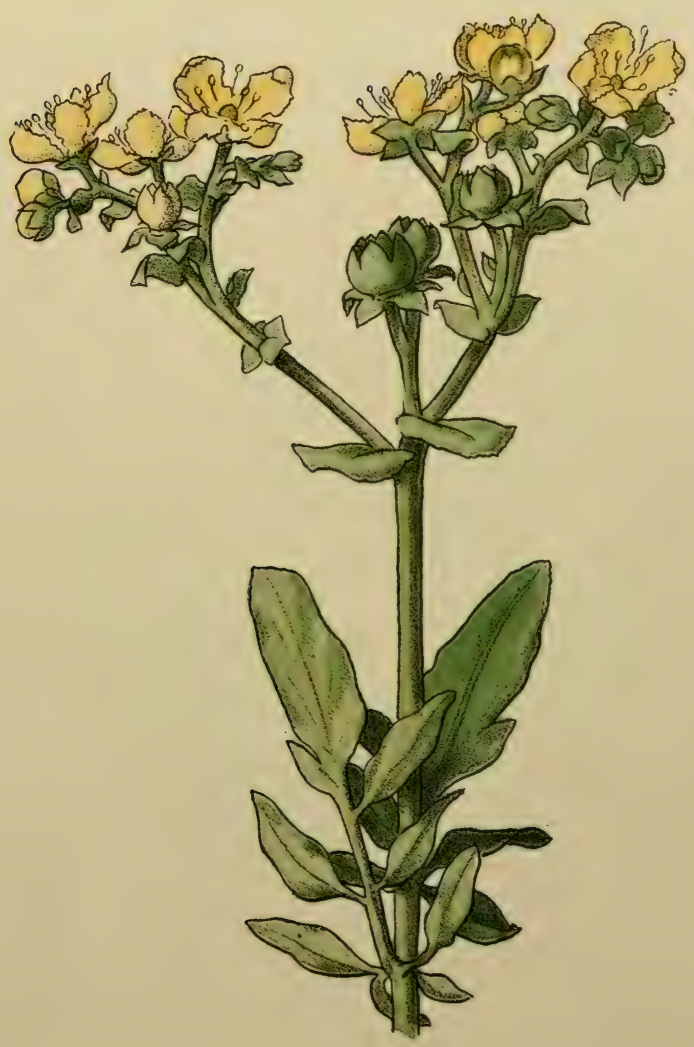

Ruta bracteosa.

Franc. Rue à grandes bractées.

Prov. Grosso Rulo.

- Rutacées. - 


$$
\text { -.- } 26-
$$

Lit des torrents; haies. - Fmril m avril ot mai.

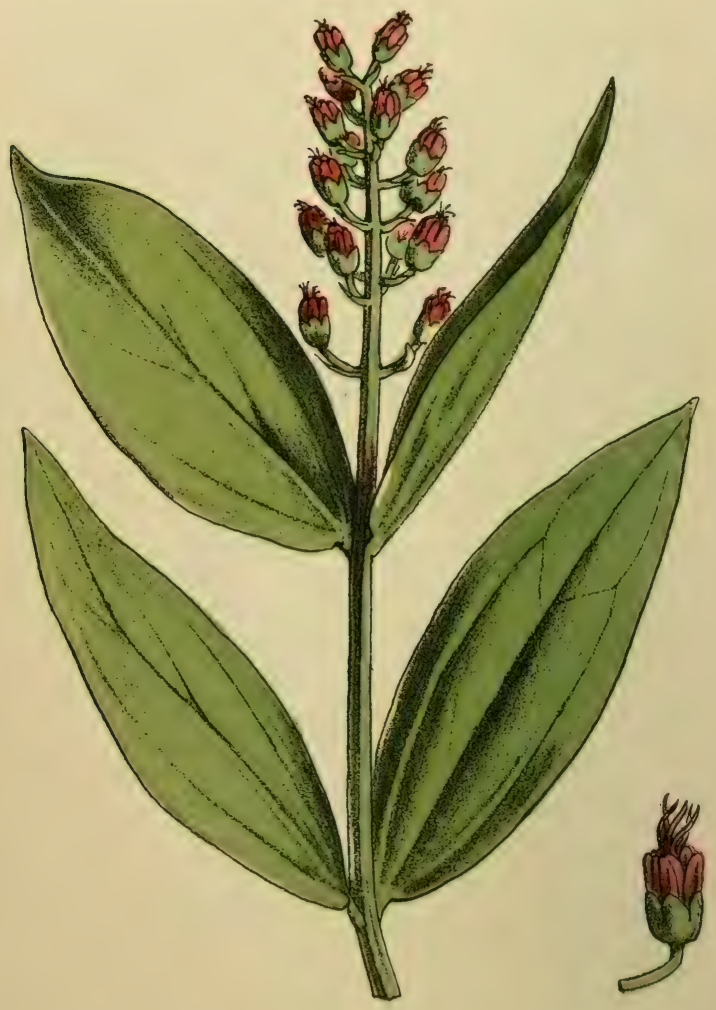

Coriaria myrtifolia.

Franc. Corroyère à feuilles de Myrte. P'rov. Rédou, Nertas, Roudous, Roudoun. 


\section{CORIARIA MYRTIFOLIA.}

Ligur. : Embriaghi, Ifurlareize; Espagn. : Embarruharubras, Roldon.

Arbrisseau de 1 à 3 mètres de hauteur, à rameaux droits, sarmenteux, à feuilles persistantes, herbacées : fréquente dans les haies, aux bords des bois, aux endroits pierreux de la région littorale. Les fleur's, en petites grappes opposées, ont peu d'apparence, ayant l'involucre formé de petites folioles vertes ; seulement les stigmates filiformes (les extrémités des organes centraux, femelles) ont une teinte rouge. Les fruits sont de pelites baies succulentes, noires, luisantes.

Le Coriaria est un genre curieux qui, par la structure de ses fleurs, s'éloigne tellement de toutes les autres familles de notre Flore, que les botanistes ont été forcés de le mettre dans une famille à part, les Coriariées.

Dans toutes les parties du Coriaria, il y a une substance vénéneuse, narcotique, qui rend la plante dangereuse pour les bêtes qui en broutent les feuilles, et pour les enfants qui se laissent tenter par ses fruits un peu sucrés. Il semble cependant que certains oiseaux peuvent en manger impunément : l'effet du poison est une narcose, semblable à celle qui est produite par l'opium ou par certaines Solanacées ou par l'alcool; et c'est à cause de cela que les paysans de la Riviera appellent cette plante a embriaghi s ( embriago »=ivre). Du reste, les parties vertes contiennent beaucoup de tanin et peuvent servir dans la tannerie et dans la teinture. 


\title{
RHAMNUS ALATERNUS.
}

\author{
Ital. : Alaterno.
}

Arbrisseau ou pelit arbre de 2 à 3 mètres de hauteur, touffu, à feuilles persistantes, coriaces, luisantes, d'un beau vert intense. Fleur's petites, disposées en grappes serrées à l'aisselle des feuilles, vertes, formant des petites étoiles à cinq rayons.

Cet arbrisseau est caractéristique de la zone littorale et, uni aux lentisques, à l'arbousier, au myrte et à d'autres plantes à feuilles persistantes, il joue un rôle important dans la composition des maquis qui couvrent une bonne partie du littoral et des iles de la Méditerrancée. En France, il se troure encore dans l'Isère, l'Ardèche, l'Aveyron, le Lot, la Vienne, le Maine-et-Loire el en Bretagne.

$\Lambda$ cause de son feuillage persistant, touffu et sombre, le Rhammus Alaternus est sourent cultivé dans les parcs, comme plante ornementale, pour former des massifs ou des haies compactes; il fait un très joli effet, surtout lorsqu'il est chargé de ses fruits qui sont des baies globtileuses, luisantes, rouges.

C'est l'unique espèce européenne de Rhamnus à feuilles persistantes : les autres espèces communes dans le Nord, Rh. catharlica (Nerprun), Rh. Frangula (Bourdaine) et plusieurs autres formes, habitant des hautes montagnes, ont les feuilles caduques, herbacées.

Ses baies ont une faible action purgative, mais ne sont guère employées en médecine; son bois, d'un grain fin et compact, peut servir à des travaux de menuiserie. 
Bois des collines; maquis. - Flmmil m mai of juin.

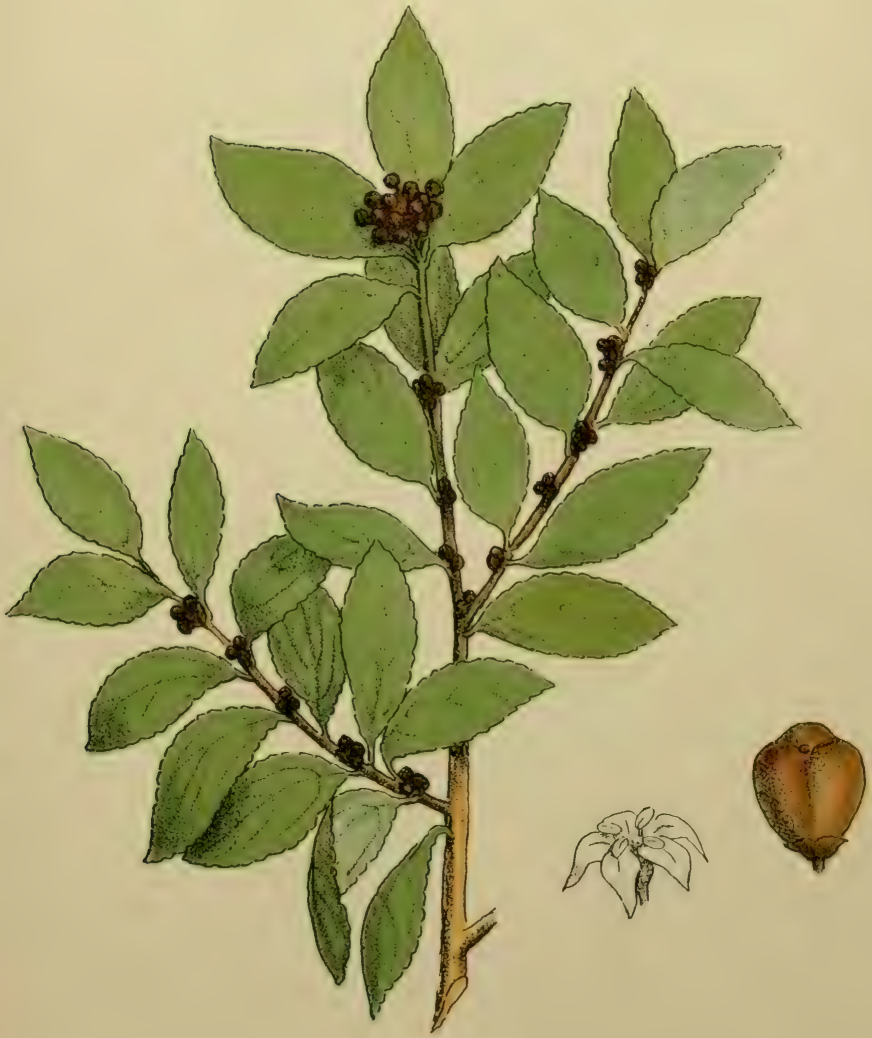

Rhamnus Alaternus.

Nerprun alaterne.

- Ruanacées. - 
$-28-$

Rochers maritimes. - Fleurit en mars et arril.

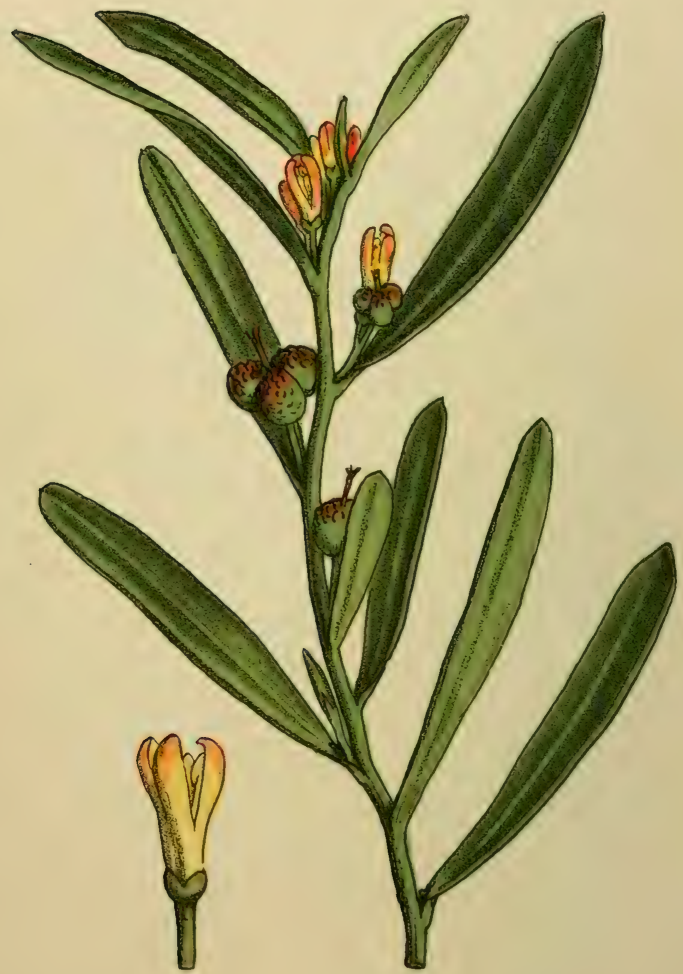

Cneorum tricoccum.

Frane. Camélée à trois coques. Prov. Calmolea. 


\title{
CNEORUM TRICOCCUM.
}

\author{
Espagn. : Olivilla.
}

Petit arbrisseau de 60 centimètres à 1 mètre 1/2 de hauteur, à rameaux dressés, aux feuilles coriaces, luisantes, persistantes. Dans les endroits secs, rocailleux de la région littorale, çà et là dans la partie occidentale (à l'ouest de la Roja) de la Riviera; mais peu commun.

N'ayant rien d'attrayant, cette plante peut paraitre indifférente aux profanes; mais elle est très appréciée des botanistes, parce que c'est l'unique représentant en Europe d'une famille qui est propre aux flores tropicales et subtropicales. C'est peut-être un dernier survivant de la flore tertiaire d'Europe qui était représentée, dans des conditions de climat très différentes de celles d'aujourd'hui, par des types de plantes qui sont limités maintenant aux régions plus chaudes. 


\section{PISTACIA LENTISCUS.}

Ital. : Lentisco: Ligur. : Fistece! survergu; Espagn. : Lentisco, Mata; Allem. : Mastixpistacic.

Arbrisseau ou petit arbre touffu, à feuilles persistantes (c'est-à-dire qui restent sur la plante toute l'année, par opposition aux feuilles caduques), coriaces, d'un vert foncé, qui pendant l'hiver prennent une teinte pourpre, très marquée.

Très commun sur les rochers maritimes et sur les collines arides, pierreuses de la zone littorale, le Lentisque est un des éléments les plus caractéristiques de cette région. Sur notre littoral, il n'atteint généralement qu'une faible hauteur (3 à 4 mètres); mais l'espèce peut derenir un arbre de taille considérable. Dans le jardin de la villa Giribaldi, à Bordighera, on peut admirer un Lentisque gigantesque d'environ 14 mètres de hauteur el couvrant une surface de cent mètres carrés.

Les fleurs du Lentisque sont insignifiantes, vertes, en petites grappes serrées; les deux sexes sont distribués sur des individus différents; les fruits sont de petites baies rouge foncé. 'Très souvent on aperçoit sur les feuilles des galles curieuses, en forme de bourse, et causées par la piqûre d'un puceron.

Toute la plante est résineuse, aromalique. Dans plusieurs îles de l'Ar'chipel grec, notamment à Chios, elle est cultivée pour l'extraction de la résine appelée mastic; en Orient, celle-ci sert à divers usages : les dames orientales la mâchent pour raffermir leur's gen- 
Maquis; collines près de la mer. - Fleurit en octobre.

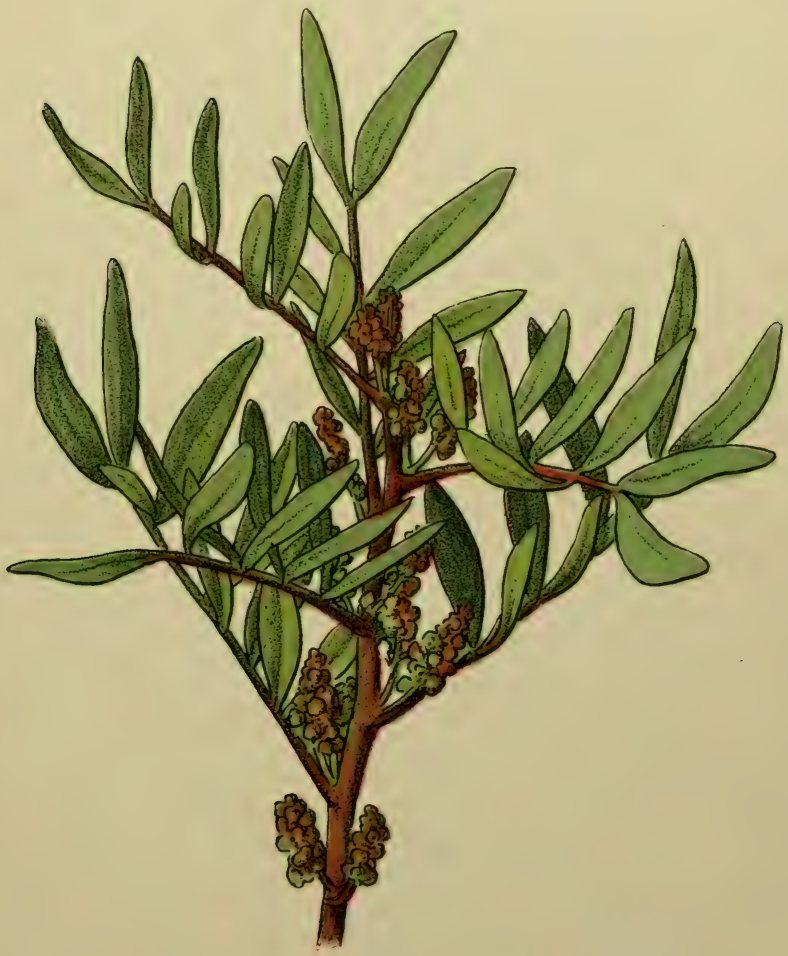

Pistacia Lentiscus.

Franc. Lentisque saurage. Prov. Réstincle, Petelin, Repolin 
$-30-$

Lieux herbeux: haies. - FMnil mil aril of mil.

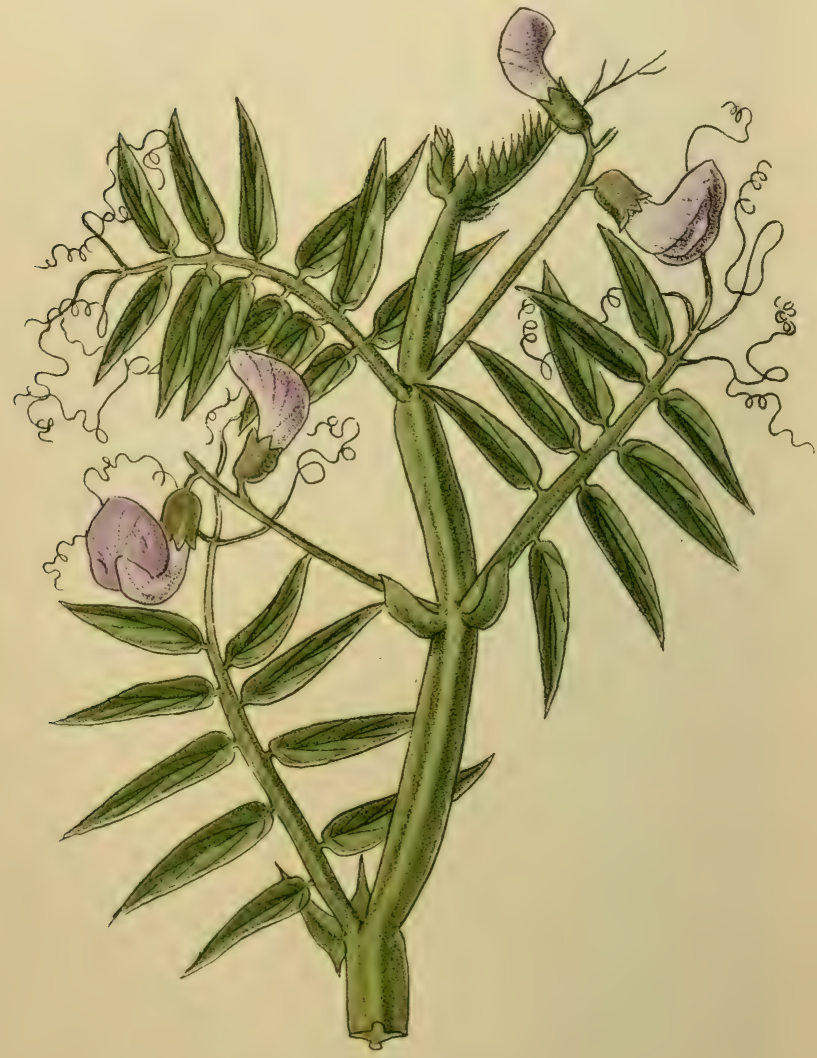

\section{Lathyrus Clymenum.}

Frane. Gesse clymène. Prov. Jaisso fèro. 


\section{$-30-$}

cives ou pour parfumer leur haleine; on l'emploie dans la confection de certaines confitures et d'une espèce de liqueur très répandue dans tout l'Orient, également sous le nom de mastic.

Le Térébinthier et le Pistachier, qui sont des espèces voisines du Lentisque, sont souvent cultivés, le premier également pour une résine (térébenthine) qu'il contient; le second pour ses graines comestibles (pistaches).

\section{LATHYRUS CLYMENUM.}

Plante annuelle, à tiges herbacées, ailées, longues de 30 centimètres à un mètre, faibles et grimpantes à l'aide de vrilles foliaires.

Les feuilles offrent un cas d' a hétérophyllie » assez remarquable, car les feuilles inférieures sont réduites à un simple pétiole largement ailé, pourvu ou dépourvu de vrilles; les feuilles supérieures, au contraire, portent sur un pétiole étroit 2-5 paires de folioles (ou petites feuilles) latérales et se terminent en vrille composée. Les fleurs, réunies par 2 à 5 à l'extrémité d'un pédoncule filiforme, sont très jolies, avec leur étendard pourpre et leurs deux ailes bleues ou blanchâtres. La gousse est fortement comprimée.

Cette jolie espèce de gesse est assez commune dans les pelouses, les haies, sous les oliviers de la Riviera ainsi qu'en Corse.

C'est une excellente plante fourragère, comme toutes les espèces du même genre. 


\section{CERCIS SILIQUASTRUM.}

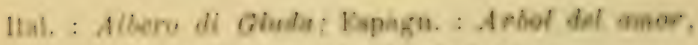
Ciarrofer bart: Angl. : Judiss-lreve.

On pretend, et on sont les noms populaires en usage dans plusieurs nations qui le laissent supposer, que Judas, apres sa trahison at son repentir. aurait choisi cet arbre pour s'y pendre. Je ne saurais indiquer l'origine de cette triste lagende, qui forme un contraste des plus tranehés aveo laspect si grai et si riant que eet arbre offee a Típoque di sa foraison. Peut-etre celle tradition est-elle due a ux feuilles du Cercis, rondes of plates comme des momnates; ou hien aux gousses noires, seches, aplaties, qui pendenten automme des ramesux deponillis : mais pen importe.

A part le nom el la légende populaims, le Crris est un arbre fort joli par sa floralson pricoce el tris abondante of par son fenillage touffu, d'un beau rert, qui to fait employer somvant, et avec beaucoup de suceis, dans les pares el jardins publies, pour des allées, ete.

Son bois, très risistant, veiné en vert et noiràlrr. est appréciè pour les travaux d'Wbênisterie. Les boutons des fleurs, eonservés dans le vinaigre, peuvent remplacer les câpres. 
Bois des eollibes - ytermi en axtl +1 wai

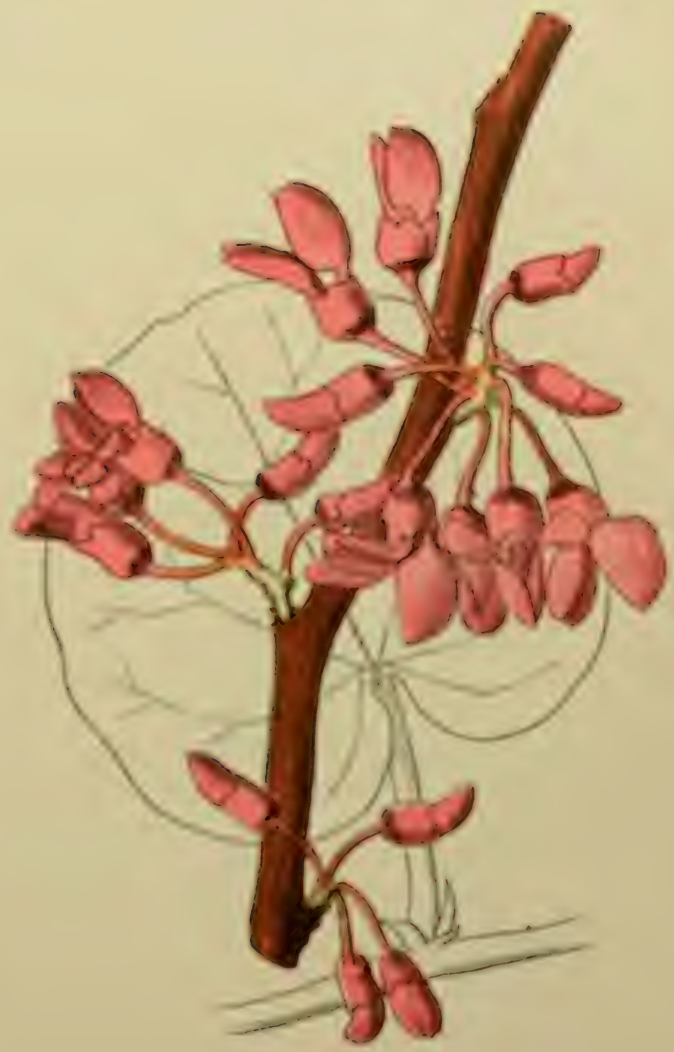

Cercis Siliquastrum.

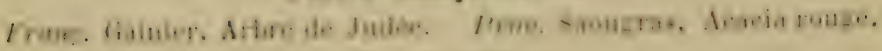


$-32-$

Bois des collines. - Fleurit nn mai et juin.

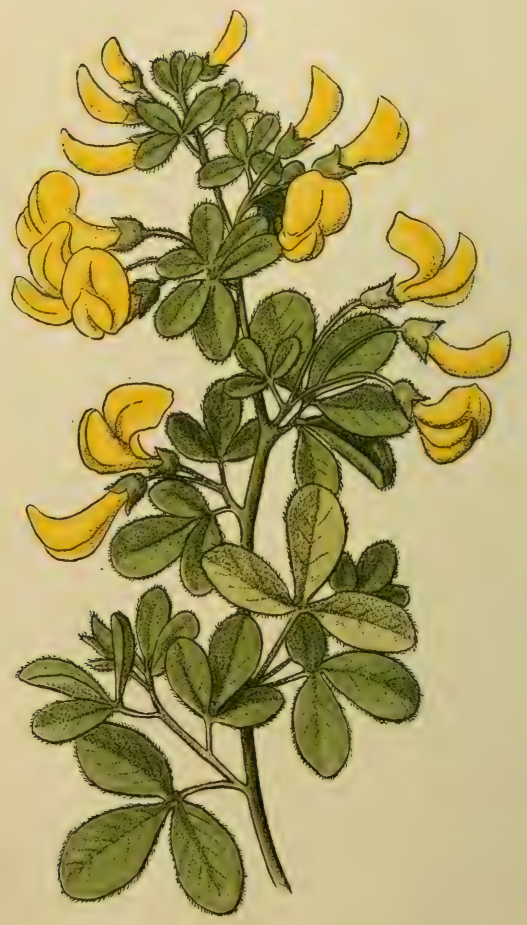

Cytisus triflorus.

Frane. Cytise ì trois fleurs.

Prov. Mournankin. 


\section{CYTISUS TRIFLORUS.}

Arbrisseau touffu ou petit arbre de 2 à 4 mètres do hauteur, à feuilles caduques, trifoliolées, poilues. Ses fleurs se développent aux mois de mai et de juin, en petites grappes droites qui, pour la plupart, sont composées de 3-כ̆ fleurs, d'un jaune très pur. Les gousses sont allongées, fortement comprimées, hérissées de poils mous, gris ou jaunâtres.

Cette jolie espèce de Cytisus, qui est particulière à l'Europe méridionale, se trouve çà et là dans les bois. des collines, le long du littoral; et bien souvent on la rencontre aussi cultivée dans les jardins de la Riviera.

Ses fleurs n'ont ni l'éclat ni la grandeur de celles. de la « Pluie d'or » (Cylisus Laburnum), bien connue dans les jardins du Nord; mais elles sont si nombreuses que la plante bien fleurie offre un aspect assez agréable.

Il faut pourtant s'en méfier, parce que toute la plante est vénéneuse, par la Cytisine qu'elle contient. On dit qu'il est même dangereux d'en employer le bois pour faire des cuillères ou autres ustensiles de cuisine. 


\section{PSORALEA BITUMINOSA.}

Ligur. : Erba cavallina, Farfuia; Espagn. : Hediondo, Angelola, Yerba cabruna; Angl. : Pitch clover.

Plante bisannuelle ou vivace, herbacée, à racine pivotante. Les feuilles inférieures sont disposées en rosette et ressemblent à celles du trèfle commun; pourtant, les trois feuillettes ou « folioles s qui composent la feuille entière sont luisantes, arrondies, plus résistantes que celles du trèfle. Les liges, peu ramifiées, atteignent jusqu'à un mètre de hauteur : elles sont garnies, dans leur partie inférieure, de feuilles à trois divisions étroites, presque linéaires, et portent à leur extrémité des capitules de fleurs violacées.

Toute la plante exhale une odeur pénétrante, désagréable, bitumineuse, qui infecte l'air des contrées où elle croît en abondance. On la rencontre presque partout, dans la zone maritime de la Provence et du littoral, le long de la Corniche, sous les oliviers, sur les rochers maritimes; dans la médecine populaire, elle joue encore un rôle important contre toutes sortes de maladies. Dans les pharmacopées des siècles passés, la IIerba Trifolii bituminosi avait une très grande renommée. 
$-33-$

Lieux secs, pierreux; le long des, routes. - Fleurit 'n juin.

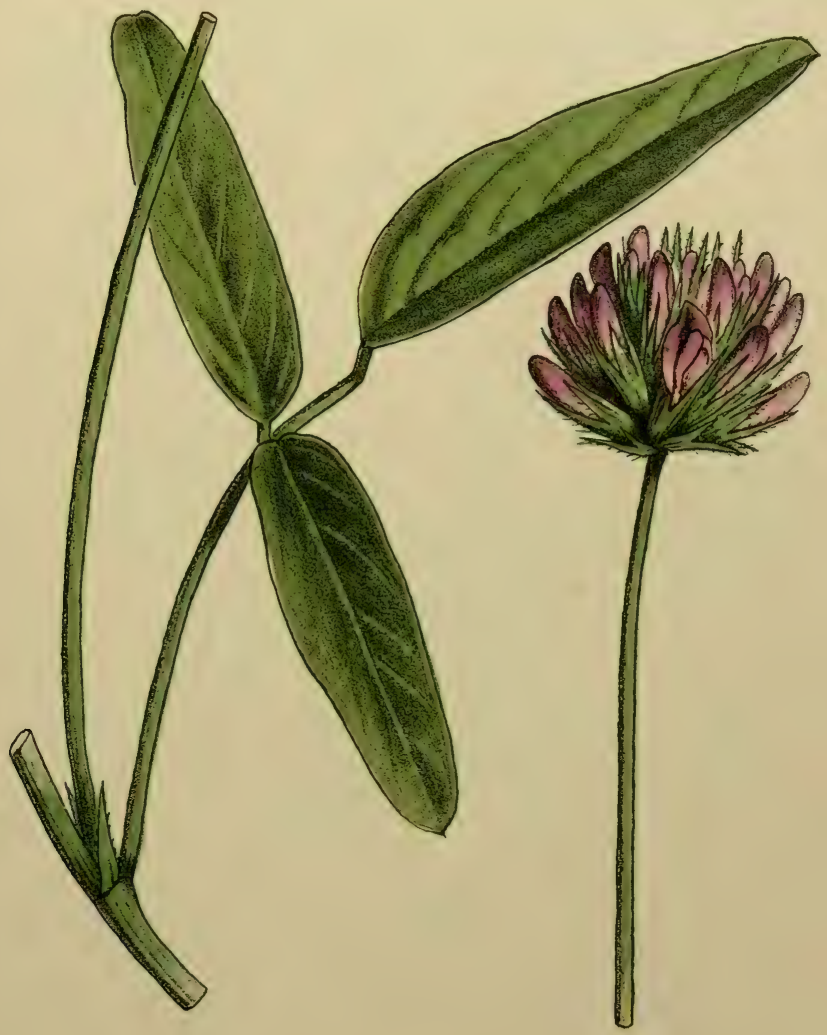

\section{Psoralea bituminosa.}

Frunc. IIrrbe au bitume. Prov. Calmirloula, Cabreireto, Ped de poulo. 
$-34-$

Rochers maritimes; maquis. - Fleurit on mai et juin.

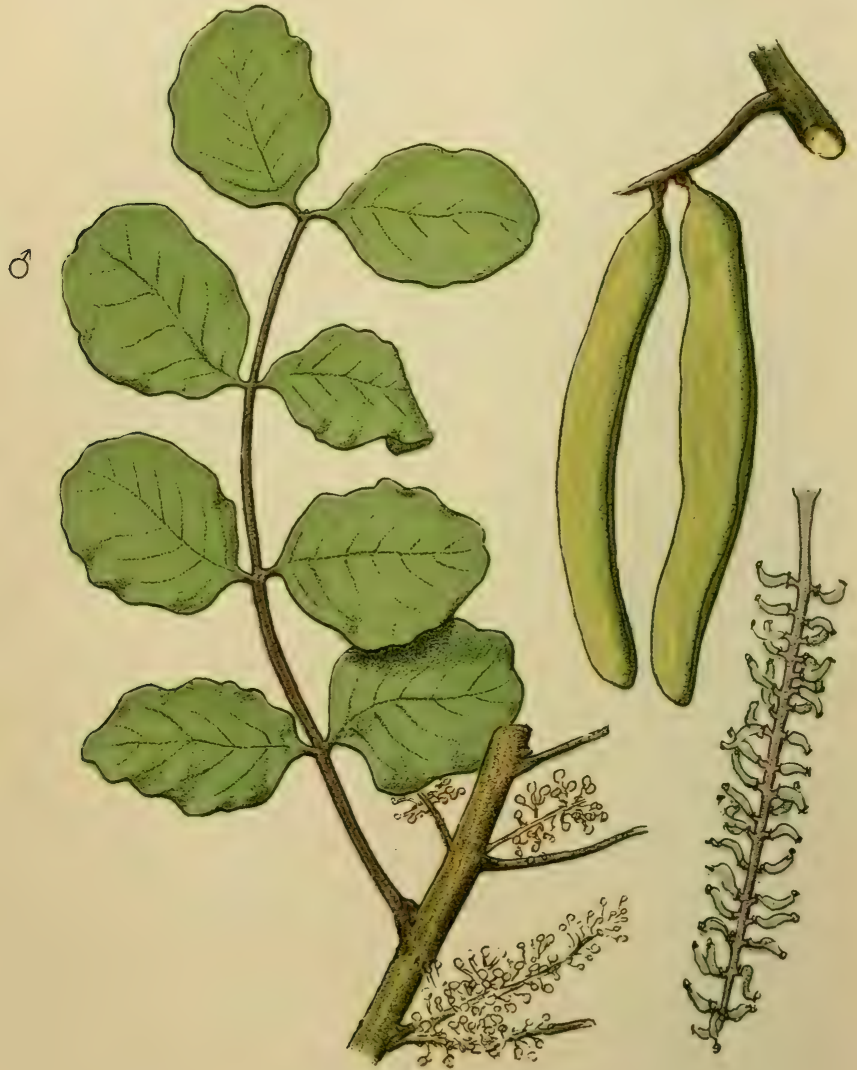

Ceratonia Siliqua.

Frane. Caroubier. Prov. Carobić.

- Césalpiniacées. - 


\section{CERATONIA SILIQUA.}

Ital. : Carubbo; Espagn. : Algarobbo; Allem. : Juhannisbrod; Angl. : Locust bean.

Le caroubier est un des arbres les plus intéressants de la Flore d'Europe. Restreint aux contrées les plus chaudes du littoral méditerranéen, où il atteint sa limite septentrionale, il impose aux profanes par sa taille, par son feuillage touffu, persistant, luisant, et par les fruits qui naissent presque directement sur le tronc ou sur les plus gros rameaux. On sent presque par instinct que c'est un intrus dans notre Flore, et qu'il n'y a aucun parent. En effet, le caroubier est l'unique représentant en Europe d'un groupe très vaste de plantes, presque toutes arborescentes, indigènes des pays tropicaux. Il y a lieu de croire qu'il est l'unique survivant de nombreuses formes voisines, qui à une époque bien éloignée de la notre peuplaient le continent européen, et qui ont dû disparaitre, a l'approche des dernières époques géologiques.

Tous les individus de caroubier ne sont pas semblables: il y en a qui portent exclusirement des fleurs mâles, et en conséquence restent stériles, tandis que d'autres individus, qui portent les fleur's femelles, sont chargés de fruits à la fin de la saison. Les gousses aplaties, coriaces, sont rertes d'abord et noires à la maturité; elles contiennent une pulpe doucâtre, et on même temps astringente, qui est goûtée par le bétail (surtout par les chevaux) et n'est pas désagréable au palais, peu difficile, de nos enfants. 
Les graines un peu allongées, aplaties, très dures, étaient employées autrefois comme des unités de poids, dans le commerce des joailliers, et encore aujourd'hui on conserve le calcul en “ carats » (ceralonia) pour évaluer les pierres précieuses.

\section{SPARTIUM JUNCEUM.}

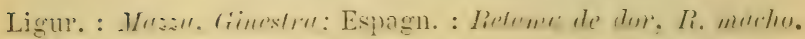

Arbrisseau de 1 à 3 mètres de hauteur, à rameaux sarmenteux, presque nus, réunis en faisceaux, à pelites feuilles caduques, simples, qui subsistent seulement pendant quelques semaines, au printemps. Plus tard, et durant tout le reste de l'année, la plante reste nue, et ses rameaux cylindriques, striés, présentent l'aspect de tiges de jonc marin.

Les fleurs, très grandes, odorantes et d'un beau jaune doré, offrent un mécanisme assez compliqué et curieux par rapport à leur fécondation. Les pétales inférieurs, soudés en carène, sont munis d'une espèce de ressort spécial, au moyen duquel, sous l'influence d'une pression verticale (p. ex. le poids d'une abeille posée sur ces pétales), la a carène s s'abaisse subitement, et aussitôt la poussière fécondante (le a pollen ») est lancée en l'air. On peut facilement obtenir cet effet, en pressant légèrement, par un doigt, sur l'extrémité de la carène dans les fleurs à peine épanouies.

A l'occasion des grandes fètes religieuses, telles que la Pentecôte et la Fète-Dieu, les fleurs fraîches du Spartium junceum servent à joncher le pavé des lues où les processions doivent passer. 
Bruyères; bois des collines - Fleurit en mai et juin.

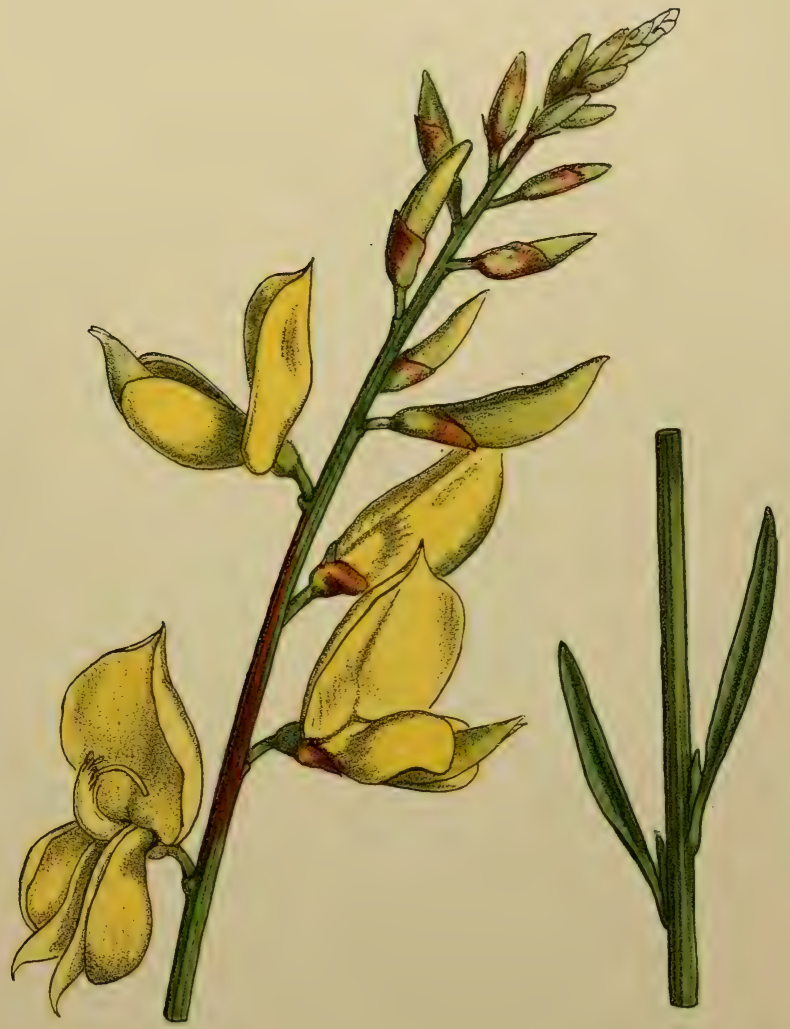

Spartium junceum.

Fran?. Genêt d'Espagne. Prov. Ginesto. 
$-36-$

Endroits herbeux et rocailleux des collines. - Fleurit en mars et arril.

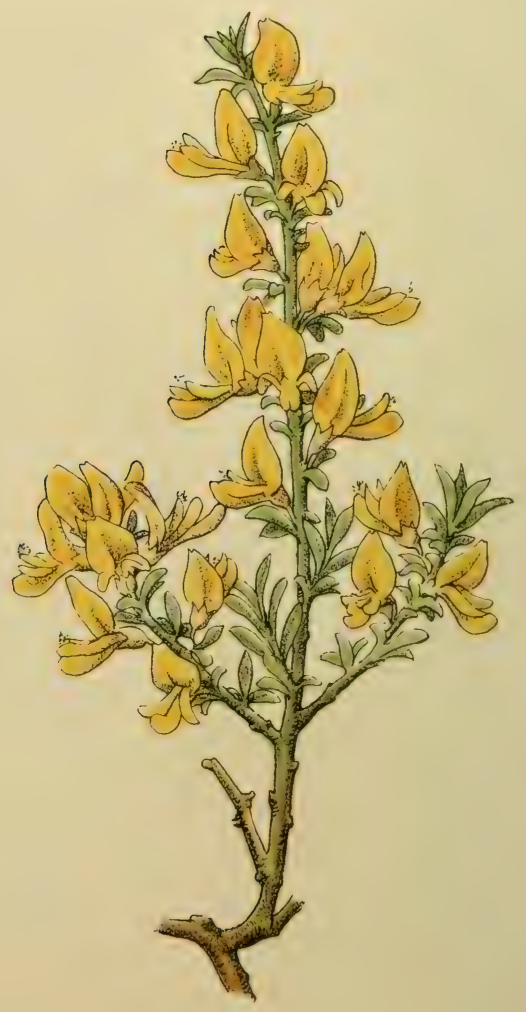

Genista pilosa.

Frane. Genêt velu.

Prov. Ginesto fèro. 


\section{GENISTA PILOSA.}

Ligur. : Zenestra; Espagn. : Giinesta pequeña.

Petit arbrisseau qui alteint rarement un mètre de hauteur, et a généralement les rameaux allongés, couchés, étalés et radicants dans le sol. Feuilles petites, rares, d'un vert sombre, couvertes, de mème que les rameaux, d'un court duvet soyeux. Fleurs en grappes courtes, à corolle jaune, soyeuse; grousse velue, comprimée, longue de 20 à 20 millimètres.

Très fréquente sur les coteaux secs, dans les endroits pierreux de la zone littorale, d'où elle monte jusqu'à la zone des châlaigniers, elle se trouve sourent associée à une autre espèce du mème genre, le G. genuensis, qui s'en distingue par les tiges el les feuilles glabres.

Elle fleurit d'assez bonne heure, quelquefois dès le mois de février. Comme toutes les espèces de genêts, elle a un goût amer, et on la soupconne même de contenir des substances vénéneuses (la Cytisine); mais, mêlée au foin, elle peut servir à la nourriture des besliaux. 


\section{TRIFOLIUMI STELLATUM.}

Celle petite espèce de trèfle se fail remarquer beaucoup plus facilement, quand elle porte ses fruits qu'à sa floraison, qui a lieu de bome heure, au mois de mars ou d'arril, selon l'exposition. Alors c'est une herbe délicate, portant des feuilles peu différentes de celles du trèfle commun des prés, avec de pelits capitules et des fleur's d'un rose pâle, presque blanc. Plus tard sa tige s'allonge et se raidit ; l'inflorescence s'accroit en longueur et en largeur; et lorsque (au mois de mai ou de juin) les dents du calice de chaque fleur s'allongent considérablement et s'étendent en forme d'étoile autour du petit fruit sec, alor's toute la plante acquiert un aspect très différent et plus remarquable que celui qu'elle offrait quelques semaines auparavant.

On la rencontre surtout dans les lieux secs le long: des routes de la région litlorale et de la colline, abondamment aussi en Corse; souvent elle se trouve unie à une autre espèce du même genre (Trifolium angustifolium), qui, comme elle, présente le caractère des calices étoilés, mais qui en diffère par ses folioles lancéolées ou linéaires, aiguës, et non arrondies.

De même que toutes les espèces de trèfle, le Trifolium stellatum donne, tant frais que sec, un excellent fourrage pour le bétail. 
Lieux herbeux, secs. - Femit ch mars of arril.

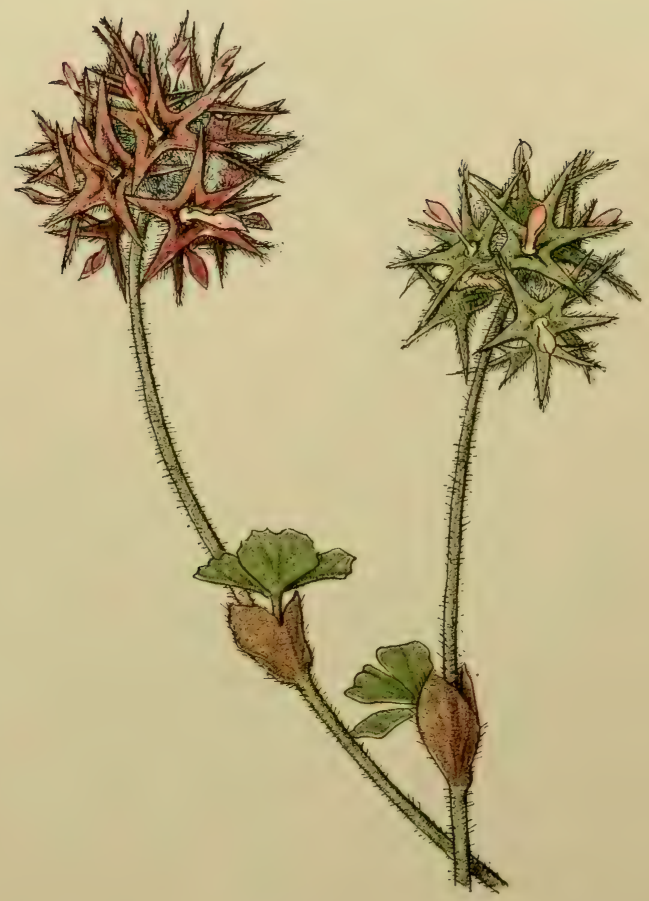

Trifolium stellatum.

Frane. Trètle étoilé. Prov. Tréu estella.

- Papllionacées. - 


\section{$-38-$}

Bois des collines. - Fleuril en férrier et mars.

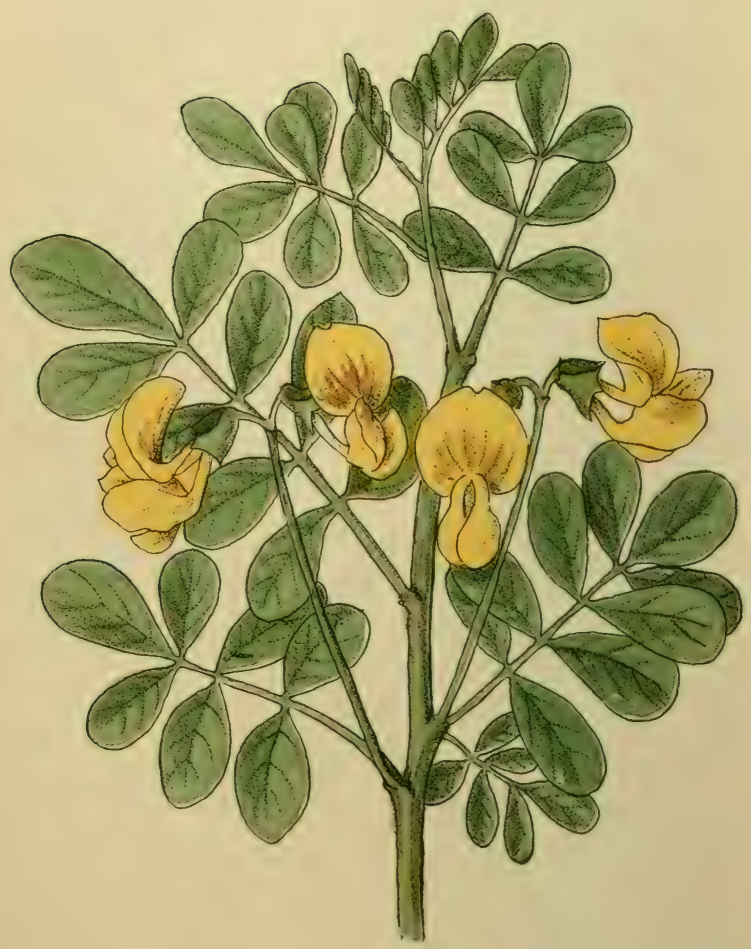

Coronilla Emerus.

Frane. Faux-Baguenaudier, Séné bâtard.

Prov. Carolino. 


\section{CORONILLA EMERUS.}

\section{Ligur. : Lerca: Espagn. : Senèt bort.}

C'est un des arbrisseaux les plus précoces du littoral. Déjà au mois de février ou de mars, sur les pentes ensoleillées des collines, on peut en trouver des échantillons fleuris. Il n'atteint pas une hauteur considérable (tout au plus 2 mètres); ses rameaux grêles, pourvus de feuilles rares, glauques, n'ont pas le charme particulier des Cytises ou des Genêts. Les fleurs mêmes, regardées de près, ont un aspect anguleux, incomplet, comme si elles manquaient de quelques-unes de leurs parties; et le fruit, formé d'une gousse trop longue, mince, grêle, un peu courbée et bosselée, n'offre rien de joli à la vue.

Malgré ces caractères de détail, qui le recommandent fort peu, le a faux baguenaudier o peut garnir agréablement les coteaux, ou par l'éclat de ses fleurs donner un peu de vie aux forêts de pins ou de châtaigniers, où il forme souvent une partie importante du sous-bois. Ses feuilles contiennent une substance très amère, purgative, et sont employées quelquefois pour falsifier ou mème remplacer les feuilles de Séné (Cassia var. sp.): d’où le nom populaire de « Séné bâtard »

Plusieurs autres espèces du même genre, à fleurs dorées (Coronilla minima, C. juncea, C. glauca) ou roses $(C$. varia) se trouvent çà et là dans les endroits pierreux du littoral. 


\section{ANTHYLLIS BARBA JOVIS.}

Arbrisseau qui atteint 1-1 mètre 1/2 de hauteur, à rameaux dressés, touffus. Le feuillage est compact, persiflant, d'un vert cendré; les jeunes pousses et les feuilles les plus tendres sont couvertes d'un duvet soyeux, argenté, très élégant. Au mois de mars ou d'avril la plante est ornée de nombreuses inflorescences en grappe serrée, d'un jaune soufré, pâle, qui s'accorde bien avec le mal du feuillage.

La « Barbe de Jupiter ` (je ne saurais indiquer l'origine de ce nom, dont le similaire, la joubarbe (Sempervivum tectorum) n'a rien à faire avec notre Anthyllis) est souvent cultivée dans les jardins du littoral. A l'état sauvage elle préfère les stations ensoleillées, dans un sol sec, perméable, chaud, près de la mer. Ce n'est pas, du reste, une plante bien commune; et c'est seulement en quelques rares endroits (rochers maritimes de Nice, Villefranche, IIonaco, Capo Berla près d'Oneglia, Capo Mele près d'Alassio, Cap de Noli, Albissola) que l'on peut l'admirer en abondance. 
$-39-$

Coteaux secs; rochers maritimes. - Fleurit en mars of arril.

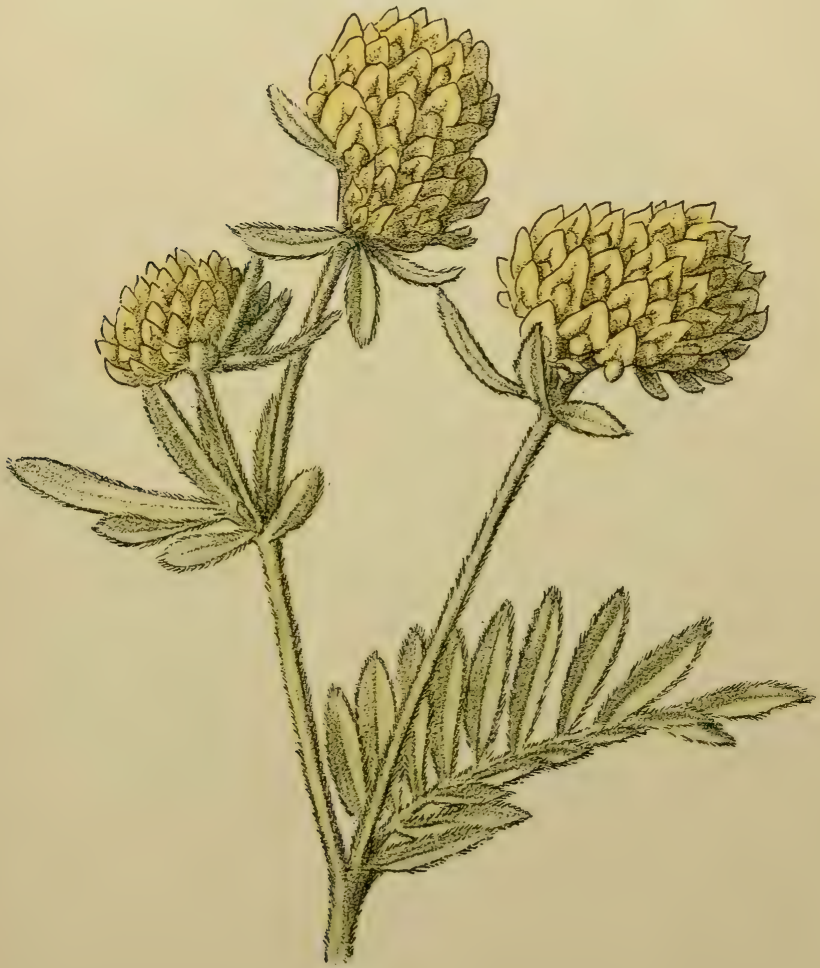

Anthyllis Barba Jovis.

Frane. Anthyllis Barloe de Jupiter.

Prov. Té, Vulnerairo. 
Bois de pins; pentes rocailleuses. - Flemit en arril of mai.

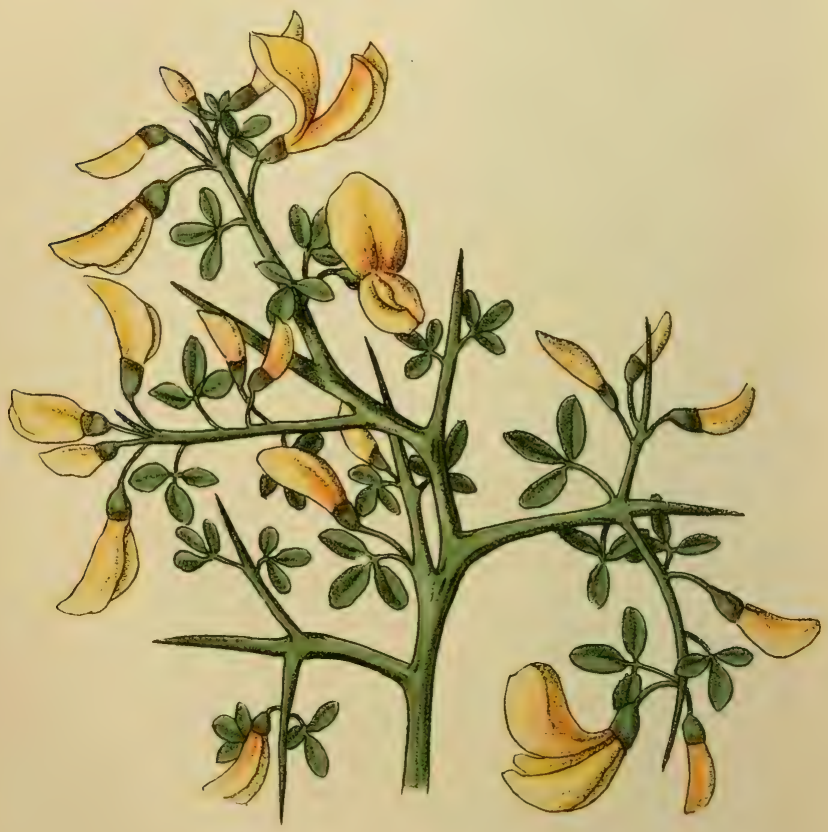

Calycotome spinosa.

Fruns. Tue-chèrres.

Prov. Argieras fer. 


\section{CALYCOTOME SPINOSA.}

Ital. : Scannabecco; Ligur. : Arastre; Espagn. : Relama espinosa.

Le promeneur qui s'éloigne des sentiers sur les collines du littoral, ne tarde point à faire la connaissance de cet arbrisseau, et quelquefois à ses dépens ou à ceux de ses vêtements; car c'est une des plantes les plus épineuses de notre région. Ses rameaux tortueux et entrelacés sont hérissés de très forles épines ramifiées, droites, qui défendent efficacement les petites feuilles contre les attaques des chèvres ou d'autres animaux herbivores. Pendant la plus grande partie de l'année, le Calycotome reste sans feuilles, et présente alor's un aspect peu attrayant; c'est seulement au mois d'avril ou de mai que toute la plante se recouvre de fleurs d'un très beau jaune doré; et les flanes arides des collines, les rochers de la zone littorale, qui sont en grande partie couverts de cette légumineuse, se font remarquer de loin par les grandes taches jaunes qu'elle forme au milieu de la verdure générale.

On emploie les rameaux épineux du Calycotome pour faire des balais grossiers. Les graines en sont vénéneuses, et toute la plante contient une substance toxique, surtout pour les ruminants (d'où le nom vulgaire de \& Scannabecco », Tue-Chèvres). 


\section{MEDICAGO MARINA.}

Cette espèce est une des plantes caractéristiques de la Flore des sables et des dunes maritimes de la Méditerranée. Elle ne manque presque jamais aux endroits où la plage descend doucement vers la mer, el est couverte non plus de galets, mais de ce sable fin qui donne envie de s'y étendre et de s'abandonner à la rêrerie. La « Minette dorée des plages ^ forme, au milieu de ces sables, des plaques blanchâtres, plus ou moins étendues; tandis que sa racine pirotante, très longue et ligneuse, s'enfonce droit dans le sol pour chercher un peu d'humidité dans les couches plus profondes, ses rameaux nombreux s'étendent, en rayonnant d'un centre commun, tout autour du point d'attache, couchés sur le sable et couvertes d'un feuillage épais, blanchâtre-cotonneux. En été, ces plantes se couvrent d'une quantité remarquable de petiles fleurs d'un beau jaune foncé, presque orange; les fruits sont revêtus du même duret tomenteux que celui des feuilles.

Parmi les plantes qui vivent dans une atmosphère très pure, comme sur les bords de la mer ou sur les hautes montagnes, un certain nombre sont couvertes d'un manteau de laine blanche qui défend leurs tissus contre l'action trop vive des rayons solaires: p. ex. les Leontopodium (Edelweiss), Diotis candidissima (pl. 66), Cineraria maritima (pl. 53), etc., etc. 
Sables maritimes. - Fleurit ou juin of juillot.

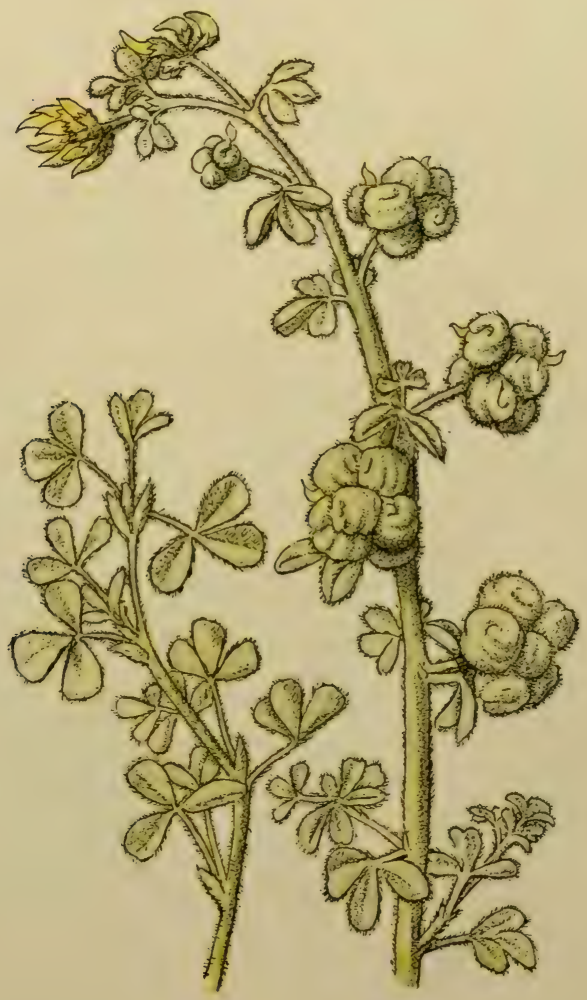

Medicago marina.

Frums: Ninette dorée des plages, Luzerne marius.

Prov. Erbo dou pardoun. 
$-42-$

Maquis; haies. - Ifemil presifur fomte limmins.

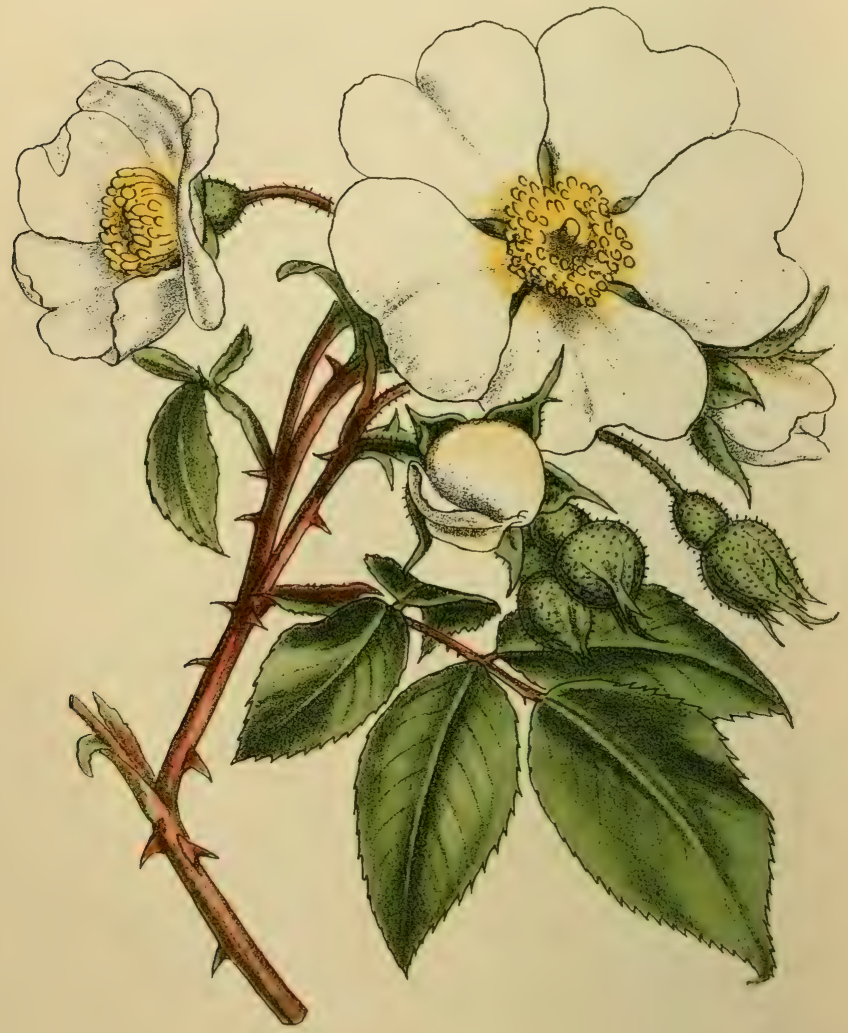

Rosa sempervirens.

Franr. Rosior toujour's rert.

Prov. Agalancié, Rousió frer. 


\section{ROSA SEMPERVIRENS.}

Ital. : Rusa sempreverde; Ligur. : Reusa; Allem. : Immergrünes Heckenrüschen; Angl. : Evergreen dog-rose.

Arbrisseau à rameaux allongés, souvent grimpant à l'aide d'aiguillons recourbés, à feuillage coriace, luisant, d'un beau vert foncé, sur lequel les fleurs, d'un blanc laiteux ou jaunâtre, ressortent vivement. On le troure assez fréquemment clans les haies, dans les maquis de la région du littoral et de la colline.

La Riviera peut à juste titre être appelée le pays des roses, à cause de l'importance qu'y a prise la culture des rosiers.

La floraison de plusieurs variélés a lieu précisément dans les mois d'hiver; et lorsque le doux climat en favorise le développement, les roses de la Riviera forment un des articles les plus importants du commerce d'exportation des fleurs coupées. Le produit net d'un hectare cultivé elı rosiers peut varier de 4.000 à 10.000 francs par an; on peut se faire une idée de l'importance de celte production, quand on lit qu'un seul cullivateur à Nice, dans la bonne saison, expédie $ّ 00$ à 600 douzaines de roses par jour!

Il y a de nombreuses variétés, parmi lesquelles celles qui appartiennent aux rosiers remontants sont les plus appréciées. 


\section{PUNICA GRANATUM.}

Ital. : Melagrano; Ligur. ; Meï-graniè; Espagn. : Granado; Allem. : Granatapfel; Angl. : Pomegranate.

Arbrisseau épineux ou arbre de moyenne taille, à feuillage dense, sombre; feuilles petites, opposées, fleurs grandes, d'un roug'e très vif, rarement blanches; fruits de la grosseur d'une grosse pomme, sphériques, brusquement rétrécis au sommel et couronnés par le calice persistant. Sous l'écorce rougeâtre et coriace du fruit, on trouve réunies en plusieurs loges, de nombreuses graines irrégulières, polyédriques, entourées chacune d'une pulpe transparente, rouge-grenat, d'un goût acidulé, agréable, qui est employée pour faire une boisson rafraîchissante. Le grenadier est renommé aussi en médecine, car toute la plante, et surtout l'écorce de sa racine, renferme une substance' particulière, antihelmintique.

Dans la mythologie de beaucoup de peuples des contrées chaudes, cette plante joue un rôle important, comme symbole de fertilité; on dit que la fameuse pomme donnée par Paris à Vénus était « une grenade Originaire peut-être de l'Asie Mineure, la plante a été introduite en Europe par les Phéniciens et par les Arabes : la ville de Grenade en porte encore le nom, et le fruit du grenadier figure dans ses armes. La plupart des exemplaires que l'on voit le long de la Riviera sont cultivés; mais le grenadier se trouve subspontané çà et là dans les rocailles. 
Rochers; souvent cultivé. - Fleurit "n juillıt.

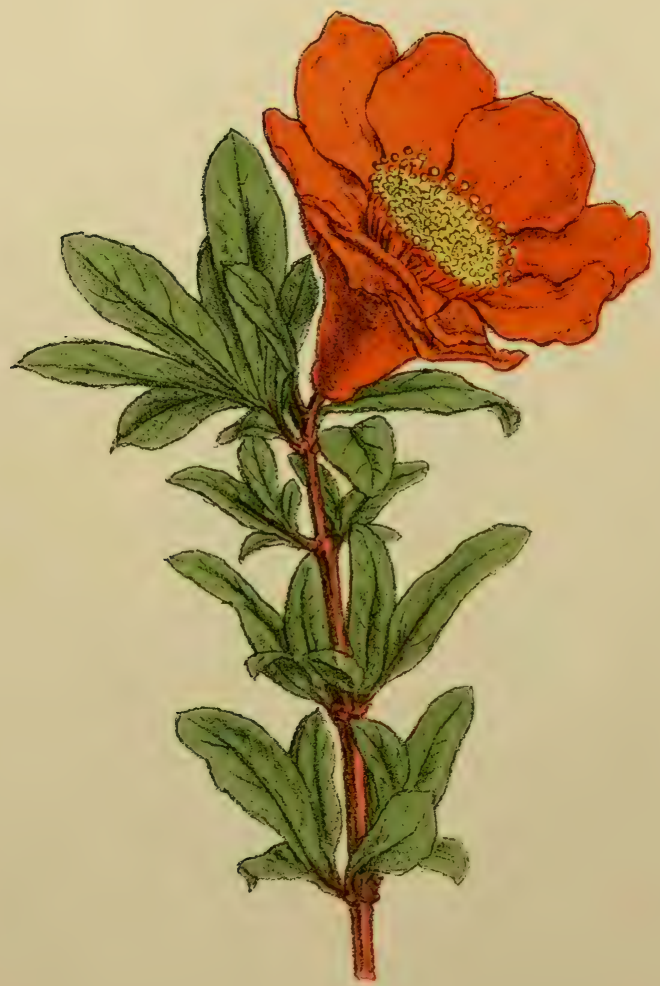

Punica Granatum.

Frune. Grenadier.

Prox. Miougranic. Mingranic. 


\section{- $44-$}

Maquis ; rochers maritimes. - Fleurit on arril et mai.

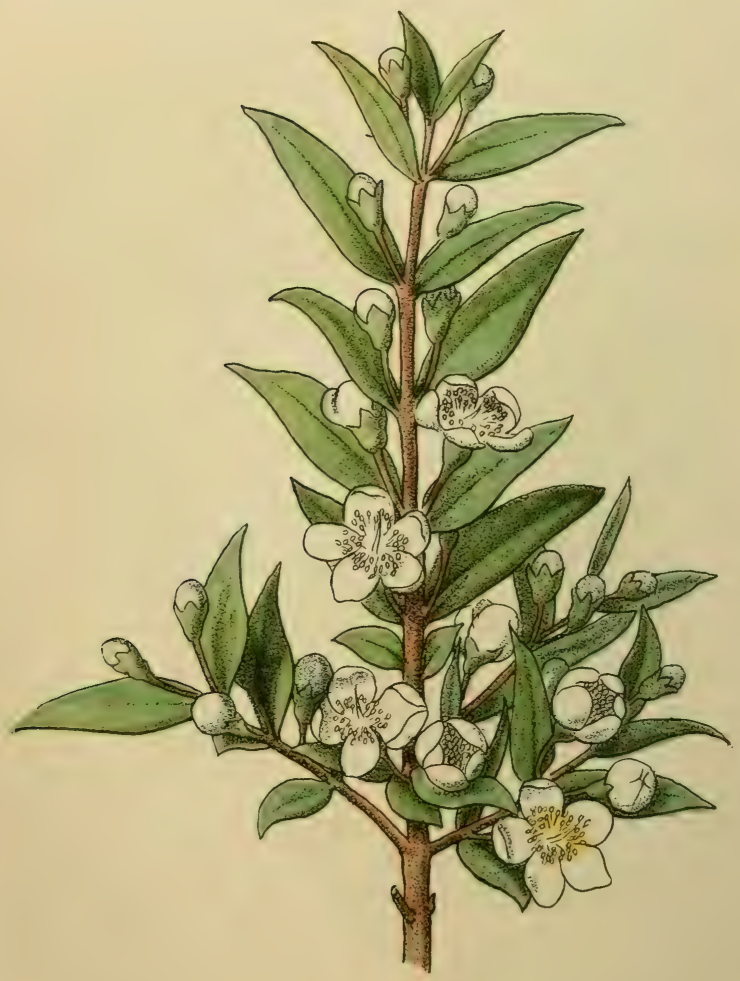

Myrtus communis.

Frane. Mrrte. Prov. Erba daou lagui, Nerto. 


\section{MYRTUS COMMUNIS.}

Ital. : Mirlo; Ligur. : Murtin, Mortora; Espagn. : Murla; Allem. : Nyrthe; Angl. : Myrtle.

Arbrisseau à feuilles persistantes, coriaces, opposées, luisantes, qui au printemps se recouvre de milliers de fleurs blanches, en étoiles. Ses fruits sont des baies sphériques d'un noir bleuâtre, couronnées par le calice. Ils ont un goût aromatique, résineux, qui se retrouve dans toute la plante, surtoul si l'on froisse les feuilles, et qui est caractéristique pour la famille des Myrtacées tout entière. En effet, bien des plantes fournissant les épices les plus renommées, comme le giroflier, le piment, le cajeput, etc., appartiennent à cette famille. L'huile essentielle du myrte commun, obtenue par la distillation de l'écor'ce, est connue en parfumerie sous le nom d'Eau-d'ange; mais ce n'est pas un arlicle de grand commerce.

Le myrte croît abondamment dans les maquis de la Riviera, sur les rochers maritimes, mêlé aux arbousiers, aux lentisques, avec le romarin, le thym et d'autres plantes odorantes. Il est très commun en Corse. Dans le Nord, on le cultive souvent dans les orangeries; et dans divers pays du Nord ses fleurs sont employées, comme symbole de virginité, dans la couronne des jeunes mariées, de même que les fleurs d'oranger dans le Sud.

Cultivé en pleine terre, on peut s'en servir, comme du buis, pour des bordures, des haies, etc., en les taillant de différentes manières. 


\section{ECBALIUM ELATERIUM.}

Ital. : Cucumero murino: Ligur. : Cisyocmue marin; Espagn. : Cohombrillo Amargo;

Allem. : Sprilsymlie: Angl. : Squirting gourd.

Plante vivace, à tiges herbacées, couchées, anguleuses; feuilles triangulaires ou un peu lobées, rudes, comme la lige, par la présence de nombreux poils courts, épineux, incrustés de substance minérale. Fleurs petites, jaunâtres, à sexes séparés : les fleur's mâles (c'est-à-dire à étamines) ont les dirisions de la corolle plus larges que les fleurs femelles. Cellesci montrent au-dessous du calice l'ovaire oblong; hérissé de poils épineux, se transformant plus tard en petit concombre. Le fruit est charnu, et possède à l'époque de la maturité une propriété singulière, bien connue des enfants. A peine a-t-on touché un Îruit bien mûr, qu'il se détache de son pédoncule par une contraction subite, et lance à travers l'ouverture qui vient de se produire au point d'attache, un jet de liquide mucilagineux, mêlé à de nombreuses graines. Ce jet est assez fort pour répandre les graines à une distance de 4 à 5 mètres : et c'est bien là le but de cette dissémination singulière. Le liquide renfermé dans les fruits est très amer et purgatif, comme le suc des coloquintes; et les paysans l'emploient parfois pour préserver leur's raisins contreles maraudeurs qui se trouvent bien punis, lorsqu'ils touchent aux grappes infectées par le suc du giclef.

Cette plante (qui avec deux espèces de Bryonia représente en Europe la vaste famille des Cucurbitacées) est assez répandue dans le littoral aux bords de la mer, clans les endroits incultes, sur les décombres ou le long des routes, et très commune en Corse. 
Endroits incultes, décombres - F leuril mu juin w juillel.

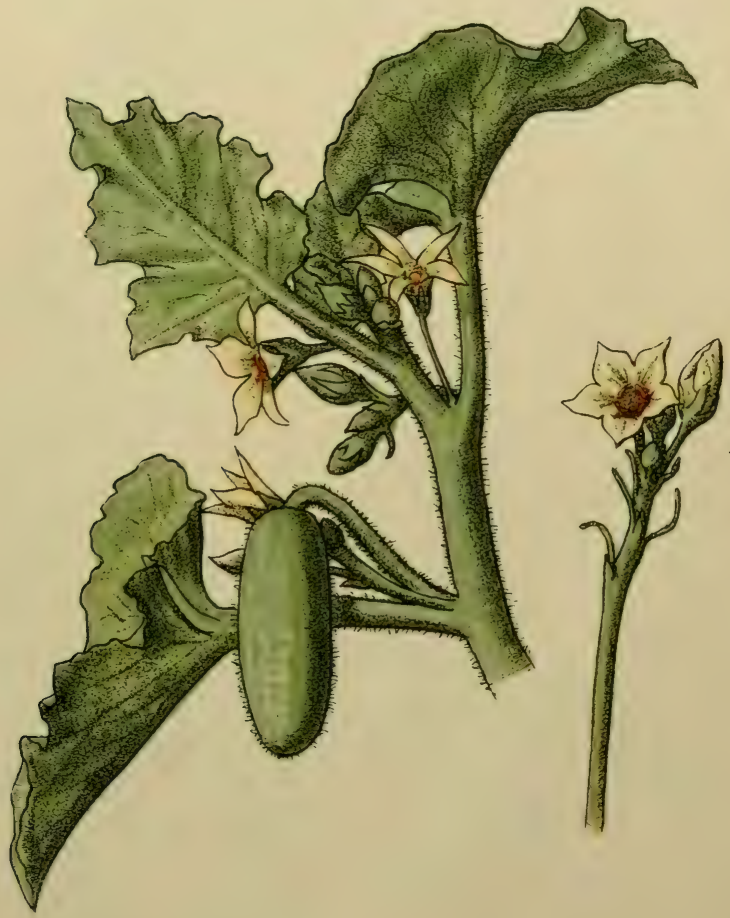

Ecbalium Elaterium.

Frane. Alomordigue, Giclef, Pistolet de dames. Prue. Counenumbre d'aze, Cougoumasso. 
$-46$

Murailles; rochers verticaux. - Fleurit en avril et mai.

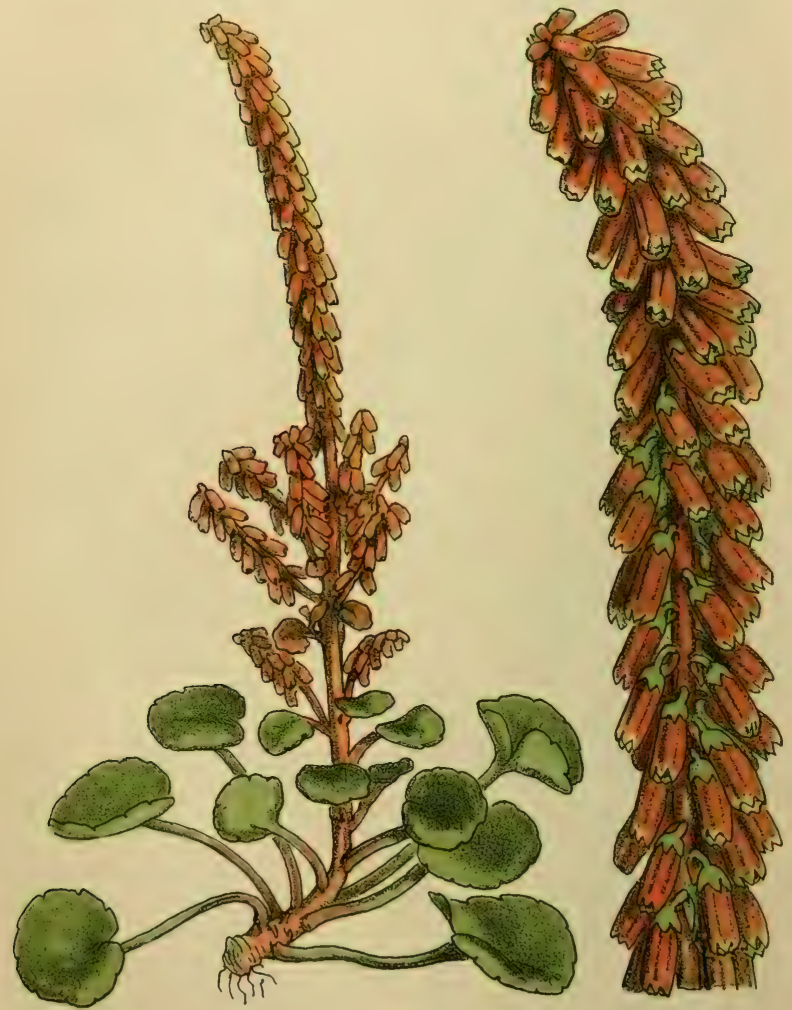

Umbilicus pendulinus.

Franc. Nombril de Vénus. Prov. Coucarèta, Escudet, Carinet. 


\section{UMBILICUS PENDULINUS.}

Ital. : Ombellico di Tenere; Ligur. : Crapletli; Espagn. : Ombligo de Venus: Allem. : Venus-Vebel; Angl. : Vavel-wort.

Plante bisannuelle, avec une rosette radicale de feuilles très charnues, d'un vert clair, de forme caractéristique, arrondie, ombiliquée (c'est-à-dire avee une dépression au centre) par suite de l'insertion centrale ou presque centrale du pétiole. La seconde année, la tige florifère s'allonge au milieu des feuilles en grappe droite, cylindrique, couverte de fleurs jusque près de la base. Les fleurs, étroitement serrées les unes contre les autres, sont vertes ou rougeâtres, en forme de cloche étroite, pendante; les fruits secs s'ouvrent à la maturité, et les graines, nombreuses, très petites, sont transportées aisément par les courants d'air dans les fentes des murs ou des rochers perpendiculaires. C'est la station préférée par notre plante; et partout sur la Riviera, cle la mer jusqu'à la hauteur de plusieurs centaines de mètres, on peut la trouver très abondante sur les murs rustiques qui bordent les routes, ainsi que dans les villages. Les feuilles frappent singulièrement la vue par leur forme. Les paysannes les emploient parfois comme amollissantes, en les broyant à l'état frais, ou bien elles les appliquent encore vivantes pour protéger le bouton de la mamelle.

Cette plante n'est pas rare en Corse et dans l'Ouest de la France. 


\section{SEDUM ALTISSIMUM.}

Ligur. : Erba risella; Espagn. : Pan d'Audel, Arros de l'ardal; Allem. : Gold-1Lauerpfeffer; Angl. : Trip-Madam.

Herbe à souche vivace, à tiges cylindriques, couchées, souvent tortueuses, recouvertes de feuilles cylindriques, charnues, aiguës, d'une teinte glauque (bleuâtre) ou d'un vert très pâle. Il faut distinguer, parmi les rameaux de la plante, les rejets stériles, vivaces, qui ne produisent jamais directement de fleurs, et les tiges florifères annuelles, droites, qui peuvent atteindre 20-20̈ centimètres de hauteur.

A l'extrémité de tig'es presque nues, s'étalent plusieurs divisions, recourbées élégamment en queue de scorpion, et portant chacune de nombreuses fleurs en étoile, d'un jaune doré très vif dans quelques variétés; plus pâles et de teinte soufrée dans d'autres.

Comme presque toutes les espèces d'orpin, le Sedum altissimum préfère les lieux très secs, pierreux, et on le trouve très commun sur les crêtes des murs, souvent associé à d'autres espèces du même genre, comme le $S$. reflexum (qui lui ressemble beaucoup, mais est de taille plus petite), le $S$. acre, $S$. bononiense, $S$. sexangulare à fleurs jaunes, el le $S$. album à fleurs blanches. Ses feuilles charnues sont rafraîchissantes et un peu astringentes; dans quelques contrées on les mange bouillies, ou l'on en fait une soupe semblable à celle d'oseille. 


\section{$-47-$}

Rochers; murailles. - Flentil ru juillel al aonil.
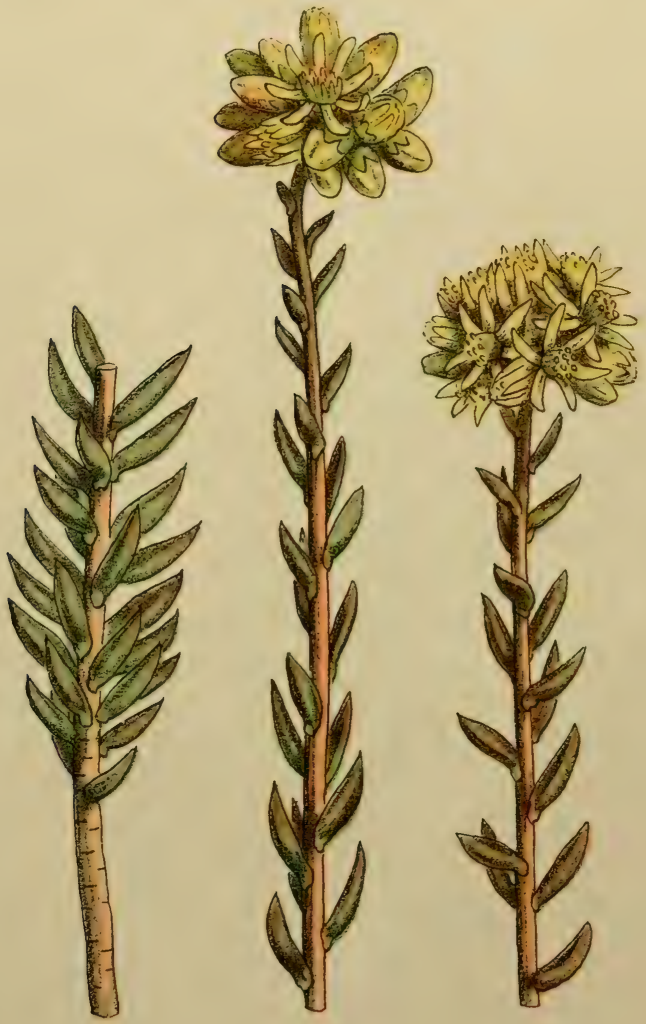

Sedum altissimum.

Franc. Orpin élevé.

Prov. Gros Rasinet. 
Murailles, haies; endroits pierreux. - Flemrit en mai.

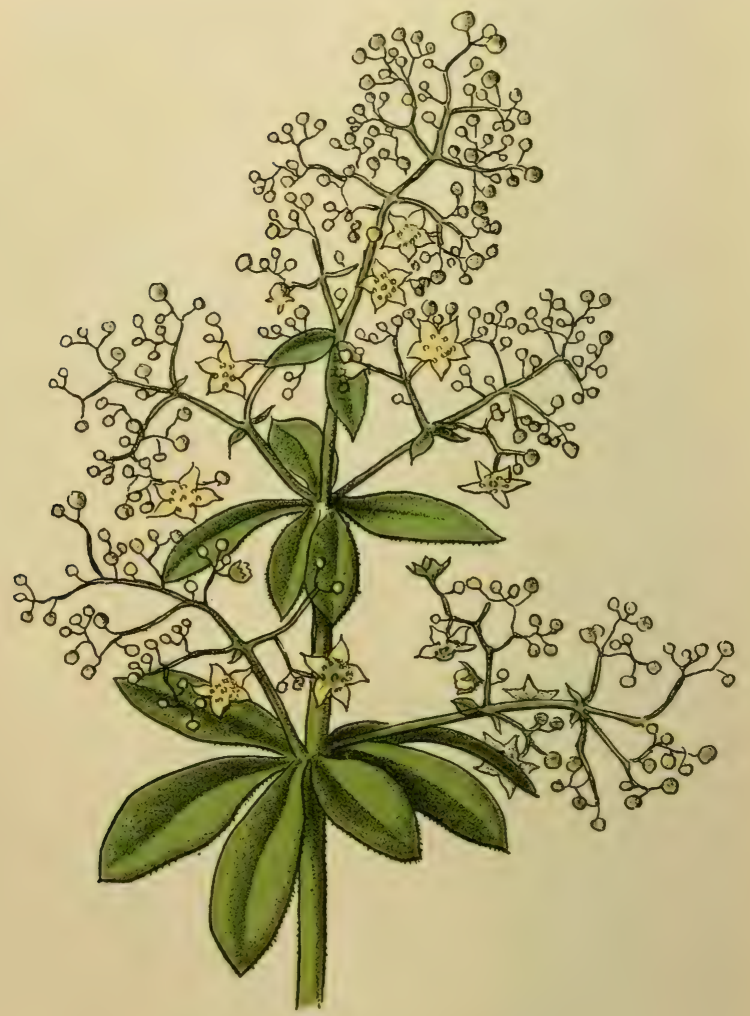

Rubia peregrina.

Frane. Garance saurage, Garance voyageuse. Prov. Réjistel, Rastelet, Rairestèu. 


\section{RUBIA PEREGRINA.}

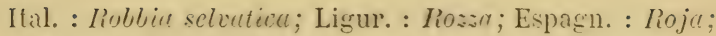
Allem. : Irille Fürberröthe; Angl. : Irild Indder.

Plante à souche vivace, à tiges herbacées, quadrangulaires, grimpantes à l'aide de nombreux petits aiguillons crochus, qui s'alignent le long des côtes de la tige et des bords foliaires. Feuilles disposées en verticilles de 4 à 8 , persistantes, coriaces, luisantes, souvent purpurines pendant l'automne et l'hiver. Fleurs en grappes étalées, d'un rert clair. Baies noires, luisantes, remplies d'un suc violacé très foncé.

Celte jolie plante est trèsfréquente dans les haies, sur les murailles, s'élevant parmi les ronces et d'autres arbrisseaux, dans toute la région du littoral. Elle ressemble beaucoup à la Garance des teinturier's (Rubia tinctorum) qui, autrefois, était cultivée en France sur une grande échelle; mais elle en diffère par les feuilles et les tiges persistantes (annuelles dans l'espèce cultivée). Actuellement l'on substitue presque partout des substances chimiques à la matière colorante de la garance. Les espèces de Rubia ont, toutes deux, la propriélé curieuse de colorer en rouge le lait et les os des animaux qui sont nourris avec leurs racines 


\section{ORLAYA MARITIMA.}

Espagn. : Cospi.

Petite plante caractéristique pour les sables maritimes, et associée souvent au Diotis candidissima, Medicago marina, Salsola Kali, Euphorbia Peplis, dont elle a presque le port. Du point d'attache de la racine pivotante, simple, sourent très allongée, s'étalent horizontalement, sur le sable, les tiges couchées, anguleuses, couvertes de poils blanchâtres. Les feuilles, finement découpées, ont une teinte jaunâtre, surtout à l'époque de la floraison et de la maturation des fruits; les fleurs, réunies en ombelles, sont blanches et très petites.

On distingue généralement une ombelle centrale, très brièvement pédonculée, et plusieurs ombelles latérales qui dépassent longuement la première; chaque ombelle n'a que 3 - כ้ rayons.

Ce qu'il y a de plus curieux dans celle plante, ce sont les fruits, réunis deux à cleux, comme dans toutes les Ombellifères, au bout de chaque pédoncule. Ils sont anguleux, à côtes très saillantes; chaque côte porte plusieurs rangs d'aiguillons de moyenne longueur, recourbés en crochet à leur extrémité. A l'aide de ces pointes recourbées, les fruits mûrs s'accrochent très facilement à la laine des animaux, aux vêtements des passants, elc., et sont ainsi dissémiriés, comme les fruits de la Bardane, de la Lampourde et de beaucoup de plantes nommées « ériophiles », c'est-à-dire aimant la laine. 
$-49-$

Sables maritimes. - Fleurit en mai et juin.

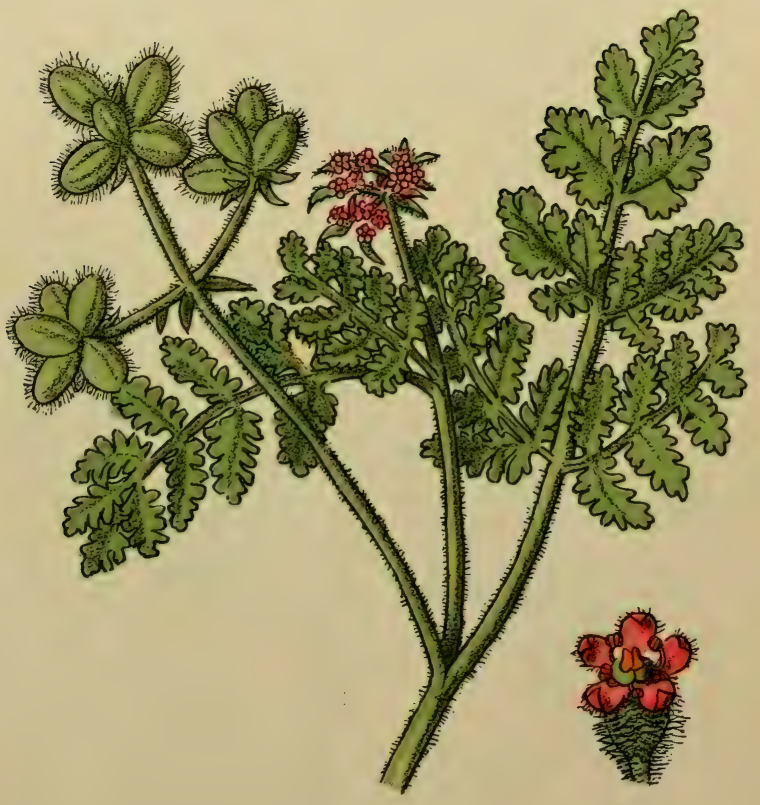

Orlaya maritima.

Orlaya maritime.

- Ombellifères. - 
$-50-$

Maquis; bois des collines. - lilenril en arril of mai.

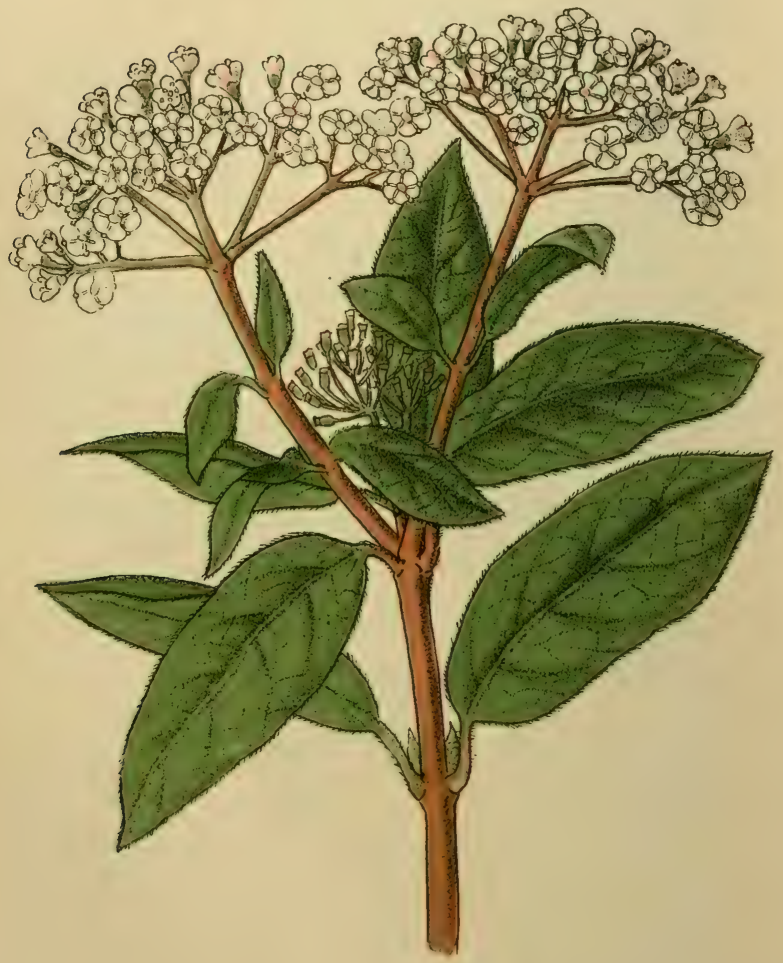

Viburnum Tinus.

Franc. Laurier-'Tin.

Prov. Fatamot, Favélou. 


\section{VIBURNUM TINUS.}

Ital. : Lauro Tino; Ligur. : Curnci; Espagn. : Durillo; Allem. : Bastardlorbeer; Angl. : Laurustinus.

Arbrisseau qui atteint la hauteur de 2 mètres, à feuilles persistantes, luisantes, de teinte sombre. Il se trouve spontané çà et là, dans la région littorale, aux lieux secs, pierreux, souvent mêlé à la Bruyère en arbre, sous les pins d'Alep; mais il ne s'éloigne guère de la mer. On le cultive beaucoup dans les parcs, parce qu'il peut constituer des massifs très compacts; c'est une plante précieuse pour le jardinier, sous plusieurs rapports: d'abord, par son feuillage; puis, par l'éclat de ses fleurs blanches qui se trouvent réunies en bouquets serrés; enfin, par ses fruits également ornementaux : ce sont des baies un peu oblongues et comprimées, d'un bleu métallique, teinte assez rare chez les fruits. Malheureusement, dans les jardins, le laurier-lin est très souvent infecté par un petit insecte du genre Thrips, qui ronge les feuilles et les fait dessécher, en leur donnant une teinte blanchâtre.

Les baies sont drastiques, purgatives; on les employait autrefois comme remède contre l'hydropisie. 


\section{$-51-$}

\section{LONICERA IMPLEXA.}

Ital. : Legabosco; Ligur. : Tïuldue; Espagn. : Madreselea; Allem. : Je-lünyer-je-lieber; Angl. : Honeysuckle.

Arbrisseau sarmenteux, à rameaux grêles, à feuilles opposées, persistantes, luisantes et d'un vert foncé sur la partie supérieure, blanchâtres et opaques en dessous. Tandis que les feuilles des rameaux stériles sont simplement sessiles (sans tige), oblongues, rétrécies à la base, celles des rameaux florifères sont soudées deux à deux, surtout vers l'extrémité des rameaux, formant ainsi au-dessous des fleurs une espèce d'involucre concave. Les fleurs sont réunies à l'extrémité des rameaux, en bouquets de 6 à 10 ; elles ont la forme de celles du Chèvrefeuille commun des jardins, mais elles sont un peu plus petites, et ont les divisions de la corolle plus prononcées. La couleur des fleurs est variable (purpurin, rose, blanc ou jaunâtre); leur parfum est plus intense pendant la nuit.

Celle espèce de Chèvrefeuille se rencontre fréquemment sur la Riviera, dans la région du littoral et des collines, dans les haies, ainsi que dans les maquis, où elle forme parfois de vraies lianes. On la trouve aussi assez communément en Corse. Souvent on la cultive dans les jardins, pour en former des berceaux, des treilles, elc. 
$-51-$

Haies, murailles. - Fleurit en arril of mai.

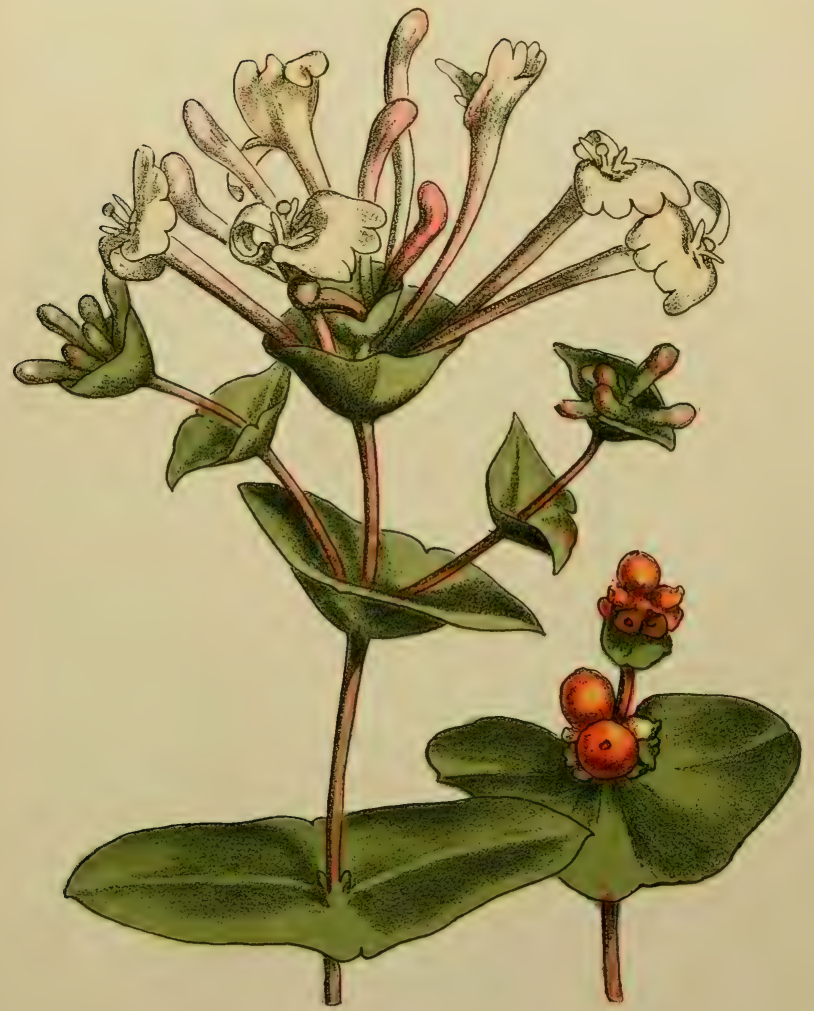

Lonicera implexa.

Froms. Chèvrefeuille entrelací. Prov. Pantacousta, Saouvo maire. 
Endroits pierreux, rochers maritimes. - Fleurit en mai et juin.

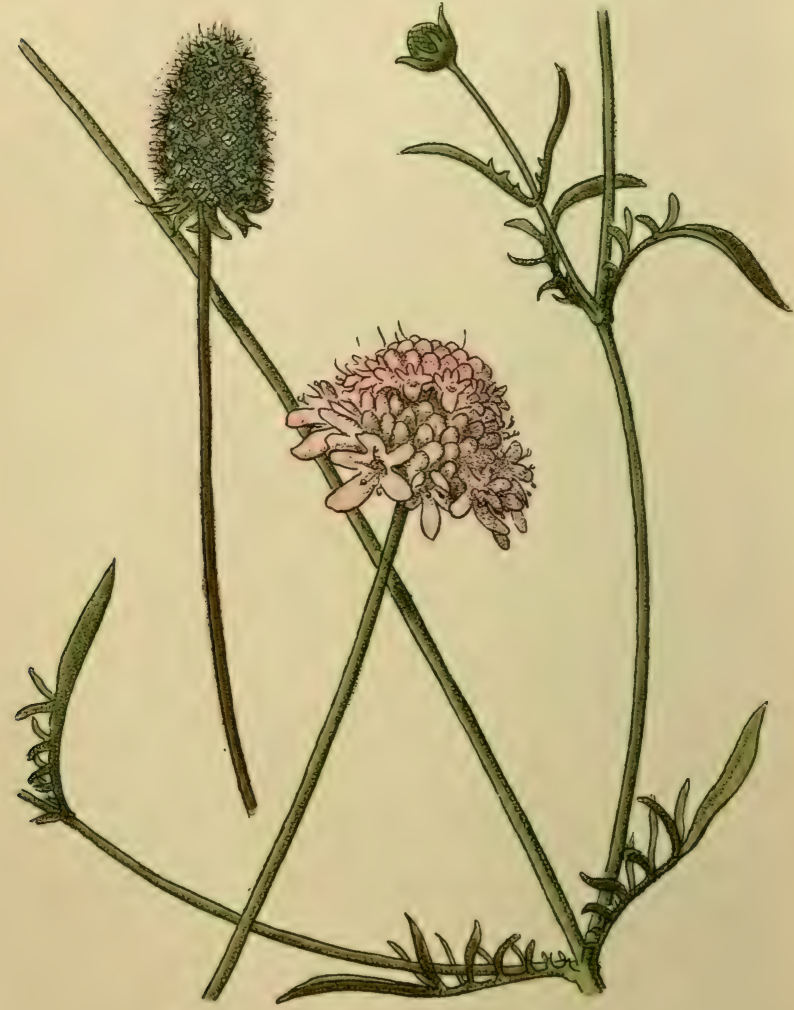

Scabiosa maritima.

Frane. Scabieuse maritime.

Prov. Escabiouso. 


\section{$-52-$}

\section{SCABIOSA MARITIMA.}

Ital. : Vedovelle; Ligur. : Viduelte; Allem. : Strand-Scabiose; Angl. : Sed-Scabious.

Plante vivace, haute de 30 à 50 centimètres, très commune dans les lieux secs, pierreux, sur les rochers maritimes de la zone littorale.

Les feuilles inférieures sont réunies en rosette radicale, souvent très élégante par suite de la disposition régulière et de la forme artistique des limbes foliaires; les supérieures, disposées par paires sur la tige, sont beaucoup plus finement découpées que les radicales, à lobes parfois presque capillaires. Toute la plante est recouverte d'un duvet tantôt soyeux, luisant, tantôt blanc-cotonneux. Les fleurs varient du rose tendre au lilas pâle : on trouve rarement la variété blanche. La Scabieuse des jardins (Scabiosa atropurpurea), à fleurs d'un beau pourpre foncé, presque noir, est peut-être une variété cultivée de la Scabieuse maritime.

Les feuilles et les fleurs de toutes les espèces de Scabieuse étaient jadis employées en tisane contre la phtisie, et comme remède externe contre la gale (Scabies, d'où le nom de a Scabieuse »); la pharmacopée actuelle les a abandonnées. 


\section{CINERARIA IMARITIMA.}

Plante à souche vivace, ligneuse, haute de 30 à 60 centimètres, ramifiée dès la base, à tiges nombreuses, ascendantes ou droites. Feuilles blanches, cotonneuses, très variables dans le contour, mais presque toujours d'une forme artistique.

La Cinéraire maritime est souvent cultivée à cause de son feuillage élégant et de ses fleurs d'un jaune doré, très vif : on en fait des bordures dans les jardins, ou bien on la met dans des vases pour orner les appartements.

Elle est fréquente le long de la Riviera, surtout sur les rochers maritimes, dans les fentes des murs, etc.; quelquefois pourtant elle s'éloigne beaucoup de la mer, comme, par exemple, dans la vallée de la Roja, au-dessus de Vintimille, où elle suit la route jusqu'à peu de distance de Saint-Dalmas de Tende. Les iles Sanguinaires, près de la Corse, en sont couvertes.

Récemment, on a beaucoup vanté l'emploi de la Cinéraire maritime contre les maladies des yeux et même contre la cataracte : le suc de la plante fraîche, filtré et versé goutte à goutte dans l'œil malade,'produirait, suivant quelques auteurs, un effet presque miraculeux. Cependant on ne sait pas encore quelle en est la substance active. 


\section{$-53-$}

Rochers et sables maritimes. - Fleurit en mai it juin.

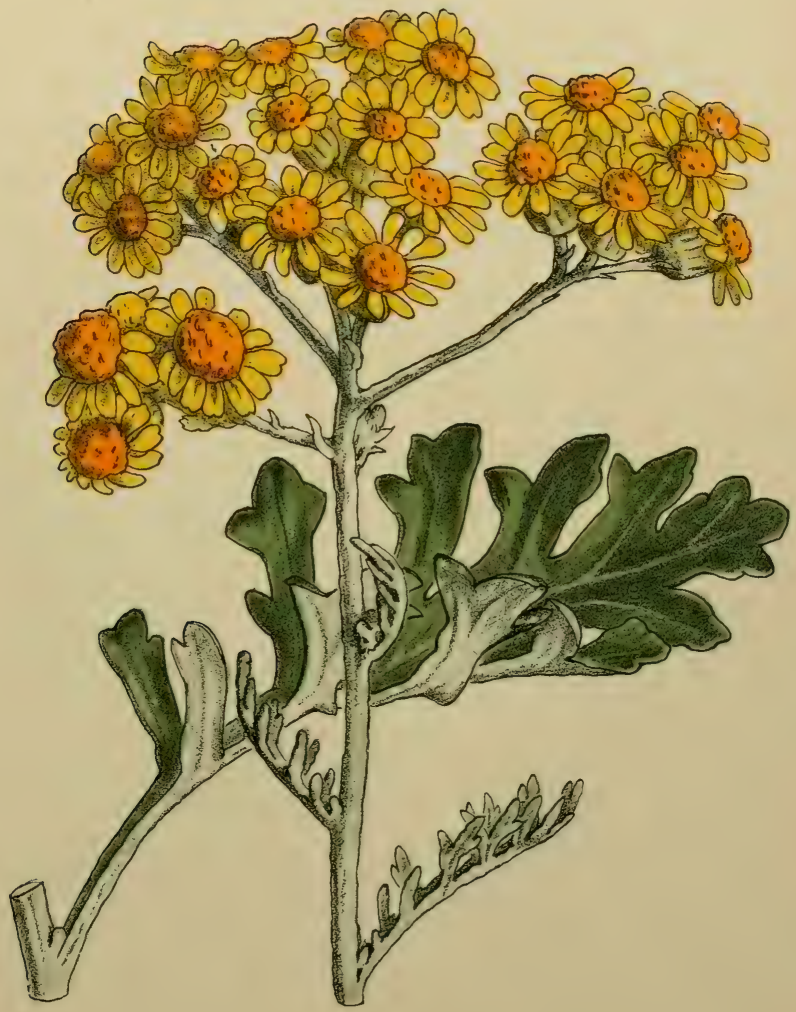

Cineraria maritima.

Frane. Cinéraire. Prov. Cinerero. 
$-54-$

Endroits pierreux; le long des routes. - Fleurit on juin et juillet.

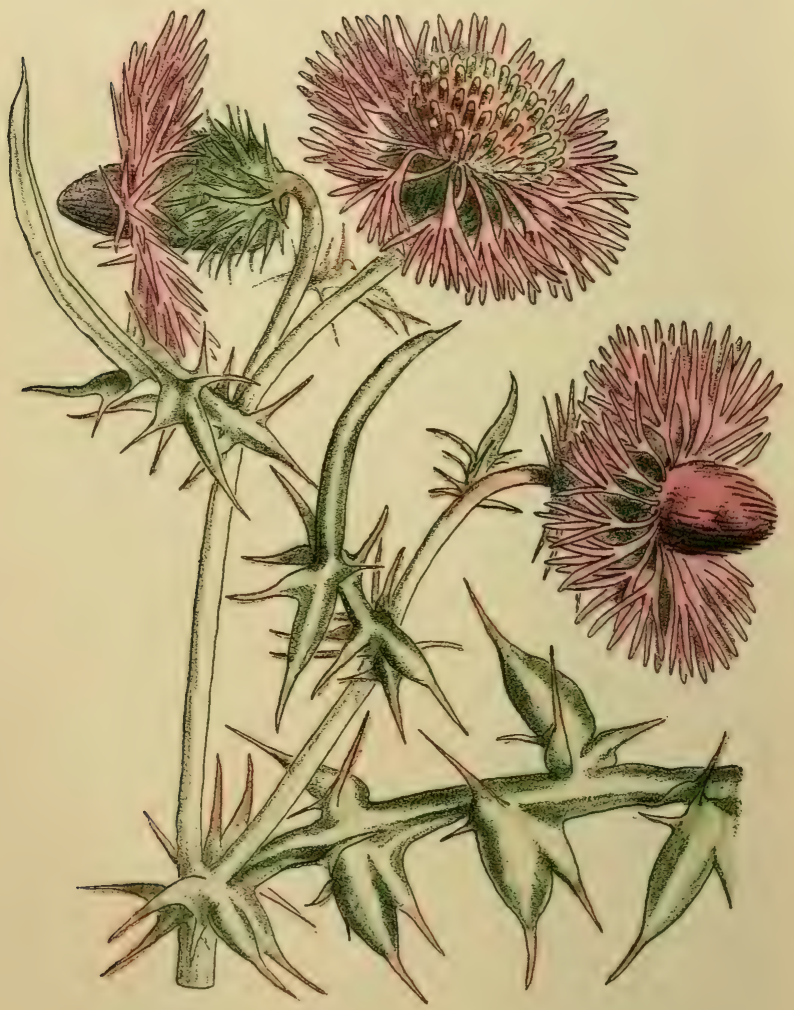

Galactites tomentosa.

Galactite cotonneuse.

- Composées. - 


\section{GALACTITES TOMENTOSA.}

\section{Ligur. : Batticristi.}

Cette espèce peut être facilement prise par les profanes pour un chardon, bien qu'elle n'appartienne ni au genre Carduus, ni aux Cirsium qui forment la masse principale de nos chardons communs. En effet, si par son port général, et surtout par les feuilles fortement épineuses, notre Galactites ressemble à un chardon, ses capitules floraux l'en distinguent aisément. Les fleurs de la circonférence de chaque capitule sont bien plus grandes que les autres, centrales, et à corolle rayonnante; en outre, elles sont tout à fait dépourvues d'organes sexuels (étamines et pistils). Ces fleurs stériles, neutres, ne servent done qu'indirectement à la fécondation et à la fructification, c'est-à-dire en attirant par leur éclat les insectes qui effectuent le transport du pollen. Un fait semblable se retrouve dans les inflorescences du bluet et de ses congénères, dans les genres Hydrangea, dans le Viburnum Opulus, etc.

Les fleurs du Galactites, avec leur teinte d'un lilas tendre, pâle, font un très joli effet; et le G.tomentosa, qui se rencontre en très grande quantité dans plusieurs localités de la route de la Corniche, en est un des ornements principaux. De plus, ses feuilles, tachetées de blanc et disposées en rosette, tant que la plante n'est pas encore en fleur, sont très élégantes et ont, comme l'on dit, \& du style architectural ». 


\section{ECHINOPS RITRO.}

Espagn. : Cardo Abadejo, C. yesquero; Allem. : Kungeldistel; Angl. : Globe Thistle.

Plante bisannuelle ou vivace, de 30 à 90 centimètres de hauteur, à tiges peu ramifiées, anguleuses, cotonneuses, à feuilles profondément lobées, épineuses, blanches-cotonneuses en dessous. Capitules solitaires à l'extrémité de la tige et des rameaux, globuleux ou en boule bleuâtre, quelquefois pâle ou blanchâtre.

L'aspect de toute la plante rappelle celui d'un chardon: mais, en comparant attentivement les capitules de ce dernier avec ceux de l'Echinops, on en trouve facilement la différence. Les Echinops manquent des écailles vertes, épineuses, qui servent de base ou d'involucre à l'ensemble des fleurs dans les Carduus, Cirsium et autres genres voisins; et, au contraire, on verra que chaque fleuron d'Echinops a un petit involucre à lui, formé d'écailles blanchâtres, transparentes, saillantes.

Les Echinops sont des plantes très ornementales, qui se conservent bien même à l'état sec; on les emploie beaucoup dans la composition des bouquels à fleurs sèches, comme les Immortelles.

L'Echinops Ritro el une espèce affine, l'E. sphaerocephalus, sont communes dans les endroits pierreux, incultes de la Riviera; en Abyssinie, il en existe une espèce gigantesque, presque arborescente, de la hauteur de plusieurs mètres, et dont les capitules mesurent environ 8 centimètres de diamètre. 


\section{— วัวั -}

Endroits pierreux; décombres. - Fenrit en juin et juillet.

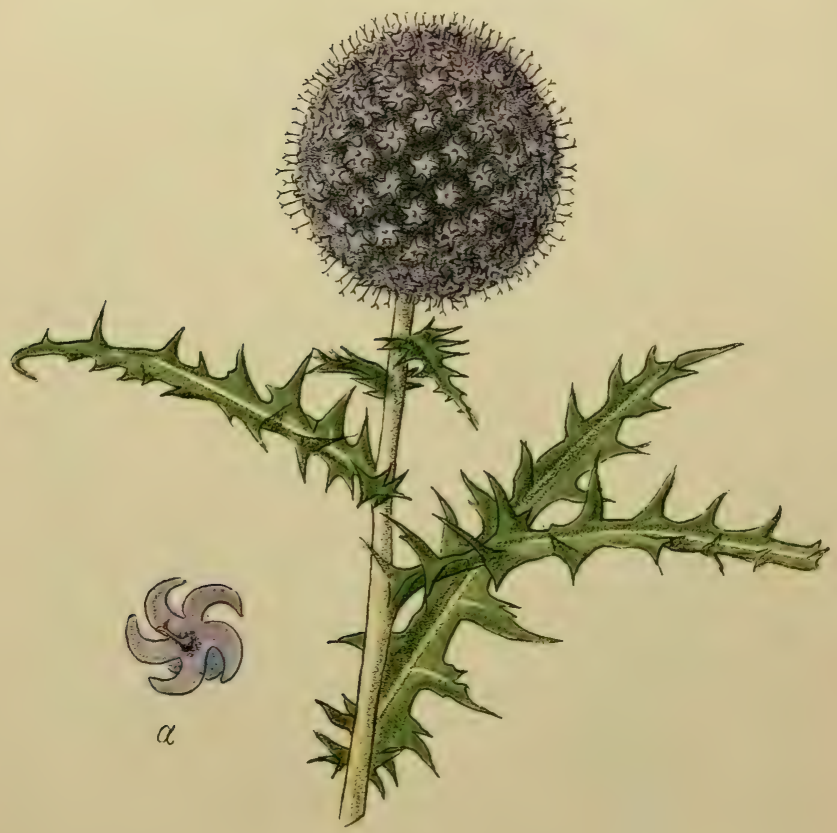

Echinops Ritro.

Prov. Bouleto.

- Composées. - 


\section{-}

Endroits herbeux; le long des routes. - Flemit en octolne et novembre.

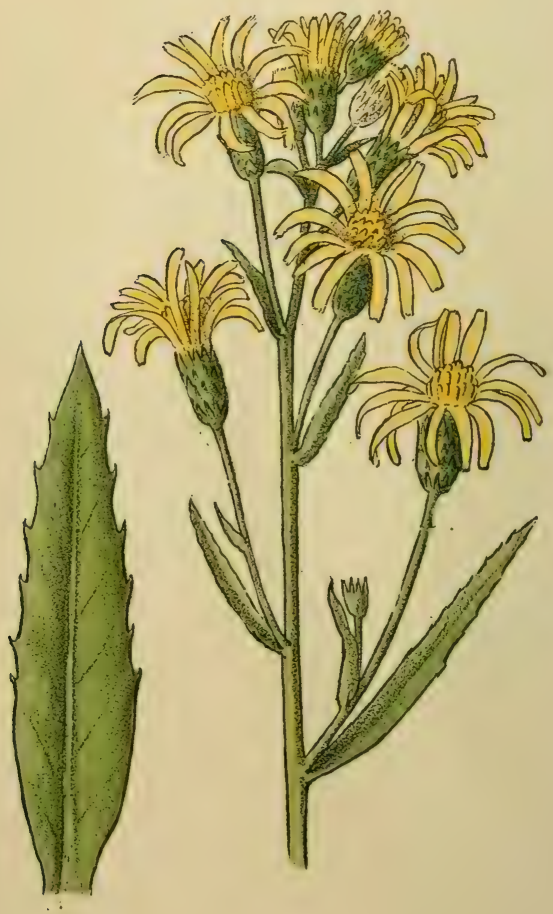

Inula viscosa.

Frune. Inule visumeuse. Prov. Erbo di maseo, Nasco. 


\section{INULA VISCOSA.}

Ligur. : Nasca; Espagn. : Olivarda, Allabaca.

Plante vivace, de $ّ 0$ centimètres à un mètre de hauteur, à tiges droites, ramifiées dès la base, aux branches ascendantes, touffues. Feuilles et branches couvertes d'un duvet visqueux, gluant; fleurs jaunes.

Toute la plante possède une odeur résineuse, aromatique, singulière mais non désagréable, d'une intensité telle que l'air en est embaumé dans les localités où le Nasca est fréquent; on pourrait, par son seul parfum et les yeux fermés, reconnaitre les stations de l'Inula viscosa, qui est très répandue sur la Riviera et en Corse; c'est elle qui accompagne presque constamment le voyageur le long de la Corniche.

La médecine populaire s'est aussi emparée de cette plante; et on vante l'emploi des feuilles fraîches contre les piqûres de vipère. A l'île d'Eubée, on emploie l'herbe fraîche pour mieux conserver le vin, peut-être en raison de la matière résineuse qu'elle contient. 


\section{CARDUUS CANDOLLEI.}

Ligur. : Baxaprêi; Espagn. : Cardo barriquerr.

Plante bisannuelle, à tige droite, rameuse, haute de 30 centimètres à un mètre, anguleuse et pourvue d'expansions latérales, foliacées, qui longent les rameaux et sont appelées a ailes §. Feuilles lobées, épineuses, blanchâtres-cotonneuses, de même que les ailes. Capitules floraux unis par deux ou trois, à l'extrémité de rameaux ailés presque sur toute leur longueur (d'autres espèces de chardon ont une sorte de hampe nue qui porte des inflorescences); fleurs d'un lilas pâle, quelquefois blanches.

Espèce commune le long des chemins, dans les lieux incultes, les décombres, etc.

Comme toutes les espèces de chardon, c'est une mauvaise herbe, qui envahit rapidement, par la dissémination facile de ses fruits plumeux, des contrées entières. Les chardons, il est vrai, sont riches en matière nutritive, mais, à cause de leurs épines, ils sont accessibles à peu d'animaux; tout au plus peuvent-ils servir à la nutrition, quand ils ont été fauchés encore jeunes. 


\section{- 57 -}

Décombres; le long des routes. - Fleurit en mai et juin.

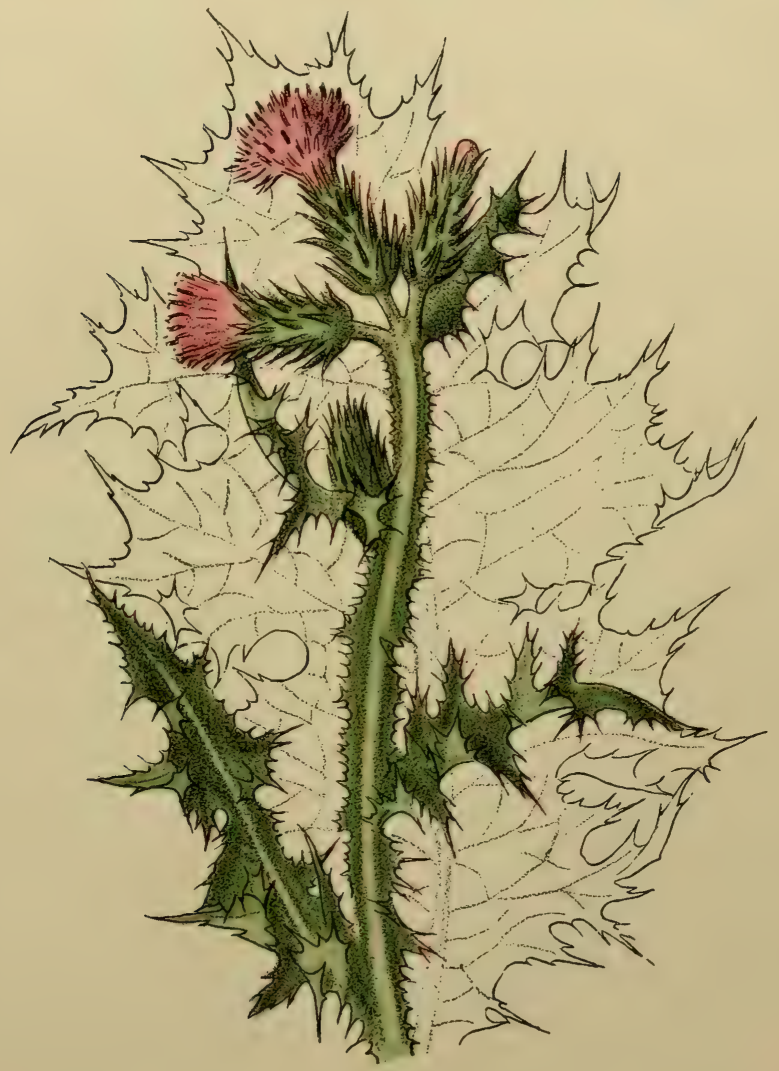

Carduus Candollei.

Frang. Chardon de Sainte-Baume. Prov. Cardoun. 


$$
-38-
$$

Chamrs, lieux cultivés. - Flmurt d'arril nn juin.

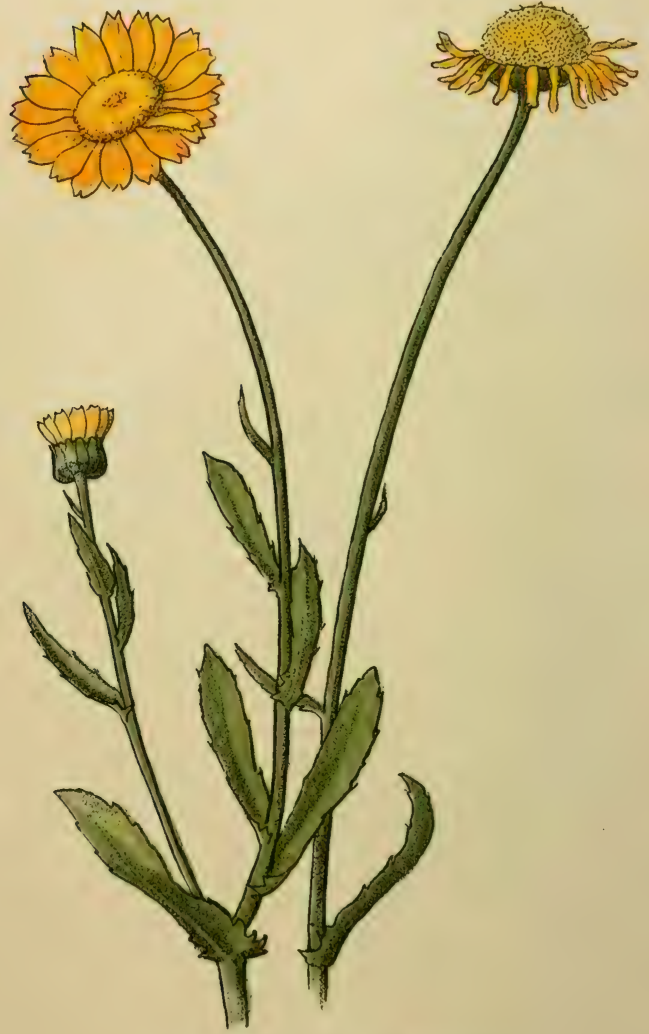

Chrysanthemum Myconis.

Frans: Chrysanthème de Mycon.

Prov. Crisantèmo. 


\section{CHRYSANTHEMUM MYCONIS.}

Ligur. : Mrrmprita sarvaja; Espagn. : Cïralde; Angl. :

Corn-Marigold.

Plante annuelle, herbacée, haute de 40 à 70 centimètres, peu rameuse, à tiges droites, anguleuses, glabres. Feuilles un peu charnues, vertes, finement dentelées sur les bords; fleurs d'un jaune doré, de très grande dimension.

C'est une des mauvaises herbes les plus communes sous les oliviers, dans les champs, les vignes, le long des routes; peut-être a-t-elle été introduite par l'homme lui-même, avec les céréales, comme c'est le cas pour le bluet, le pied d'alouette, la nielle des blés, etc. On trouve souvent aux mêmes endroits une autre marguerite à fleurs jaunes, le Chrysanthemum segetum, qui diffère du Ch. Myconis surtout par ses feuilles un peu glauques, pennatifides, c'està-dire divisées jusque vers le milieu du demi-limbe.

Jadis les fleurs du $C h$. Myconis étaient officinales, sous le nom de Flores Bellidis luteae; néanmoins, elles n'ont aucune action bien remarquable sur l'organisme humain. On peut en préparer une substance colorante jaune, assez semblable à celle du Safran bâtard (Carthamus tinctorius). 


\section{PICRIDIUM VULGARE.}

Ital. : Terracrepola; Ligur. : Raltalægua, Acciüssola; Espagn. : Cosconilla.

Plante annuelle, à racine pivotante, noire; feuilles radicales en rosette, allongées, à bords sinués ou pennatifides, celles de la tige à bords entiers ou dentelés, ovales, embrassantes. Tiges droites, peu ramifiées, glabres et glauques de même que les feuilles. Capitules solitaires au sommet de longs pédoncules, pourvus de petites écailles, qui sont plus nombreuses en haut. La forme des capitules est très caractéristique, rentrue et presque tronquée à la base. Les fruits secs, indéhiscents (ne s'ouvrant pas à la maturité), sont presque cylindriques, un peu courbés, à tubercules disposés en lignes transversales, et portant une aigrelte soyeuse, blanche.

Toute la plante, comme la plupart des espèces appartenant à la tribu des Lactucées, est pleine d'un suc laiteux, blanc, amer et gluant. De même que certaines espèces de Lactuca, Sonchus et Chondrilla, le Picridium se défend contre les insectes nuisibles, en faisant sorlir des goultelettes de ce lait visqueux, dès qu'il est touché ou frotté doucement soit à la surface externe des bractées, soit à la partie supérieure du pédoncule.

L'espèce est très commune dans les endroits pierreux, stériles, sous les oliviers de loute la Riviera; son port est fort variable, selon la fertilité du terrain où elle croît. 
$-59-$

Endroits secs, pierreux. - Fleurit presque toute l'année.

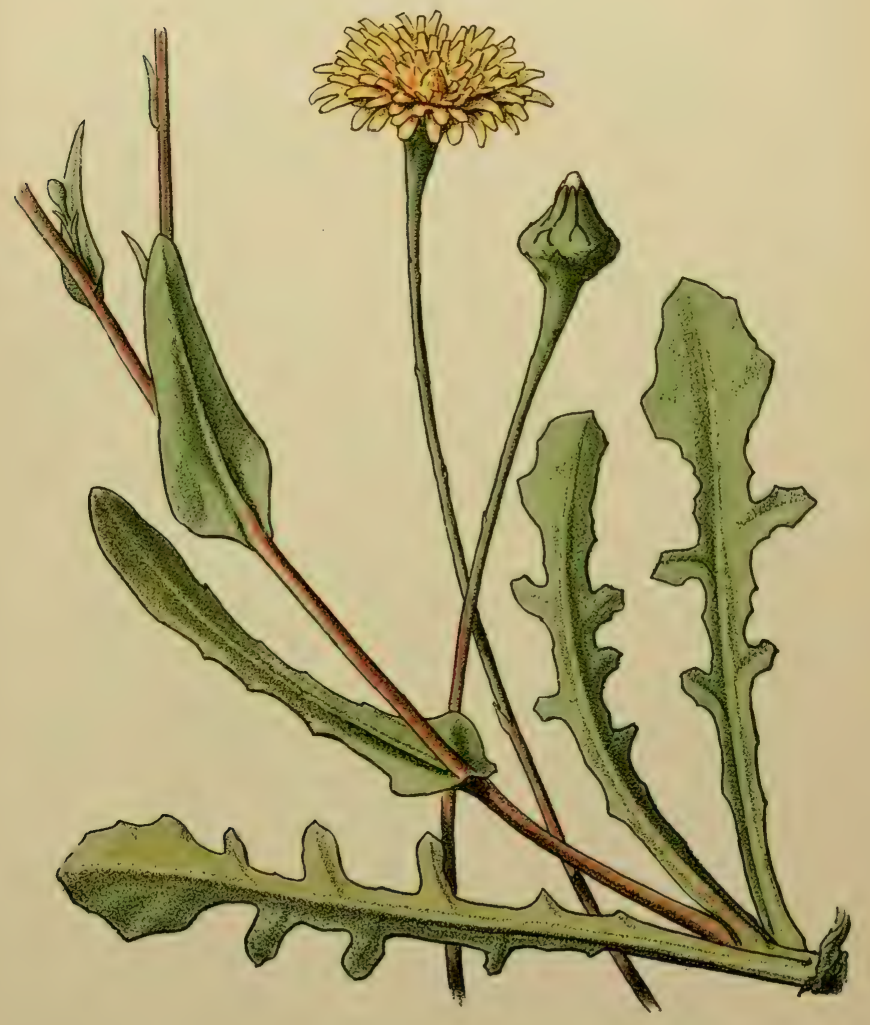

Picridium vulgare.

Frans. Picride commune. Prov. Terra-Greppia, Coustelino. 


\section{$-60-$}

Fossés, lieux cultivés. - Fleurit do mai en juillet.

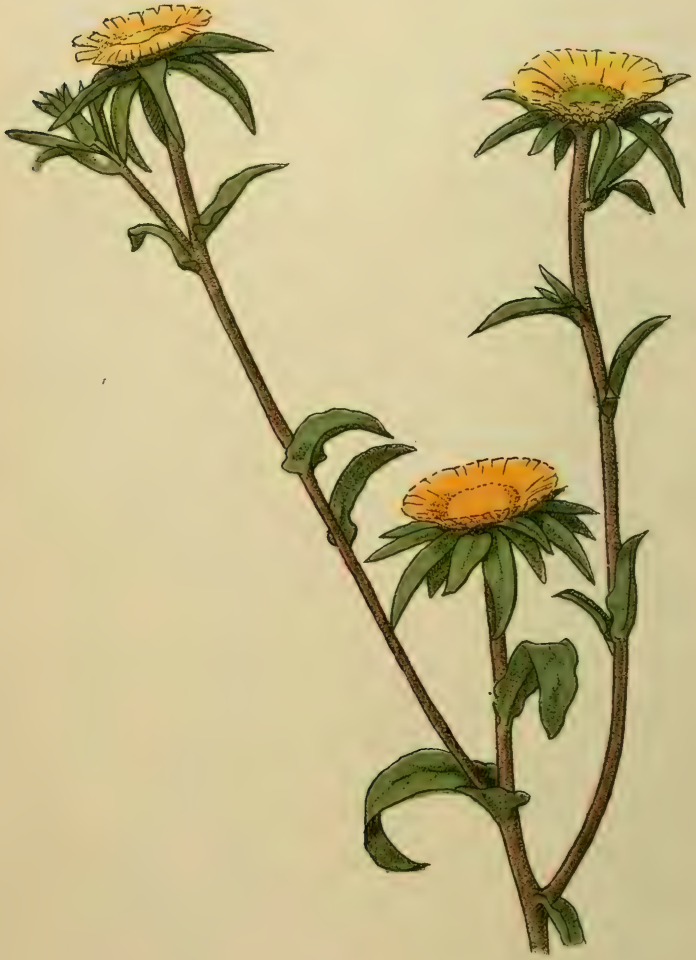

Asteriscus spinosus.

Astérolide épineux.

- Composées. - 


\section{ASTERISCUS SPINOSUS.}

Espagn. : Cevadilla.

Plante bisannuelle, c'est-à-dire qui ne produit la première année qu'une rosette stérile de feuilles radicales, et mûrit ses fruits seulement à la fin de la seconde année. Racine ligneuse, tiges droites, ramifiées, feuillées. Les capitules, solitaires à l'extrémité des branches, sont entourés de plusieurs bractées herbacées, vertes, mais qui finissent en pointe aiguë. Les fleurs sont d'un jaune vif et forment d'élégantes étoiles sur le fond sombre du feuillage.

Deux autres espèces d'Asteriscus, A. aquaticus et A. maritimus, se trourent aussi, comme l'A. spinosus, le long des routes, dans les fossés, sous les oliviers de la Riviera: elles s'en distinguent par les bractées dépourvues de pointes.

Du reste, ce sont des plantes qui n'ont aucune importance au point de vue économique ou médicinal. 


\section{UROSPERMUM DALECHAMPII.}

Ligur. : Bunòmo; Espagn. : Cuxa-Barba.

Plante à souche virace, grosse, noirâtre; liges droites, peu ramifiées, herbacées ; feuilles découpées comme celles du Pissenlit commun, à grand lobe terminal. Capitules portés par des hampes allongées épaissies au sommet; involucre velouté, en forme de cruche, formé par des bractées soudées. Fleurons d'un jaune soufré, pâle ; ceux de la circonférence de teinte purpurine en dessous. Les fruits sont surmontés, comme dans la plupart des Composées, d'une espèce d'aigretté formée par des poils soyeux, mais qui, dans notre espèce, sont rougeâtres; en cet état, la hampe florale, surmontée par une houppe de poils renfermés dans l'involucre, a l'aspect d'une brosse de peintre.

C'est une plante commune dans les pelouses, sur les coteaux secs, pierreux de la région littorale, souvent associée à une autre espèce du même genre, l'Urospermum picroides, qui s'en distingue par la tige annuelle et par l'involucre hérissé, non veloulé. Elle n'est d'aucun emploi, sauf celui de plante fourragère. 


\section{$-61-$}

Prés, lieux herbeux, ensoleillés. - Fleurit on arril ot mai.

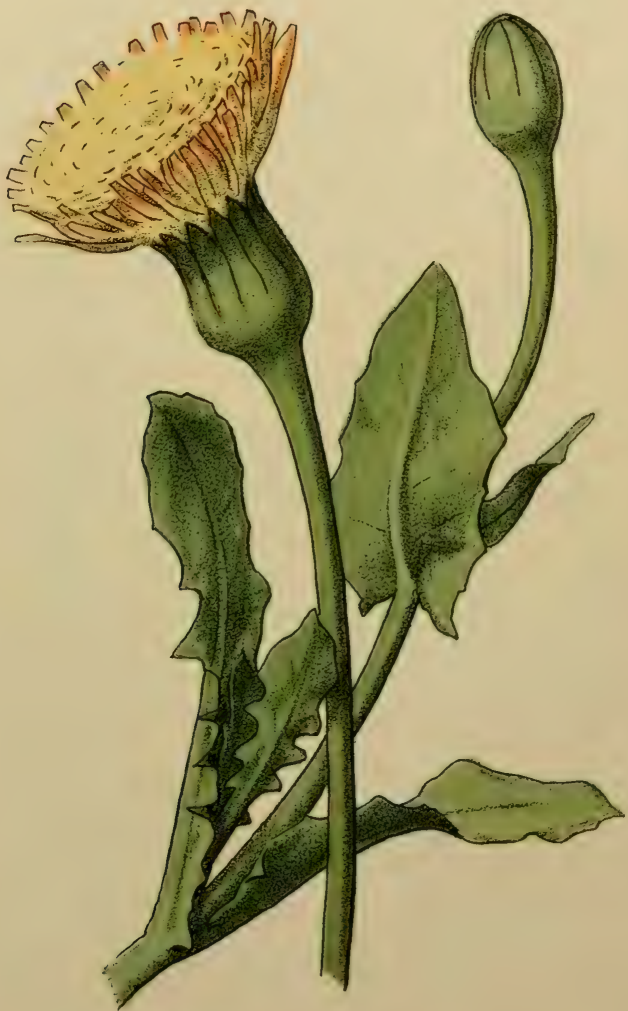

Urospermum Dalechampii. 


\section{$-62-$}

Murailles; lieux cultivés. - lleuril m man's of arril.

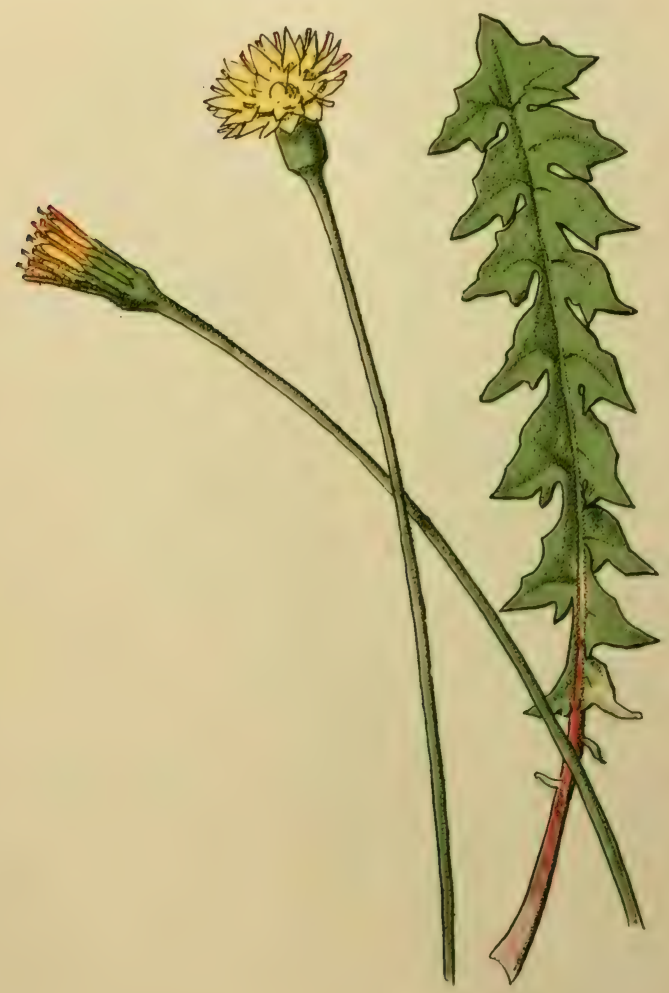

Hyoseris radiata.

Ilyoséride rayonnante.

- Compostés. - 


\section{HYOSERIS RADIATA.}

Ligur. : Taggiainetta.

Les vieux murs ont dans presque toutes les contrées un cachet particulier, par la flore ou florule qui s'y développe, et qui varie beaucoup d'un pays à l'autre. Parmi les plantes qui, dans la Riviera, revêtent les murailles, une des plus caractéristiques est le Hyoseris radiata. On voit partout les rosettes de ses feuilles allongées, découpées d'une manière analogue à celles du Pissenlit, au milieu desquelles s'élèvent les hampes florales, à peu près de la même longueur que les feuilles. Les hampes sont cylindriques, creuses, très peu épaissies au sommet; les fleurs jaunes.

Les fruits nous offrent un exemple d' * Hétéro-

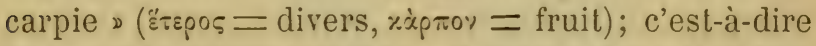
que, sur le même individu, et même dans la même inflorescence, nous trouvons divers genres de fruits. Les fleurs de la circonférence se transforment en petits fruits secs (akènes), ne s'ourrant pas à la maturité, de forme cylindrique, et couronnés d'une petite aigrette de paillettes aiguës; tandis qu'au centre du capitule les fruits sont des akènes comprimés, ailés, striés sur les deux faces. Ces akènes-ci se détachent facilement, et sont disséminés par le vent, pendant que ceux de la circonférence restent attachés à l'inflorescence, et sont mis en liberté seulement quand celle-ci pourrit. 


\section{PHAGNALON SAXATILE.}

Espagn. : Manzanilla yezguera.

Cette jolie espèce de Phagnalon se distingue du Ph. sordidum (figuré dans la planche 65) par ses feuilles plus larges, lancéolćes, un peu ondulćes et blanchâtres en dessous, ainsi que par les capitules plus grands, toujours solitaires à l'extrémité de chaque hampe, à bractées réfléchies. Vus de près, les capitules du $\mathrm{Ph}$. saxatile ressemblent à ceux d'un petit chardon jaune.

Il y a encore, dans le littoral, une troisième espèce de Phagnalon, le Ph. Tenorei, beaucoup plus rare, qui est très voisin du $P h$. saxatile, mais qui s'en distingue surtout par les bractées très étroile. ment appliquées aux capitules, jamais réfléchies.

L'habitat et l'emploi de ces deux espèces sont les mèmes que pour le $P /$. sordidum. 'Toutes les trois se trouvent aussi en Corse, le Ph. Tenorei seulement sur les rochers calcaires à Bonifacio. 
$-63-$

Rochers, murailles. - Fenrit en juin et juillet.

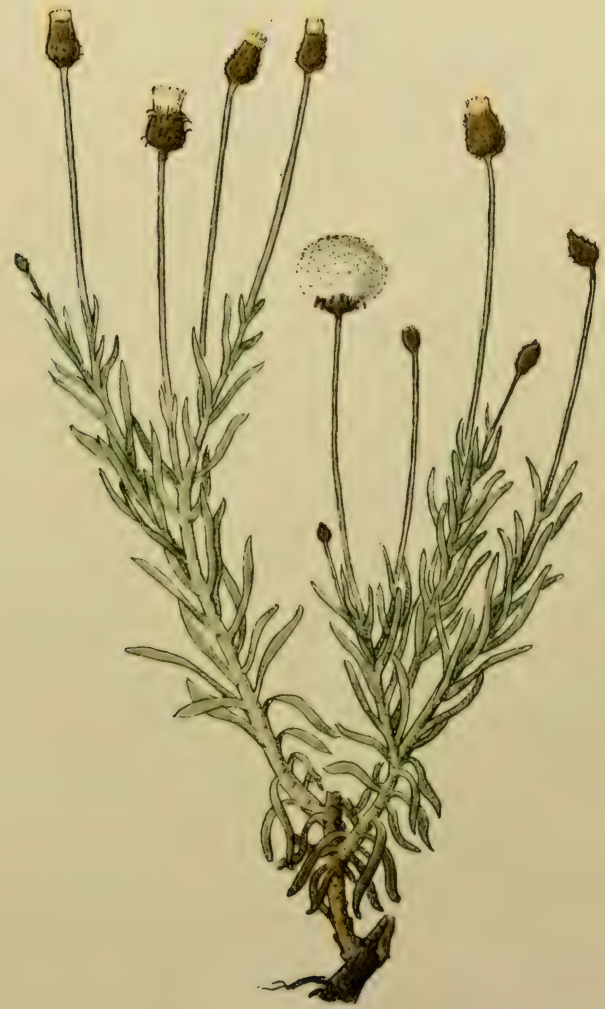

Phagnalon saxatile.

- Composíes. - 
$-64-$

Lieux herbeux; le long des routes. - Fleurit presque toute l'anníe.

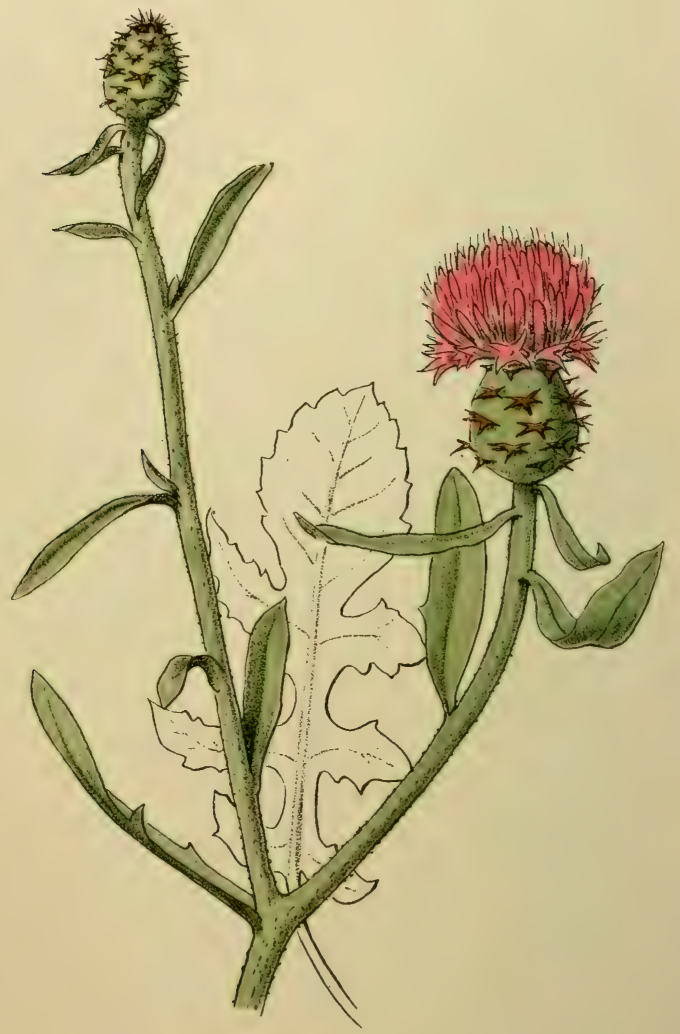

Centaurea aspera.

Frans. Centauréc rude.

Prov. Maco-muou. 


\section{CENTAUREA ASPERA.}

Ligur. : Mancamogli; Espagn. : Brasèra.

Plante à souche vivace, à tiges généralement allongées, couchées ou ascendantes, anguleuses, feuillées ; feuilles inférieures lobées, les supérieures entières, allongées ; toute la plante d'un vert sombre, couverte d'un duvet fin, grisâtre. Capitules floraux de moyenne grandeur; fleurs d'un lilas pâle. Les écailles, qui formentau-dessous du capitule ce quel'on appelle l'involucre, sont remarquables par leur conformation singulière: elles sont terminées par un petit groupe (3-气) de pointes ou d'aiguillons droits et jaunâtres. Dans d'autres espèces du mème genre, les bractées de l'involucre sont ornées d'autres appendices, frangés, très élégants et plumeux (comme dans le $C$. phrygia, $C$. pectinata); dans d'autres espèces encore on y trouve des épines droites, fortement développées ( $C$. solstitialis, $C$. Calcitrapa). Le bluet commun de nos champs de blé appartient au même genre.

Le $C$. aspera n'est point une plante qui se fait remarquer par la beaulé de ses fleurs: mais elle attire l'attention par sa fréquence le long des routes de la Riviera, dans les lieux stériles, aux bords des vignes, etc. On ne l'utilise que comme plante fourragère d'assez bonne qualité. 


\title{
PHAGNALON SORDIDUIM.
}

\author{
Espagn. : Herba murenèva.
}

Sur les parois des rochers calcaires exposés au soleil, dans les fentes des murs en eampagne, on trouve fréquemment les grosses touffes de celte plante aux feuilles cotonneuses, linéaires, aux tiges descendantes d'abord et puis recourbees en haut; le tout surmonté d'une quantité de hampes florales, terminées par plusieurs capitules petits, à fleurs jaunes.

Froissée entre les doigts, toute la plante dégage une odeur aromatique, semblable à celle des Santolina; et on l'emploie parfois, comme celle-ci, pour préserver les vêtements des teignes. 
$-6 \ddot{3}-$

Rochers ; murailles. - Flourit en juin ol juillet.

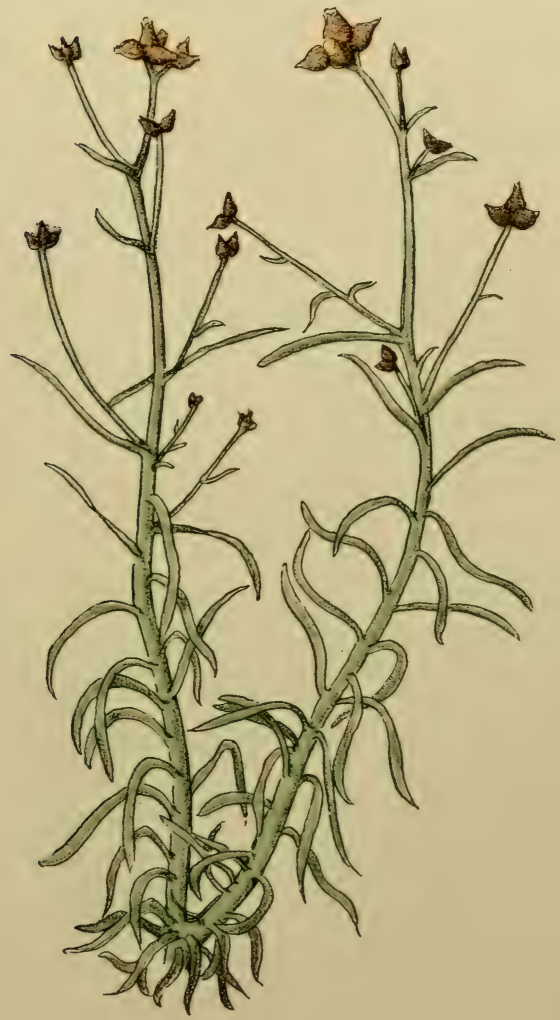

Phagnalon sordidum. 
$-66-$

Sables maritimes. - Fleurit en juin et juillet.

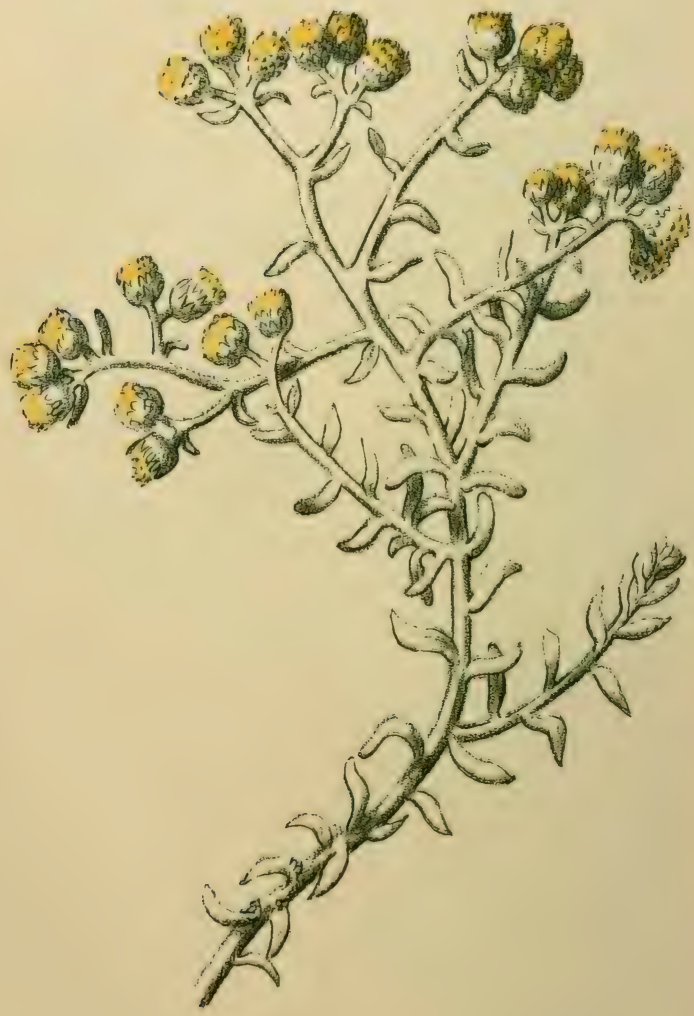

Diotis candidissima.

Diotis cotonneux.

- Composées. - 


\section{DIOTIS CANDIDISSIMA.}

Espagn. : Carrascas de San Juan; Allem. : Baumwollenkraul; Angl. : Sec.Cudweed.

Plante vivace, à souche ligneuse, enfoncée profondément dans les sables maritimes; à tiges cylindriques couchées, ramifiées, blanches, cotonneuses, de même que les petites feuilles qui couvrent les rameaux. Fleurs jaunes, en petits capitules sphériques, entourés d'un involucre à écailles blanches, colonneuses.

Nous avons déjà parlé (pag’e 41) de l'importance du duvet blanc pour les plantes des plages marines ou des hautes montagnes: le Diotis candidissima nous en fournit un autre exemple très instructif.

Toute la plante est amère au goût, aromatique, astringente; on l'emploie dans la médecine populaire contre l'hémophtisie, et parfois aussi en cas de maladie des reins.

Elle est fréquente sur la plage, là où le sol est sablonneux, comme à Alassio, Bordighera, Antibes, Cannes, etc., ainsi qu'en Corse. 


\section{SCOLYMUS HISPANICUS.}

Lig̣ur. : Boèssaï; Espagn. : Cardillos; Cardo Maria.

Plante bisannuelle, à tiges ramifiées, droites, hautes de 30 à 60 centimètres; feuilles sessiles, pennatifides, à lobes épineux, d'une couleur vert clair, un peu jaunâtre. Capitules presque sessiles, entourés de trois bractées grandes, foliacées, piquantes; fleurs jaunes.

Le genre Scolymus répète, dans la tribu des Chicoracées, le type des chardons; ce sont de mauvaises herbes, envahissantes, trop communes le long: des routes, dans les endroits pierreux, dans les lieux incultes et les décombres.

Les bêtes n'aiment pas les brouter, à cause des épines ; mais ce sont de bonnes plantes fourragères; la racine longue et noirâtre de l'Epine jaune peut être mangée comme celle du scorzonère; en Grèce et en Espagne, les jeunes pousses se mangent comme des asperges. Les anciens Grecs employaient la racine comme diurétique, et de nos jours encore le peuple en fait une décoction médicinale.

Les corolles jaunes des fleurs servent à falsifier le safran. 


\section{$-67-$}

Lieux incultes, décombres. - Fleurit m septemlire et octobre.

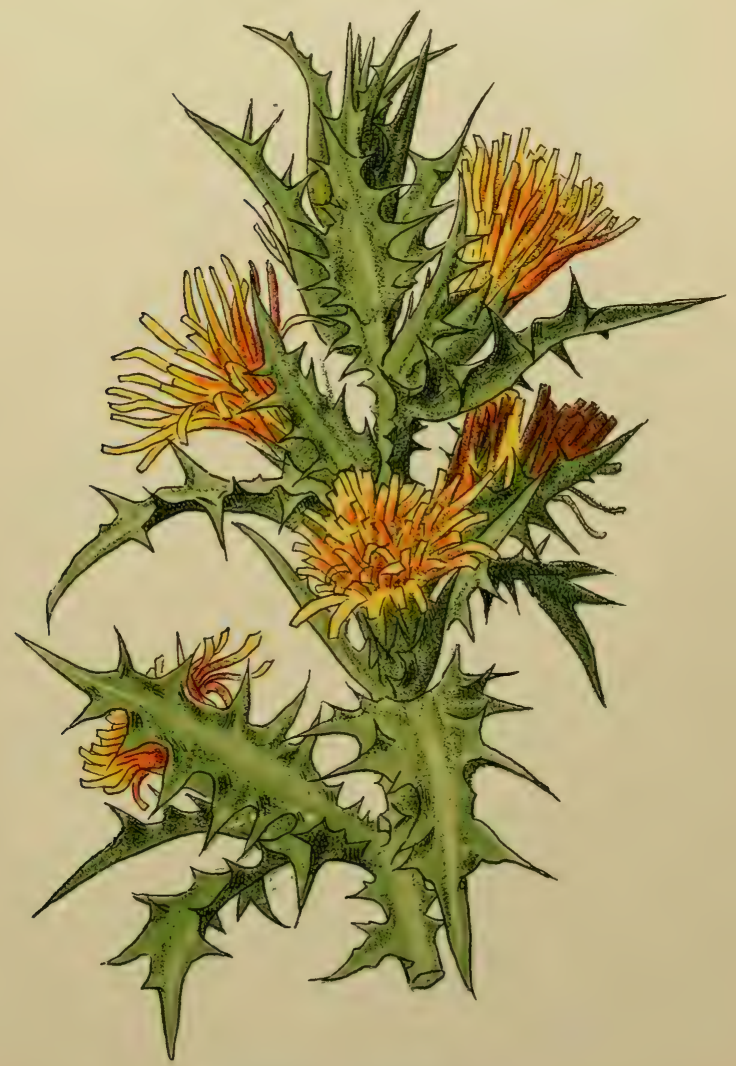

Scolymus hispanicus.

Frans. Épine jaune. Prov. Cardousse, Cardoun, Pèis de nourú. 
$-68-$

Bois; endroits pierreux. - Fleurit on avril et mai.

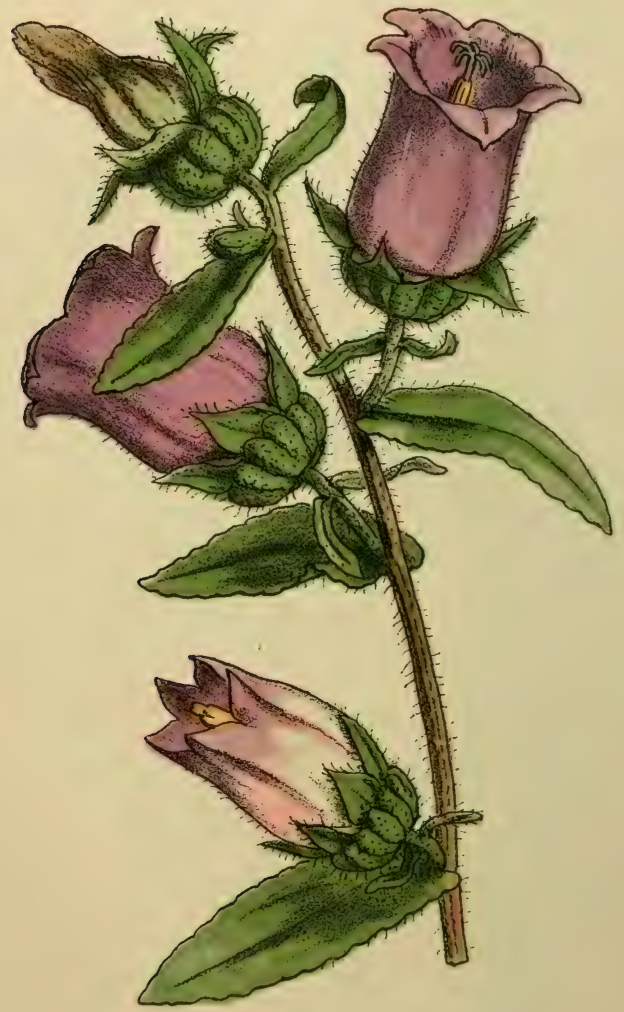

Campanula Medium.

Frune. Carillon, Violette de Marie.

Prov. Gantelet.

- Cimpanulacées. - 


\section{CAIMPANULA MEDIUIM}

Ligur. : Calucciu; Espagn. : Campanetas; Allem.: Murienglocke; Angl. : Bellflower.

Plante annuelle, haute de 30 à 70 centimètres, à tiges droites, peu ramifiées, feuillées; feuilles ovales, les supérieures oblongues, à bords dentés, garnies de poils longs, raides. Fleurs grandes, solitaires, en forme de cloche. Ce qui distingue cette espèce de la plupart de ses congénères, c'est la conformation singulière du calice : on y voit, dans chaque angle des cinq lobes calicinaux, un appendice vert, herbacé, gonflé, qui est recourbé de manière à recouvrir presque entièrement le tube calicinal.

Le $C$. Medium est peut-être l'espèce la plus ornementale du genre Campanula, par ses fleurs très grandes, élégantes; fréquente dans les bois, dans les endroits pierreux de toute la Riviera, elle est aussi cultivée dans les jardins, et ses fleurs figurent parfois sur le marché.

La racine est douceâtre, et mangée dans quelques contrées; dans la pharmacopée ancienne elle figurait, sous le nom de Radix Violae Marianae ou Radix Medii comme remède contre les inflammations de la gorge. 


\section{XANTHIUM SPINOSUM.}

Espagn. : Floravia.

Plante annuelle, très rameuse, de 40 à 60 centimètres de hauteur; rameaux armés de nombreuses épines longues, tripartites, jaunes ou blanchâtres ; feuilles allongées, 3-ว̆-lobées, blanchâtres en dessous. Fleurs unisexuées, les mâles différentes des femelles, et séparées en inflorescences très dissemblables. Les fleurs mâles sont réunies en petits capitules involucrés, semblables à ceux des Composées ; les femelles se trouvent renfermées deux à deux dans une espèce de capsule herbacée, formée par la soudure de deux bractées, et surmontée de deux pointes, au milieu desquelles passent les styles. Quand les fieurs se transforment en fruit, ces a capsules o des fleurs femelles se recouvrent d'épines courbées, dures, qui accrochent facilement le fruit aux vêtements des passants ou à la laine des animaux. C'est ainsi que le Xanthium spinosum, une vraie plante migratrice, s'est répandu en peu de temps dans toute l'Europe. Il est originaire des steppes de la Russie; et c'est surtout par suite des transports de laine, qu'il a envahi, en marchant continuellement vers l'Ouest, toute l'Europe centrale et occidentale. Il est assez commun maintenant le long des routes, dans les lieux incultes de la Riviera, ainsi que dans certaines parties de la Corse. 
$-69-$

Lieux incultes, décombres. - Fleurit en juillet et aoùt.

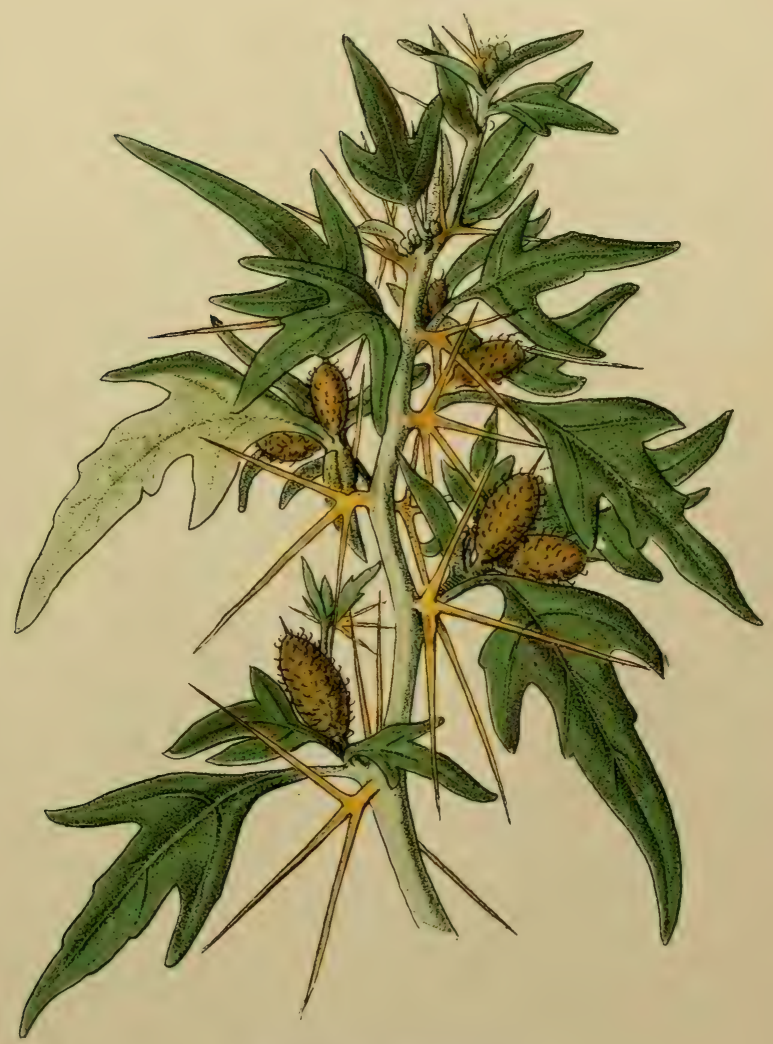

Xanthium spinosum.

Frane. Lampourde épineuse. Prov. Lampourdié.

- Ambrosiacées. - 
$-70-$

Maquis; rochers maritimes. - fletrit on mass of arril.

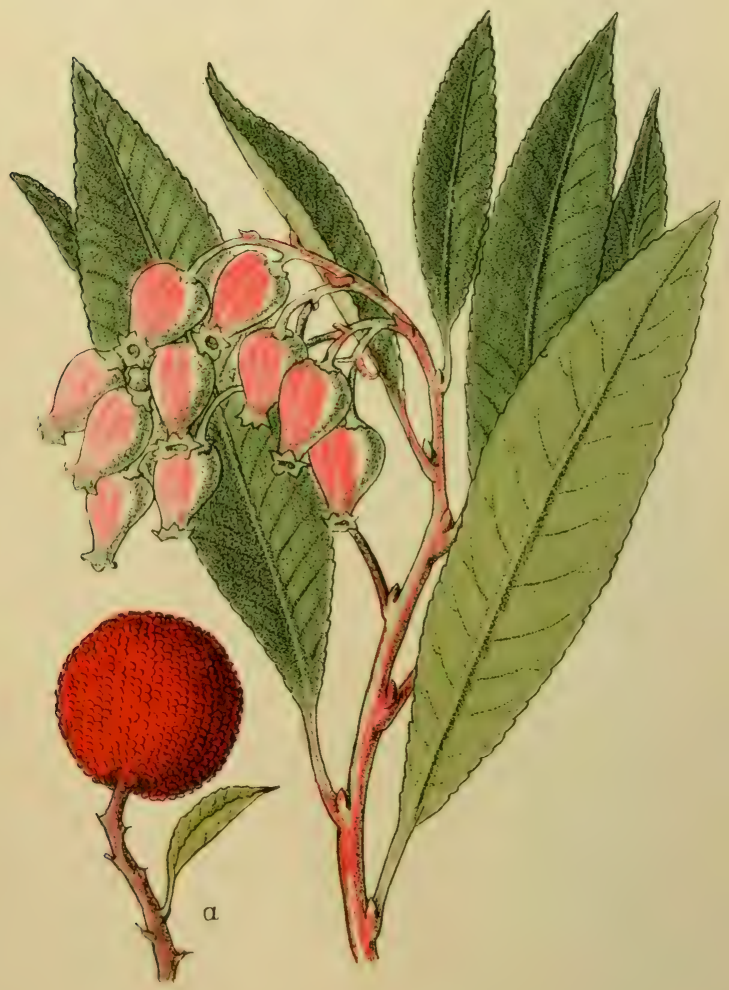

Arbutus Unedo.

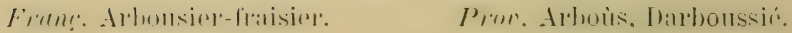




\section{ARBUTUS UNEDO.}

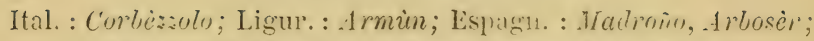
Allem. : Erdberbarm; Angl. : Strmberry-Tree.

Arbrisseau ou arbre de taille moyenne, à rameaux dressés, à feuilles persistantes, coriaces, luisantes, dentelées sur les bords; fleurs en pelites grappes blanches, pendantes, en forme de petite cruche ventrue à ouverture étroite (三 fleurs urcéolées); baies sphériques, de la grandeur d'une petite cerise, rouges, fortement verruqueuses, à chair molle, douceâtre, jaune, avec de nombreuses graines.

Très commun sur les rochers maritimes, dans les bois de pins ou dans les a maquis o de la Riviera et de la Corse, et souvent cultivé dans les parcs.

Les fruits de l'arbousier ont quelque peu l'aspect de fraises, mais ils n'en onı ni le parfum, ni le goût ; ils ont bien peu de saveur, etl'on dit que, mangés en quantité, ils peuvent causer des rerliges. En Corse, on en prépare pourtant une espèce de vin, et dans quelques contrées d'Italie on distille des fruits une qualité spéciale d'eau-de-vie. Toute la plante est très riche en tanin et pourrait être employée pour le tannage ou en leinture; l'écorce et les feuilles servent en médecine comme remède astringent. 


\section{ERICA ARBOREA.}

Ital. : Erica; Ligur. : Brügo; Espagn. : Bruch, Urce, Dinada Allem. : Baum-Heide; Angl. : Heathtree.

Arbrisseau ou petit arbre qui rarement dépasse la hauteur de 3 mètres, à rameaux droits, fins, très serrés, blancs, cotonneux à l'état jeune, plus tard glabrescents, densément couverts de petites feuilles linéaires, raides, mais non piquantes. Fleurs très nombreuses, « urcéolées » comme celles de l'arbousier, penchées, blanches, à anthères presque noires, saillantes.

C'est encore une des plantes caractéristiques de la Riviera et de la Corse qui saute aux yeux des profanes; elle est très commune dans les maquis, dans les bois de pins, très souvent associée à l'arbousier, au myrte, au lentisque et à une autre espèce semblable d'Erica, l'E. scoparia, qui s'en distingue par'les rameaux glabres et par les fleurs vertes, insignifiantes. L'E.arborea est d'un grand effet, quand elle est couverte de ses milliers de, petites fleurs blanches, étroitement serrées les unes contre les autres, et exhalant un parfuin de miel très prononcé. Les abeilles qui en sont très friandes, en retirent une grande quantité de miel.

On emploie les rameaux secs pour en faire des balais ou pour former des haies comme abri contre le soleil ou les vents de la mer. Celte bruyère joue aussi un grand rôle dans l'élevage des vers à soie ; ceux-ci montent dans ses brindilles, pour y faire leurs cocons. 
Maquis; bois de pins, bruyères. - Fleurit en mars et arril.

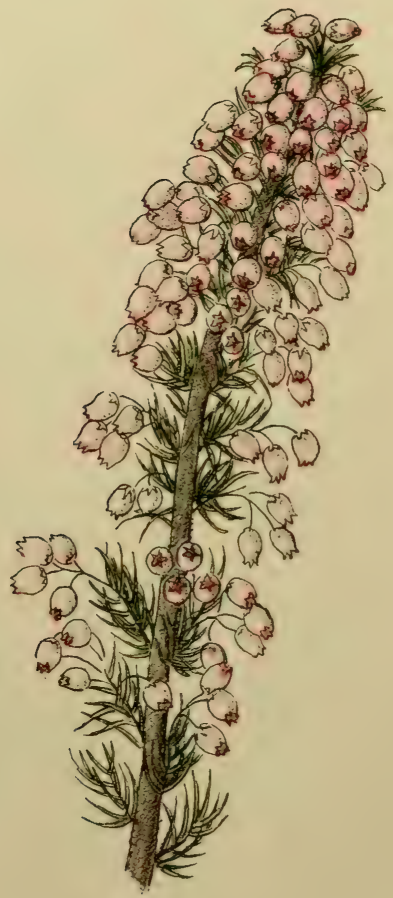

Erica arborea.

Franc. Bruyère nu arbre.

Pror. Brus, Brugas masclo.

- Erigacées. - 
$-72-$

Cultivé dans la zone littorale et des collines. - Fleurit en avril et mai.

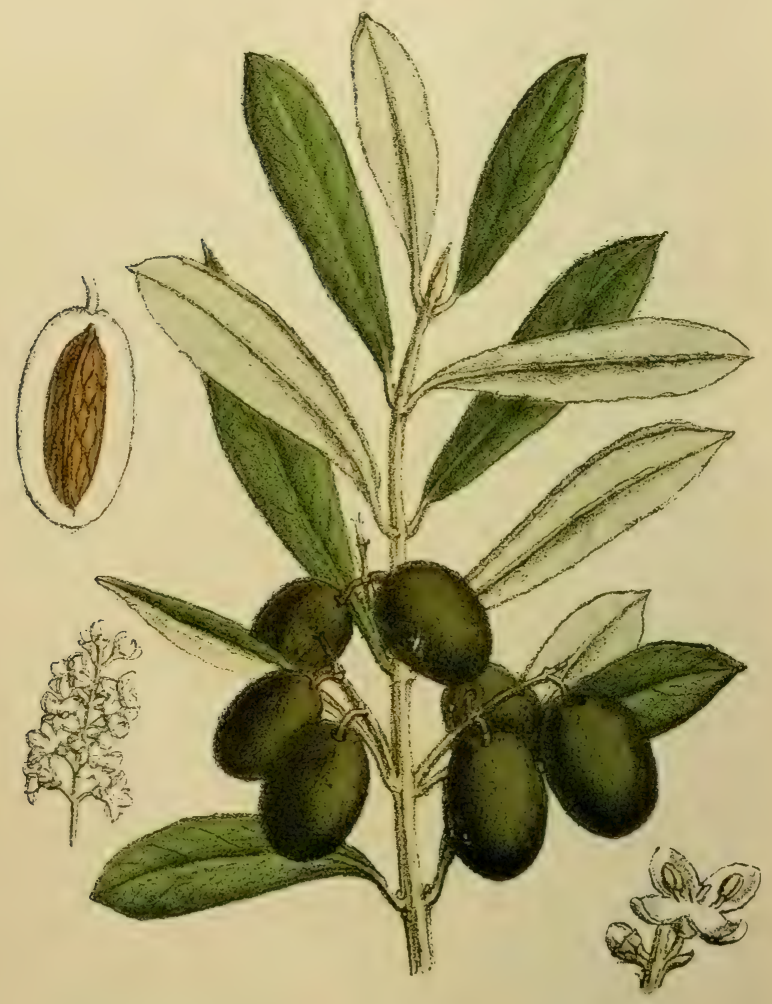

Olea europaea.

Fran. Olivier.

Prov. Oulivié.

- OléacÉEs. - 


\section{OLEA EUROPAEA.}

Ital. : Llivo; Ligur. : Liva; Espagn. : Olivera;

Allem. : Oelbaum; Angl. : Olive tree.

Arbre de taille moyenne, qui arrive pourtant à 12 ou 15 mètres de hauteur, à tronc très irrégulier, à rameaux torlueux. Feuilles opposées, persistantes, coriaces, d'un vert pâle, grisâtre en dessus, blanches argentées en dessous. Fleurs blanches-verdâtres, en grappes serrées; baies oblongues, d'abord vertes, puis noires, luisantes, à un seul noyau.

L'olivier est sans doute l'arbre le plus important de toute la Riviera. Importé de l'Orient, d'où il est originaire, en Europe, il est cultivé sur une grande échelle, particulièrement aux alentours de la Méditerranée, jusqu'à une hauteur, variable selon l'exposition, entre 400 et 600 mètres. Il peut supporter des froids de 7 à 8 degrés au-dessous de zéro, el mème des froids plus intenses, pourvu qu'ils ne se prolong'ent pas. Sa floraison s'étend d'avril en juin, et les fruits demandent environ 5 à 6 mois pour arriver à maturité. La récolte se fait dans les mois d'hiver, entre novembre et avril; généralement on suit la mauvaise habitude de gauler les fruits pour les ramasser, au lieu de les cueillir. La production des olives et de l'huile a beaucoup diminué aujourd'hui par suite des dégâts de quelques insectes nuisibles, dont les plus terribles sont : la mouche de l'olivier (« Keiroun s en Provençal, Dacus Oleae), un petit coléoptère ( ‘ Neiroun », Phloeotribus Oleae) et une espèce 
de Thrips ( ver noir, Barban ", Phloeothrips oleae).

Outre les fruits, l'olivier nous fournit encore un bois compact, très veiné, qui convient aux travaux de menuiserie. Les étrangers apprécient beaucoup les petits objets en bois d'olivier, fabriqués surtout à Nice et à Naples, et qui sont vendus partout dans la Riviera.

\section{PHYLLIRAEA ANGUSTIFOLIA.}

Arbrisseau de 1 à 3 mètres de hauteur, à rameaux grêles, très écartés, à feuilles persistantes, coriaces, opposées, lancéolées, aux bords faiblement crénelés, d'un vert pâle, glabres. Fleurs en petites grappes à l'aisselle dẹs feuilles, petites, blanchâtres ou verdàtres, semblables à celles de l'olivier; baies petites, globuleuses, un peu pointues, noirâtres à la maturilé, renfermant un seul noyau.

Le genre Phylliraea, très voisin au genre Olea, est représenté en Europe par trois espèces, $P h$. angustifolia, Ph. media et Ph. latifolia, qui se trouvent aussi toutes trois dans le littoral et en Corse.

Les deux dernières espèces se distinguent de la première, figurée dans notre planche 73 , surtout par leurs feuilles plus larges, luisantes, d'un vert plus foncé.

Le $P h$. angustifolia est fréquent dans les maquis (bois composés presque entièrement d'arbres etarbrisseauxà feuilles persistantes) caractéristiques pour les bords de la Méditerranée. Les feuilles contiennent du tanin ; mais on en fait rarement usage dans la tannerie. 
$-73-$

Maquis, bois des collines. - Flnurit m mai nt juin.

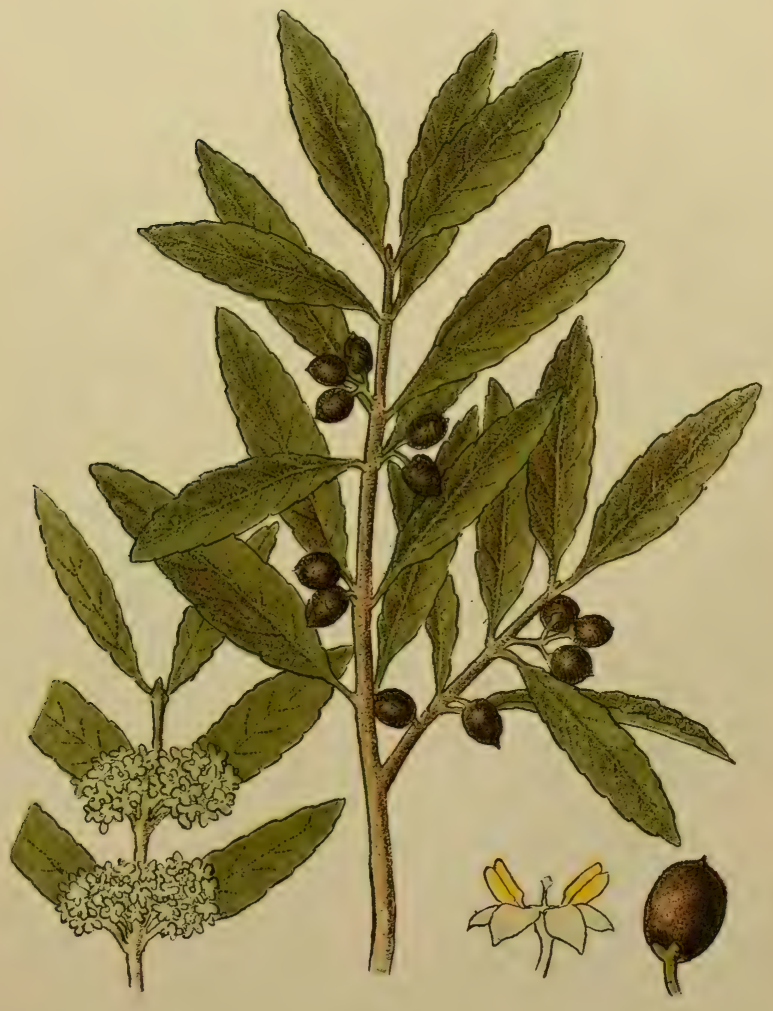

Phylliraea angustifolia.

Philaria à feuilles étroites. 
Bois de pins; rochers maritimes. - Fleuril en arril ot mai.

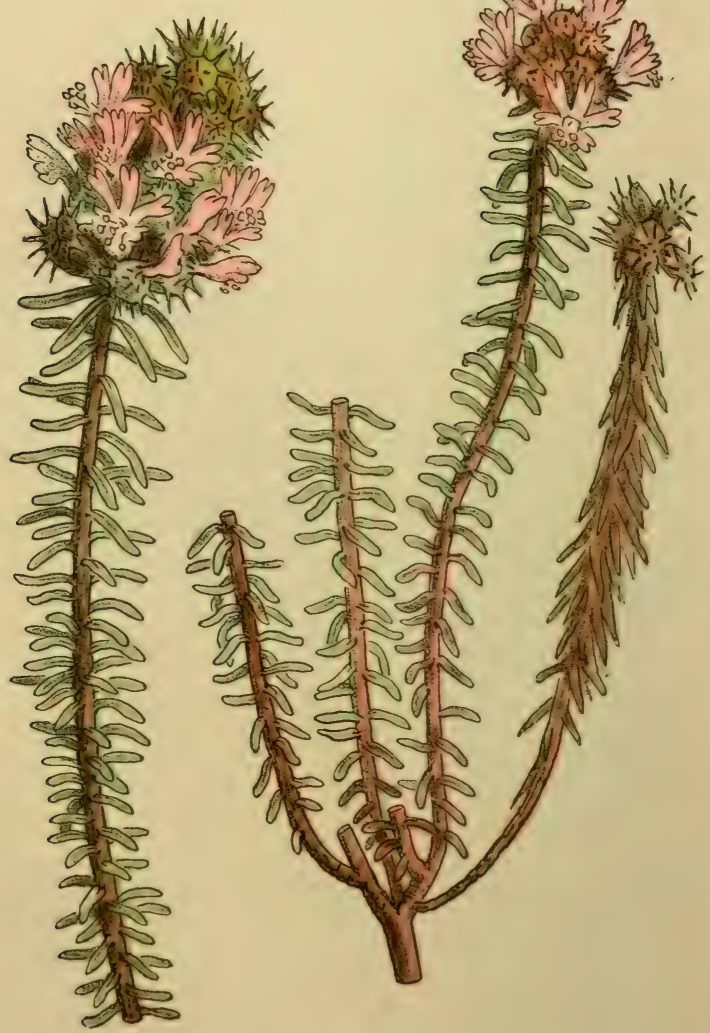

Coris monspeliensis.

Frans. Cor'ss de Montpellier. Pror. Té di collo. 


\section{CORIS MONSPELIENSIS.}

Espagn. : Yerba pincel; Allem. : Erdkiefer.

Plante bisannuelle, de 10 à 20 centimètres de hauteur ; tige ligneuse à la base, peu rameuse, à rameaux allongés, étalés ou ascendants. Feuilles petites, linéaires, très nombreuses sur les rameaux, horizontales ou réfléchies, les supérieures quelquefois dentelées aux bords.

Fleurs en grappe allongée à l'extrémité des rameaux, presque sessiles, roses.

Fréquent dans les lieux arides, pierreux, sous les oliviers dans la zone littorale, mais non partout.

C'est une plante fort curieuse, qui par son port singulier et parla structure de ses fleurs peut intriguer non seulement les profanes, mais aussi les botanistes qui la rencontrent pour la première fois. Bien qu'elle appartienne à la famille des Primulacées, elle s'en éloigne beaucoup par son port (qui est celui d'une bruyère), et par ses fleurs irrégulières. Le calice, de consistance sèche, presque membraneuse, et se regonflant autour du fruit, montre 10 divisions sur deux rangs, dont les cinq extérieures sont inégales, épineuses, les internes triangulaires; la corolle est à cinq divisions, dont trois plus grandes.

On employait jadis les feuilles et les graines contre la syphilis; maintenant la racine, réduite en poudre, est parfois employée comme remède astringent. 


\section{NERIUM OLEANDER.}

Ital. : Leandro; Ligur. : Lielladonian; Espagn. : Adelfa, Baldedre; Allem. : Oleander; Angl. : Oleander.

Arbrisseau ou petit aribe de 2 à 4 mètres de hauteur, à branches droites, flexibles, à feuilles persistantes, coriaces, lancéolées, veinées, réunies en verticilles de trois; fleurs grandes, en bouquets, roses ou rouges, plus rarement blinches.

Cette plante si populaire ct comnunément cultivée en caisses dans toute l'Europe, a pour patric les bords de la Médilerranée. Dans la Riviera, ce sont surtout le cours des torrents, comme de la Roja, de la Nervia près de Vintimille et de Menton, la vallée d'Andora, etc., qui sont ornés de superbes plantes de laurierrose.

C'est une plante fort rénéneuse. Les feuilles et l'écorce des branches contiennent une substance très amère, brûlante, narcotique, qui fail rougir la peau. On les emploie pour tucr les insectes parasites et les rats. En pharmacie, on employait autrefois les Folia oleandri contre l'eczéma et les maladies du cœeur.

Plusieurs autres espèces de Nerium, surtout le $N$. odorum des Indes, sont cultivées dans les jardins de la Riviera; on en connaît des rariétés à fleurs roses, blanches el d'un roug'e-écarlate très vif.

Entre Patrimonio el la mer, près de Bastia, en Corse, cet arbrisseau est très commun; il parail ne pas exister ailleurs dans cetle île, sauf à l'état cultivé. 


$$
-75-
$$

Lit des torrents. - Fleurit คn juillet et août.

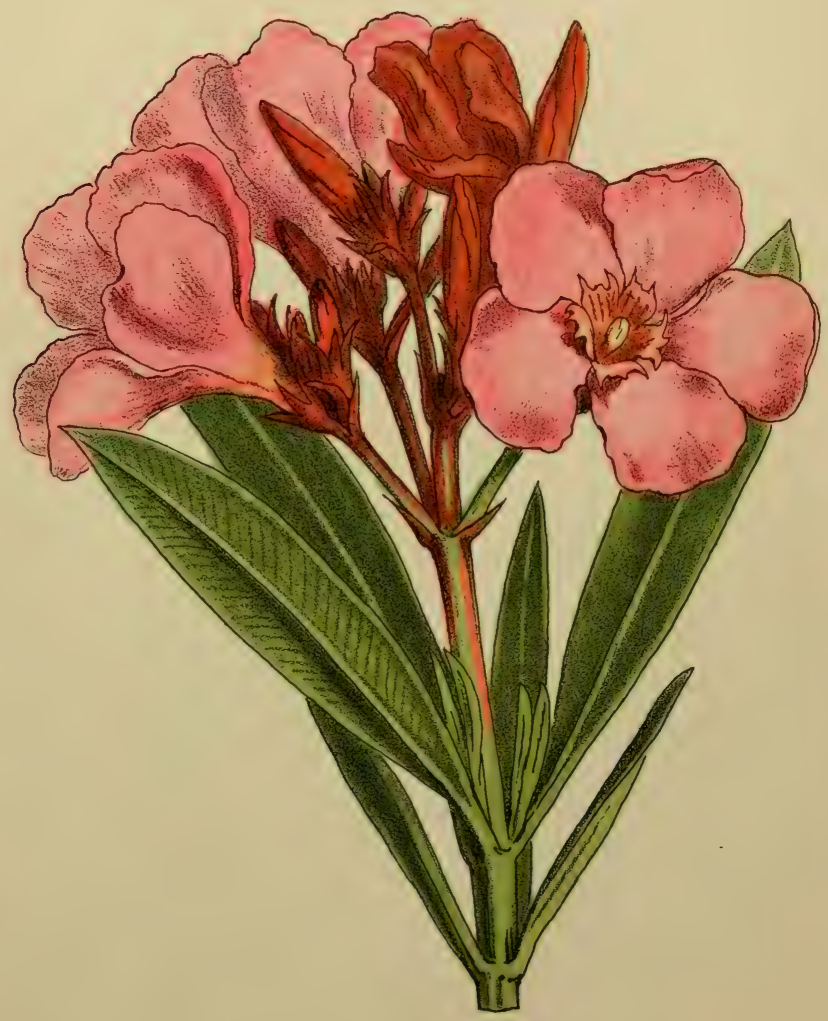

Nerium Oleander.

Franc. Laurier-rose Prov. Laurié roso. 
$-76-$

Bois des collines. - Flemit on arril et mai.

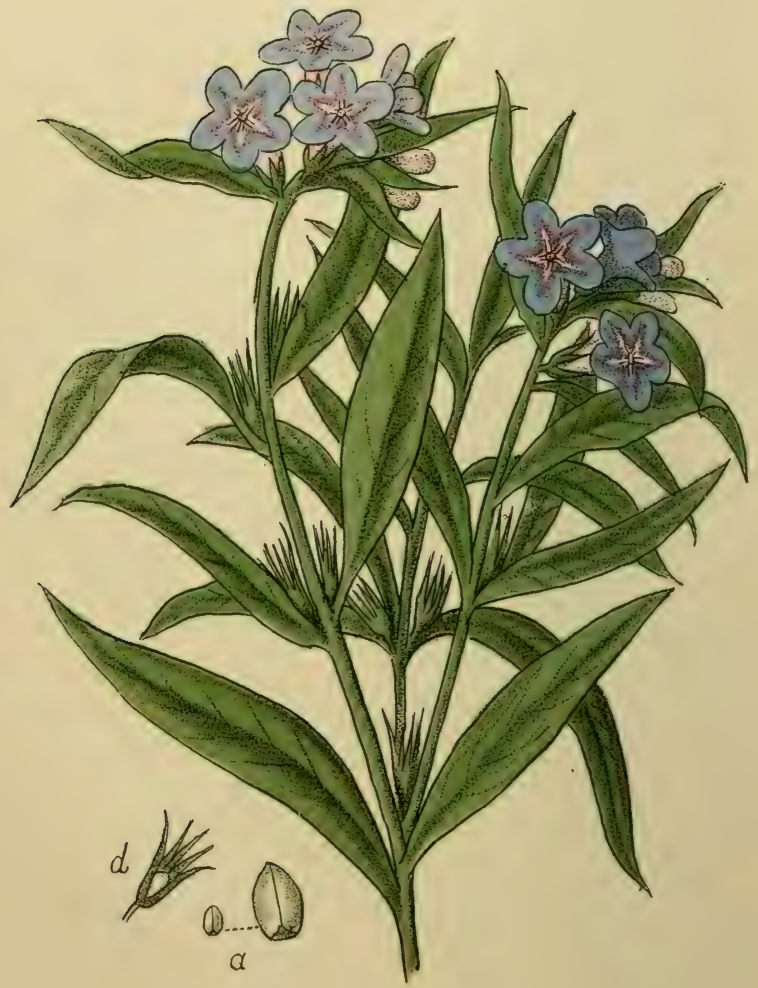

Lithospermum purpureo-cœruleum. Frane. Gremil violet. Prov. I'issolo. 


\section{LITHOSPERMUM PURPUREO-CERULEUM.}

Plante vivace, à souche souterraine, horizontale ou ascendante; tiges herbacées; les stériles couchées, étalées, les fertiles dressées, feuillées; feuilles nombreuses, lancéolées, rudes, d'un vert foncé, plus pâles en dessous. Fleurs en grappes, à l'extrémité des branches fertiles, grandes, d'abord purpurines, puis d'un bleu foncé. Fruits en forme de petits akènes réunis par 4 dans le même calice, blancs, durs, luisants. Elle se trouve çà et là dans les haies, les bois et les lieux ombragés.

Les racines de toutes les espèces de Lithospermum contiennent une substance rouge, semblable à celle de l'Alkanna tinctoria, mais elles n’ont jamais été exploilées par l'industrie.

La superstition populaire voyait dans les graines, très dures et semblables à de petits cailloux luisants

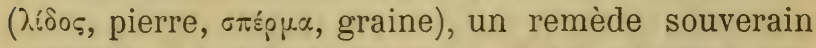
contre le a mal de la pierre „; et les paysans emploient encore aujourd'hui une émulsion de ces graines dans les maladies des reins et des voies urinaires. On attribuait jadis la même vertu à toutes les plantes qui poussent dans les crevasses des rochers, aux Saxifrages par exemple, à l'Asplenium Ruta muraria, seulement parce qu'elles ont le pouvoir de c fendre les pierres ». 


\section{VITEX AGNUS CASTUS.}

Ital. : Agnocasto: Ligur. : Tremeire: Espagnn. : Sunzgatillo, Aloch; Allem. : Abrahams-Strauch.

Arbrisseau ou arbre de petite taille, qui ne dépasse pas 3 ou 4 mètres; feuilles opposées, composées de 5 à 7 feuillettes lancéolées, entières, d'un vert foncé en dessus, blanches tomenteuses en dessous, de même que les calices et les jeunes rameaux. Fleurs en épis terminaux, verticillées, d'un bleu pâle, rarement blanches. Baies petites, noires, à 4 graines chacune.

Ce joli arbrisseau croît de préférence le long des torrents ou dans le lit sec et pierreux des rivières; il est assez rare en Corse.

Son nom curieux provient de l'usage particulier qu'en faisaient les dames de l'ancienne Grèce: les feuilles protég'eaient, dit-on, la vertu. Cette renommée singulière, passée en tradition au moyen âge, fit que les feuilles et les fruits furent employés aussi intérieurement comme calmant; un des noms vulgaires allemands : Moenchsp/effer (poivre des moines), fait allusion évidemment à cet emploi des baies dans les couvents.

Toute la plante est aromatique; les fruits ont un goût poivré. 
Bords des torrents; dunes maritimes. - Fleurit en juil. et août.

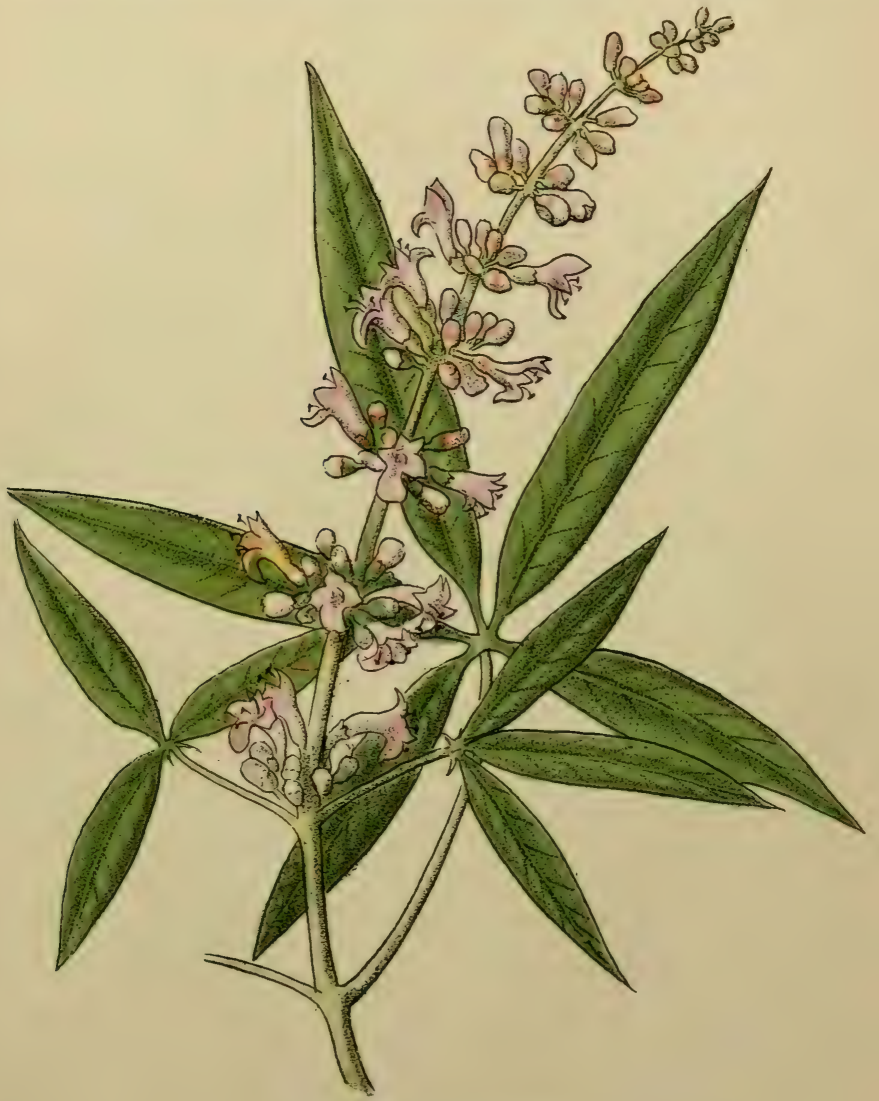

Vitex Agnus-castus.

Franc. Galtilier. Prov. Pebrié.

- Verbénacées. - 
$-78-$

Lieux secs, pierreux. - Fleurit on arril et mai.

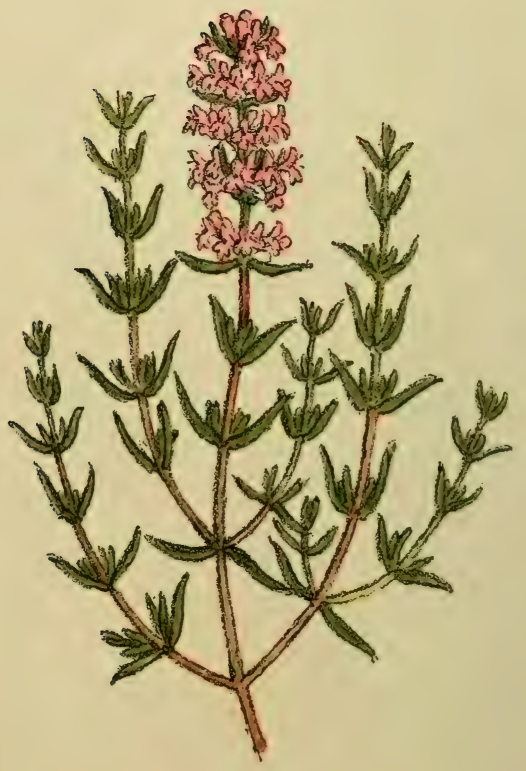

Thymus vulgaris.

Frans. Thỵm. Prou. Frigoula, Pôta, Pébriana, Farigoulo. 


\section{THYMUS VULGARIS.}

Ital. : Timo; Ligur. : Tümau, Ferugole; Espagn. : Tomillo, Farigolo; Allem. : Thymian: Angl. : Garden-Thyme.

Plante vivace à souche ligneuse, gazonnante: tiges nombreuses, très rameuses, tortueuses, ligneuses, non radicantes, formant un petit buisson serré. Feuilles linéaires, à bords roulés en dessous, blanchâtres comme les tiges; fleurs d'un rose clair, rarement blanches, rapprochées en petits capitules terminaux.

C'est une des plantes les plus communes de la Riviera et des plus sympathiques aussi. Elle croît en abondance dans les lieux secs, pierreux, sur les pentes des collines arides; et aux mois d'avril et de mai, quand les nombreux gazons sont tous couverts de milliers de fleurs, elle est vraiment ravissante. Elle parait manquer en Corse. Le parfum du thym est très fort, pénétrant et agréable; l'essence de thym (Oleum Thymi æthereum) est employée comme remede stomachique, tonique, et contient une substance éminemment antiseptique, le thymol. Aussi le thym est-il cultivé depuis longtemps dans le Nord; on l'emploie en médecine et surtout en cuisine comme assaisonnement. 


\section{AJUGA IVA.}

Ligur. : Erba de musc; Espagn. : Pinillo oloroso; Yerba clin; Allem. : Mos:hus-Günsel; Angl. : Musk Bugle.

Plante à souche vivace; tig'es herbacées ou un peu ligneuses à la base, minces, hautes de 5 à 15 centimètres, densément feuillées, hérissées de poils mous. Feuilles linéaires, allongées, étalées, les inférieures pourvues aux bords de 2 -4 dents, velues; fleurs purpurines, solitaires ou par deux dans les aisselles des feuilles supérieures; fréquente dans les endroits pierreux, secs de la zone litlorale et dans les champs maigres du Nord de la Corse.

Toute la plante sent fortement le musc, à cause d'une huile essentielle qui se trouve dans les poils de la tige et des feuilles. Elle joue un grand rôle dans la médecine populaire comme remède diurétique, diaphorélique, et est employée contre les affections rhumatismales, arthritiques, etc.

Une autre petile espèce du même genre, à fleurs jaunes et à feuilles trifides, qui est fréquente aussi dans les champs et sous les oliviers (Ajuga Chamæpitys) possède à peu près les mêmes qualités, mais elle est moins efficace. 


$$
-79-
$$

Endroits secs, pierreux. - Fleurit en mars of arril.

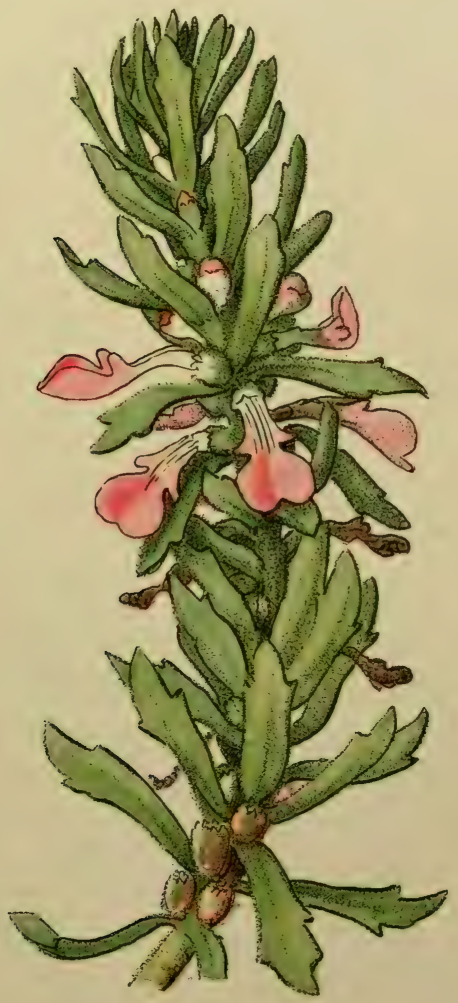

Ajuga Iva.

Bugle musquée.

- Labiées. - 


\section{$-80-$}

Lieux secs, ensoleillés. - Fleurit en juin et juillet.

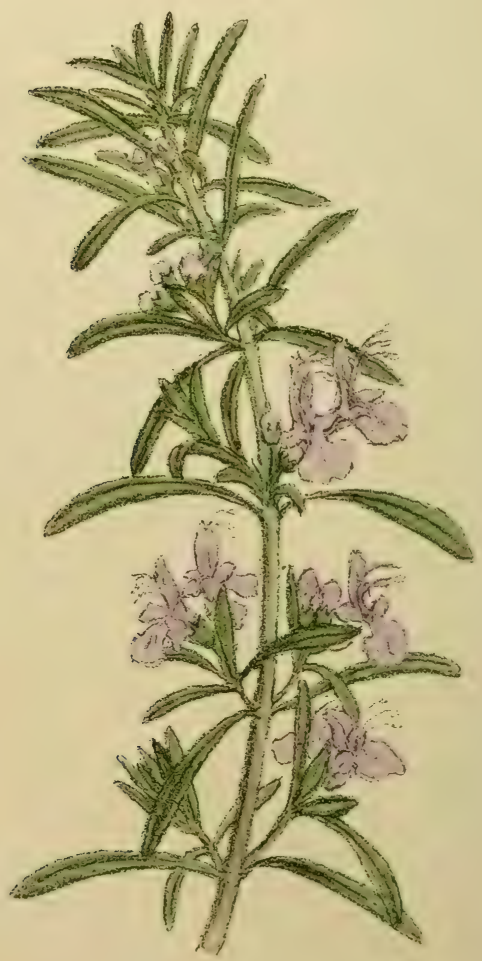

Rosmarinus officinalis.

Frans. Romarin officinal. Prov. Roumaniou. 


\section{ROSMARINUS OFFICINALIS.}

Ital. : Posmurino; Ligur. : Romanin; Espagn. : Romero, Romani; Allem. : Rosinarin; Angl. : Rosemary.

Arbrisseau qui arrive à 2 mètres de hauteur, à rameaux dressés, touffus, très feuillés ; feuilles linéaires, à bords roulés en dessous, coriaces; la face supérieure d'un vert clair, l'inférieure blanchâtre; fleurs par deux dans les aisselles des feuilles supérieures, bleuâtres, ponctuées.

Le romarin croît à peu près dans les mêmes localités que le thym, la lavande, le myrte, le lentisque; il préfère les lieux pierreux, ensoleillés, et ne s'éloigne pas trop de la mer. Il n'est pas rare en Corse.

C'est une plante très connue et populaire depuis l'antiquité. Les anciens Romains lui donnaient la préférence pour en faire des couronnes et la brûlaient comme de l'encens (Libanotis des anciens auteurs). L'huile essentielle, très abondante dans toutes les parties de la plante, est distillée et joue un rôle important dans la composition de l'Eau de Cologne et de la fameuse a Eau de la Reine de Hongrie ».

Les fleurs contiennent une très grande quantité de miel excellent et sont fréquemment visitées par les abeilles. On dit que le miel de Narbonne doit sa renommée à la saveur particulière donnée par le miel de romarin. 


\section{TEUCRIUIM POLIUM.}

Ligur. : P'urglial; Espagn. : Zamaralla, Tumillu blunco, Herba cuquera; Allem. : Poley-Gamander.

Plante a souche vivace, ligneuse; tiges nombreuses, sourent gazonnantes, ascendantes, ligneuses à la base, hautes de 10-20 centimètres. Feuilles linéaires ou cunéiformes, courtes, souvent crénelées aux bords, blanches cotonneuses, de même que les tiges. Fleurs en têtes serrées, terminales à l'extrémité des rameaux, blanchâtres.

Commune sur les rochers, dans les bois de pins, dans les lieux secs, pierreux, de la mer jusqu'aux montagnes.

Herbe aromalique, amère, qui est employée (herba ser summiates Polii lutei) pour faire des infusions toniques, stomachiques.

Plusieurs autres espèces indigènes ont des propriétés semblables, comme les Teucrium montanum, $T$. Botrys. Une espèce à tiges ligneuses, en petit arbrisseau, le T. Marum, est très appréciée des chats. Ceux-ci aiment brouter les feuilles et les jeunes pousses de cette " herbe aux chats » el s'enivrent de son parfum pénétrant. Dans les jardins botaniques, on est parfois obligé de protéger le T'eucrium Marum par des cloches en fil de fer, contre les dégâts que font ces animaux, dans leur excitation, en se roulant sur cette plante et en écrasant ce qu'ils n'ont pas mangé! 


\section{$-81-$}

Rochers, bois de pins. - Fleurit nn mai 't juin.

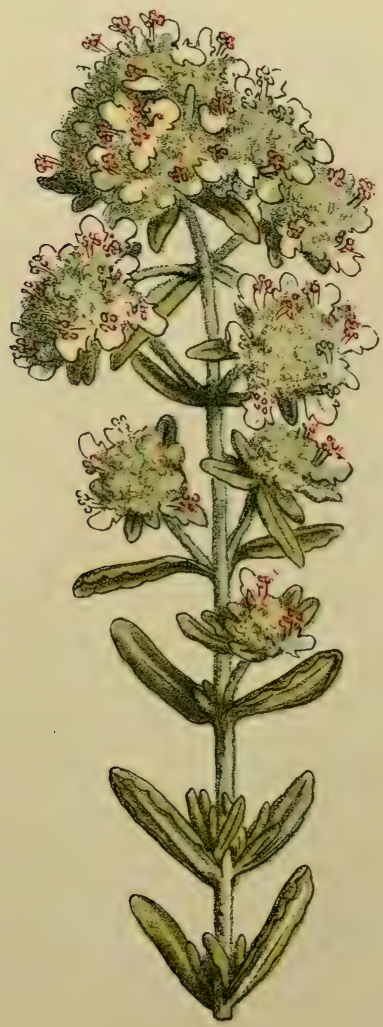

Teucrium Polium.

Germandrée blanche. 
$-82-$

Bruyères, bois de pins. - Fleurit en avril et mai.

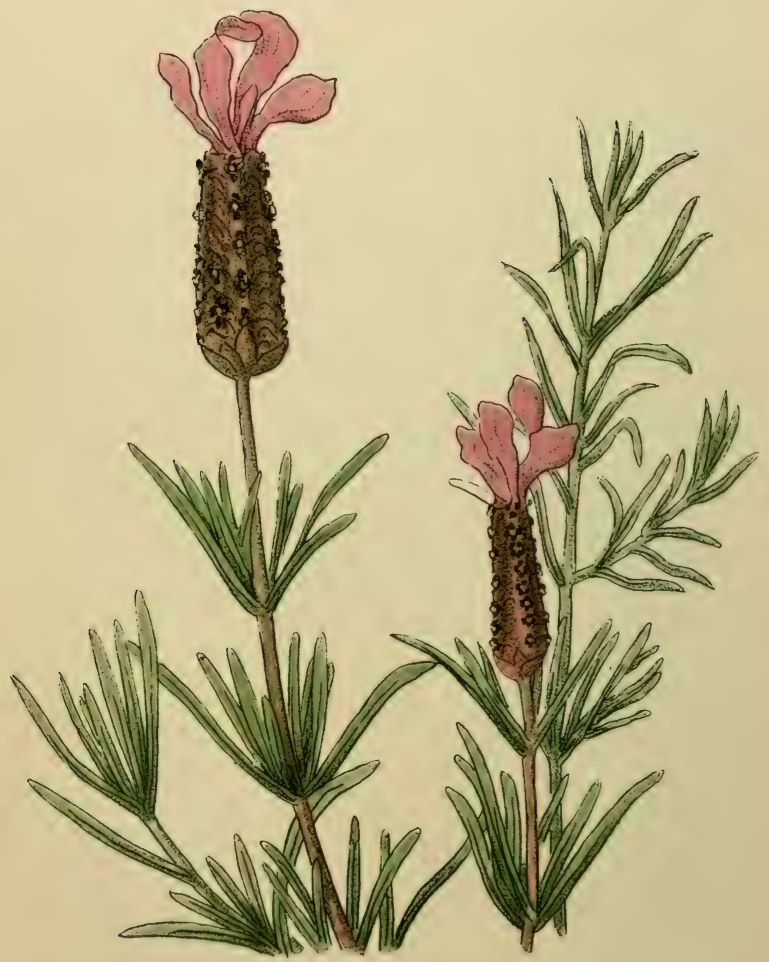

\section{Lavandula Stoechas.}

Frans. Lavande des Stoechades.

Prov. Keirelet. 


\section{LAVANDULA STOECHAS.}

\section{Ligur. : Steccadi; Espagn. : Cinulueso, Culp dirse: Angl. : Cassidony, French Lavender.}

Plante rivace, à tiges dressées, ligneuses à la base, un peu quadrangulaires; feuilles opposées, linéaires, roulées aux bords, couvertes d'un duvet grisâtre, de même que les tiges. Les inflorescences sont curieuses : elles consistent en épis terminaux denses, de forme oblongue et à section quadrangulaire, formés de 4 séries de bractées larges, foliacées, grisâtres. A l'aisselle de chaque bractée, on trouve une petite fleur sessile, labiée, d'un pourpre foncé, presque noir. Le tout est surmonté d'une houppe de bractées allongées, larges, membraneuses, d'un très beau violet, formant une sorte de bouquet terminal.

Cette jolie espèce est commune dans les lieux stériles et surtout dans les bois de pins, les bruyères, dans les maquis, sur le littoral et en Corse. Elle est très aromatique, mais elle n'a pas le parfum aussi agréable que le Lavandula Spica et le L. latifolia, les lavandes connues en parfumerie et en médecine. On l'emploie beaucoup dans la Riviera pour préserver les vêtements des mites et pour parfumer la lingerie : elle est souvent confondue (à cause du nom populaire commun aux deux espèces) avec le Helichrysum Stoechas, qui est aussi très aromatique et utilisé de la même manière. 


\section{SALVIA HORMINOIDES.}

Espagn. : Gallocresta.

Plante bisannuelle, herbacée, haute de 20 à 50 centimètres. Feuilles inférieures en rosette radicale, étalées sur le sol, allongées, souvent lobées ou incisées; les supérieures opposées, sessiles, élargies en cœur à la base; toutes rugueuses, crépues, pubescentes. 'Tige quadrangulaire; fleurs en grappe terminale, petites, de couleur pâle, bleue ou violette.

Commune sur les pelouses, dans les endroits herbeux, secs; moins abondante en Corse.

Cetle petite espèce de sauge remplace souvent dans le Midi le Salvia pratensis ou Sauge des prés, qui pousse dans le Nord. Llle est aromatique, un peu amère et tonique, et peut être employée pour faire des infusions stimulantes, toniques, diaphorétiques; tlle est toutefois beaucoup moins efficace que la Sauge cultivée (Salvia officinalis).

On peut rencontrer dans la Riviera une autre belle Sauge, le S. Horminum, distinct par une houppe de bractées stériles, analogue à celle du Lavandula Stoerhas, ou (bien rarement) le $S$. Sclarea. Dans les bois des haules montagnes, le long des ravins, l'on trouve souvent une espèce de Sauge à fleurs jaunes, tachetées de pourpre, très grandes : c'est le $S$. glutinosa. 


\section{-83 -}

Pelouses, lieux herbeux, secs. - Flutit en mars ol arril.

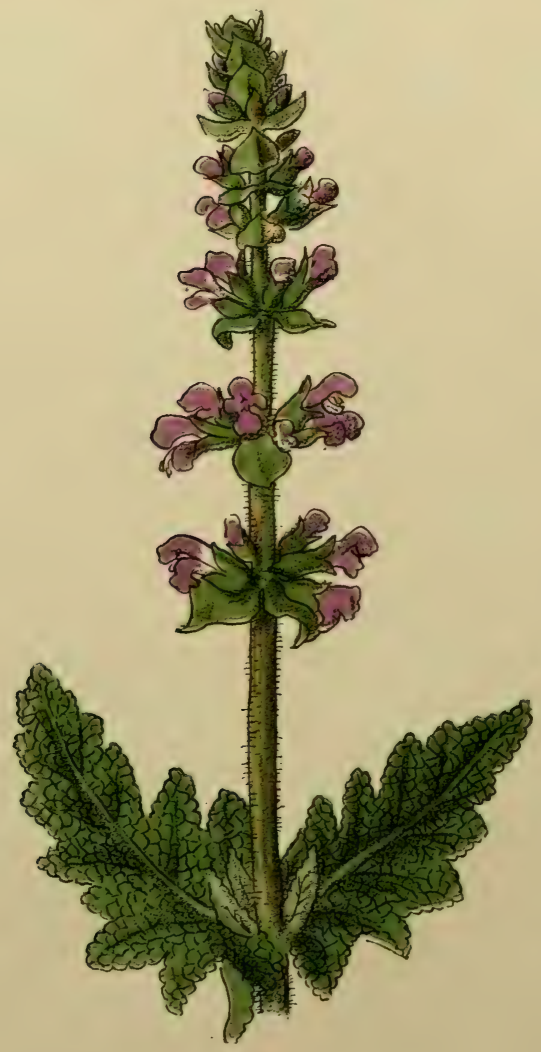

Salvia horminoides.

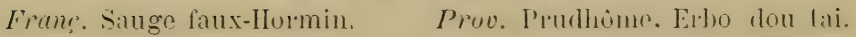




\section{$-84-$}

Bruyères; lieux secs, pierreux. - Flınrit 'n nctoln'r.

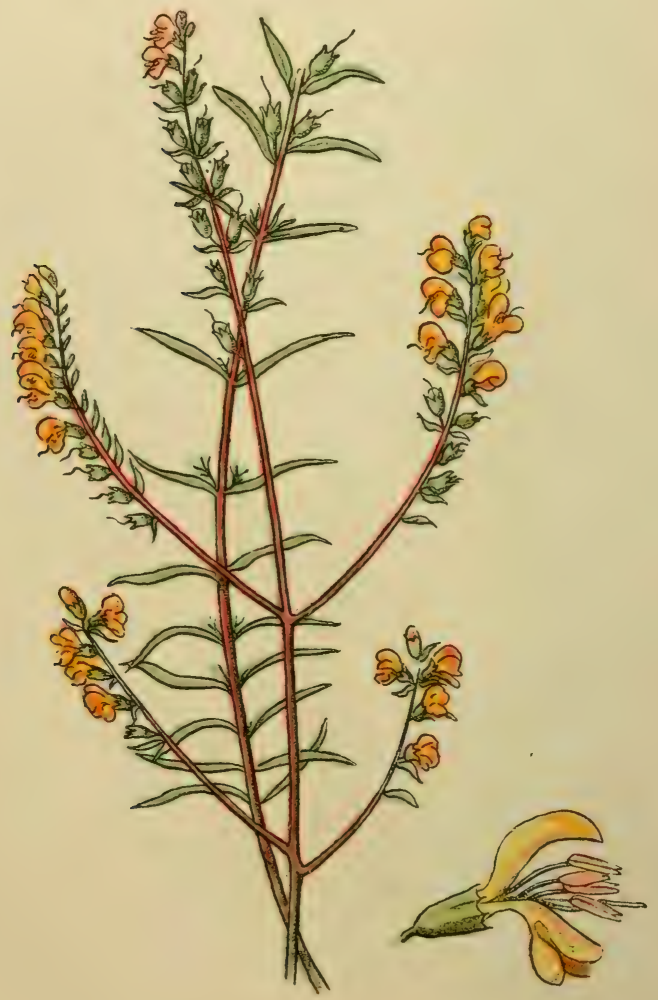

Odontites lutea.

Odontitès jaune. 


\section{ODONTITES LUTEA.}

Espagn. : Algaravia.

Plante annuelle, haute de 10 à 50 centimètres; tiges droites, minces, roides, presque ligneuses; rameaux étalés, horizontaux, allongés; feuilles linéaires, d'un vert foncé, pubescentes de même que la tige. Fleurs en épis terminaux, unilatéraux, d'un jaune vif; étamines et style saillants.

Trés commune en automne dans les lieux stériles, pierreux, surtout dans la zone des collines el dans les maquis de la Corse.

C'est une jolie petite plante, mais sans aucune importance au point de vue médical ou industriel. Parmi les genres voisins, il y a les Rhinanthus, qui sont intéressants comme plantes parasites, ou, au moins a semi-parasiles ". On emploie ce terme pour des plantes rertes qui ont la faculté de se nourrir par elles-mêmes, comme la plupart des plantes vertes, en absorbant des substances gazeuses et des solutions inorganiques; mais qui vivent aussi aux dépens de végétaux voisins, en fixant çà et là, sur les racines de ceux-ci, des espèces de suçoirs en forme de pelits disques adhérents. Les genres Euphrasia et Odontites sont suspects de cette sorte de parasitisme. 


\section{SCROPHULARIA PEREGRINA.}

Plante annuelle, à racine pivotante, à tige herbacée, quadrangulaire, simple, feuillée ; feuilles ovales, en cœur ou tronquées à la base, glabres de même que la tige, grossièrement dentées sur les bords. Fleur's réunies en petits bouquets lâches, à l'aisselle des feuilles, petites, pourpres.

Fréquente dans les lieux cultivés, sous les orangers et oliviers, dans les vignobles, toujour's à l'ombre ou dans les lieux fertiles, humides. Commune aussi en Corse.

Le nom de peregrina, donné par les botanistes à cette plante, indique déjà que c'est une plante migratrice. En effet, on la retrouve le long de la Riviera, exclusivement dans les lieux cultivés, et il parait qu'elle y a été introduite par l'homme, comme beaucoup de nos plantes subspontanées, peut-être avec l'olivier ou avec la vigne.

Nous avons dans notre Flore plusieurs autres espèces de Scrofulaires bien indigènes, comme les S. nodosa, S. aquatica, S. lucida, S. canina: toutes ont un goût amer, astringent, et étaient très renommées comme remède contre les scrofules (d'où le nom du genre), contre le goître, etc. 


$$
-85-
$$

Lieux cultivés, ombragés. - Fleurit cn mars et arril.

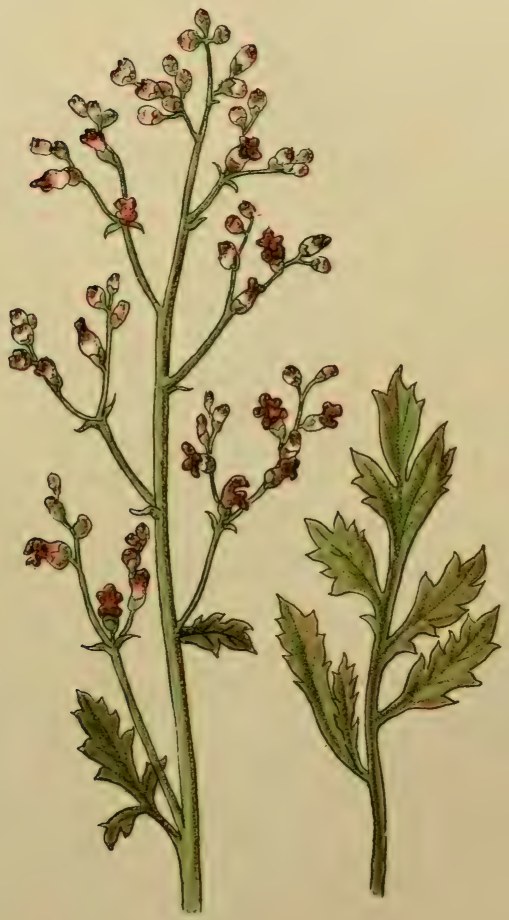

Scrophularia peregrina.

Scrofulaire voyageuse.

- Scrophularinées. - 


\section{$-86-$}

Rochers, murailles. - Fleurit on mai ot juin.

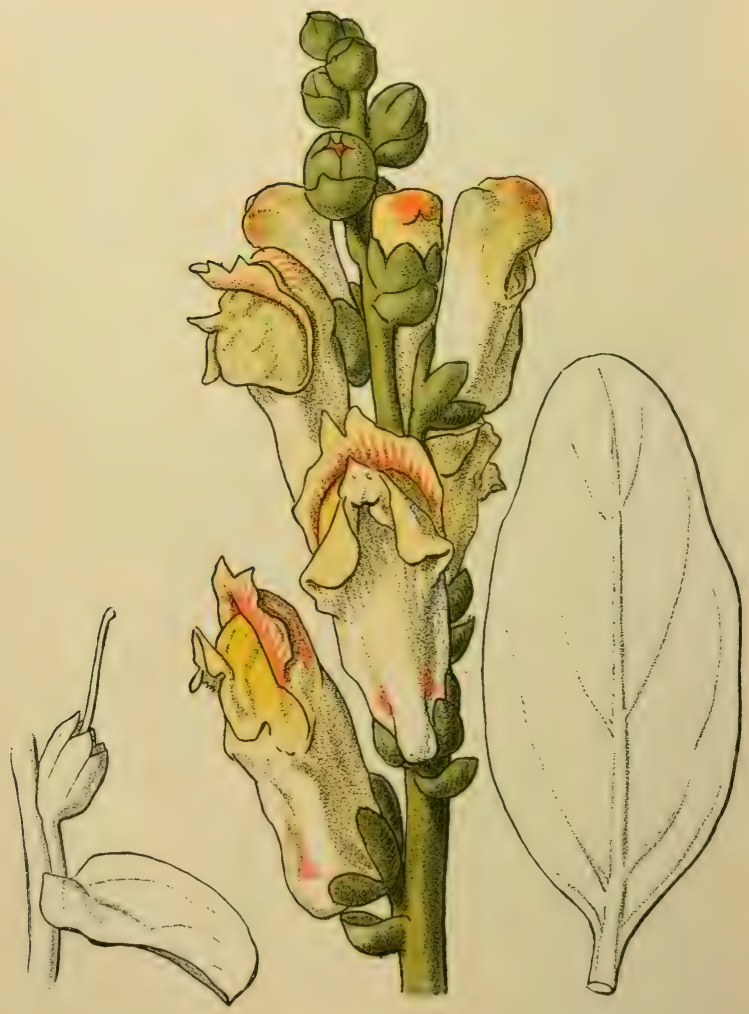

Antirrhinum latifolium

Frane. Muflier jaune. Prov. Lapinou.

- Scrophularinées. - 


\section{ANTIRRHINUM LATIFOLIUM.}

Ital. : Bocca di leone: Ligur. : Bucche de Liin; Espagn.: Conejetes; Allem. : Cielbes Löwenmaul; Angl. : Yellow Snap-Dragon.

Plante vivace, à tiges dressées, velues, ligneuses à la base, hautes de 30 à 70 centimètres. Feuilles sessiles, ovales, pubescentes ou glanduleuses; fleurs en grappe terminale allongée, très grandes, jaunes, à palais orangé.

Fréquent sur les rochers de la région littorale, dans les endroits pierreux, sur les vieux murs.

Espèce très voisine du grand muflier de nos jardins, à fleurs pourpres, violettes ou blanches, dont elle diffère surtout par les feuilles plus larges et par le duvet glanduleux. Les capsules sont très curieuses : elles s'ouvrent à la maturité par plusieurs petits trous disposés de telle sorte que toute la capsule prend l'aspect d'un tout petit crâne d'un étrange animal, d'un singe, d'un veau, etc. De là beaucoup de noms populaires, comme Tête-de-veau, Tête-demort, etc. Nous n'en connaissons aucun usage. 


\section{CROZOPHORA TINCTORIA.}

Espagn. : Giradol, Cenclia.

Plante annuelle, herbacée, haule de 20 i 50 centimètres; tiges couchées ou ascendantes, rameuses, velues; feuilles triangulaires ou rhomboïdales, un peu crinclées sur les bords, courertes d'un duvet blanchâtre. Flcurs unisexuelles : les nâles très petites, veltes, en petites grappes dressées; les femelles portées deux à deux par un pédoncule allongé, courbé. Fruils à trois coques, velus, tuberculés. Fréquente sous les olivier's, dans toute la Riviera occidentale el dans le Nord de la Corse, mais probablement introduite de l'Orient ou de l'Afrique septentrionale.

Toute la plante est vénéneuse et on l'employait autrefois comme purgative et émétique; elle n'est plus usitée ainsi de nos jours. On peut en préparer une substance colorant en bleu, connue sous le nom de Tournesol, qui sert à teindre des élofies d'indienne, des fromages, du vin, etc. Les chimistes se servent de pelites bandeleltes de papier buvard mouillé de teinture de tournesol, pour connaitre le degré d'acidité ou d'alcalinité des liquides. Il ne faut pas confondre celle substance arec l'Orseille, autre tournesol fourni par plusieurs espèces de lichens (Roccella) qui vivent sur les rochers maritimes de la Méditerranée el de l'Océan. 
$-87-$

Lieux cultivés; décombres. - Flıurit on mai ct juin.

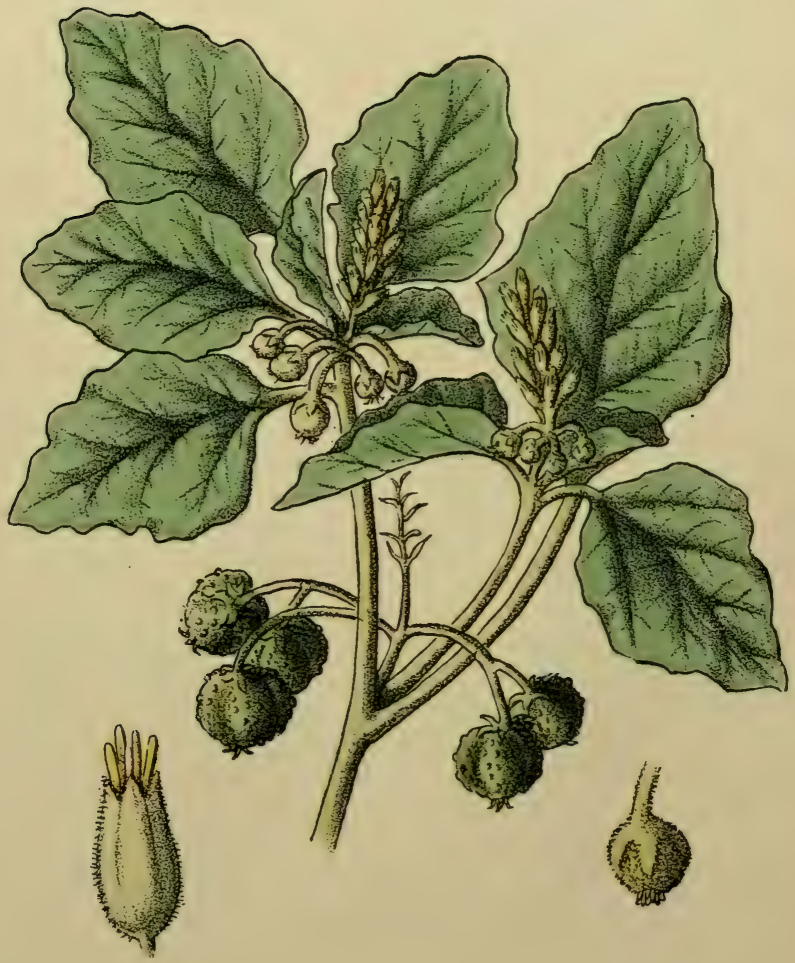

Crozophora tinctoria.

Frans. Croton des teinturiers. Prov. Maourèta, Mourelo, Faióu fer. 
- $88-$

Lieux ombragés; le long des torrents. - Flourit on fir. nt mars.

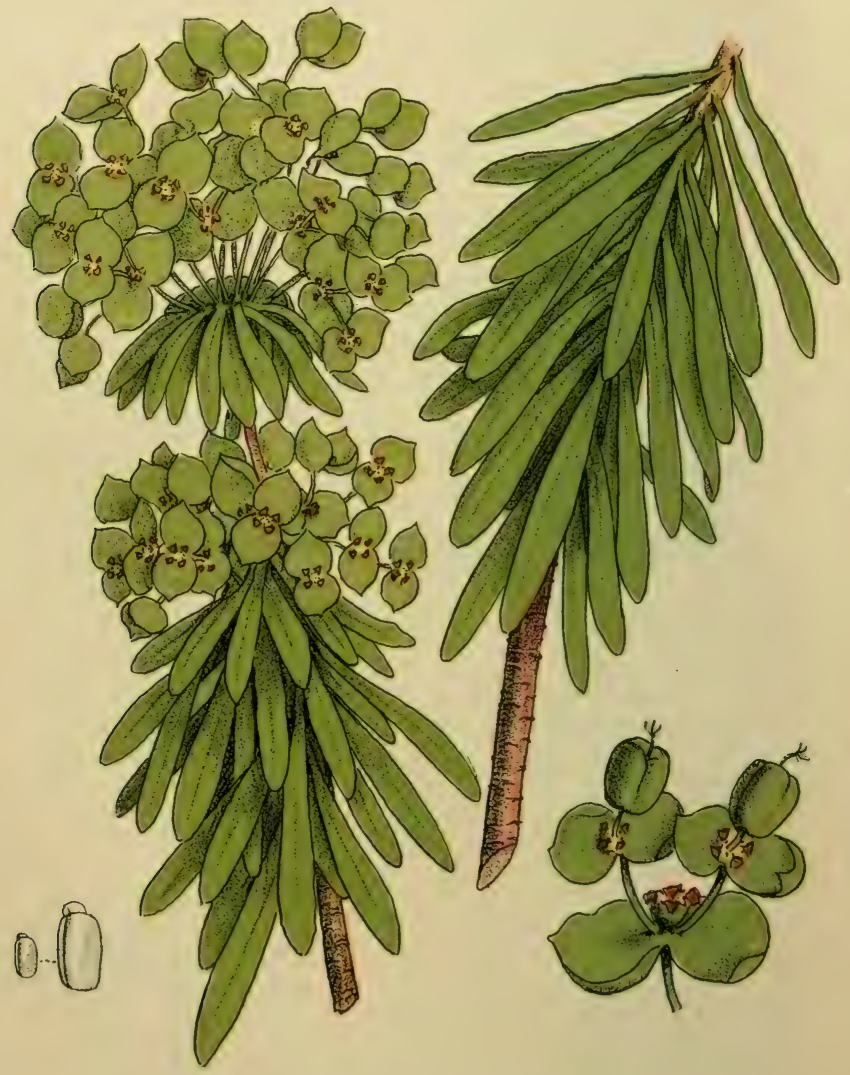

Euphorbia Characias.

Frene? Euphorthe des vallons.

Prov. Lanchousclo grosso.

- Euphorbiacées. - 


\section{EUPHORBIA CHARACIAS.}

Plante vivace, à souche ligneuse ; tiges ascendantes, ligneuses à la base, hautes de 60 à 100 centimètres. Feuilles en rosette à la base des tiges, les supérieures éparses, persistantes, herbacées, lancéolées, obtuses, réfléchies, velues; inflorescence terminale en grappe très allongée; fleurs à périgone de 5 pièces semilunaires d'un pourpre foncé, rarement jaunes, entourées d'un involucre formé par la soudure de deux bractées concaves, foliacées, d'une teinte vert pâle.

Commune dans les ravins, le long des torrents, sous les oliviers du littoral, moins abondante en Corse.

On distingue facilement cette espèce parmi la plupart de ses congénères par le duvet presque velouté qui couvre les feuilles et la tige, et par sa taille remarquable. Elle est très ornementale et mériterait d'être introduite dans nos jardins.

Les médecins de l'antiquité faisaient grand cas de cette plante, très fréquente en Grèce, et l'employaient pour beaucoup de maladies; aujourd'hui, elle est presque complètement délaissée. Son suc laiteux est vénéneux. 


\title{
EUPHORBIA DENDROIDES.
}

\author{
Ligur. : S'variglio.
}

Arbrisseau ou pelit arbre de 1-2 mètres de hauteur: les rameaux, sortant d'une tige principale, sont très nombreux, touffus et donnent à la plante l'aspect d'une boule. Feuilles lancéolées linéaires, herbacées, tombant pendant l'été, d'une teinte vert-glauque. Fleurs en ombelles, jaunes, entourées de bractées de la même couleur.

Fréquente sur les rochers maritimes calcaires, dans les garrigues de la zone littorale, plus disséminée en Corse.

C'est peut-être la plus intéressante des nombreuses espèces d'Euphorbe que nous avons en Europe, et certainement celle qui attire le plus l'attention.

Sa taille extraordinaire, son port curieux, en boule, la couleur glauque des feuilles, la teinte vive des fleurs, et le phénomène très rare de la chute estivale des feuilles la font remarquer facilement, même par les profanes.

Elle est très vénéneuse, comme toutes les espèces congénères; son lait, blanc et très abondant, irrite fortement la peau et surtout les muquéuses. Les graines sont purgatives, drastiques, et sont parfois usitées par les paysans pour remplacer celles du ricin. 


\section{$-89-$}

Rochers maritimes. - Fleurit en mars of arril.

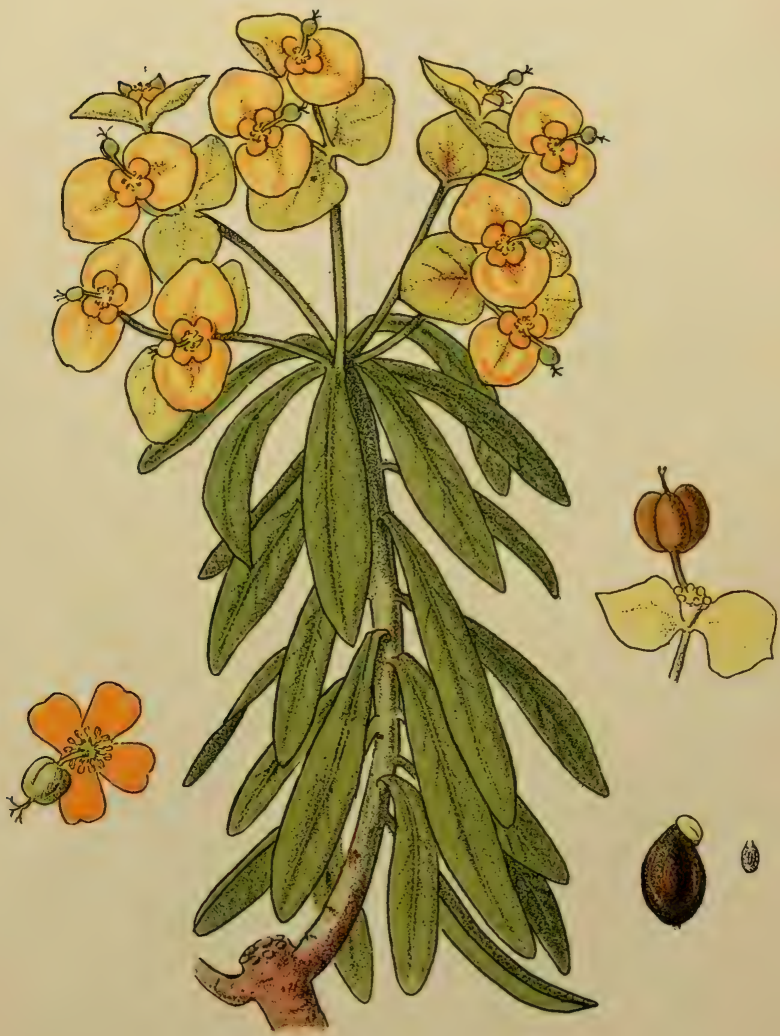

Euphorbia dendroides.

Euphorbe en arbre.

- Euphorbiacées. - 
$-90-$

Rochers, murailles; sous les oliviers. - Flmmil nn avil cl mai.

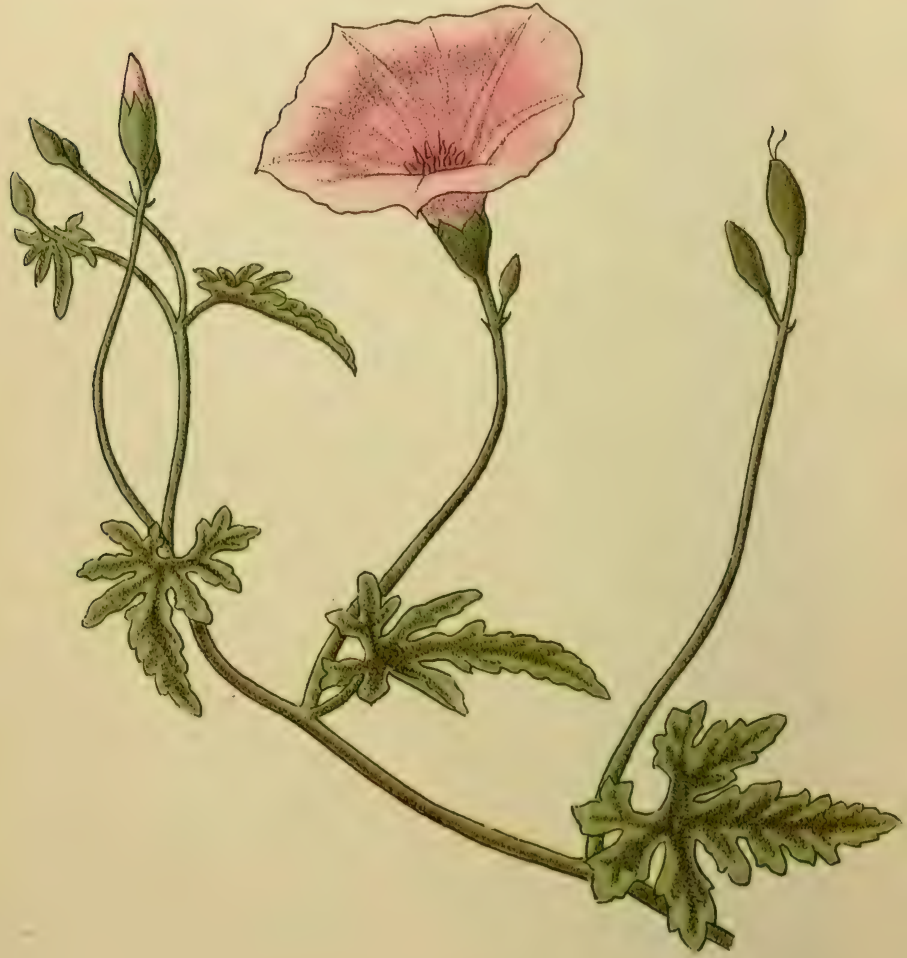

Convolvulus althaeoides.

Liseron fausse Guimauve.

- Convolvulacées. - 


\title{
CONVOLVULUS ALTHAEOIDES.
}

\author{
Ligur. : Scursoea, Curiola.
}

Plante à souche rivace, à tig'es allongées, rameuses, quelquefois très longues, volubiles; feuilles inférieures en cœur, crénelées sur les bords, les supérieures digitées à lobes linéaires; toutes hérissées de poils, de même que les tiges. Fleurs axillaires, solitaires ou réunies par deux ou trois, grandes, d'un lilas-rose pâle.

Commune dans les haies, dans les endroits pierreux, ensoleillés, sous les oliviers surtout, dans la partie occidentale de la Riviera, moins répandue en Corse.

C'est une plante très élégante et ornementale, et il est à regretter qu'elle ne soit pas introduite dans nos cultures. Les feuilles ont la forme éminemment artistique, et les fleurs sont parmi les plus belles de notre Flore.

Les feuilles, les tiges et la racine sont amères et contiennent une substance résineuse, fortement purgative, semblable à celle du Jalap. Elles peuvent être substituées à toules les drogues analogues.

Plusieurs espèces de Convolvulus se rencontrent -encore le long de la Riviera (outre les espèces communes au Nord, par exemple: C. arvensis, C. sepium): ce sont le $C$. cantabrica, à tiges non volubiles, à fleurs roses, feuilles linéaires, $C$. siculus, C. tricolor et $C$. lineatus. 


\section{OSYRIS ALBA.}

Espagnol : Retama blanca.

Petit arbrisseau à tig'es grêles, striées, dressées, vertes ; feuilles éparses, persistantes, lancéolées, très entières; fleurs petites, en longues grappes étroites, d'un rert jaunâtre, unisexuelles: les mâles (staminifères) en petits bouquets sur des rameaux très courts, les femelles (à pistils seuls dans une corolle à 3 lobes) solitaires. Baies rouges, presque sphériques.

Commune sur les collines, et mèmejusqu'au sommet des montagnes, aux bords des bois, dans les lieux secs, ensoleillés, sur le littoral et en Corse.

C'est une plante plus intéressante pour le botaniste que pour les profanes, comme représenlant presque unique en Europe (arec quelques espèces du g'enre Thesium) de la famille des Santalacées, largement répandue dans les tropiques. Les Thesium sont de petites herbes à fleurs blanchâtres, encore semi-parasites comme les Rhinanthus (voir page 84); parmi les Santalacées tropicales sont remarquables les diverses espèces de Santalum des Indes orientales, qui foumissent le bois odorant de santal.

De l'Osyris alba aucun usage ne nous est connu. 


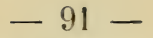

Endroits secs et rocailleux des collines.

Flemit en arril et mai.

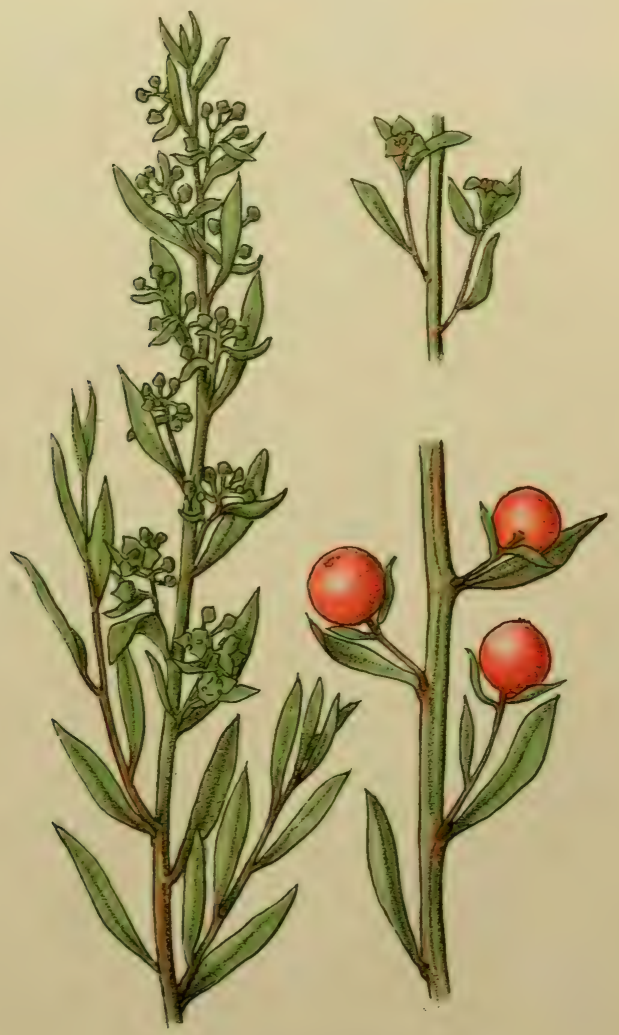

Osyris alba.

Frune. Osyris blanc. Prov. Rouret, Brugas ferr. 
$-92-$

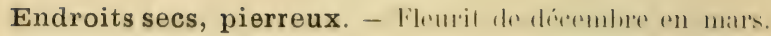

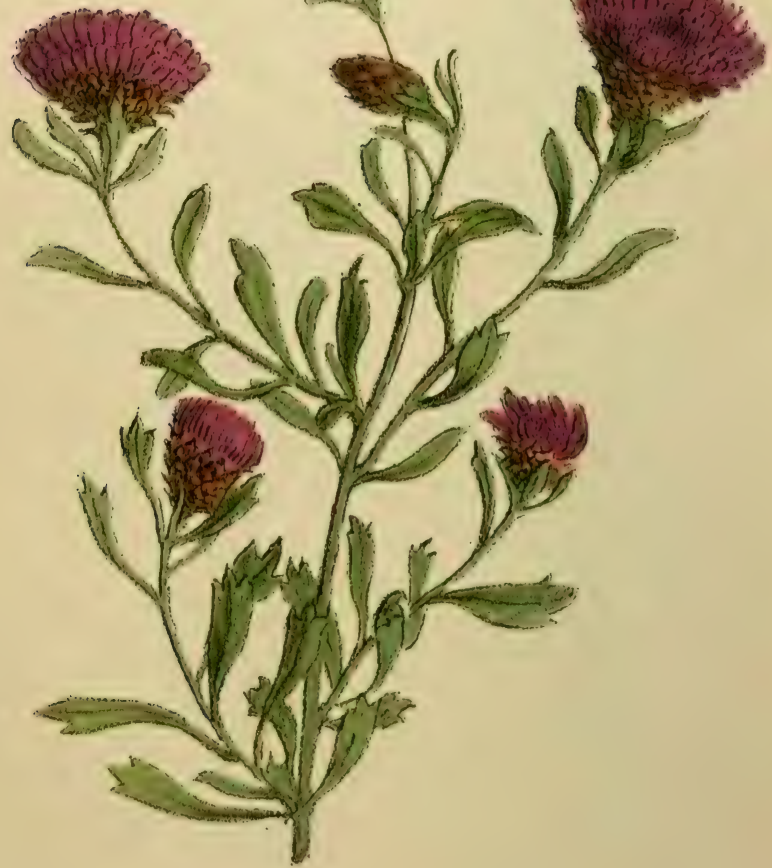

Globularia Alypum.

Frane. 'T'umbith blane, Séné des Provenẹaux. Prov. 'Tumbith blane, séné, lie de passeroun. 


\section{GLOBULARIA ALYPUM.}

Ligur. : Tümaro engàn; Espagn. : Cebolluder, Corrona de Rey; Allem. : Strauch-Kugelblume.

Plante vivace, ligneuse, de 30 à 50 centimètres de hauteur, à liges allongées, minces, roides, rameuses, couvertes de petites feuilles spatulées, coriaces, persistantes, d'un vert foncé. Fleurs réunies en capitules terminaux, presque sphériques, bleues, rarement blanches.

Commune dans les endroits secs, pierreux de la zone littorale el en Corse.

C'est encore une plante qui intrigue beaucoup les profanes: son aspect est tout à fait celui d'une Composée ou d'une Dipsacée, quoiqu'elle n’ait rien à faire avec ces familles: ses pelites fleurs ont une constitution semblable à celles des Labiées ou des Verbénacées. Lor'squ'elle s'épanouit, surtout dans les. mois d'hiver, on remarque facilement ses jolies fleurs.

E!le est aussi médicinale: le nom provençal de « Séné » indique que l'on peut employer les feuilles pour remplacer celles de Senna, comme remède purgatif. La décoction des feuilles est donnée quelquefois contre l'hydropisie et les fièvres intermittentes.

Deux autres espèces du même genre sont également trouvées sur le littoral: le Globularia vulgaris, à capitules solitaires bleus, sur des tiges droites, herbacées, et le G. cordifolia, habitant les rochers. dans les haules montagnes. 


\section{$-93-$}

\section{STATICE PUBESCENS.}

Plante à souche vivace, ligneuse, rameuse, noiràtre, couverte au collet de la racine par les restes des feuilles anciennes. Feuilles en rosettes serrées, spatulées, coriaces, roides, recourbées, un peu roulées sur les bords, à pubescence courte. Inflorescence haute de 15 à 30 centimètres, très rameuse, à arlicles courts de $1 / 2$ à 1 centimètre de longueur, égaux; fleurs en petits épillets de 2-3, à l'extrémité des articles fertiles, petites, d'un bleu très pâle.

Cáa et là sur les rochers maritimes, à proximité de la surface de l'eau.

Ce sont de jolies petites plantes que l'on pourrait dire presque amphibies : enracinées dans les fentes des rochers, elles ont besoin de beaucoup d'humidité, et elles sont presque constamment mouillées par l'écume ou par la poussière d'eau salée qui monte jusqu'à leur station. Presque toutes les espèces de Statice (on en trouve plusieur's sur les rocher's maritimes ou dans les marais du littoral) ont la propriété de pouvoir supporter sans détérioration le contact de l'eau salée.

Nous ri'en connaissons aucun emploi. 
$-93-$

Rochers maritimes. - Fleurit en septembre et octobre.

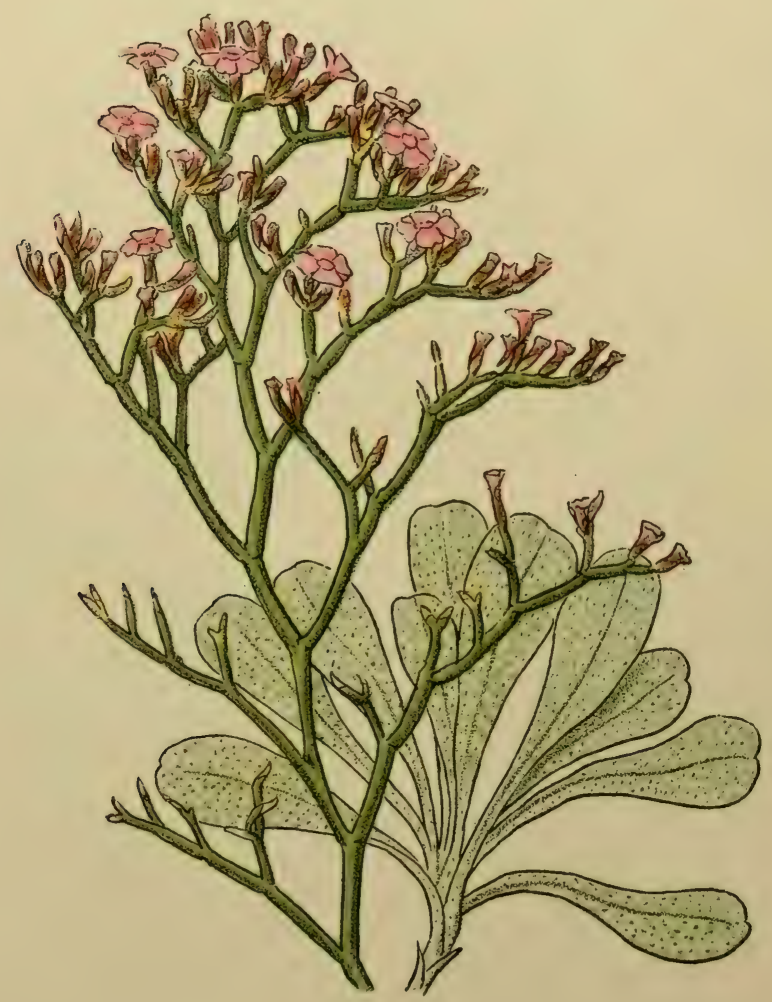

Statice pubescens.

- Plumbaginées. - 


$$
-94-
$$

Sables maritimes, dunes. - Flnurit en mai et juin.

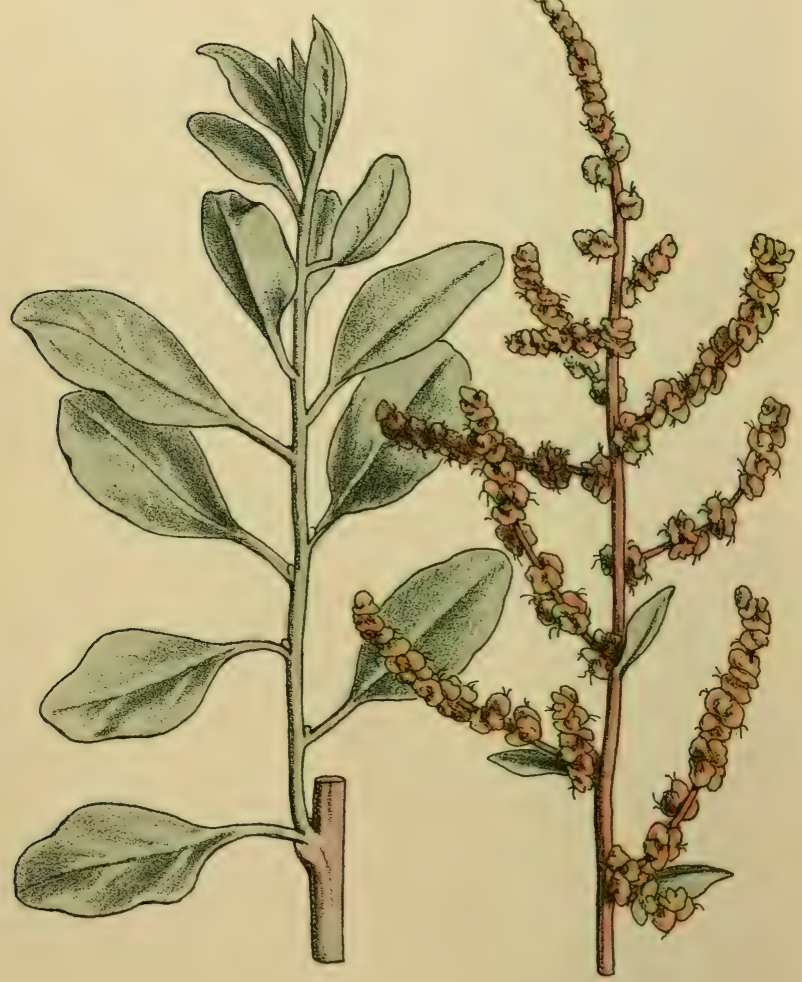

Atriplex Halimus.

Frans. Arroche de mer. Prov. Bouis blanc. 


\section{ATRIPLEX HALIMUS.}

Espagn. : Salyada verre, Saludo blanco; Allem. : Mrer-Ifelde.

Arbrisseau de 1-2 mètres de hauteur, à rameaux touffus, dressés, à feuilles ovales, persistantes, d'une couleur blanchâtre-argentée, courertes de petites écailles luisantes, de même que les branches et toutes les parties vertes de la plante. Fleurs en grappes terminales, très petites, insignifiantes, verles; fruits renfermés entre deux petites feuilles bractéiformes, presque triangulaires.

Spontanée cà et là sur les sables maritimes; très souvent cultivée pour former des haies.

De même que chez toutes les Cliénopodées, on trouve dans l'Atriplex Halimus une quantité relativement grande de sels sodiques et polassiques, qui dans quelques espèces (Salsola Soda, S. Kali, Salicornia $p l$. sp.) peuvent être exploités par l'industrie.

L'Atriplex Halimus aussi est employé parfois pour la préparation de la soude. Ses jeunes pousses peuvent être mangées et sont apprêtées comme les câpres. Dans l'Afrique septentrionale et l'Australie, oì notre espèce croît aussi, on la considère comme un bon fourrage, surtout pour les moutons. 


\section{PLANTAGO BELLARDI.}

Plante annuelle, à racine pivotante, sèche; feuilles en rosette radicale, couchées, lancéolées, très velues; plusieurs hampes florales, hautes de 5 à 10 centimètres ; fleurs en épi ovoïdal ou oblong à l'extrémité des hampes, petites, vertes.

Fréquente et souvent agylomérée dans les pelouses sèches, sur les coleaux arides, le long des routes dans la zone littorale et en Corse : humble plante, qui attire difficilement l'attention des passants. C'est une bonne plante fourragère, comme tous les plantains; et ses graines, oblongues, brunes, luisantes, ont (comme celles du Plantago arenaria et P. Psyllium) la propriété de fournir, au simple contact de l'eau tiède, un mucilage très abondant, qui peut être utilisé pour l'apprêt de la toile, de la soie, etc. 


\section{$-950$}

Pelouses sèches; coteaux arides. - Flnurit en mars nt arril.

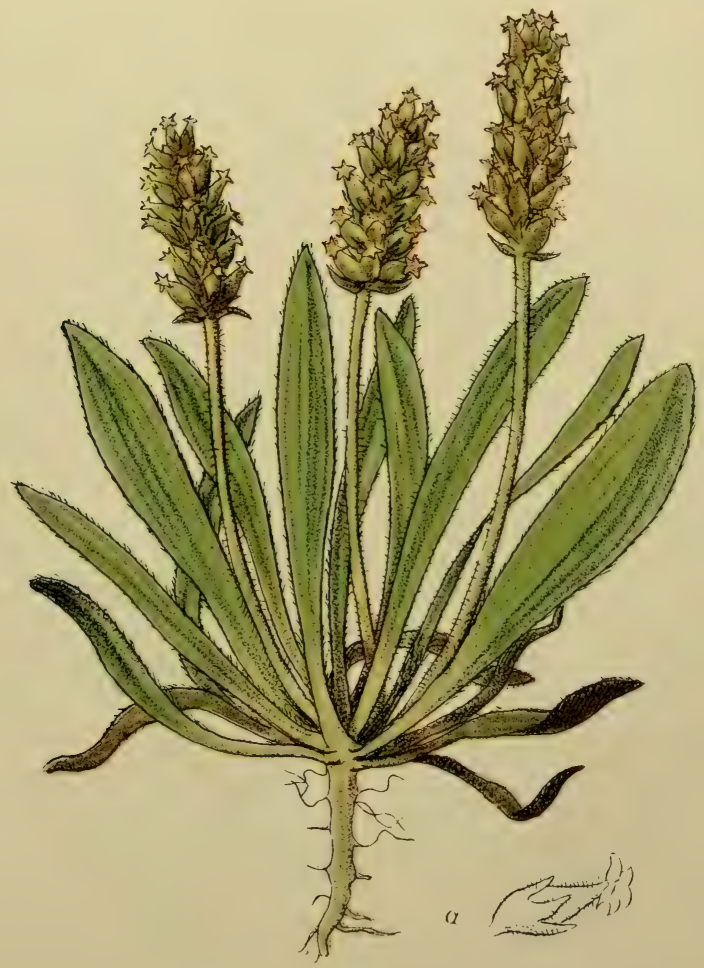

Plantago Bellardi.

Frons. Plantain poilu. Prov. Plantage. 


\section{- 96 -}

Lieux cultivés, ombragés; sous les oliviers. - Fleuril m févirier et mar's.

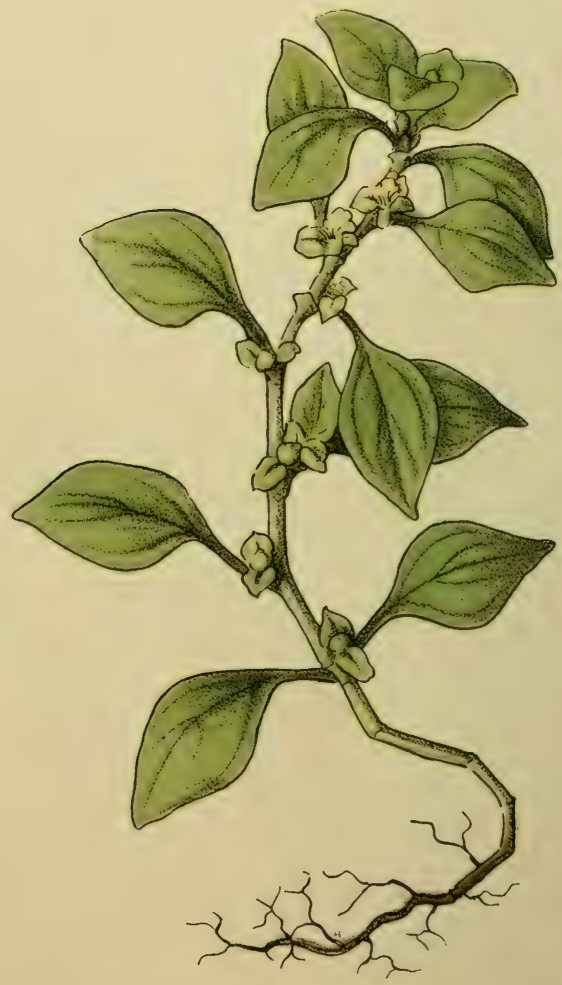

Theligonum Cynocrambe.

Théligone étalé.

- Théligonacées. - 


\section{$-96-$}

\section{THELIGONUM CYNOCRAMBE.}

Ligur. : Bazarigì survaigo; Allem. : Hundskohl.

Plante annuelle, haute de 5 à 20 centimètres, molle, à lige simple, dressée ou couchée, un peu charnue, glabre ; feuilles éparses, plus rapprochées vers le sommet de la lige, herbacées, charnues, glabres. Fleurs unisexuelles : les mâles naissant par la tigge hors des aisselles foliaires (ce qui est un fait très rare) deux à deux, avec 10-20 étamines à filets très minces, capillaires; fleurs femelles axillaires, solitaires : les unes comme les autres très petites, verdâtres, insignifiantes.

Très commune et abondante dans les terrains cultivés, sous les oliviers, dans les lieux ombragés, sous les ronces, répandue également en Corse. Elle échappe facilement à l'observateur, parce qu'elle n'a rien d'altrayant ou de ce qui appelle l'attention: c'est une humble petite herbe, semblable en apparence au Mouron blanc, mais appartenant à une famille différente.

La disposition singulière et la structure des fleurs ont souvent embarrassé les botanistes, qui ne sont pas encore d'accord sur la position du genre Theligonum dans le règne végétal. Il se rapproche, sous certains rapports, des Urticacées et des Euphorbiacées ; mais, en général, on la met dans une famille à part, les Théligonacées.

Nous n'en connaissons aucun emploi. 


\section{DAPHNE GNIDIUM.}

\section{Ligur. : Iareigo: Espagn. : Torvisco.}

Petit arbrisseau de 1 à 1 mètre 50 de hauteur, à rameaux dressés, droits, courerts de feuilles denses, allongées, persistantes, aiguës, glabres, d'un rert pâle: fleurs blanehes en petiles grappes à l'extrémité des branches, à pédicelles cotonneux. Baies rouges, petites.

Fréquent dans les bois de pins, dans les maquis et les endroits pierreurs. sees de la Ririera et de la Corse.

Plante très vénéneuse, comme les autres espèces congénères : toutes les parties contiennent une résine molle, verte, et un alealoide très amer, appelé Taphnine. De mème que le Bois-gentil (Daphne mezereum) et la Lauréole (D. Laureola), le Garou est une plante médicinale. On emploie surtout la poudre de son écorce pour préparer une pommade vésicatoire et les papiers épispastiques, contre diverses maladies de la peau, des yeux, etc.; les baies et les feuilles sont fortement purgatires et drastiques.

Les braconniers, en Corse, se servent de cette plante pour empoisonner les rivières et pècher la truite. 


\section{- 97 -}

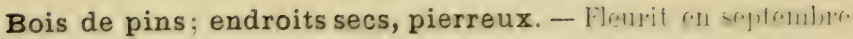
et octobre.

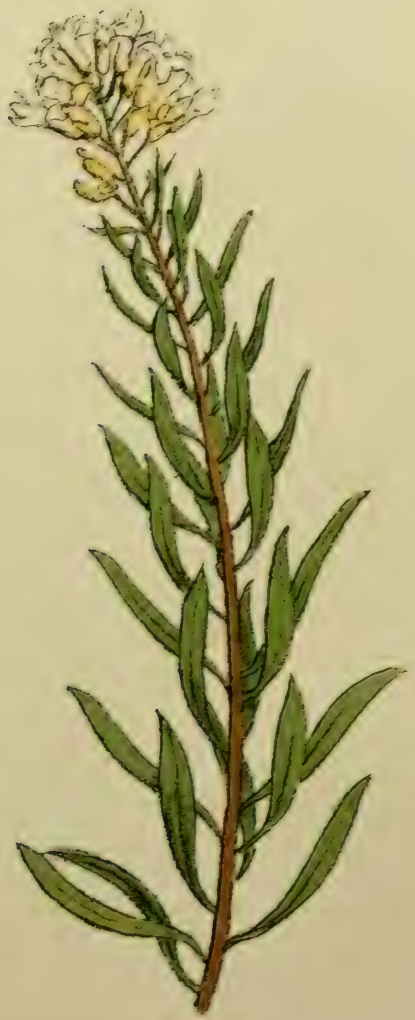

\section{Daphne Gnidium.}

Frane. Garou, Sain-l,ois. Proc. Canta-prerlris, Trintaneta, Gurou. 
$-98-$

Bois des collines, maquis. - Horil "ll aril.

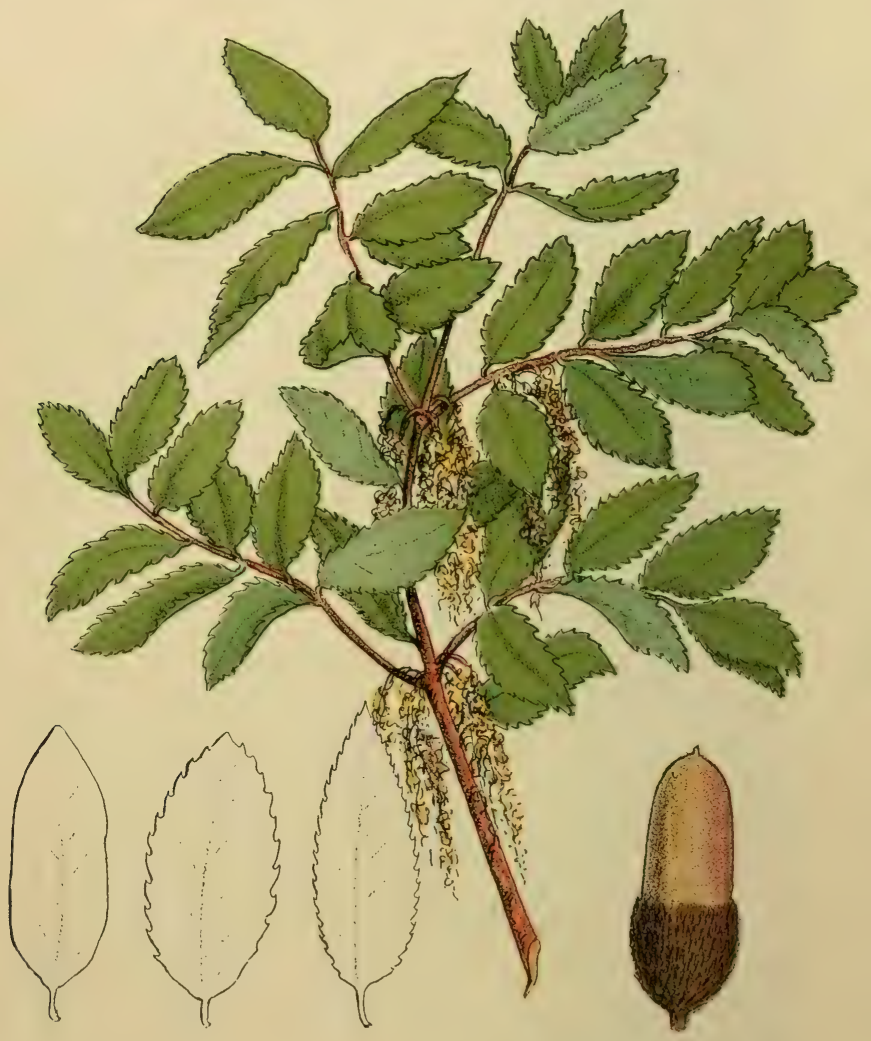

Quercus Ilex.

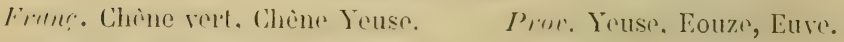




\section{QUERCUS ILEX.}

Ital. : Elce; Ligur. : Erxu; Espagn. : Encina comun, Alsina; Allem. : Stein-Eiche; Angl. : Holm oak.

Arbre forestier d'une certaine importance pour la région méditerranéenne, à tronc tortueux, à écorce rugueuse, grisâtre; branches irrégulières, touffues ; feuilles persistantes, coriaces, vertes en dessus, blanchâtres en dessous, de forme et grandeur extrêmement variables. On peut trouver sur les différentes branches du même individu, des feuilles totalement différentes dans la grandeur, le contour (elliptique ou allongé), les bords (très entiers, ou dentelés, très souvent roulés en dessous) et le duvet plus ou moins abondant. Les fleurs mâles et femelles sont analogues à celles des chênes communs; les glands allongés, pointus.

Le Chêne vert constitue, avec les diverses espèces de pins, la masse principale des forêts dans la Riviera et la Corse; il est beaucoup cultivé à cause de son feuillage compact, persistant: les vieux troncs, que l'on peut admirer dans divers jardins anciens du littoral, ont un port magnifique. En outre, c'est une plante fort utile, d'abord par son bois, résistant et dur comme celui du chêne commun, puis par son écorce très riche en tanin et employée dans la tannerie; et enfin par ses glands qui servent à la nourriture des pores.

Le Chêne-liège (Quercus Suber) qui se trouve mêlé au Chêne vert, çà et là dans la Piviera, et abondamment au S.-E. de la Corse, lui ressemble beaucoup et n'en diffère guère que par la structure de l'écorce. Sur le littoral on ne l'exploite presque pas. 


\section{QUERCUS COCCIFERA.}

Espagn. : Coscoja, Malarubia, Carrasca.

Arbrisseau ou petit arbre d'un à deux mètres de hauteur, à écorce rugueuse, grise; branches touffues, presque gazonnantes; feuilles plus petiles que dans le chêne vert, coriaces, glabres sur les deux faces, dentées-épineuses. Glands plus petits que ceux du chêne vert; écailles de la capsule du fruit étalées.

Çà et lá dans les maquis, les garrigues de la Provence, mais fréquent seulement dans la partie plus occidentale de la Riviera. On ne trouve plus celte espèce de chêne à l'Est de Menton, dans la Riviera d'Italie : mais elle réapparaît dans la presqu'île balkanique et dans l'Orient, où elle se montre plus développée, atteignant la hauteur de plusieurs mètres.

Le nom spécifique de « coccifera indique que cette plante a pour parasite une espèce de cochenille, petit insecte dont les femelles non ailées produisent une substance colorante rouge, connue sous le nom d'alkermès, et employée dans diverses industries. Le « Chêne au kermès s produit aussi une espèce de manne qui peut remplacer la manne du frêne. 
$-99-$

Maquis; garrigues. - Flnmit nn mars of arril.

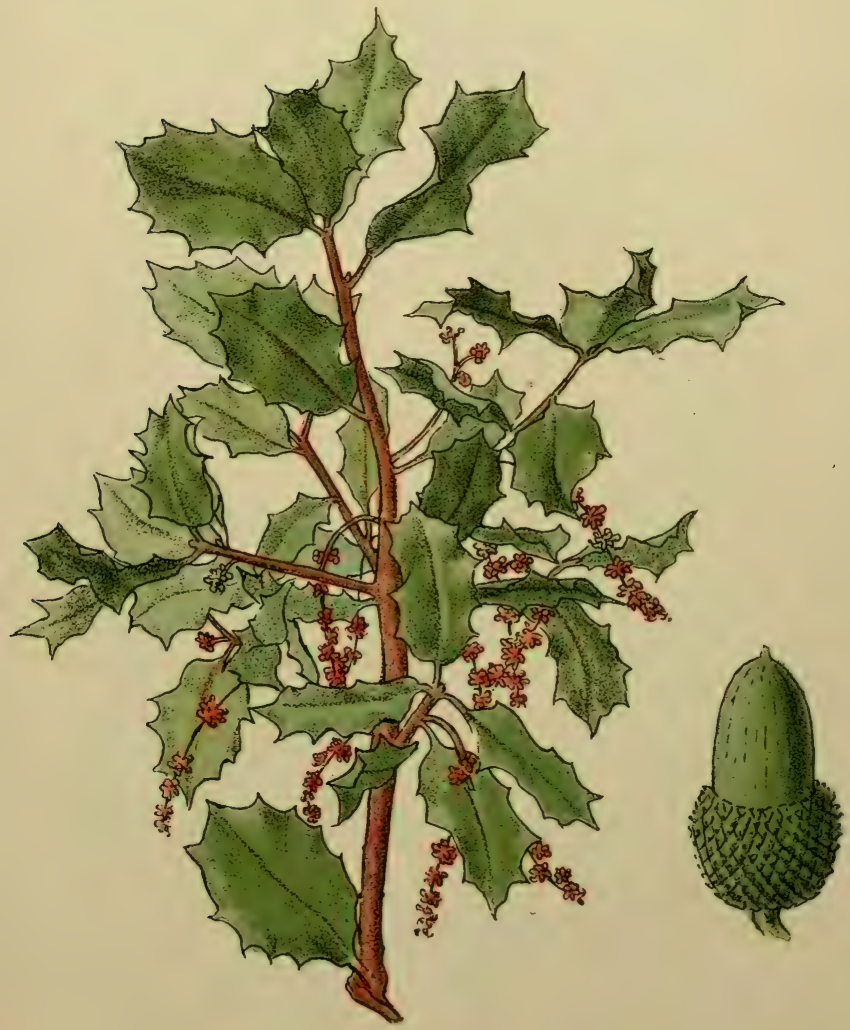

\section{Quercus coccifera.}

F'iang. Chène au Kermès, Chêne à Cochenilles, Chêne des Garrig̣ues. Prov. Avalse, Garoulia, Avaus, Garus. 
$-100-$

Bois, endroits pierreux. - Fleurit en mars of arril.

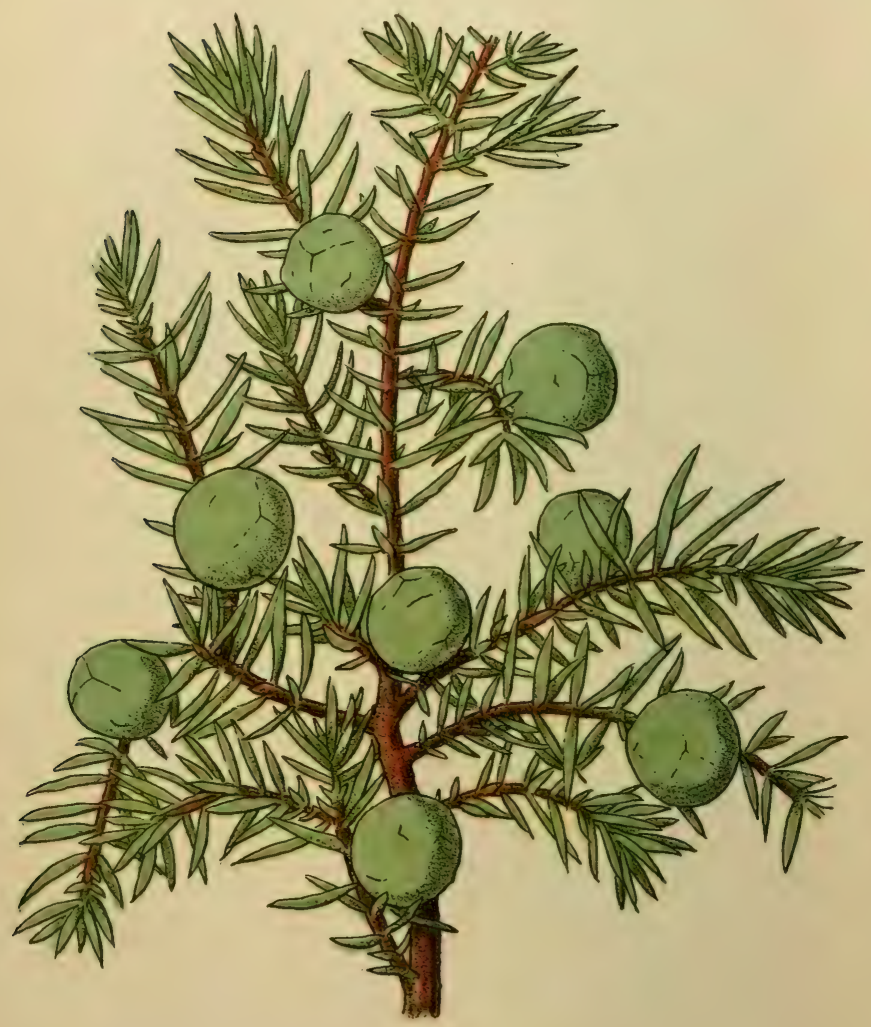

Juniperus Oxycedrus.

Frane. Cinnivrier Cade, Cèdre piquant. Prov. Cade acadrić. 


\section{JUNIPERUS OXYCEDRUS.}

Ital. : Ginepro; Ligur. : Agaïso; Allem. : Ceder-Wachholder.

Arbrisseau ou petit arbre (parfois de 3-4 mètres de hauteur) touffu, à rameaux entrelacés, à feuilles disposées en rerticilles, linéaires, aiguës, piquantes, persistantes, vertes avec deux lignes glauques en dessous. Fleurs unisexuelles, comme dans tous les Conifères : les mâles en forme de petits chatons ovales, qui tombent bientôt après la fécondation; les femelles en petits cônes globuleux, dont les écailles supérieures deviennent plus tard charnues, formant une espèce de fausse baie sphérique, rouge, du diamètre de 1 à $11 / 2$ centimètre.

Très commun dans les bois, dans les endroits pierreux, sur les pentes des collines, jusqu'à 300 mètres de hauteur, souvent associé au genévrier commun (qui s'en distingue par les feuilles marquées d'une seule ligne blanchâtre et par les fruits petits, noirs ou bleuâtres). Assez rare en Corse.

Ses baies, très appréciées par les anciens, sont employées comme celles du genévrier commun. Le bois, utilisé pour la fabrication des crayons, est rougeâtre, odorant et contient une espèce de résine semblable à la résine de Sandaraque. Dans le Languedoc on fail usage de l'huile de Cade (Oleum cadinum) contre les maux de dents. 


\section{PINUS PINEA.}

Ital. : Pino da pigne; Ligur. : Pin da pigniö; Espagn. : Pino piñonero; Allem. : Pinie; Angl. : Pine-tree.

Arbre de haute taille, à tronc dressé, ramifié seulement en haut; branches touffues, élalées, redressées au sommet, formant une masse compacte telle, que le tronc avec sa têle élargie ressemble à un parasol gigantesque ouvert. Feuilles réunies par deux, persistantes, filiformes, presque ligneuses, aiguës,

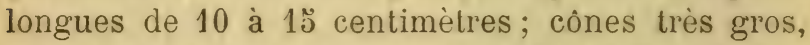
ovales, obtus, réfléchis, à écailles luisantes, grosses.

Le pin parasol ou a pin pignon ne semble pas indigène dans le littoral méditerranéen et en Corse, pas même en Italie. Originaire de l'Asie, il a été introduit d'abord en Grèce et est passé, à une époque très lointaine, en Italie. A présent, on le trouve parfois subspontané, et il se propage facilement par ses graines. Celles-ci sont beaucoup plus grosses que dans nos espèces de pins indigènes, allongées, et contiennent dans leurs amandes une huile grasse de goût agréable. Les cônes privés des graines, sont employés généralement pour allumer le feu. Une autre espèce de pin à graines comestibles, le cembro ou alviès (Pinus Cembra) croît sur les montagnes les plus élevées des Alpes et des Alpes-Maritimes. 
$-101-$

Bois des collines; souvent cultivé. - Fmil milril.

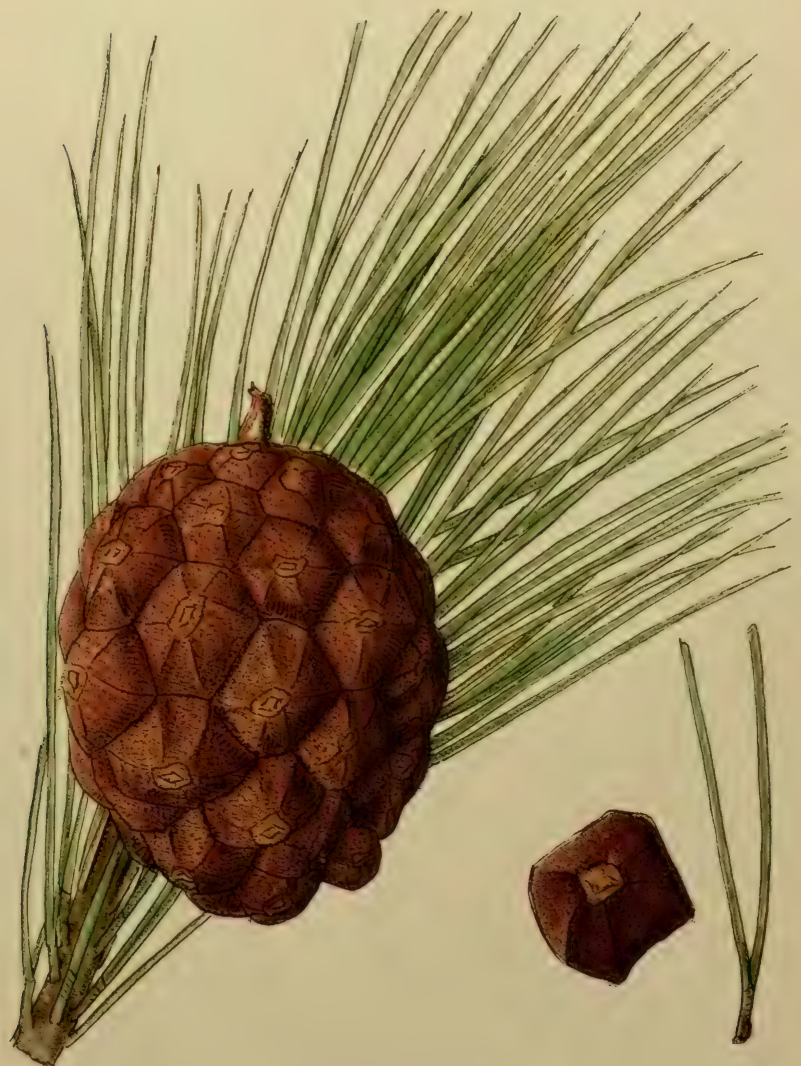

Pinus pinea.

Frume. P'in pignon, Pin parasol, Pin d'Italie.

Prov. Pin pignoun. 


\section{$-102-$}

Bords de la mer; bois des collines. - Fleurit $n$ avril.

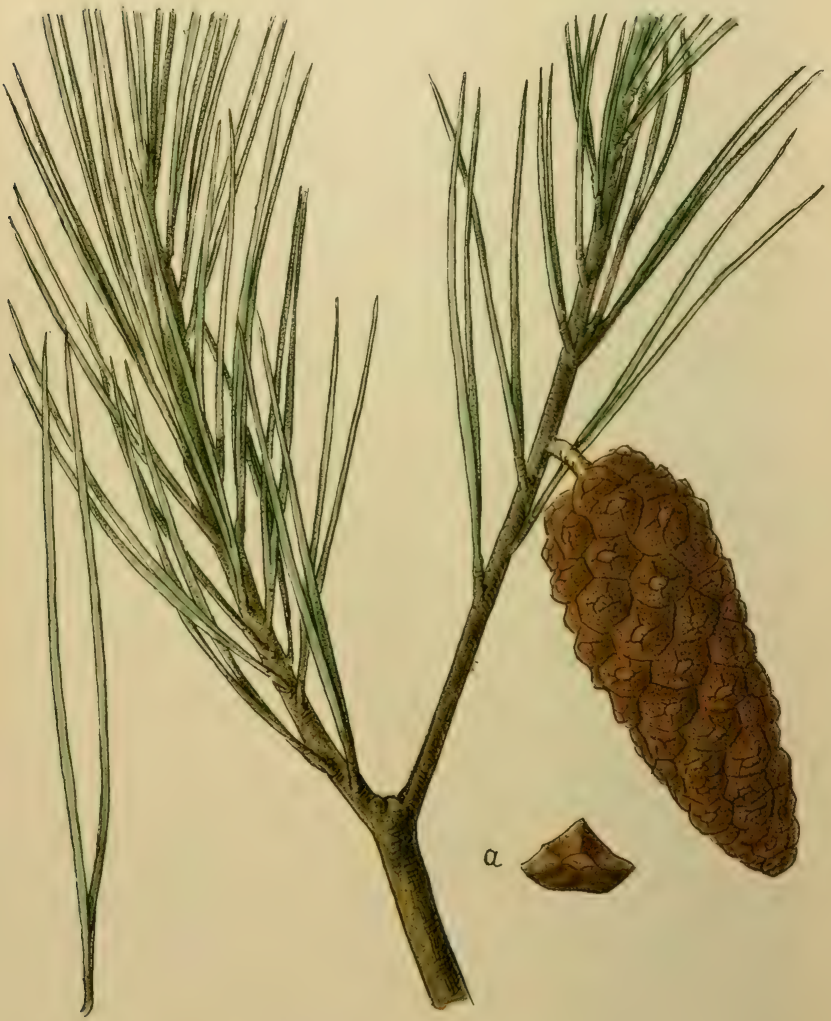

Pinus halepensis.

Frans. P'in de Jérusalem, l'in d'Alep.

Prov. Pin blanc. 


\section{PINUS HALEPENSIS.}

Ital. : Pino d'Aleppo; Ligur. : Pin gianco; Espagn. : Pino Carrasco; Allem. : Aleppo-Kiefer.

Arbre de haute taille, qui ressemble dans son port au Pin parasol, mais a la tête moins régulière, moins compacte, et le tronc souvent courbé, tortueux. Ses feuilles, en forme d'aiguilles, réunies par deux, sont beaucoup plus courtes que celles du $P i$ nus Pinea, n'atteignant que 6 à 8 centimètres de longueur; en outre, elles sont moins raides et d'un vert plus clair.

Les cônes sont petits, de la longueur de 8 à 10 centimètres, allongés, à écailles ligneuses qui plus tard devienner.t grisâtres.

Le Pin d'Alep ou Pin de Jérusalem est l'espèce de pin la plus commune sur le littoral, où il forme des forêts plus ou moins étendues. Il prédomine surtout dans les terrains calcaires, tandis que dans les terrains siliceux, granitiques, il est remplacé par le Pinus maritima ( $P$. Pinaster ${ }^{2}$ à feuilles plus longues, à cônes plus gros.

Plus éloignés de la mer, nous pourrons trouver encore le Pin commun( $P$. sylvestris) à feuilles courtes, glauques, et sur les montagnes plus élevées le Pin à crochets $(P$. uncinata $)$. Le bois de toutes ces espèces de pin est très apprécié et on l'utilise dans les constructions. Le $P$. halepensis et le P. maritima fournissent aussi en abondance de la résine et de la térébenthine. 


\section{JUNIPERUS PHAENICEA.}

Arbrisseau de 1 à 1 mètre 50 de hauteur; tiges généralement couchées, étalées ou ascendantes; rameaux touffus, couverts partout de petites feuilles très courtes, obluses, en forme d'écailles vertes, imbriquées, glabres. Fruits (fausses baies) petits, globuleux, roussâtres.

Cà et là sur les rochers escarpés de la région littorale, surtout dans les terrains calcaires. Très commun aux environs de Bonifacio, en Corse, et devenant quelquefois un arbre dans quelques autres régions de cette île.

Cette espèce est sourent confondue arec la Sabine, Juniperus Sabina, dont elle imite le port; elle en diffère par la couleur des fruits (bleuâtres dans le J. Sabina), et par la position des fleur's mâles, terminales dans le $J$. phonicea et latérales dans le J. Sabina. Elle est vénéneuse comme la Sabine et peut la remplacer ; pourtant il faut en user, en médecine, arec beaucoup de prudence. 
$-103-$

Rochers calcaires. - Flenit en mars of arril.

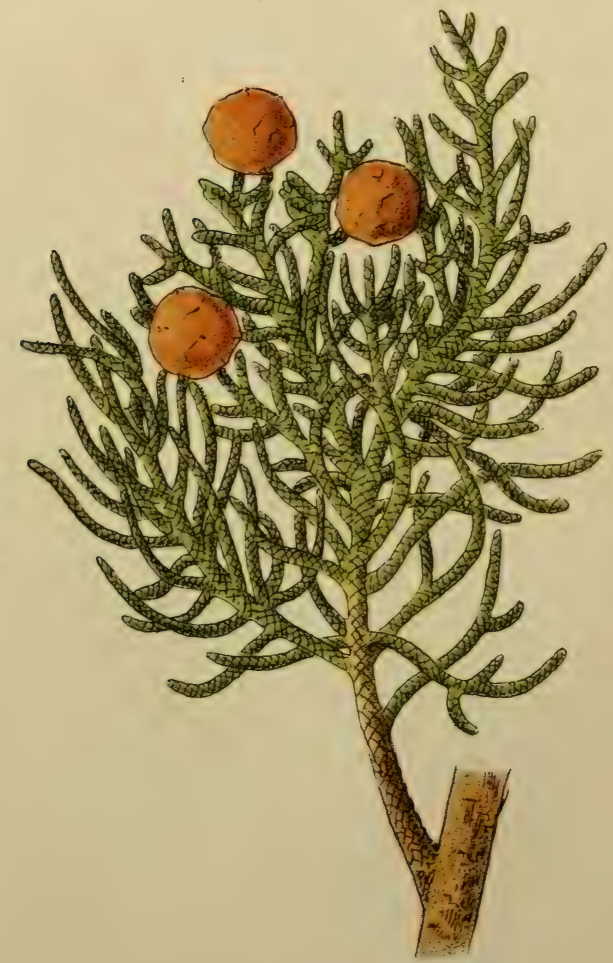

Juniperus phœenicea.

Frang. Genérrier de Phénicic. Prov. Mourvis, Cade Mourvis.

Cade endourmi. 
Murailles, haies; endroits pierreux. - Fleurit en arril.

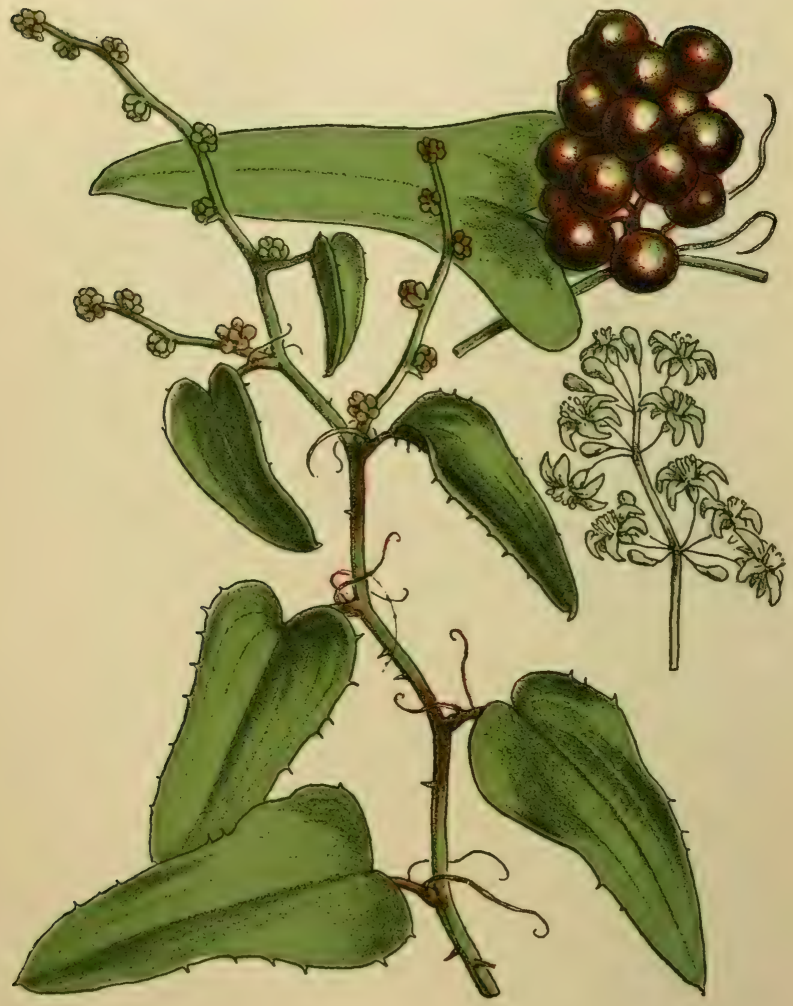

Smilax aspera.

Fan!. Liseron épineux, Salsepareille d'Europe.

Prov. Salièje, Arièje, Esclario, Rin-vierge. 


\section{SMILAX ASPERA.}

Ital. : Salsapariglia nostrana; Ligur. : Siga, Agru, Regaggi; Espagn. : Zariaparilla de España.

Plante vivace, ligneuse, à tiges souvent très longues, grimpantes à l'aide de vrilles, tortueuses, munies d'épines droites, piquantes. Feuilles persistantes, coriaces, un peu luisantes, très variables quant à la forme. Parfois elle présente des feuilles très larges, en cœur ou en forme de rein; ou bien des formes étroites, en fer de flèche ou de hallebarde, aux bords plus ou moins épineux. Les feuilles plus étroites sont très sourent tachetées de vert-pâle. Fleurs petiles, blanchâtres, en grappes, unisexuelles, parfumées; baies rouges, noircissant ensuile.

Très commune dans les haies, dans les buissons, sur les murs, dans les lieux pierreux, secs, de toute la Riviera et de la région littorale en Corse.

C'est l'unique représentant, en Europe, d'un genre très riche en espèces et répandu dans les pays tropicaux, surtout dans l'Amérique centrale et méridionale. Parmi ces espèces étrangères, nous trouvons des plantes médicinales de haute importance, comme celles qui fournissent la Salsepareille. Notre espèce aussi contient un peu de la substance active Pariglina, et on l'appelle a Salsepareille des pauvres », à cause de l'emploi qu'en fait la médecine populaire.

On dit que le a lierre » des anciens, si souvent cité comme ornement de Bacchus et de ses prêtresses, était notre smilax. 


\section{ASPARAGUS ACUTIFOLIUS.}

Ital. : Asparayo pengente: Ligur. : Sparugu sarvaegu;

Espagn. : Esparrago.

Plante rirace, à racines réunies en faisceaux, très longues; tiges ligneuses, flexueuses, grimpantes, très ramifiées, à rameaux enchevêtrés, rudes, horizontaux ou réfléchis. Feuilles réduites à de petites écailles blanchâtres, membraneuses ; elles sont remplacées par des faisceaux de petits rameaux verts, capillaires, lisses et piquants au sommet, longs de 3 à 5 millimètres. Fleurs axillaires, petites, penchées, verdâtres; baies noires.

Très commun dans les haies, dans les maquis ou garrigues, grimpant sur d'autres plantes ou parmi les pierres, à l'aide de ses rameaux réfléchis.

On mange les jeunes pousses, à peine sorties de terre, comme les asperges cultivées : elles sont un peu amères, mais très savoureuses. Elles contiennent beaucoup d'asparagine; aussi peuvent-elles être employées pour la confection du sirop d'asperges, remède diurélique très efficace. 
$-105-$

Haies, murailles. - Fleurit on mars et arril.

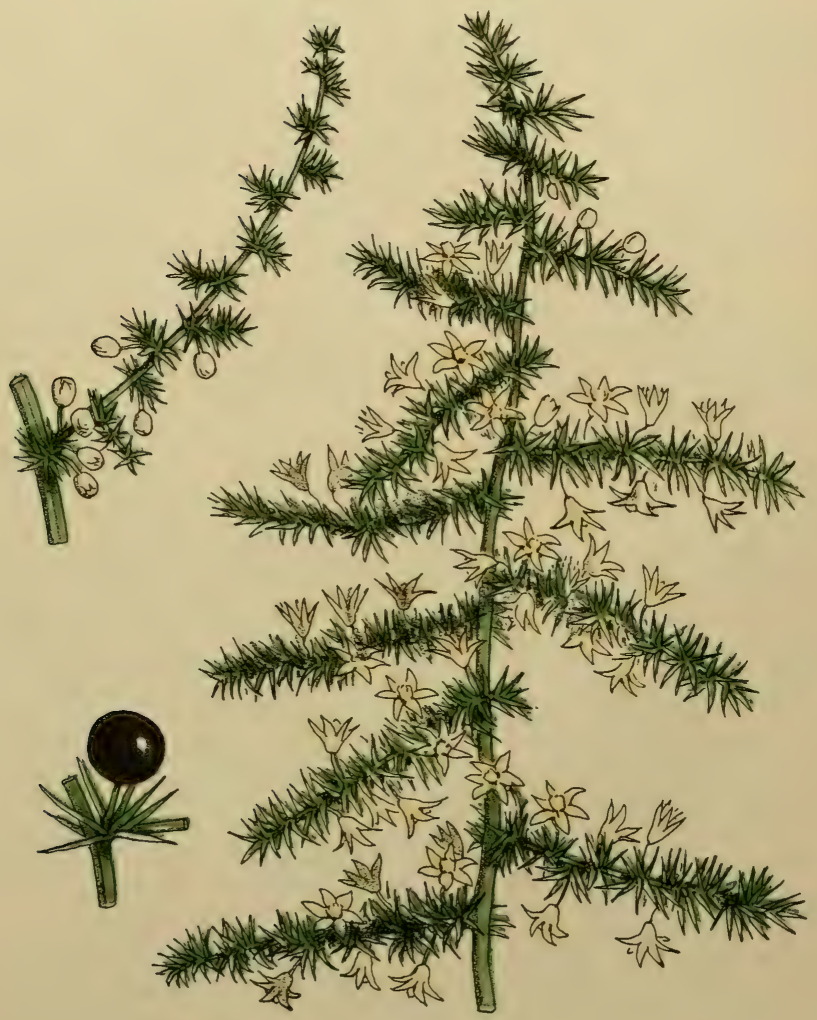

\section{Asparagus acutifolius.}

Franc. Asperge saurage. Prov. Rama-counil, Ramocouniè. 
$-106-$

Rochers des hautes montagnes. - Flumil m juill of juill,

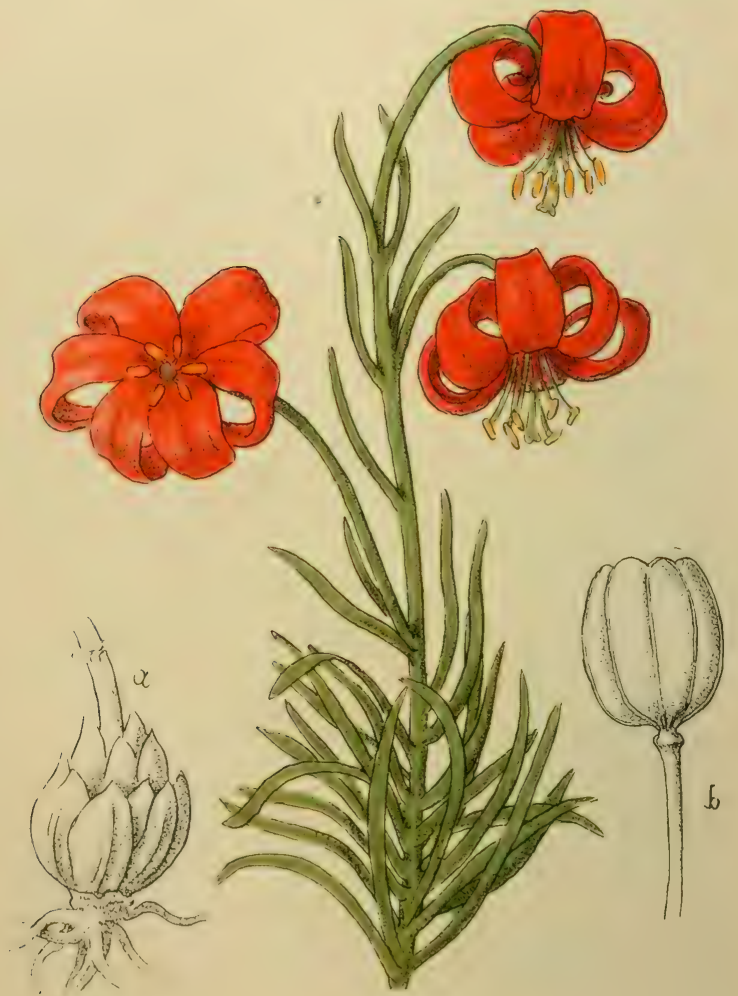

Lilium Pomponium.

Lis Lurban. 


\section{LILIUM POMPONIUM.}

Plante vivace, herbacée, haute de 50 à 90 centimètres. Bulbe souterrain couvert d'écailles charnues, blanchâtres, lancéolées; tiges droites, simples, pourvues de nombreuses feuilles éparses, linéaires, aiguës. Fleurs 3-7 en grappe terminale, grandes, penchées sur un pédoncule recourbé, à six pétales à peu près égaux, étalés et réfléchis en arc, d'un rouge vermillon, ponctués d'une teinte plus foncée.

Se trouve sur les montagnes de la Riviera, à plus de 500 mètres de hauteur, mais non fréquemment, et seulement dans la partie occidentale. Elle ne se rencontre plus à l'Est des Alpes-Maritimes, dans l'Apennin.

C'est une des plus belles espèces européennes de ce genre, très ornementale et digne de figur ıdans nos jardins.

Les bulbes écailleux, cuits dans l'eau, peuvent être mangés, comme ceux d'un autre lis à fleurs jaunes (Lilium bulbiferum ou $L$. croceum), qui est commun dans les bois des collines. Le $\boldsymbol{L}$. croceum se distingue facilement du L.Pomponium par ses fleurs dressées, à pétales non recourbés. 


\section{TULIPA PRECOX.}

Plante vivace, à bulbe ovoïdal, de la grosseur d'une noix, profondément enterré. Feuilles larges, elliptiques, vertes, charnues. Hampe florale haute de 20.30 centimètres; fleur grande, d'un rouge éclatant en dehors et en dedans : les six divisions sont marquées intérieurement, à la base, d'une large tache d'un violet noirâtre, bordée de jaune.

Cà et là dans les vignobles, dans les terrains cultivés, moins fréquente que celle décrite à la page suivante. Cette espèce ressemble, par la teinte de ses fleurs, aux tulipes de nos jardins, mais elle en diffère par les pétales terminés en pointe.

On suppose que cette espèce de tulipe a été introduite, au moyen âge, de l'Orient, de même que plusieur's autres du même genre (Tulipa oculus solis, T. maleolens). Chez nous, on ne la trouve jamais hors des lieux cultivés, et il est très difficile de la détruire là où elle a pris pied. Ses fleur's sont portées en grande quantité sur les marchés de Marseille, Nice et Gênes. 


$$
-107-
$$

Champs, lieux cultivés. - Fleurit en fúrrier ot mars.

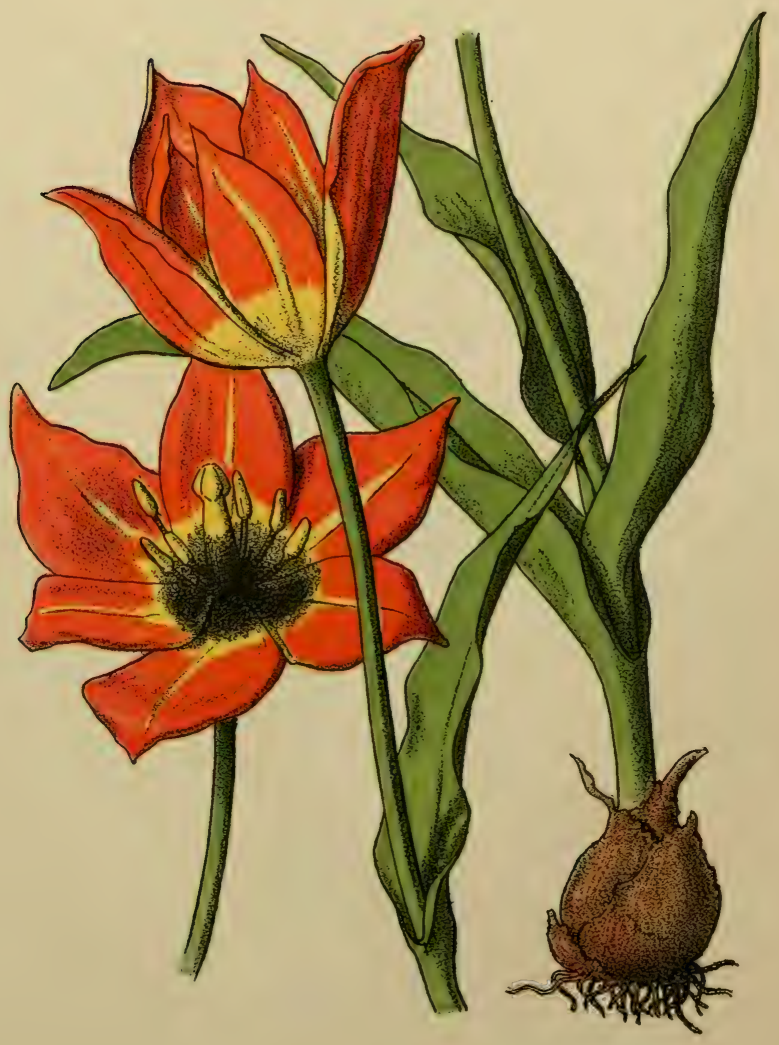

Tulipa praecox.

Frans. Tulipe précoce. Prov. Toulipan. 
Sous les oliviers. - Fleurit en dícembre et janvier.

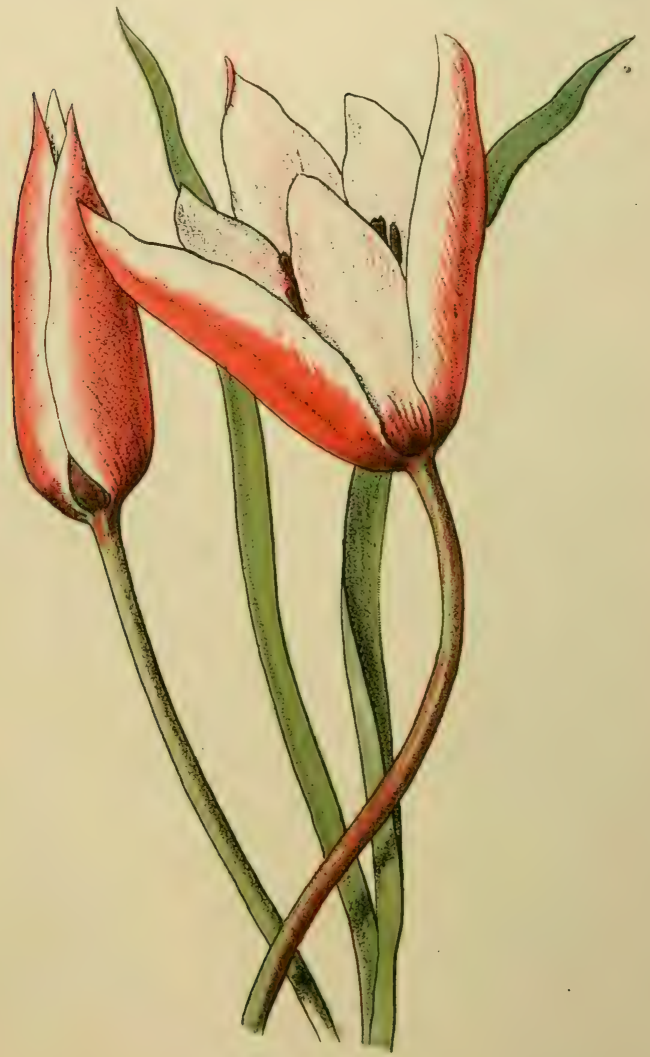

Tulipa Clusiana.

Frane. Tulipe de l'Eeluse.

Prov. Toulipan. 


\section{TULIPA CLUSIANA.}

Plante vivace, herbacee, naissant d'un bulbe ovoïde ou un peu allongé, enraciné à une grande profondeur sous la surface de la terre; feuilles lancéolées, un peu charnues, glauques. Pendant les premières années, la plante produit seulement une feuille par an; après 3 ou 4 ans, il se produit une hampe florale entre deux feuilles, se terminant par une fleur très élégante, plus petite et plus allongée que dans les tulipes de nos jardins; les trois pétales extérieurs sont d'un rouge-rose en dehors, blancs en dedans, de même que les trois pétales intérieurs. La fleur s'ouvre seulement quand elle est en plein soleil, autrement elle reste fermée.

Cette jolie espèce de tulipe se trouve en quantité sous les oliviers du littoral et est probablement introduite, comme l'espèce précédente; mais on la voit rarement avec ses fleurs, parce que les paysans les cueillent pour les vendre en ville. 


\section{A.SPHODELUS ALBUS.}

Ital. : Asfulelu; Ligur. : Asfodile; Espagn. : Gamon.

Plante vivace herbacée; racines en faisceaux à renflements allongés, en fuseau, noires en dehor's, blanches en dedans. Feuilles en touffe radicale, allongées, linéaires, glauques; hampe haute de 80 à 120 centimètres, simple ou peu rameuse; fleurs en grappes denses, très allongées, grandes, blanches avec une ligne pourprée sur le dos de chaque division; bractées d'un pourpre noirâtre, plus longues que les boutons floraux.

Très fréquente sur les pelouses des montagnes de toute la Riviera, descendant rarement au-dessous de 500 mètres.

C'est une plante très élégante qui mériterait d'être cultivée dans nos pares. Ses grappes florales avant la floraison sont presque noires, à cause des bractées et de l'extrémité des fleurs purpurines; et le contraste entre les boulons floraux et les fleurs déjà épanouies est très frappant.

L'Asphodèle était très apprécié par les médecins grecs, dans l'antiquité. Les racines allongées, tubéreuses, contiennent beaucoup de fécule et de sucre : elles ne peurent être utilisées pour la nourriture de l'homme, parce qu'elles sont très rénéneuses; mais on a tenté d'en extraire le sucre, pour en distiller de l'alcool. Quoique sa richesse en sucre soit considérable, son exploitation industrielle ne parait pas devoir être assez rémunératrice. 
Pelouses des montagnes. - limit "n mii.

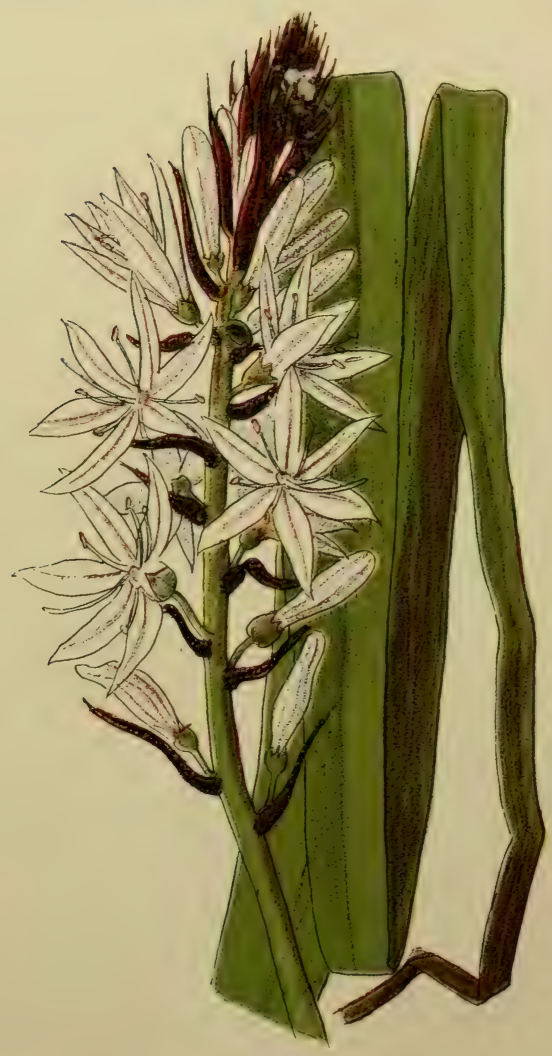

\section{Asphodelus albus.}

Frone. Asphodele blanc. P'rur. Alapèda, I'ourraco. 


\section{$-110-$}

Lieux cultivés, sous les oliviers. - Flenrit en mars et arril.

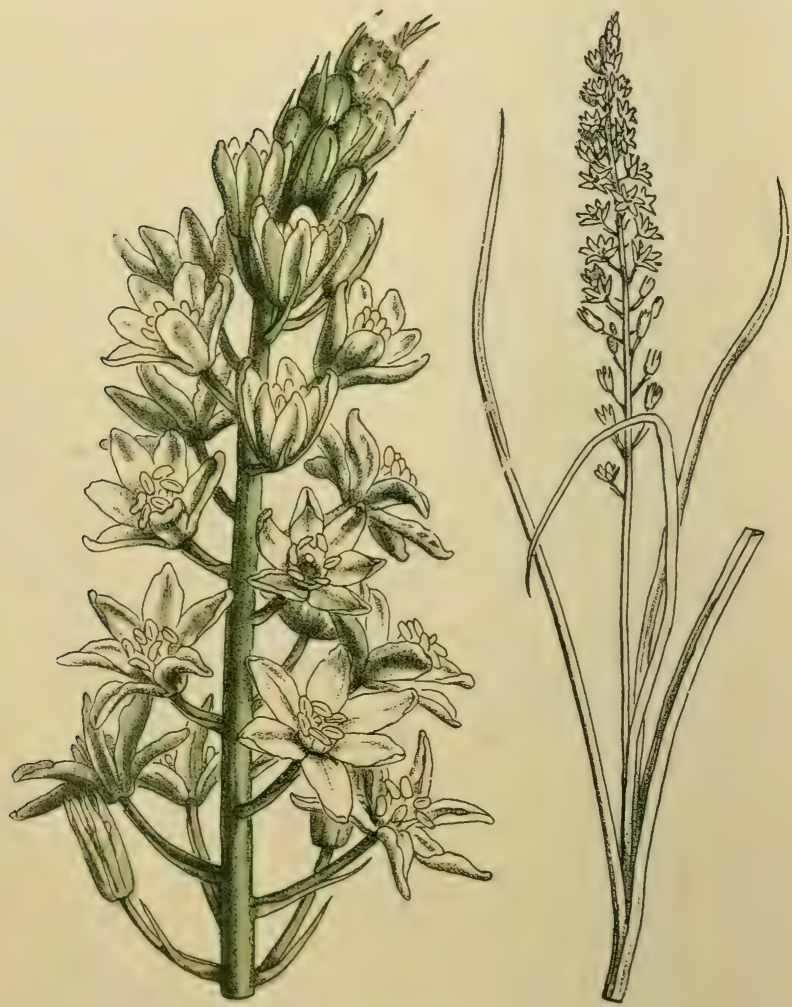

Ornithogalum narbonense.

Ornithogale de Narbonne. 


\section{ORNITHOGALUM NARBONENSE.}

Plante bulbeuse, vivace, à feuilles largement linéaires, creusées en gouttière; hampe florale haute de 50 à 80 centimètres, se terminant en grappe longue en forme d'épi. Fleurs dressées, sur de courts pédoncules, en forme d'étoiles blanches; chacune des six divisions de la corolle a une ligne verte sur le dos.

Fréquente dans les lieux cultivés de la zone littorale, assez rare en Corse.

Les bulbes, gros comme des noix, étaient employés autrefois (Bulbi Ornithogali majoris) en médecine pour guérir les abcès et les ulcères: on les faisait rôtir à cet effet. Dans quelques contrées, on mange les jeunes pousses comme les asperges.

Sur les collines et sur les hautes montagnes de la Riviera et de la Corse, on rencontre une autre espèce d'Ornithogalum très semblable, mais à fleurs plus petites, jaunâtres, l'O.pyrenaicum. D'autres espèces à fleurs plus grandes, étoilées, disposées en corymbe, sont très abondantes dans les lieux herbeux de la zone littorale et sur les collines : ce sont les 0 . umbellatum, 0 . divergens, o. tenuifolium. 


\section{ALLIUM NEAPOLITANUM.}

Ligur. : Poràche.

Plante rirace, bulbeuse; bulbe simple ou en plusieurs petits bulbes agglomérés, de la grosseur d'une cerise; feuilles très allongées, linéaires, en gouttière, un peu charnues; hampe florale haute de 25-50 centimètres, trigone (à section triangulaire); fleurs en umbelle, longuement pédonculées, de moyenne grandeur, à six divisions lancéolées, obtuses, concaves, blanches; anthères violettes.

Très commune dans les lieux cultivés, sous les oliviers de toute la région littorale; assez répandue dans les vignes autour de Bastia, en Corse.

Ses jolies fleurs, un peu odorantes, sont fréquemment cueillies et vendues en bouquets; il est fâcheux que l'odeur d'ail très forte, exhalée par les parties vertes de la plante, la rende moins sympathique. 
Lieux cultivés, endroits herbeux. - Fleurit on mars ct arril.

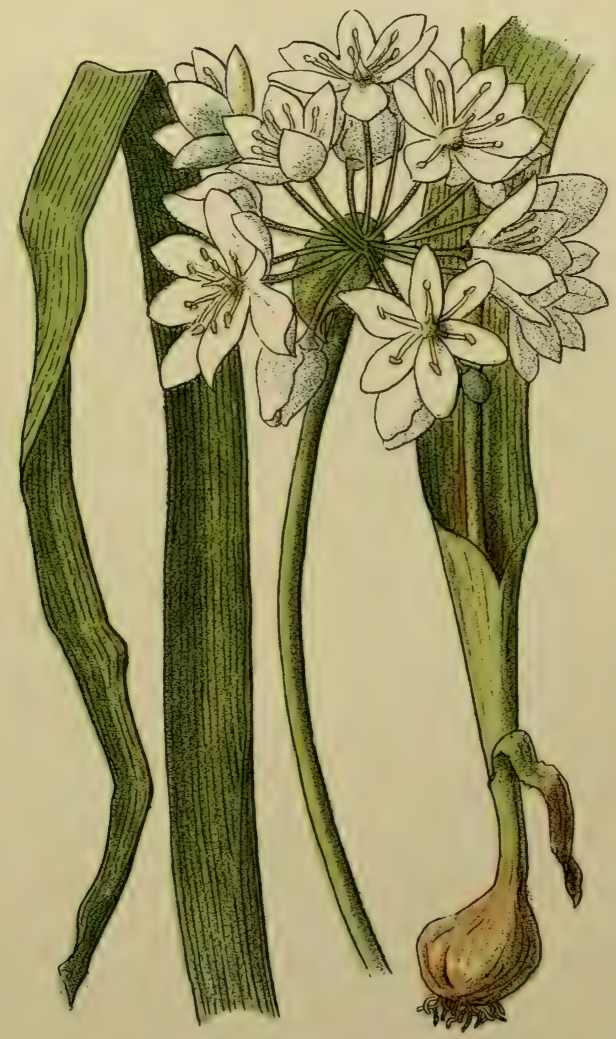

Allium neapolitanum. Ail blanc-de-lait. 


$$
-112-
$$

Bords des fossés, lieux ombragés. - Flmull wh mans at aril.

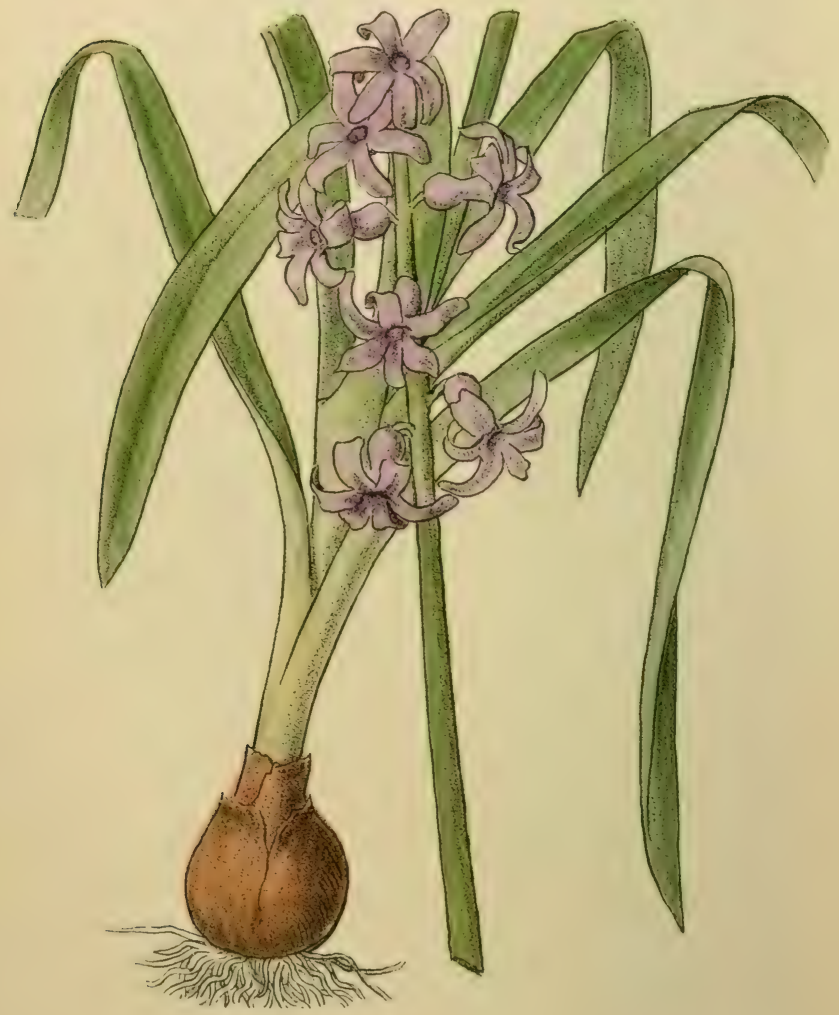

Hyacinthus orientalis.

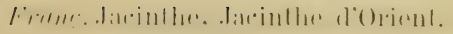

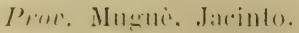




\section{HYACINTHUS ORIENTALIS.}

Ital. : Giacinto; Ligur. : Giasintu; Allem. : Hyacinthe; Angl. : Hyacinth.

Plante vivace, herbacée, bulbeuse; bulbes gros, charnus. Feuilles longues, obtuses, charnues, canaliculées. Hampe florale haule de 20 à 40 centimètres; fleurs en grappe plus ou moins dense (à peu de fleurs dans la forme spontanée), horizontales, à divisions soudées en tube ventru à la base, étalées et réfléchies au sommet, charnues, d'un bleu pâle.

C'est notre jacin the commune des jardins que nous trouvons sous une forme spontanée ou subspontanée dans les lieux herbeux, le long des ravins, sous les oliviers de la région littorale de la Riviera (Nice, Menton, San Remo): mais on tarderait à la reconnaitre, parce que la plante saurage est beaucoup plus maigre, plus mince, que la forme cultivée. Son inflorescence arrive à peine à 3-7 fleurs.

La jacinthe est d'origine orientale, comme l'indique son nom; cultivée sur une grande échelle par les Turcs au moyen âğe, elle a été transporlée dans l'Occident vers le $x v^{\circ}$ siècle; et les plantes que nous trouvons dans la Riviera sont probablement des restes d'anciennes cultures. La * Hyacinthe » des anciens auteurs n'était point très probablement la même plante que nous appelons de ce nom aujourd'hui : peut-étre était-ce une espèce de Gladiolus, ou, selon d'autres, de Scilla ou de Muscari : mais il est difficile de le démontrer. 


\section{ALLIUM ROSEUM.}

Ligur. : Aggiu de bisciu; Espragn. : Ajo de culebra.

Plante vivace, bulbeuse, très voisine de l'Allium neapolitanum, dont elle diffère surtout par la couleur rose violacée des pétales; puis aussi par la tige cylindrique, non trigone, par les feuilles de couleur glauque, et par plusieurs autres caractères secondaires.

Elle croît à peu près dans les mêmes localités que l'A. neapolitanum; mais on la trouve plus fréquemment dans les bois, dans les lieux herbeux, parmi les buissons de chênes ou de genèts. Ver's la fin de la floraison, on observe très souvent dans les ombelles de cette espèce le phénomène de la prolification, c'est-à-dire de la production de nombreux petits bulbes charnus, sessiles, parmi les fleurs. Ces bulbilles, qui plus tard tombent à terre, servent à multiplier la plante. Beaucoup d'espèces d'ail et d'autres plantes ont ce mode spécial de multiplication végétative; et il est curieux d'observer que la plupart des plantes capables de se propager ainsi ne portent presque jamais de fruits ou de graines. 
Endroits herbeux; bois des collines. - Fleurit en arril of mai.

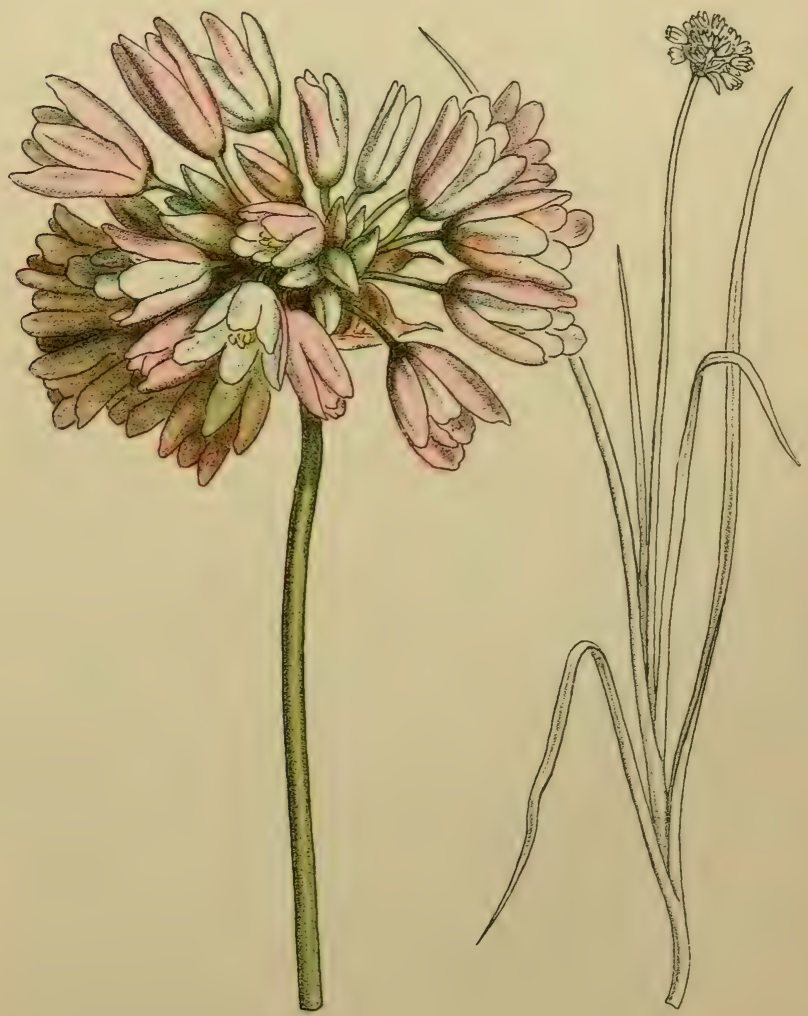

Allium roseum.

Frans. Ail rose.

Prov. Aiet fer. 


\section{$-114-$}

Bois de pins, bruyères. -. limlil mh hini of juin.

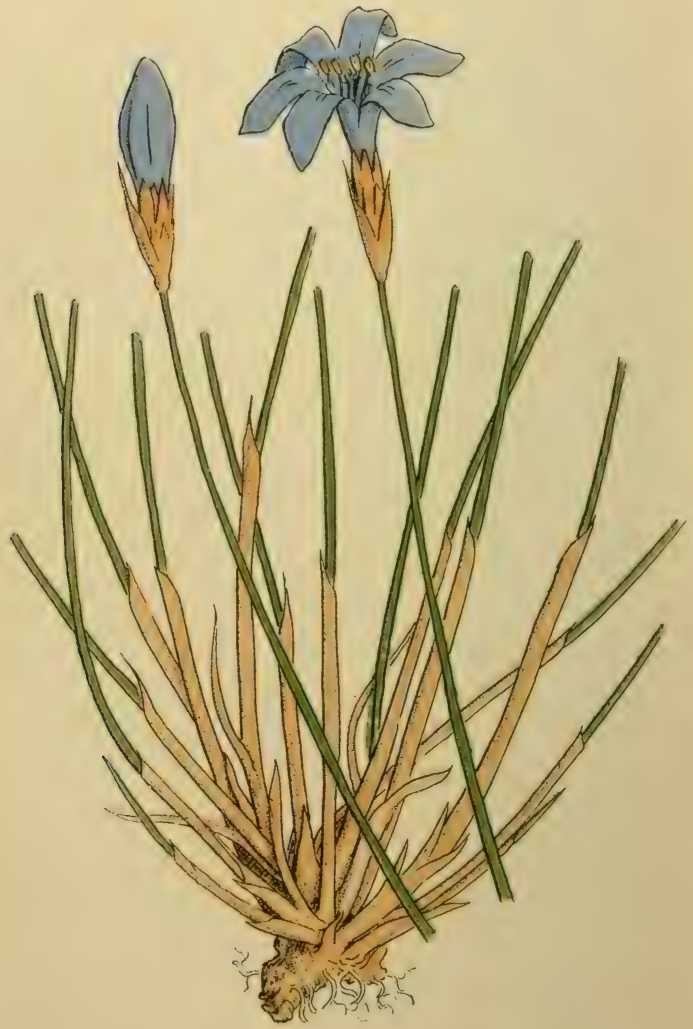

\section{Aphyllanthes monspeliensis.}

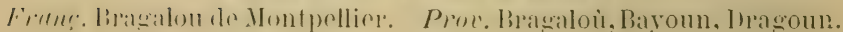




\section{APHYLLANTHES MONSPELIENSIS.}

Ligur. : Abragoin, Brustiaire; Angl. : Leafless Lily.

Plante vivace à souche rampante, souterraine, noueuse, irrégulière; tiges simples, hautes de 20 à 50 centimètres, grêles, cylindriques, striées, semblables à celles des joncs. Feuilles réduites à des gaines courtes, brunâtres, luisantes, à la base des tiges. Fleurs solitaires ou disposées par deux à l'extrémité des tiges, en tourées d'écailles membraneuses, luisantes, rougeâtres, à 6 divisions réfléchies, obtuses, d'un bleu pur.

Fréquente dans les bois de pins, les bruyères, et sur les coteaux arides, pierreux de la zone littorale.

La plante sans ses fleurs ressemble tout à fait à un jonc; et comme dans la structure et la disposition des fleurs, elle présente aussi certaines particularités, quelques botanistes l'ont placée dans une petite famille à part, entre les Liliacées et les Joncacées. Ses jolies fleurs s'ourrent seulement en plein soleil, et une fois cueillies, elles se ferment aussitôt pour ne plus se rouvrir. Cela empêche de les utiliser pour en former des bouquets.

Avec les tiges raides de l'Aphyllanthes, on fabrique à Nice une sorte de brosse. 


\section{SCILLA ITALICA.}

Plante vivace, à bulbe sphérique; feuilles peu nombreuses, ordinairement deux, allongées, obluses, en gouttière, charnues; hampe florale haute de 20 à 40 centimètres, se terminant en une grappe simple, courte, conique au moment de la floraison; fleurs sur des pédicelles inégaux (les inférieurs plus allongés), d'une couleur bleu clair. Sous chaque pédoncule on observe deux bractées blanches, membraneuses, allongées.

C'est une des plus jolies espèces du genre Scilla, qui croît en abondance dans les bois de châtaigniers, dans les ravins, toujours dans des lieux ombragés, un peu humides; elle fleurit assez tôt, quelquefois déjà au mois de mars.

Parmi les autres espèces de Scilla qui se rencontrent sur le littoral, il y en a trois à fleurs bleues ( $S$. hyacinthoides, rare, à grappe très allongée; $S$. bifolia, à grappe composée de 2-8 fleurs seulement, d'un bleu foncé; $S$. autumnalis, à fleur's très petites, autumnales), et une espèce à fleurs blanches, le scilla maritima. Celle-ci croit sur les rocher's maritimes, dans quelques rares localités de la Riviera (Monaco, Menton); ses feuilles sont larges; l'inflorescence atteint parfois plus d'un mètre de hauteur. Les bulbes de celte espèce, gros comme une tête d'enfant, sont très usités en médecine; leur suc mucilagineux irrite fortement la peau. Toutes les espèces de Scilla sont vénéneuses. 
$-1132-$

Bois ombragés; bords des fossés. - Fleuril mll fivrien mills.

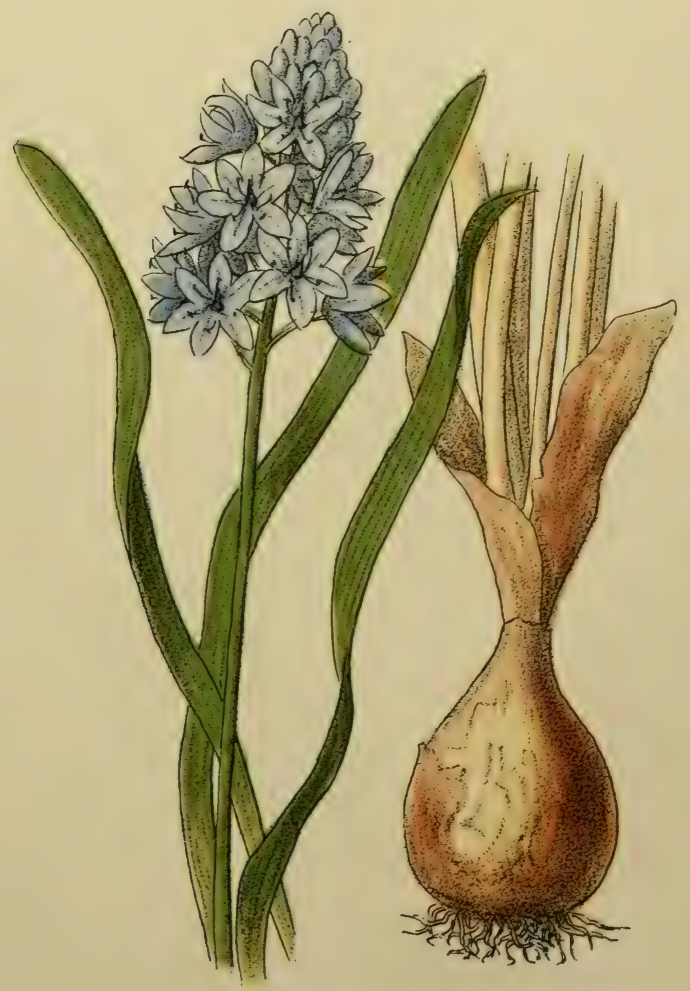

Scilla italica.

Scille d'Italie, Jacinthe des jardiniers.

- Liliacées. - 


\section{$-116-$}

Champs, lieux cultivés. - Fleurit en mai ol juin.

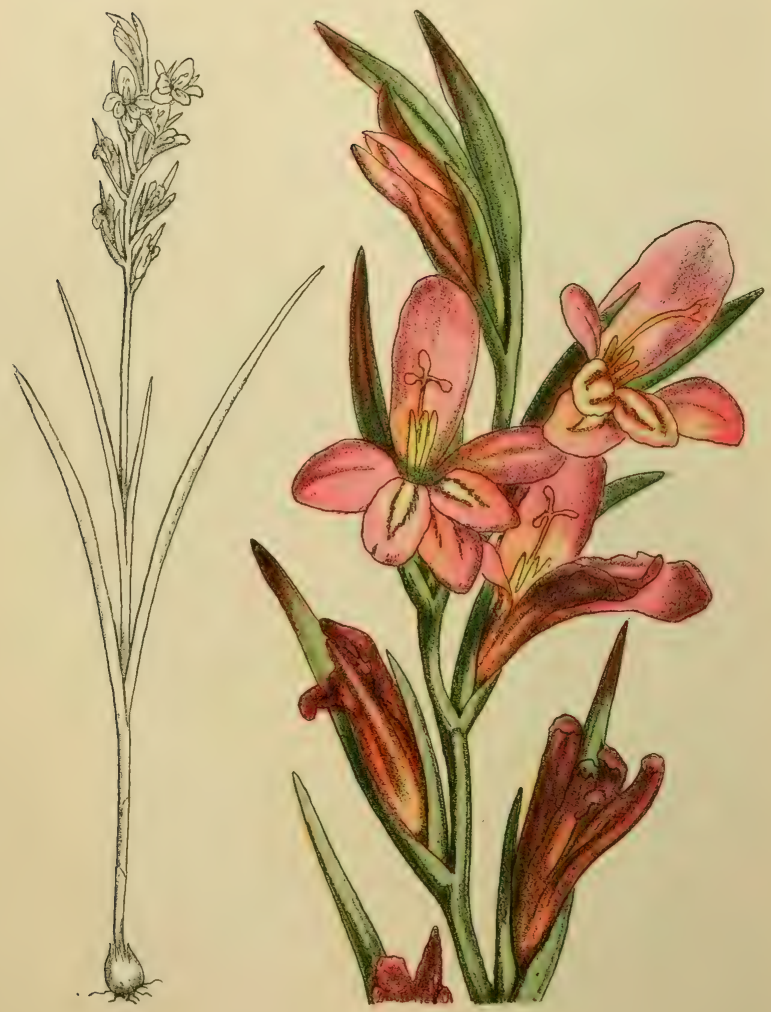

Gladiolus segetum.

Franc. Gliärul desmoissons. Prov. Coutelassa, Couten, Embriago. 


\section{GLADIOLUS SEGETUM.}

Ital. : Gaggiòlo; Ligur. : Baxadonne; Allem. : Sieguvurz;

Angl. : Corn-flag.

Plante vivace, herbacée, à bulbe solitaire, globuleux, de la grosseur d'une noix, couvert d'un réseau de fibres. Tige haute de 60-90 centimètres, simple, dressée, entourée à la base de plusieurs (3-4) feuilles dressées en forme de sabre, striées, glabres. Fleurs en grappe terminale, unilatérale (c'est-à-dire toutes les fleurs tournées d'un même côté), grandes, purpurines; les trois divisions inférieures de la corolle courbées arec une tache blanche à la base, bordée de rouge foncé.

Fréquente dans les champs de blé, dans les vignes, sous les oliviers; assez commune également en Corse.

Cette jolie espèce de Glaïeul remplace, pour ainsi dire, dans le lilloral, le bluet, qui se rencontre seulement dans les champs des collines et des montagnes; elle mériterait bien d'être introduite dans nos jardins.

Les nombreuses formes de Glaïeuls cultivées dérivent du Gladiolus psittacinus, espèce encore plus remarquable par l'ampleur et la richesse de coloris de ses fleurs. Les races hybrides obtenues par les horticulteurs de Gand (Glad. gandavensis) et de Nancy, sont particulièrement ornementales.

Les bulbes des glaïeuls, très riches en fécule, peuvent être mangés ; celui des champs a passé pour une plante médicinale, comme le Gl. communis, autrefois très renommé. De nos jours il n'en est plus. fait aucun usage. 


\section{$-117-$}

\section{IRIS GERMANICA}

Ilal. : Iride; Ligur. : Erba Spàa Allem. : Veilchonwur.

Plante virace, à souche horizontale, rameuse, grosse, couverte de cicatrices annulaires; tiges droites, à 2-6 fleurs, hautes de 50 centimètres à 1 mètre; feuilles en forme de sabre, aiguës. Fleurs très grandes, d'un violet intense.

Cá et là sur les vieux murs, sous les oliviers, dans Jes endroits rocailleux, souvent cultivée comme plante ornementale.

C'est une des trois espèces d'Iris (I. germanica, I. florentina, I. pallens) très connues pour le parfum exquis, particulier aux rhizomes desséchés. On emploie communément les rhizomes pulvérisés pour en former des sachets parfumés. Autrefois on se serrait de la poudre de la a racine d'Iris » pour donner de l'apprêt à la toile ou à la soie.

L'usage de donner un morceau de rhizome d'Iris aux petits enfants qui font leurs dents, est très ancien ; Pline en parle déjà dans son Histoire naturelle.

Sur le littoral, les paysans plantent très souvent quelques pieds d'Iris germanica autour des figuiers, en croyant à quelque influence bienfaisante de ce voisinage : et en effet, un des noms populaires de notre espèce est a scampa-fighe s (sauve-figues). Nous n'avons pas réussi à découvrir la raison ou l'origine de cel usage, qui semble ne reposer sur aucune base réelle. 


\section{$-117-$}

Vieux murs; endroits rocailleux. - Flenlit chl arril of mai.

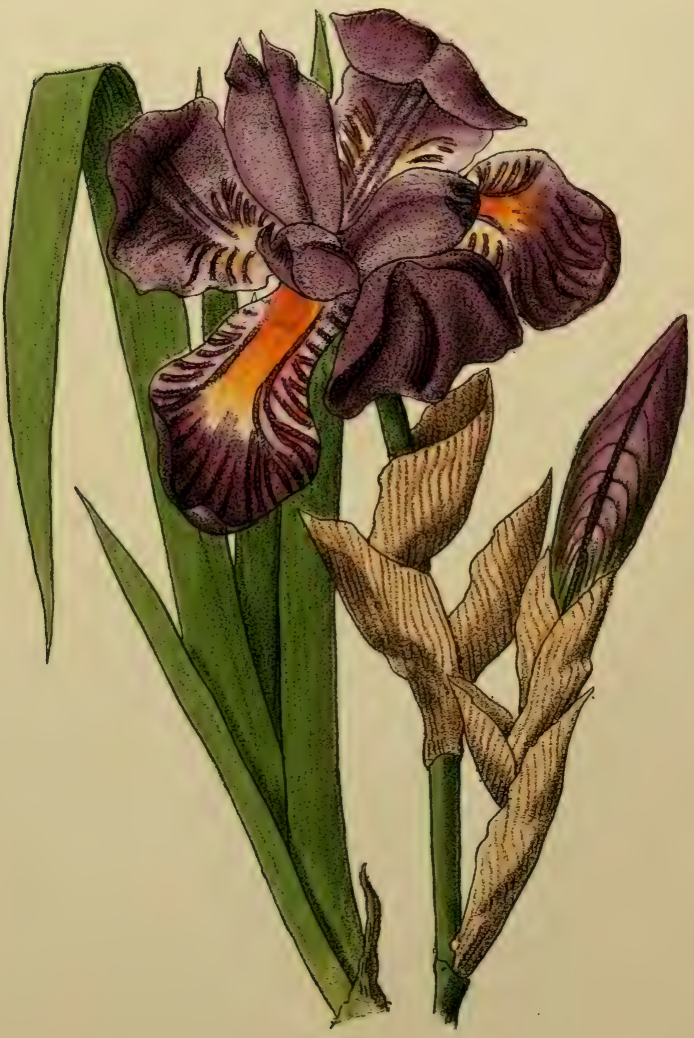

Iris germanica.

Frane. Flambe, Iris d'Allemagne.

Proc, Coutela, Giloujaì.

- IridéEs. - 


\section{$-118-$}

Lieux cultivés; pelouses des collines. - Flurit en fív, of mar.

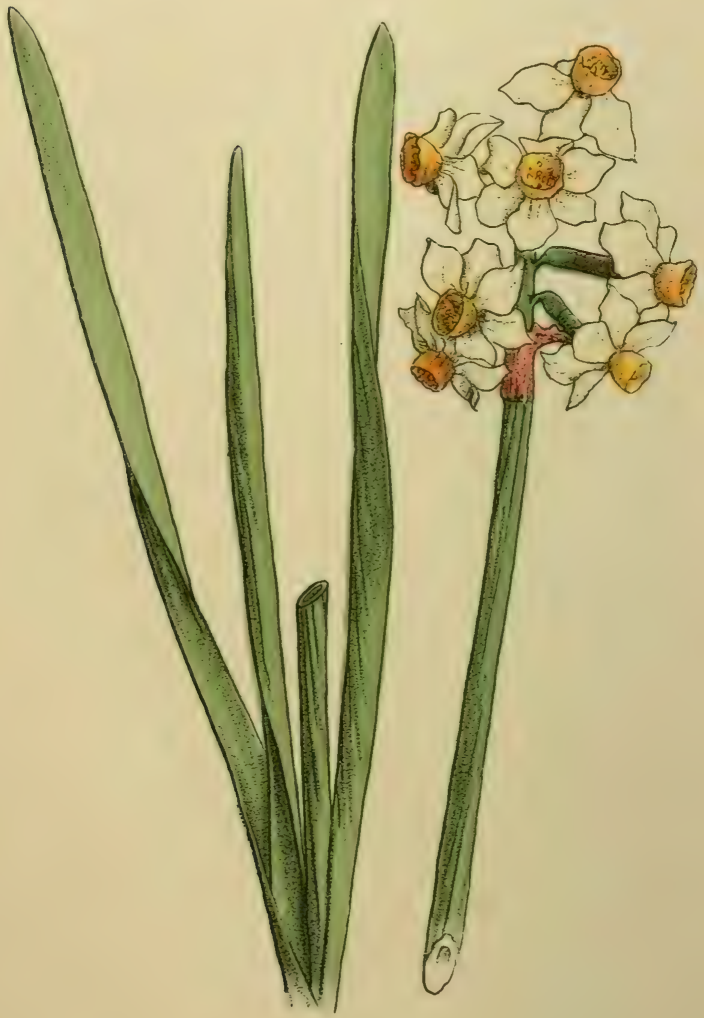

Narcissus Tazzetta.

Fime. Nareiss à bouruels. Prot. Bioto, Muguet. 


\section{NARCISSUS TAZZETTA.}

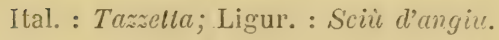

Plante vivace, herbacée, à bulbe ovoïdal, revêtu de membranes minces. Feuilles linéaires, obtuses, charnues, un peu glauques, renfermées à la base dans une sorte de gaine membraneuse blanche, formée par les feuilles inférieures. Hampe florale haute de 30 à 60 centimètres, biconvexe, à deux còtes saillantes. Fleurs en ombelle, pédonculées, penchées ; les six divisions de la corolle sont d'un blanc jaunâtre, tandis que la petite coupe intérieure a une teinte dorée.

Très commun sur les pelouses, dans les lieux herbeux, sous les oliviers de la zone littorale et colline, ainsi que dans certaines localités en Corse.

Cette espèce de Narcissus, et quelques autres (N. poeticus, N. biflorus, N. Pseudo-Narcissus), est réellement indigène dans la Riviera ; mais il y a un grand nombre d'espèces et de formes qui y ont été importées, de même que la jacinthe, les tulipes et d'autres plantes bulbeuses. Parmi ces formes subspontanées il y en a de très jolies, comme le $N$. papyraceus à fleurs entièrement blanches, le $N$. aureus, avec les divisions de la corolle en jaune, etc. Tous les Narcisses sont objet de commerce pour les paysans qui en cueillent les fleurs et les portent au marché en grande quantité; l'on en cultive de nombreuses variétés dans nos jardins. 


\section{PANCRATIUM MARITIMUM.}

Plante vivace, herbacée, à bulbe globuleux de la grosseur d'une noix, enfoncée très profondément dans le sol. Feuilles en bouquet radical, dressées, très sourent tournées en spirale, charnues, glauques. Hampe florale haute de 30 à ə̈0 centimètres, cylindrique; fleurs en ombelles pédonculées, très grandes, blanches, odorantes. Dans la corolle de chaque fleur nous distinguons six dirisions linéaires, entourant une couronne ou coupe ample en forme d'entonnoir, se terminant en 12 dents.

Fréquente par places, sur les rivages sablonneux de la mer, sur le littoral et en Corse.

Outre la qualité ornementale qui pourrait assurer au Lis Nathiole une bonne place dans nos jardins, cette plante possède celle d'être une plante médicinale. Ses gros bulbes, remplis d'un suc mucilagineux très amer au goût, sont employés comme ceux du Scilla maritima, sous le nom de Radix Scillæ minoris.

Les fleurs sont visitées par des Lépidoptères crépusculaires du genre Sphinx, qui erı suçant le miel se chargent du transport du pollen pour opérer la fécondation.

Il est rare, du reste, de voir des fruits du Pancratium, peut-être à cause de la facilité de sa multiplication végétative. 


\section{$-119--$}

Sables maritimes. - Flemil ril aonl of september.

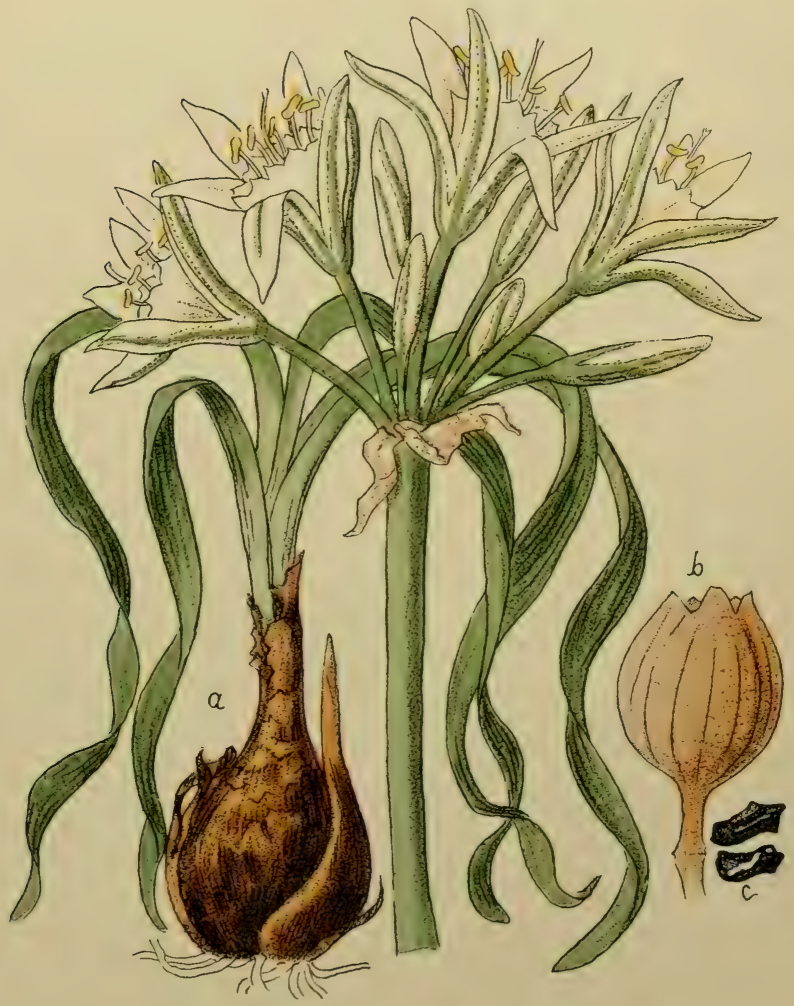

Pancratium maritimum.

Frane. Lis Mathiole. Prov. Lis de mar. 
$-120-$

Bois, lieux herbeux. - Fleurit en mars ot arril.

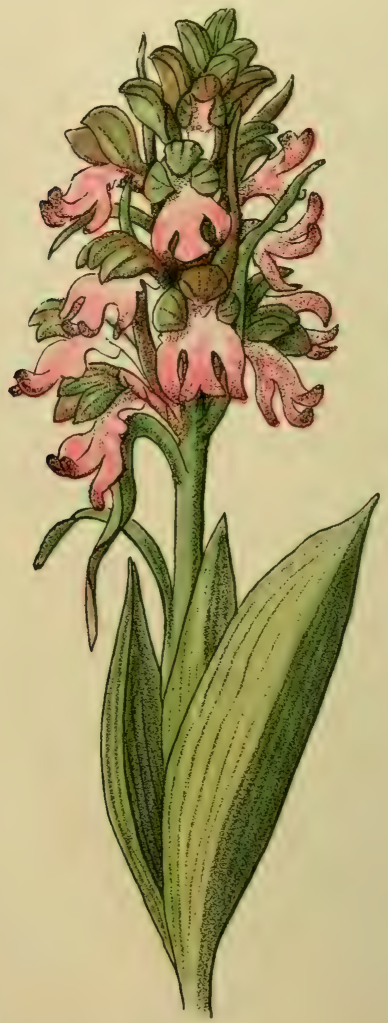

Barlia longibracteata.

Or'chis à longues bractées.

- OrGHidéEs. - 


\section{BARLIA LONGIBRACTEATA}

Plante virace, herbacée; haute de 40 à 80 centimètres ; feuilles charnues, elliptiques ; fleurs en épi dense, gros, d'un rose mêlé de pourpre et verdâtre.

Pas trop fréquent dans les lieux frais et ombragés de la zone littorale, seulement dans la moitié occidentale de la Riviera.

C'est une des Orchidées les plus remarquables de notre Flore, par le développement vigoureux et la beauté de ses fleurs. En général la petite casquette de la fleur est verdâtre, tandis que le labelle est rose, parsemé de taches purpurines.

Comme presque toutes les Orchidées indigènes d'Europe (du moins celles de la section des Ophrydées), le Barlia a deux bulbes radicaux charnus, très riches en mucilage et en fécule. On cueille ces bulbes et on les fait sécher : ils sont mis dans le commerce sous le nom de « Salep s et employés comme un remède reconstituant, nourrissant, de facile digestion. C'esi surtout de l'Orient que l'on introduit de grandes quantités de salep; les bulbes réduits en farine et mélangés avec du miel et de l'eau servent encore à préparer une boisson mucilagineuse et rafraîchissante. 


\section{OPHRYS BERTOLONII.}

Ligur. : Oxeletti che se spegian.

Plante vivace, herbacée, bulbeuse comme les précédentes; fleurs en grappes de 2-6 ; hampe florale haute de 10 à 2 ö centimètres.

Fréquent dans les lieux herbeux, sur les pelouses des collines dans toute la Riviera.

C'est peut-être la plus singulière et la plus gracieuse de nos Ophrydées; il est certain que les orchidophiles feraient de rraies folies pour elle, si c'était une espèce exotique et très rare. Les cinq divisions supérieures de la fleur sont plus petites, concaves, souvent réfléchies et d'un rose tendre : la sixième division (ou labelle) est beaucoup plus grande, d'un pourpre noir et à surface veloutée, à l'exception d'une tache de forme variable, qui est très lisse, luisante.

L'imagination populaire a nommé cette fleur a le petit oiseau qui se regarde dans le miroir »; et en effet l'appendice curieux qui couronne le profil, a à peu près la figure d'une tête d'oiseau penchée sur le petit miroir du labelle. L'on sait que beaucoup d'Orclidées imitent à merveille le corps d'insectes, tels qu'abeilles, bourdons, mouches ou papillons ; c'est un mimélisme dont il est difficile d'expliquer la raison. 
Lieux herbeux, pelouses des collines. - Fleurit en mars et arril.

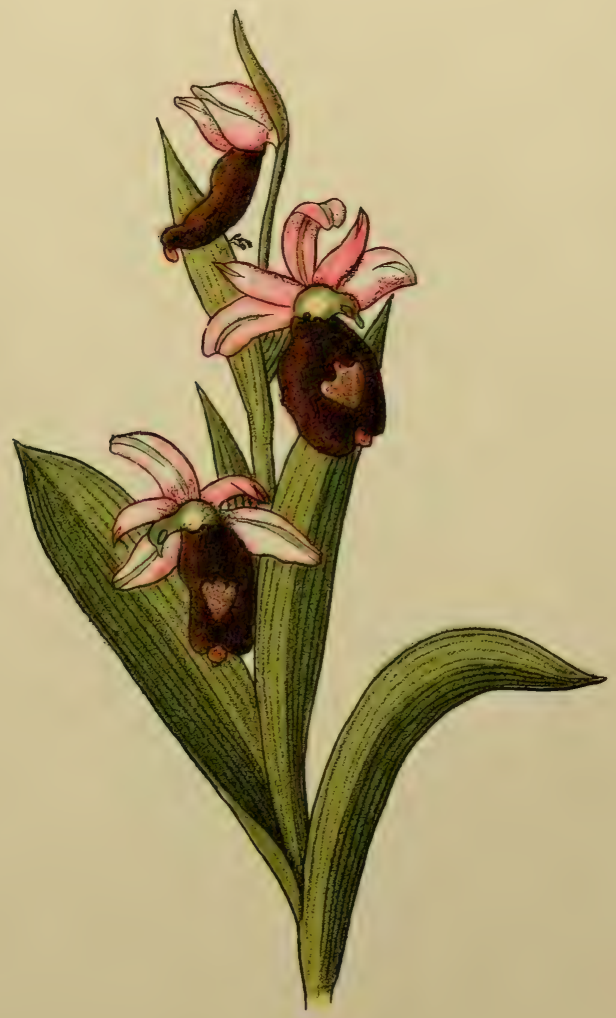

Ophrys Bertolonii.

Ophrys de Bertoloni.

- Orchidées. - 
$-122-$

Lieux herbeux des collines. - Fleurit en mai.

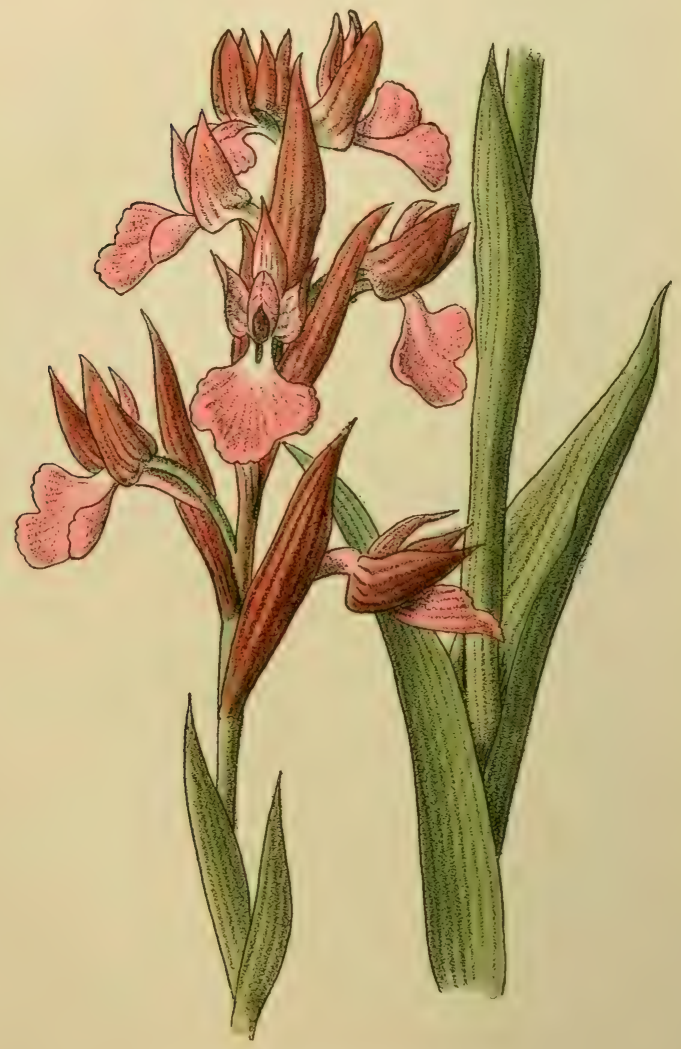

Orchis papilionacea.

- OrchidéEs. - 


\section{ORCHIS PAPILIONACEA.}

Ligur. : Sipressina de montagna.

Plante vivace, herbacée, pourvue de deux bulbes charnus comme la précédente. Feuilles souvent réfléchies, étalées ; hampe florale haute de 10 à 20 centimètres, à 4-7 fleurs, colorées en rose, mêlé de rouge et de violacé.

Fréquente, souvent en groupes sur les prairies des collines et des montagnes, cà et là dans la Riviera et en Corse.

On peut très facilement observer dans celle espèce, comme dans d'autres, lo mécanisme très singulier de la fertilisation chez les Orchidées. Leur's étamines (réduites à une seule ou à (leux) ne produisent pas le pollen sous forme de poussière colorée en jaune ou violet, comme la plupart de nos fleur's; mais en deux petits corpuscules mous, elliptiques, que l'on peut extraire facilement de la fleur, en y introduișant la pointe d'un crayon, ou un brin d'herbe quelconque. Ces deux a masses polliniques » sont pourvues à l'extrémité inférieure d'un petit disque qui se colle facilement aux corps introduits dans le tube floral, comme aussi à la tête ou au corselet des insectes (abeilles, guêpes ou bourdons) qui visitent les fleurs.

Les insectes, ainsi chargés de corpuscules polliniques, les déposent ensuite sur le stigmate proéminent d'une seconde fleur, en effectuant de cette manière la fécondation croisée. 


\section{SERAPIAS IINGUA.}

\section{Ligur. : Bocca de gallina.}

Plante vivace, herbacée, du même port que les précédentes, pourvue de deux bulbes radicaux. Hampe florale haute de 1 à à 30 centimètres, à 2-ö fleurs étalées horizontalement. Fleurs d'un rose pâle, marquées de lignes plus foncées.

Commune dans les lieux herbeux, sur les collines du littoral et dans une partie de la Corse.

Les Sérapias, dont nous pouvons trouver quatre espèces dans la Riviera, ont un type un peu différent des autres Ophrydées d'Europe : elles s'en distinguent au premier coup d'œil par la soudure des ¿ٌ divisions supérieures de la fleur; le labelle, étalé dans le Serapias Lingua, réfléchi en bas dans les autres espèces, sort d'une espèce de tube ou petit capuchon, terminé en pointe.

En ouvrant une fleur, on observera à la base du labelle une callosité noire, luisante, dont le tissu, riche en sucre, est rongé par les abeilles. 
$-123-$

Près des collines. - Fleurit en mar's et avril.

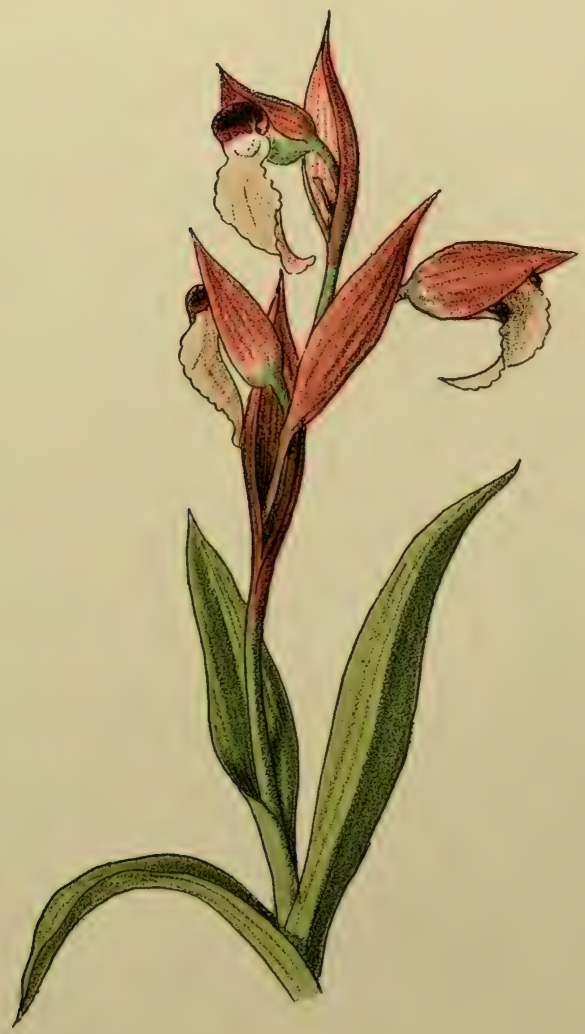

Serapias Lingua.

Frans. Helléborine à languette.

Prov. Lebourino.

- OrchidéEs. - 
Plante submergée, dans la mer. - Fleurit en septembre.

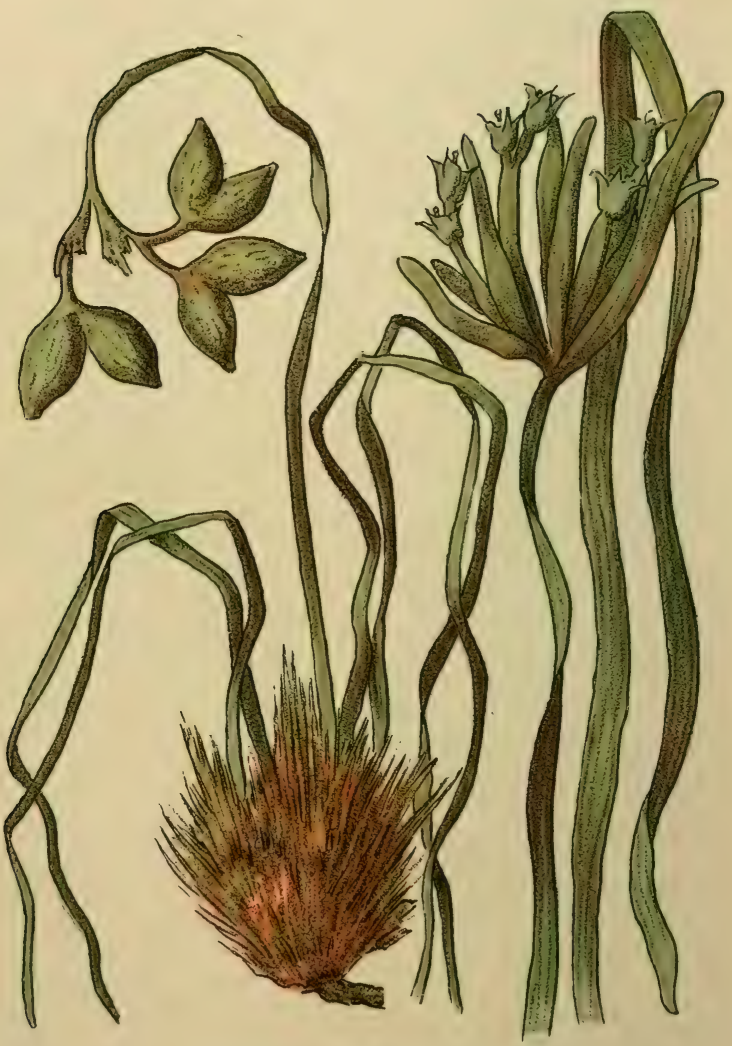

Posidonia Caulinii.

Frane. Posidonia de Caulini.

Prov. Aouha de mar, Augo. 


\section{POSIDONIA CAULINII.}

Ligur. : Alga; Allem. : Seegras.

Plante vivace, à souche grosse, rameuse, densément couverte de fibres (les débris de feuilles pourries); feuilles très longues (jusqu'a 7 ว̊ centimètres environ), linéaires, en ruban, arrondies à l'extrémité, larges d'un centimètre. Hampe florale longue de 20-40 centimètres; fleurs réunies par 5-6, dans une espèce de bractée foliacée; fruits semblables à une petite olive.

Très abondante au fond cle la mer, à la profondeur de 2 à 5 mètres, où elle forme de vastes prairies sous-marines.

La Flore phanérogamique sous-marine d'Europe est très pauvre en espèces; la Méditerranée, le long de la Riviera, en compte trois seulement : le Posidonia Caulinii, qui est l'espèce la plus abondante,le Zostera marina (à souche grêle, mince, non hérissée de fibres), et le $Z$. nana (très rare).

Les feuilles en ruban du Pos. Caulinii, arrachées de la souche par les vagues, et les souches mêmes, sont rejetées en grande quantité par la mer, et couvrent la plage, surtout après les tempêtes. On observe aussi le long de la plage, une grande abondance de boules ou pelotes arrondies, de grandeur variable, parfois grosses comme le poing, formées par les fibres entrelacées de la souche de Posidonia, et qui ont l'aspect de crotin d'âne. On ne trouve que rarement les fleurs ou les fruits du Posidonia, car les plantes ne fleurissent pas régulièrement chaque année. Les feuilles desséchées appelées a Paille de mer s servent à garnir les matelas ou pour emballer 


\section{$-125-$}

des objets fragiles; on les emploie aussi pour en faire des engrais, à cause des sels de soude et de kali qu'elles contiennent.

\section{ARISARUM VULGARE.}

Ligur. : Galio, Guaglio; Espagn. : Candilles, Fronlillos,

Rabiacana.

Plante vivace, herbacée, à bulbes charnus, de la grosseur d'une noix. Feuilles charnues; pétioles et hampes souvent pointillés en pourpre. La grande bractée (appelée « spathe » par les botanistes), qui renferme l'inflorescence, est de couleur variable, entre le brun clair et une teinte pourpre, presque noire; les baies un peu anguleuses sont vertes.

Très commun partout dans les lieux cultivés, à l'ombrage des oliviers, sous les haies.

C'est une des plantes qui frappent le plus l'œil du touriste venu du Nord; soit par la forme étrange de son inflorescence, soit par l'époque de sa floraison, dans les mois de décembre et janvier. Elle est vénéneuse, comme la plupart des Aroïdées; mais les bulbes, riches en fécule, surtout quand ils sont séchés ou cuits, peuvent servir à l'alimentation des pores.

On observera très souvent sur les feuilles de l'Arisarum de grandes taches rondes jaunâtres ou blanches, de la largeur d'un centime, jusqu'à celle d'un sou : elles sont produites par la présence d'une algue parasite très curieuse, appelée Phyllosiphon Arisari. Il est bien rare qu'une algue verte attaque d'autres plantes vivantes, pour s'en nourrir. 


\section{$-125-$}

Bords des chemins; sous les oliviers. - Fleurit en janvier et février.

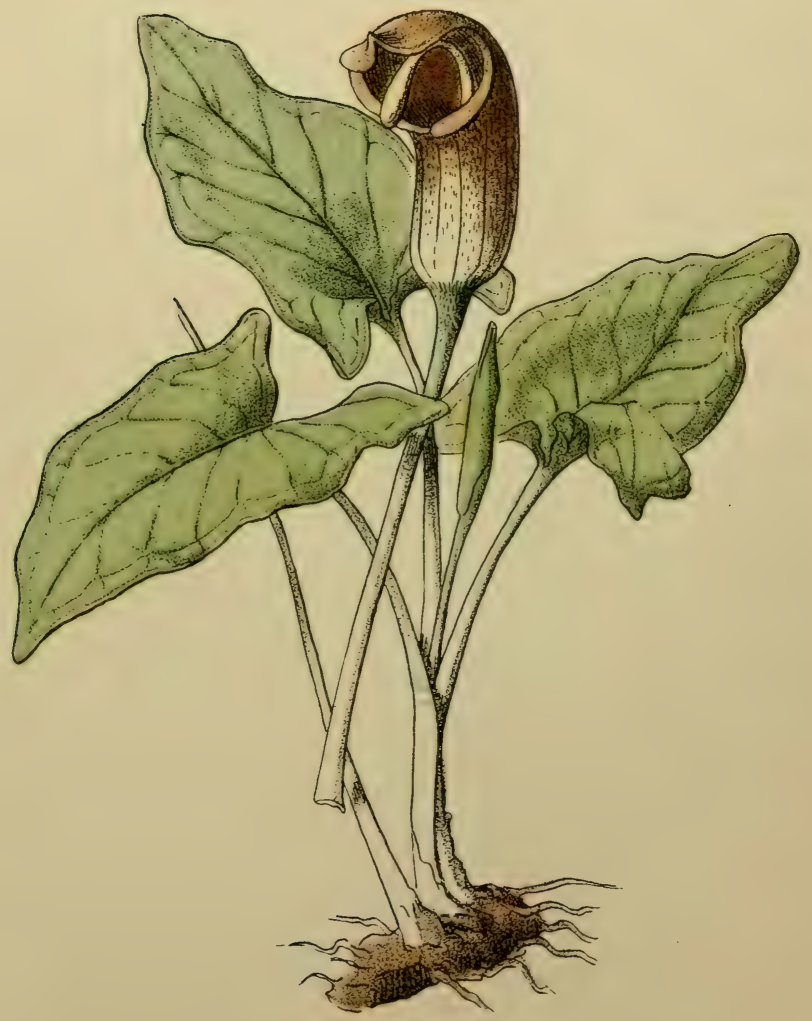

Arisarum vulgare.

Capuchon.

- Aracées. - 


$$
\text { - } 126-
$$

Rochers humides ; lieux marécageux. - Fleurit en mai et juill.

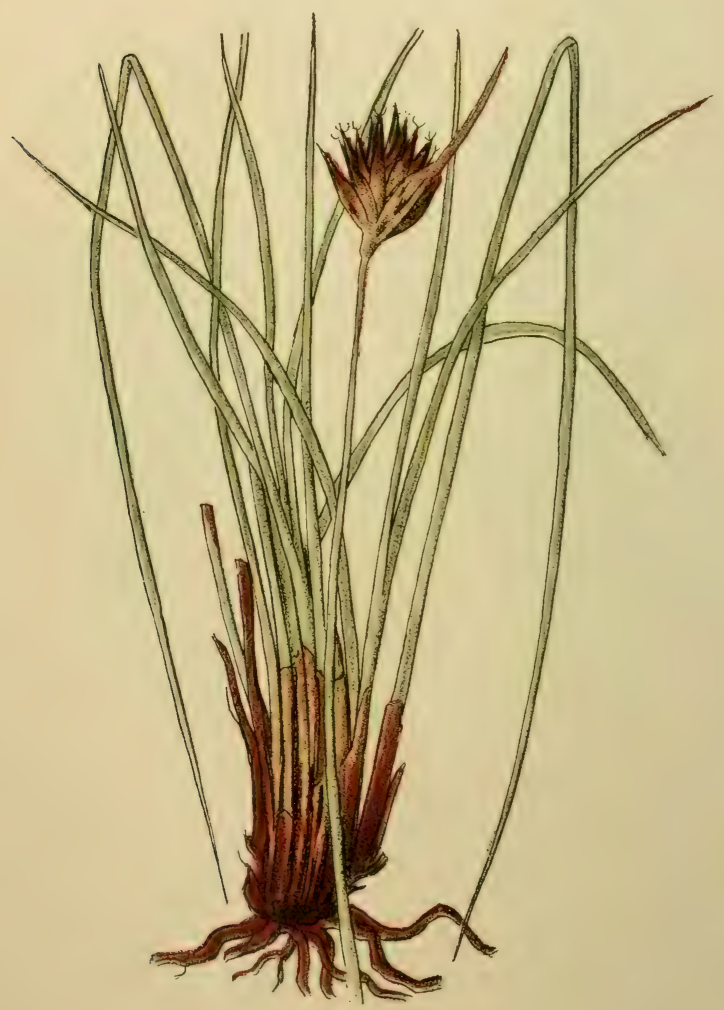

Schœenus nigricans.

- Cipéracées. - 


\section{SCHOENUS NIGRICANS.}

Plante vivace, à souche grosse, fibreuse. Tiges herbacées, dressées, raides, grêles, haute de 25 centimètres à 1 mètre, entourées à la base de feuilles engaînantes, linéaires, roulées en gouttière; gaînes d'un brun noirâtre, luisantes; fleur's en petits épillets, réunis en 5-10 à l'extrémité des lig'es, renfermés dans un involucre formé de plusieurs bractées, dont l'inférieure plus longue, terminée en pointe verte dépassant les fleurs.

Assez commun dans les lieux marécageux, sur les rochers fangeux, d'où souvent pendent des touffes très grosses, gazonnantes, de cette espèce de choin. Se retrouve également en Corse. C'est une mauraise herbe, que le bétail évile de manger, à cause de la dureté de ses tiges et de ses feuilles. Les tiges peuvent être employées pour tresser de petits paniers. 


\section{LAGURUS OVATUS.}

Plante annuelle, à tiges solitaires ou réunies en faisceaux, grêles, dressées, hautes de 10 à 30 centimètres ; feuilles pubescentes ; inflorescence en forme de capitule ou thyrse ovoïde, blanchâtre, fortement soyeuse.

Fréquent au bord de la mer, sur les terrains sablonneux. Très commun en Corse.

C'est une charmante petite Graminée, dont les inflorescences blanches, soyeuses, sont très décoratives. On les cueille pour les insérer dans les bouquets de fleurs sèches; et les fleuristes parfois les colorent avec des teintes d'aniline. Nous n'en connaissons pas d'autre emploi. 
$-127-$

Sables maritimes. - Fleurit en mai et juin.

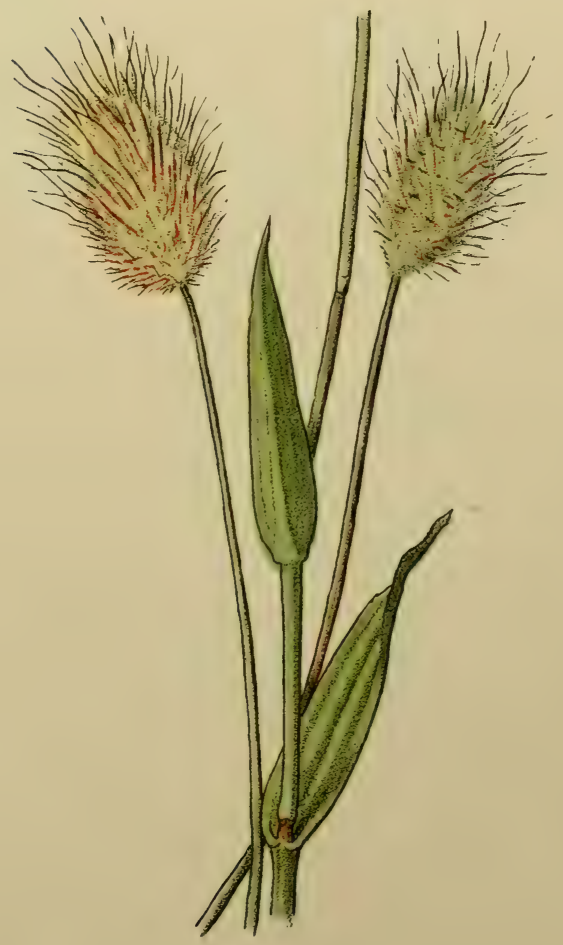

\section{Lagurus ovatus.}

Frans. Queue de lièvre. Prov. Coueta de lapin.

- Graminées. - 


$$
-128-
$$

Lieux secs, pierreux. - Flenrit on arril et mai.

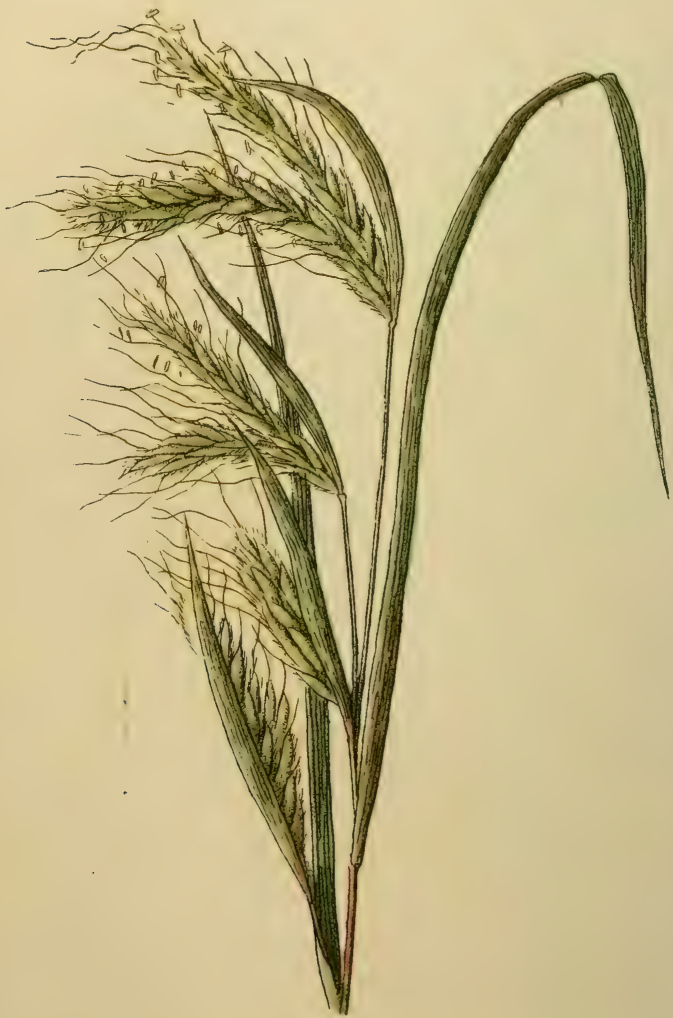

Andropogon hirtus.

Barjon hérissé. 


\section{ANDROPOGON HIRTUS.}

Plante vivace, à racines réunies en faisceaux, à tiges cylindriques, creuses, noueuses, ramifiées, hautes de 60 à 90 centimètres; feuilles linéaires, étalées, velues; épis nombreux, linéaires, groupés par deux ou trois au sommel des pédoncules flexueux, rameux, couverts de longs poils plumeux, étalés, épillets rougeâtres, à poils soyeux.

Très commun dans les lieux secs, pierreux, le long des routes : plante fourragère, mais pas trop bonne.

D'une autre espèce commune dans la Riviera, Andropogon Ischaemum, différant par les épis plus allongés, sessiles, disposés presque en ombelle, on emploie les racines pour la confection de brosses grossières.

Beaucoup d'espèces du même genre sont indigènes des pays tropicaux; et plusieurs d'entre elles (Andr. Nardus, A. Schoenanthus, E. citratus) sont cultivées sur une grande échelle, pour leurs racines, très odorantes, fournissant des essences très précieuses (Huile de Vétiver, d'Ivarancousa, Lemon gras oil, huile de Namur), usitées dans la parfumerie et la médecine.

Les espèces de Sorghum, genre très voisin et considéré, par quelques auteurs comme une section du genre Andropogon, sont cultivées comme céréales (S. Caffrorum) ou comme plantes à sucre (S. saccharatum). 


\section{ARUNDO DONAX.}

Ital. : Canna; Ligur. : Canna ; Espagn. : Caña comun; Allem. : Rohr; Angl. : Great Reed.

La plus grande graminée d'Europe; ses chaumes noueux à feuilles larges, étalées, atteignent la hauteur de 3 à 4 mètres. Panicule terminale, ample, violacée, très poilue.

Subspontanée el cultirée dans les lieux un peu humides.

Le * Grand roseau » est une des plantes les plus utiles pour les paysans. Les chaumes durs, ligneux, très résistants, servent à beaucoup d'usages : on les emploie dans la construction des maisons rustiques, et pour former les voutes des plafonds; les haies des potagers sont très souvent tressées arec ces roseaux; on y appuie ou on y fait grimper les tomates, les haricots, etc.; on en fabrique des échalas, des cannes à pêche, des quenouilles et mille autres objets. Les tiges d'un an, fendues en lames, sont très recherchées, dans le Midi, pour fabriquer ces lég'ers paniers dans lesquels on expédie les fleurs coupées pendant l'hiver. C'est, pour ainsi dire, le bambou d'Europe.

Les racines et les rhizomes, longuement rampants sous terre, qui contiennent beaucoup de sucre et de fécule, sont diurétiques et diaphorétiques; on les emploie comme les tiges souterraines du chiendent. 
Lieux humides; souvent cultivé. - Flmit on octol. wt nor.

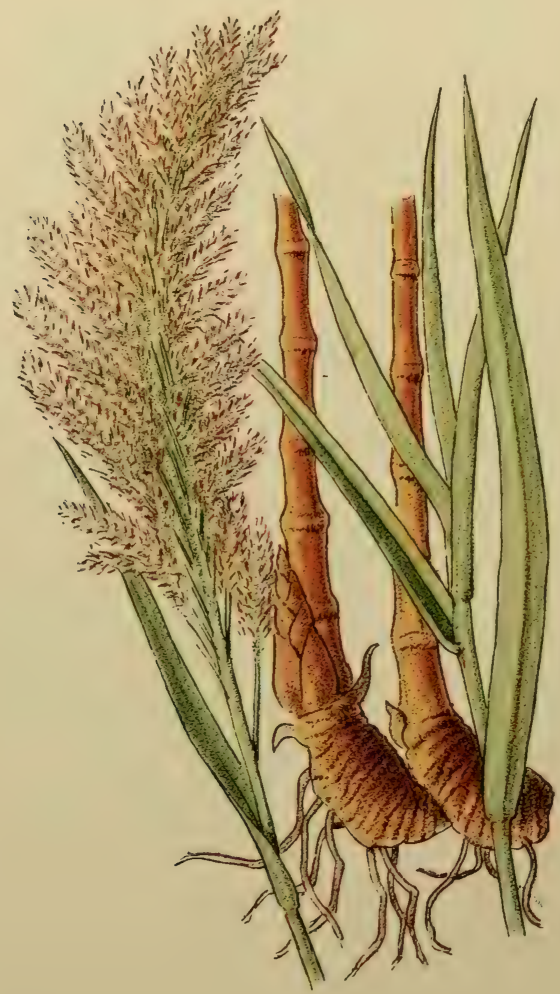

\section{Arundo Donax.}

Frane. Grand roseau. Canne de Provenec. Roseau à upuenouille. Prov. Cano. 
$-130-$

Rochers humides; vieux murs.

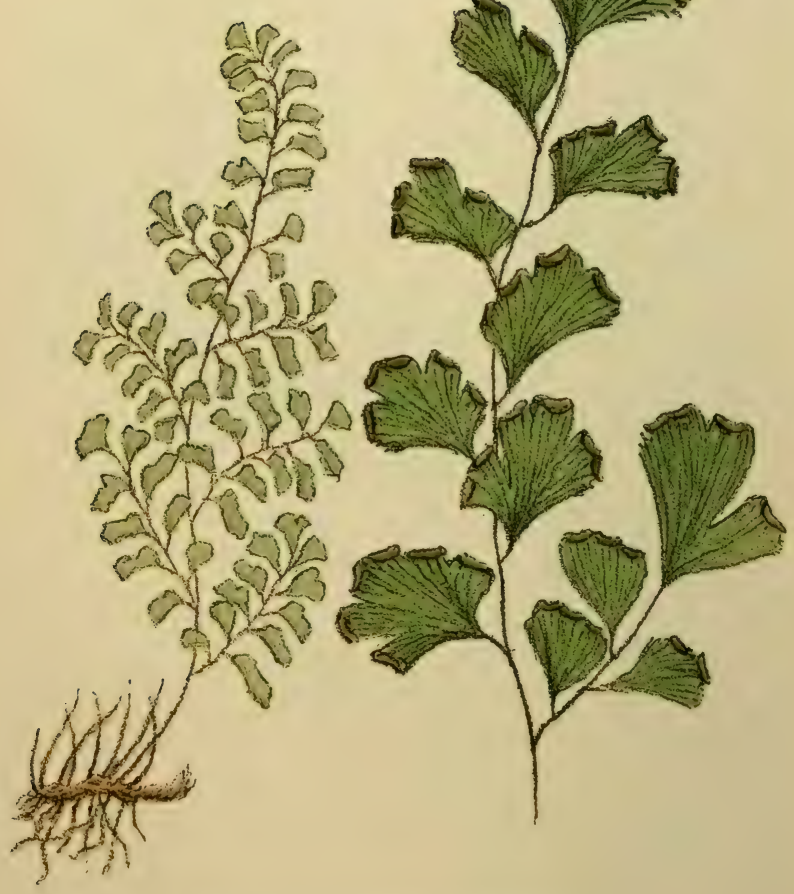

Adiantum Capillus-Veneris.

Frane. Capillaire, Chereux de Vénus. Prov. Capillerà, Capilero. 


\section{ADIANTUMM CAPILLUS VENERIS.}

Ital. : C'apelcener'; Ligur. : Capuvenere; Allen. : Ianenhaa'; Angl. : Maidenhair-Fern.

Cette charmante petite fougère, à souche vivace, aux pétioles très noirs, luisants, est très commune dans le littoral, sur les rochers un peu humides, dans les fentes des murs, et surtout sur les parois des citernes et des puits.

C'est l'unique espèce européennc d'un genre très vaste, qui compte des centaines d'espèces dans les régions plus chaudes. Beaucoup d'entre elles sont cultivées dans nos serres, el les amateurs en ont produit des variétés très décoratives. Les petites écailles demi-lunaires, noirâtres, que l'on observe le long des bords des feuilles dans la plante adulte, courrent les a sporanges s, c'est-à-dire de petites capsules renfermant les spores destinées à la reproduction des cryptogames.

On emploie, en médecine, les feuilles de l'Adiantum Capillus Veneris, les infusions et le a sirop capillaire sélant reconnus très efficaces contre les affections catarrhales.

Autrefois, on attribuait aux \& cheveux de Vénus s beaucoup de vertus magiques, ainsi que l'inclique ce nom populaire. 


\section{PITTOSPORUM TOBIRA.}

Arbrisseau ou petit arbre de la hauteur de 3-4 mètres, très touffu, à têle arrondie. Feuilles persistantes, coriaces, d'un vert luisant; fleurs en grappes compactes, blanches, plus tard jaunâtres, à pétales un peu charnus, très odorantes, avec un parfum semblable à celui des fleurs d'oranger.

C'est un arbrisseau très précieux pour les villas et jardins du littoral, parce que son beau feuillage résiste très bien aux vents de la mer. Aussi le plantet-on très souvent pour en former des massifs, des haies, des brise-vents qui protègent les autres plantes; il s'y prête très bien, car il supporte la taille sans en souffrir.

Indigène de la Chine, il se trouve à son aise dans le climal de la Riviera, et peut endurer des froids de 7 à 8 degrés au-clessous de zéro.

Les feuilles et l'écorce contiennent une résine aromatique, balsamique, amère.

On cultive souvent aussi, dans nos jardins, le Pittosporurn undulatum, à feuilles coriaces, ondulées, provenant de l'Australie, et plusieurs espèces à fleurs noires, comme le $P$. crassifolium et le $P$. Mahi. 


\section{-131 -}

Cultivé. - Fleurit en arril et mai.

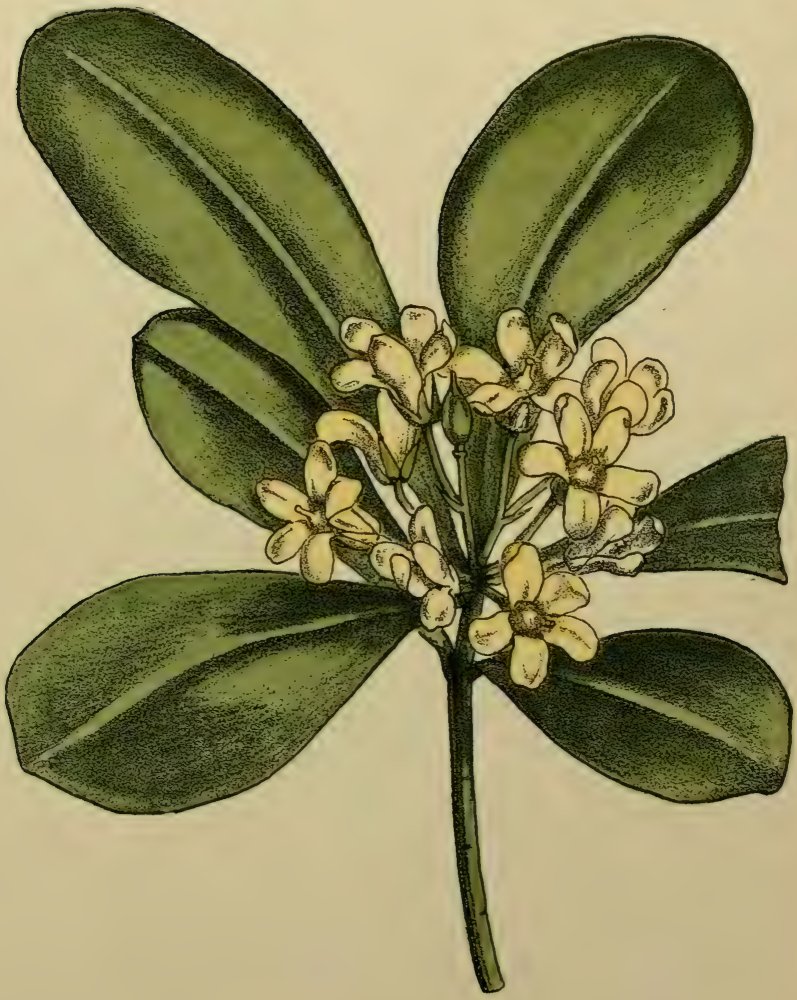

Pittosporum Tobira.

Pittospore de Chine.

- Pittosporées. - 


\section{CITRUS AURANTIUM.}

Ital. : Arancio dolce: Ligur. : Portugà; Espagn. : Waranjo; Allem. : Apfelsine; Angl. : Sweet Orange.

Arbre de pelite taille, à branches touffues, à feuillage sombre, persistant, coriace, luisant; à fruits sphériques, très variables en grandeur et en aspect, selon les variétés.

L'Asie semble être la patrie de l'oranger doux, comme celle de la plupart de ses semblables; il a été importé en Europe par les Portugais, beaucoup plus tard que le cédratier, le citronnier et l'oranger amer. Il est cultivé sur une grande échelle dans le littoral, étant moins sensible au froid que le citronnier : on en trouve des plantations considérables à Hyères, Cannes, Grasse, Nice, Menton, Bordighera, San Remo, Savone et Nervi, ainsi qu'en Corse; et le commerce de ses fruits est très important pour ces contrées.

Outre ses fruits, on peut en utiliser presque toutes les parties; son bois est très dur, de grain fin, jaunâtre et bon pour l'ébénisterie ; les fleurs fournissent par la distillation a l'eau de fleurs d'orang'er » et " l'essence de Néroli ๖ très appréciée (on paie 300 à 500 francs le kilo de celte essence). Les petits fruits, tombés encore rerts, donnent l'huile nommée a essence de petit grain $\gg$.

L'oranger est sujet à beaucoup de maladies, dont plusieurs causées par des parasiles végétaux (par exemple, le noir ou la morfée) ou animaux (cochenilles, pucerons, teignes), et d'autres dont on ne connail pas encore bien la cause (par exemple, la gommose). 


\section{CITRUS LIMONUM.}

Ital. : Limone; Ligur. : Limuin; Espagn. : Limonéro; Allem. : Citrone; Angl. : Lemon tree.

Petit arbre ne dépassant g’uère 4 à ơ mètres, à rameaux étalés, plus rares que dans l'oranger ; feuilles d'un vert plus clair, jaunâtre, de sorte qu'il est facile, à distance, de distinguer un citronnier d'un oranger, sans observer en détail les différences présentées par les fruits ou par les feuilles.

Le citronnier est originaire de l'Asie tropicale; on a pourtant trouvé des citronniers parfaitement sauvages dans les bois des montagnes d'Abyssinie. Il est plus délicat que le bigaradier et l'oranger, et commence à souffrir à trois degrés au-dessous de zéro : c'est pour cela qu'il est cultivé seulement dans les endroits les plus chauds et les mieux abrités du littoral et de la Corse. Très souvent on le cultive en espalier. Ses fruits, dont on fait une exportation considérable, mûrissent en toutes saisons; on trouve presque toute l'année sur le mème arbre des boutons, des fleurs, des fruits en formation et des fruits mûrs.

Il y en a une grande quanlité de rariétés, très différentes en ce qui concerne la taille, l'aspect et l'épaisseur de l'écorce, du fruil, la proportion et l'acidité de la pulpe. Les citrons qui conviennent le mieux pour l'exportalion sont les citrons d'été, appelés verdami, à écorce du fruit épaisse, verle. Plusieurs variétés ont le suc moins acide, un peu sucré, à ce point qu'elles peuvent être mangées comme les oranges. 


\section{$-133-$}

Cultivé; originaire de l'Asie tropicale et d'Abyssinie. Fleurit en mars et avril.

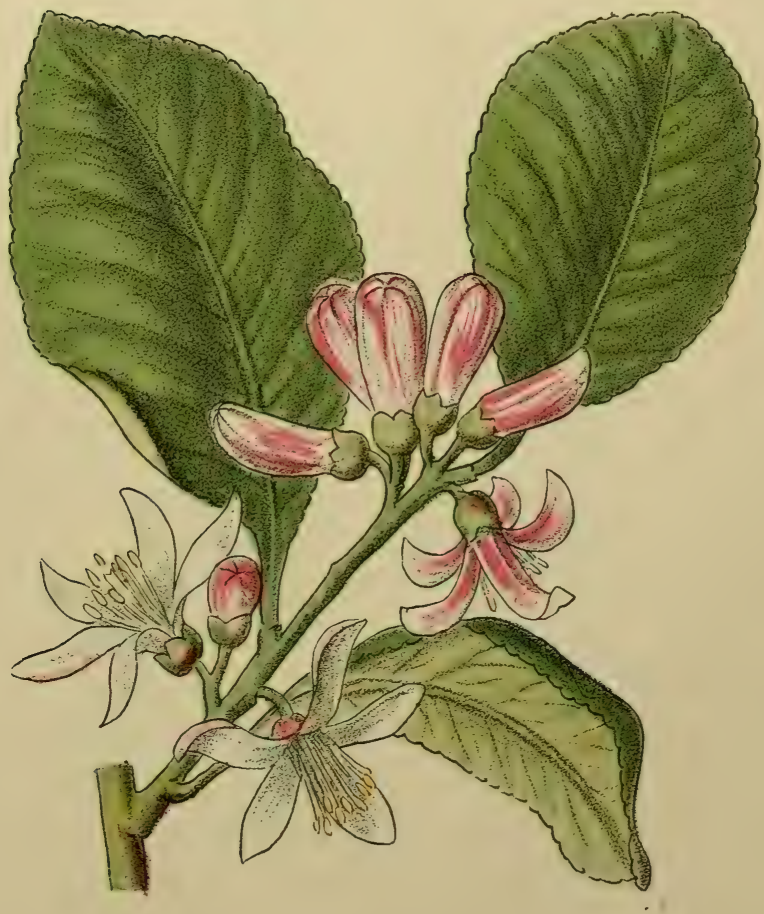

Citrus Limonum.

Franc. Citronnier.

Prov. Limoùn, Limounié. 
Cultivé. - Fleurit en mai et juin.

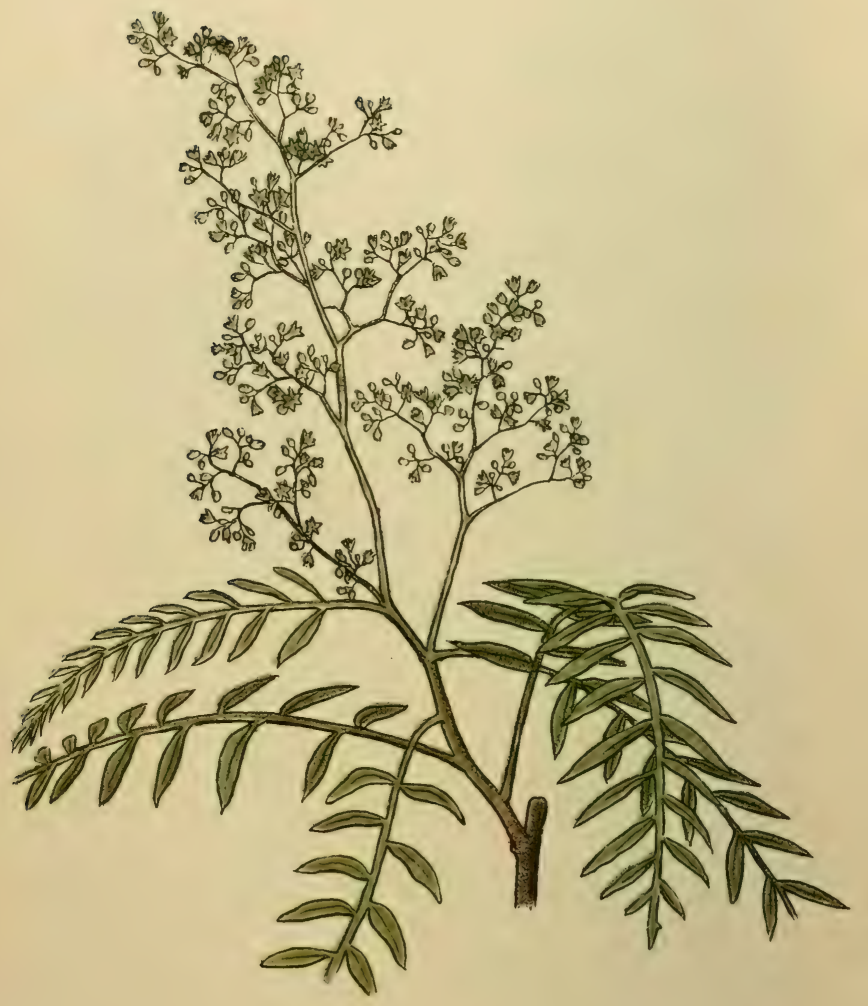

Schinus Molle.

Faux poivricr. 


\section{SCHINUS MOLLE.}

Ligur. : Albero del pepe.

Arbre de moyenne taille (8-10 mètres de hauteur), à rameaux grêles, effilés, flexueux, souvent pendants; feuilles légères, pendantes. Fleurs en grappes allongées, petites, vertes; baies rouges, de la forme et de la grosseur d'un grain de poivre.

Le « faux poivrier » provenant de l'Amérique centrale, est planté depuis longtemps dans les jardins et dans les promenades du littoral; il est très estimé pour son port élégant, pleureur, son feuillage brillant, persistant, lég'er, et ses jolies grappes de fruits, très décoratives.

Toute la plante, surtout les graines et les feuilles froissées, ont une odeur et un groût de poivre très marqués, ce qui fait que les graines sont employées parfois pour falsifier le poivre. Les folioles contiennent beaucoup d'huile essentielle : quand, aussitôt cueillies, on en jette quelques-unes dans l'eau, l'huile sortant rapidement du point d'attache de la foliole, sert de propulseur, et on voit alors les petites feuilles accomplir des évolutions très curieuses, en nag'eant à la surface de l'eau. Dans sa patrie, le Schinus molle sert à beaucoup de choses:on prépare avec ses baies du sirop, du vinaigre, et une boisson rafraîchissante; les feuilles sont empIoyées en teinture; l'écorce fournit une résine odorante, semblable au mastic, expectorante et purgative. 


\section{ACACIA LONGIFOLIA.}

Arbrisseau ou arbre de taille moyenne, à écorce grisâtre; branches flexueuses, touffues.

Outre ses qualités ornementales, cette espèce australienne, qui depuis longtemps a été introduite dans les jardins du Midi, nous offre quelques particularités de structure remarquables.

Les feuilles, par exemple, qui ne sont pas étalées horizontalement, mais verticalement, de manière à ne donner que très peu d'ombre, ne sont pas, au point de vue botanique, de vraies feuilles : ce sont des pétioles dilatés, imitant la forme de feuilles et appelés a phyllodes s. Il est très facile de s'en convaincre, en observant attentivement les jeunes pousses à la base de l'arbre, ou mieux encore, les petites plantes de semis qui naissent en abondance tout autour du tronc. On voit alors que les premières feuilles ont un pétiole grêle, cylindrique, qui porte de nombreuses folioles bipennées. Puis, plus en haut, des pétioles aplatis, verts, terminés par 2.6 petites folioles; et enfin, les branches de la plante plus avancée, ne produisant que des pétioles entièrement privés de folioles, et qui remplacent les vraies feuilles.

Le bois des Acacia est très compact et de grain fin; beaucoup d'espèces fournissent de la gomme (la gomme arabique provient de plusieurs espèces d'Acacia de l'Afrique tropicale); d'autres contiennent dans leurs cosses une quantité considérable de tanin; enfin, une quantité d'espèces sont cultivées pour la beauté et le parfum de leurs fleurs. 
$-135-$

Cultivé; originaire de l'Australie. - Flemrit en díc. et janvier.

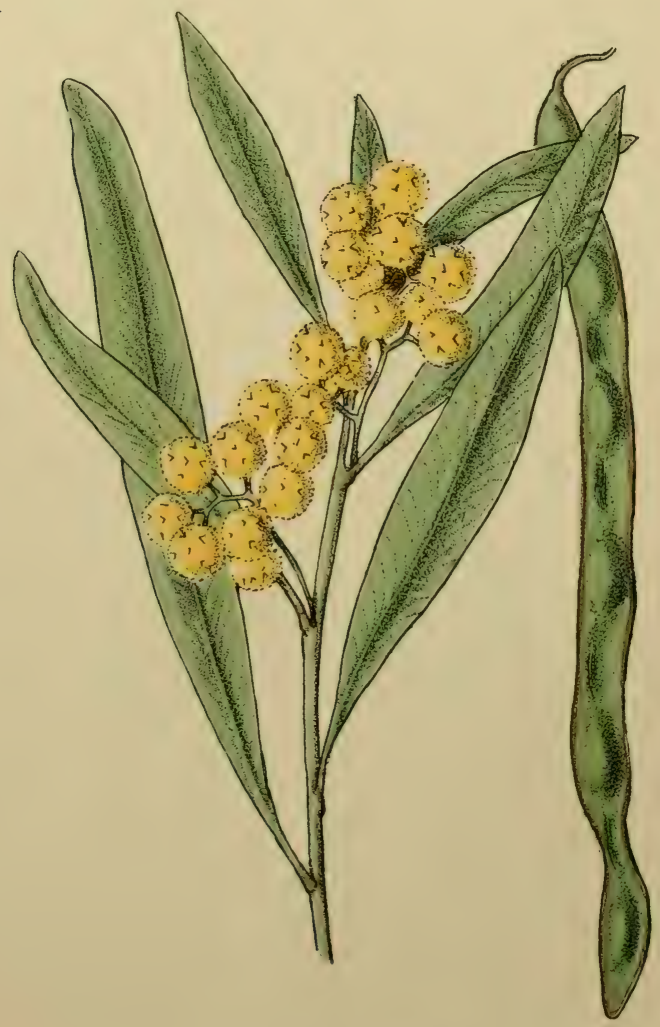

Acacia longifolia.

Frane. Acacia à longues feuilles.

Prov. Acacia. 
$-1: 6-$

Cultivé; originaire d'A ustralie. - Flnuril on firrior ol mars.

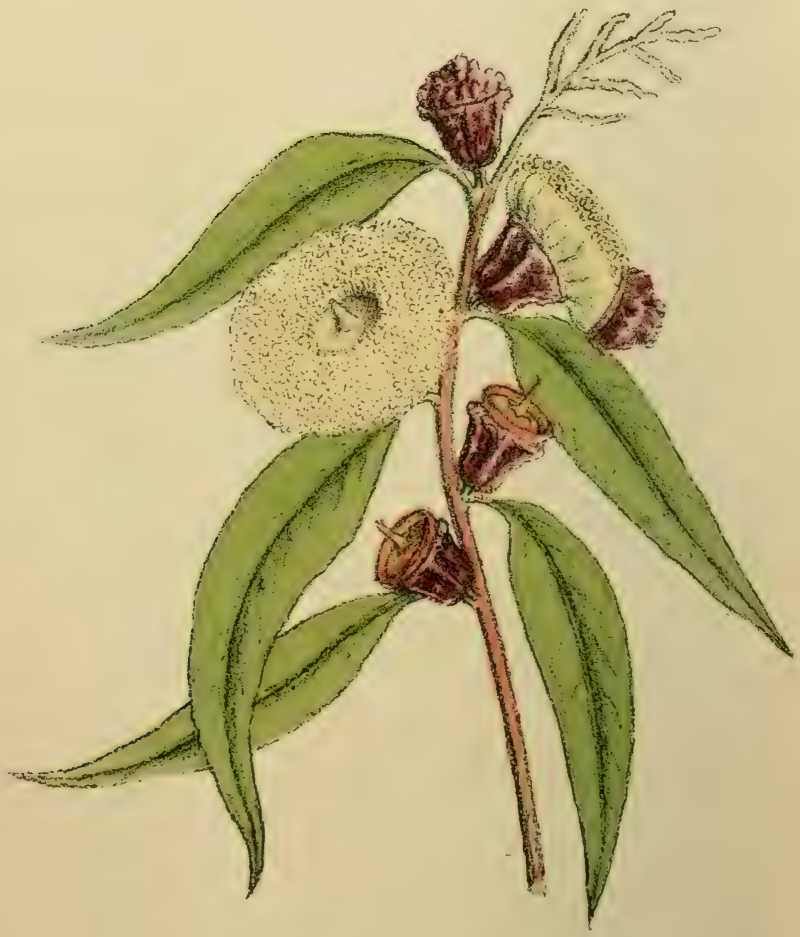

Eucalyptus Globulus.

- Myracáés. - 


\section{EUCALYPTUS GLOBULUS.}

Ital. : Eucalitto; Angl. : Blue Gum-tree.

Arbre de haute taille, atteignant, dans sa patrie, la hauteur de 60 à 100 mètres, et s'élevant, dans le midi de l'Europe, de 25 à 30 mètres; à écorce grise, se détachant en plaques et en bandes dans le sens de la longueur du tronc. Les feuilles offrent le phénomène connu sous le nom d' "Hétérophyllie s: l'arbre jeune porte sur des branches quadrangulaires des feuilles opposées, sessiles, ovales, couvertes d'un duvet cireux bleuâtre ou blanchâtre; mais sur l'arbre adulte, nous voyons des feuilles tout à fait différentes: elles y sont alternes, péliolées, pendantes, coriaces, et en forme de lame de coutelas. Ses belles fleurs sont remarquables par la structure singulière de la corolle, qui tombe, lors de l'épanouissement des fleurs, tout unie en forme d'un petit couvercle convexe ou d'un bonnet.

Provenant de l'Australie, comme la plupart des Eucalyptus connus, cette espèce est peut-être la plus répandue en Europe. On lui attribue la vertu d'assainir les terrains marécageux et infectés par les germes de la malaria, soit par l'effet de sa végétation très rapide et vigoureuse, soit par l'huile essentielle contenue dans toutes les plantes et qui est un bon antiseptique. On a fait, dans ce but, des plantations très étendues de l'E. Gl.obulus en Algérie, en Corse et dans la province de Rome; et l'on dit que plusieurs localités jadis malsaines ont été beaucoup améliorées depuis l'introduction des Eucalyptus.

On retire des feuilles une huile essentielle, qui sert à aromatiser une liqueur dans le genre de celle de la Chartreuse. 


\section{OPUNTIA FICUS INDICA.}

Ital. : Fica d'India; Ligur: : Figo d'India; Allem. : Kaktus; Angl. : Prickly pear.

Arbrisseau de 1-2 mètres de hauteur, d'un port très bizarre: les rameaux sont charnus, aplatis, de contour ovale ou elliptique ; les feuilles sont remplacées par des faisceaux d'épines de différentes longueurs. Les fleurs naissent le long des côtes des rameaux ; les fruits, charnus, ovales, de couleur violacée, de la grosseur d'un œuf, portent sur leur surface de nombreux faisceaux de petites épines, qu'il faut enlever avec soin avant de goûter au fruit.

Ils contiennent une pulpe de couleur rose, très sucrée et fondante, un peu parfumée, qui renferme de nombreuses petites graines.

Comme toutes les autres espèces d'opuntia, le - Figuier de Barbarie s est indigène dans l'Amérique centrale; mais depuis très longtemps il a été introduit dans l'Europe méridionale et en Afrique. A part les fruits, qui sont vendus en grande quantité sur les marchés, la plante n'est guère utile que pour en former des haies, presque infranchissables. Les villages en Abyssinie et en d'autres parties de l'Afrique sont souvent entourés de haies d'Opuntia qui les protègent contre l'assaut des ennemis et des bêtes féroces. Les opuntia se propagent très facilement par boutures; les rameaux s'enracinent d'eux-mêmes en peu de temps. Ils résistent admirablement à une sécheresse prolongée. Plusieurs espèces sont cultivées dans les jardins, comme plantes ornementales.

Notre planche représente une grotte aux environs d'Ajaccio, entourée d'Opuntia, où Napoléon I $^{\text {er }}$ jouait, étant enfant. 
$-138-$

Gultivé et subspontané. - Fleurit en mars of avril.

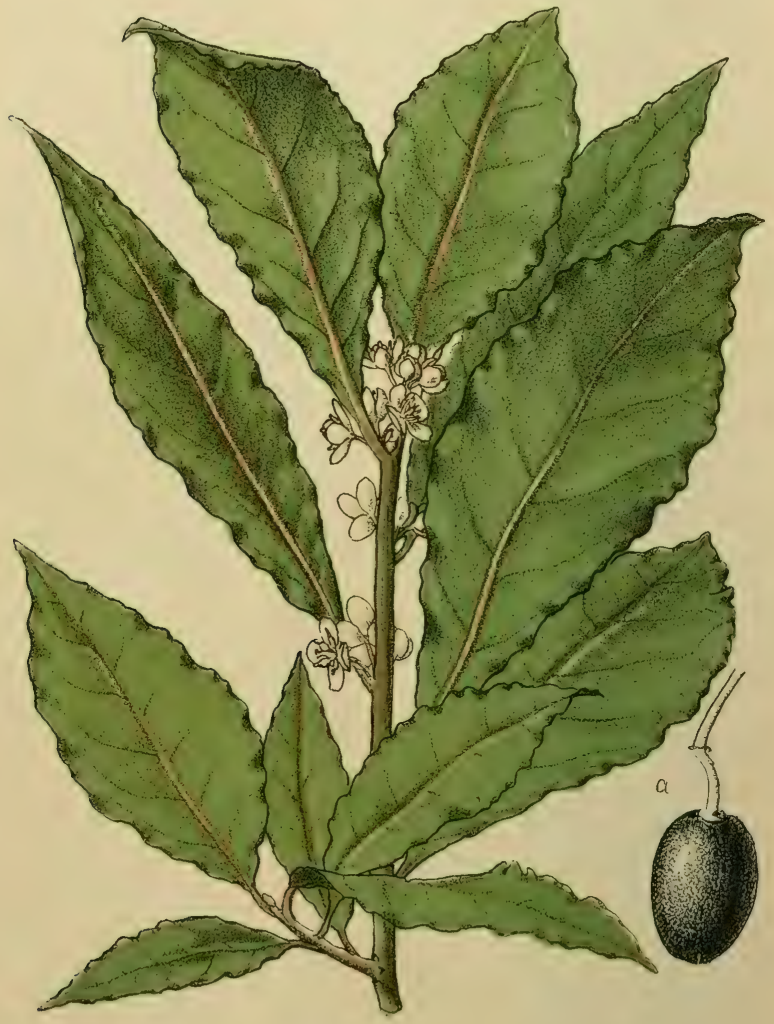

\section{Laurus nobilis.}

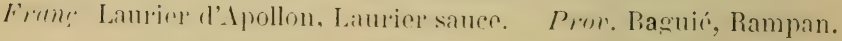




\section{LAURUS NOBILIS.}

Ital. :Alloro; Ligur. : Orfoeggiu; Allem. : Lorbeer; Angl. : Roman Laurel.

Arbrisseau ou arbre qui atteint 10 à 12 mètres de hauteur, à écorce noirâtre, lisse, à feuillage sombre, compact, touffu, persistant, luisant. Fleurs d'un vert blanchâtre ; baies de la grosseur des olives, noires, luisantes, avec un noyau gros, sphérique, verdâtre.

Le laurier est originaire de la presqu'ile balkanique et peut être indigène aussi de l'Italie centrale etméridionale : il était très connu et célèbre chez les anciens, comme arbre consacré à Apollon. Sur le littoral, on ne le trouve qu'à l'état cultivé ou parfois subspontané ; il est précieux dans les parcs, car on en forme des massifs, des haies, des palissades pour abriter des vents, auxquels il résiste très bien.

Dans l'antiquité le laurier jouait un rôle important en médecine : aujourd'hui on en faitplus spécialement usage dans la cuisine, pour l'assaisonnement. Les feuilles et les baies de laurier sont toutefois comprises dans notre Pharmacopée : l'huile exprimée des baies sert comme médicament externe, dans la composition de diverses pommades.

Les branches de Laurier remplacent en Italie le sapin du Nord, comme arbre de Noël; pendant la semaine de Noël, on en orne tous les magasins, surtout ceux de comestibles. 


\section{MESEMBRIANTHEMUM ACINACIFORME.}

Plante vivace, herbacée, à tiges longues, noueuses, rampantes ou pendantes en festons, gazonnantes; feuilles opposées, sessiles, persistantes, charnues, vertes, allongées, à section triangulaire. Fleurs très grandes, à calice charnu, violettes, roses ou blanches.

Communément cultivée sur le littoral pour garnir les murs, les rocailles, les pentes des jardins, ou pour former du gazon; et subspontané çà et là, dans le voisinage de la mer.

La grande résistance que cette espèce (originaire du Cap de Bonne-Espérance) offre à la sécheresse et aux vents salés de la mer, la rend très précieuse pour les jardins du littoral. Elle s'y est presque naturalisée, de même que le $M$. edule, espèce très voisine, car elles se propagent facilement par l'enracinement de ses branches.

Une seule espèce du même genre, le 11 . nodiflorum, est réellement indigène du littoral, et peut être trouvée, par exemple, dans le lit du Paillon à Nice et autres lieux semblables; beaucoup d'espèces, qui presque toutes viennent du Cap, sont cultivées dans nos jardins, pour la singularité de leur port et la beauté de leurs fleurs. Elles portent le nom de $\mathbf{M e}$ sembrianthemum (三 fleur de midi), parce que les fleurs ne s'ouvrenl que vers midi, pour se refermer bientôt; dans les journées brumeuses elles restent closes.

Les fruits du $\boldsymbol{M}$. acinaciforme et du $\boldsymbol{M}$. edule sont bons à manger ; le suc mucilagineux des feuilles est astringent, diurétique. 
$-139-$

Rochers, murailles. - Cultivé et sulsspontané.

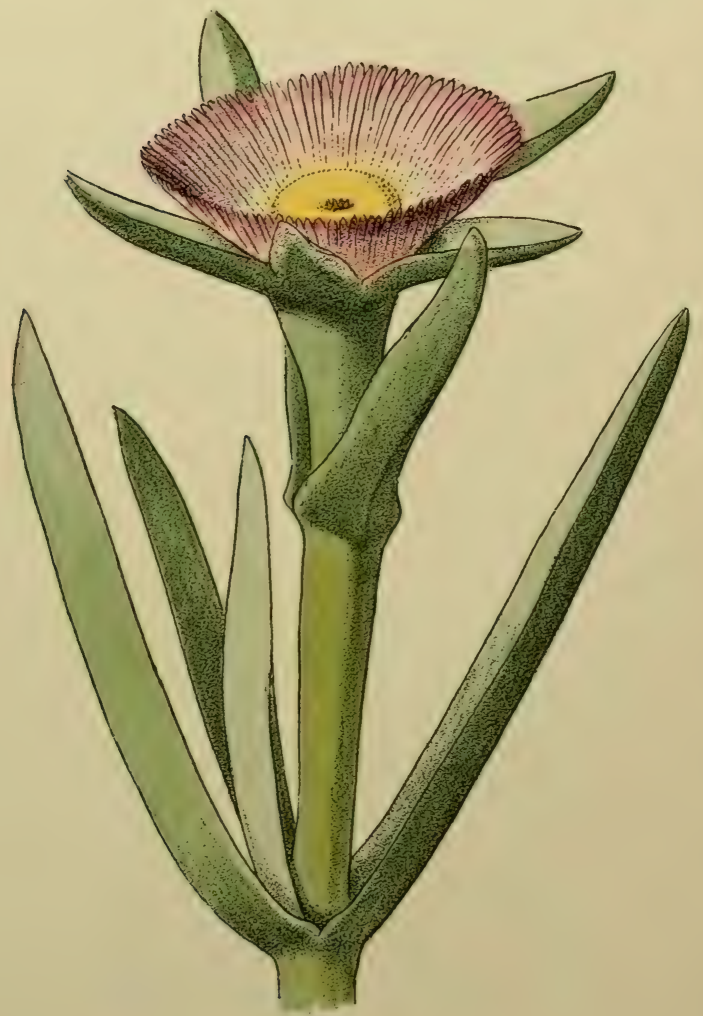

Mesembrianthemum acinaciforme.

Ficoïle.

- FicoÏdÉEs. - 


\section{$-140-$}

Cultivé et subspontané. - Originaire de l'Amérifure centrale.

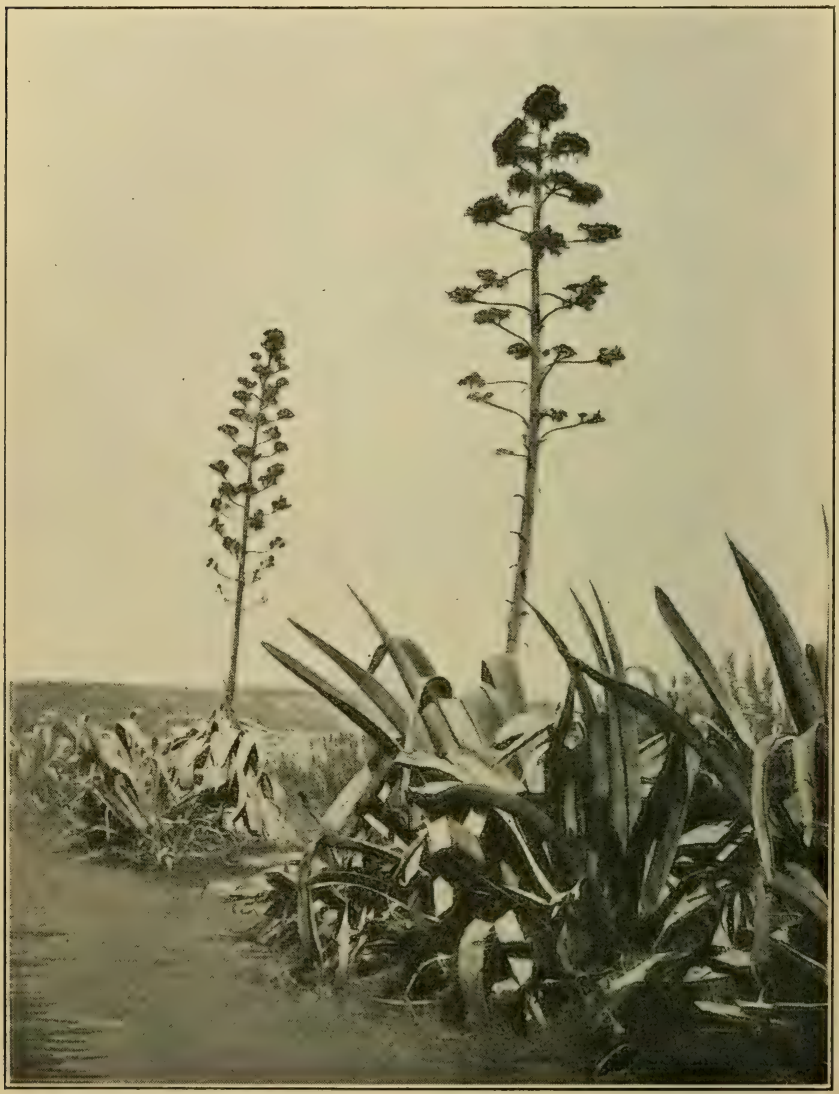

Agave americana.

Frane. Agave d'Amérique. Prov. Aloues. 


\section{AGAVE AMERICANA.}

Ligur. : Alö̈.

Plante vivace, à souche souterraine, rampante; feuilles en rosette radicale, de dimensions très variables selon la station de la plante; elles peuvent atteindre plusieurs mètres de longueur. Leur texture est coriace; les bords sont armés de pointes crochues, très dures comme la pointe terminale; la couleur d'un vert glauque : très souvent on cultive des variétés à feuilles striées de blanc et de vert. La hampe florale, qui ne se développe qu'après plusieurs années de végétation (autrefois on disait que l'Agave fleurissait seulement tous les cent ans!), ressemble d'abord à une asperge gigantesque; puis, quand elle est complétement développée, à un candélabre à branches horizontales, couvertes de milliers de fleurs. Celles-ci sont dressées, d'un vert jaunâtre, et produisent du miel en grande abondance. La hampe peut alteindre 5 - 6 mètres de hauteur.

Introduite de l'Amérique centrale, l'Agave est devenue une plante populaire, très répandue clans tout le Midi de l'Europe, et avec beaucoup d'autres plantes de provenance exotique (dattier, figuier de Barbarie, oranger, cyprès), elle est devenue presque caractéristique du paysage méridional. On la plante souvent pour faire des haies et pour orner les murs des jardins où elle se reproduit naturellement.

La moelle de la hampe, blanche et tendre, peut remplacer le liège, par exemple pour tapisser le fond des boîles à insectes. 


\section{PHCENIX DACTYLIFERA.}

Ital. : Dattero; Ligur. : Daltao, Parma; Espagn. : Datilero; Allem. : Dattelpalme; Angl. : Date palm.

Palmier haut de 15 à 20 mètres, à tronc cylindrique, noueux, couronné par une tête touffue de feuilles pennées, persistantes, élégamment recourbées. Les fleurs, unisexuelles, sont distribuées sur des individus différents, de sorte qu'un pied de dattier ne porte que des fleurs mâles, tandis qu'un aulre en a exclusivement de femelles. Ces fleurs des deux sexes sont agglomérées en grappes multiflores, serrées, renfermées dans une grande bractée lig'neuse appelée \& spathe $\%$

Le daltier est indigène dans l'Afrique subtropicale, et cultivé en grand dans toute l'Afrique septentrionale et le long des côtes de la Méditerranée. Il résiste à un froid de 7-8 degrés au-dessous de zéro; mais il ne mûrit bien ses fruits que dans les pays où il ne gèle point.

Les dattes du commerce proviennent presque exclusivement d'Afrique; chez nous on préfère les variétés à chair molle, mais les dattes les plus en usage en Afrique pour la nourriture des hommes et des animaux, ont la chair dure, moins sucrée. Il est superflu de parler ici de la grande importance qu'ont les dattiers pour les peuples de l'Afrique septentrionale. Sur le littoral on les cultive presque uniquement comme plantes d'ornement; souvent aussi les feuilles sont employées pour former des haies, des brise-vent; on en couvre les cabanes; on en tresse des paniers; enfin, ce sont les feuilles du dattier, blanchies par la ligature de la tête de palmier, qui servent à la confection des a palmes sacrées o de l'Eglise romaine et à la Pâque des Juifs. 
Cultivé; originaire de l'Afrique. - Flomit on mai et juin.

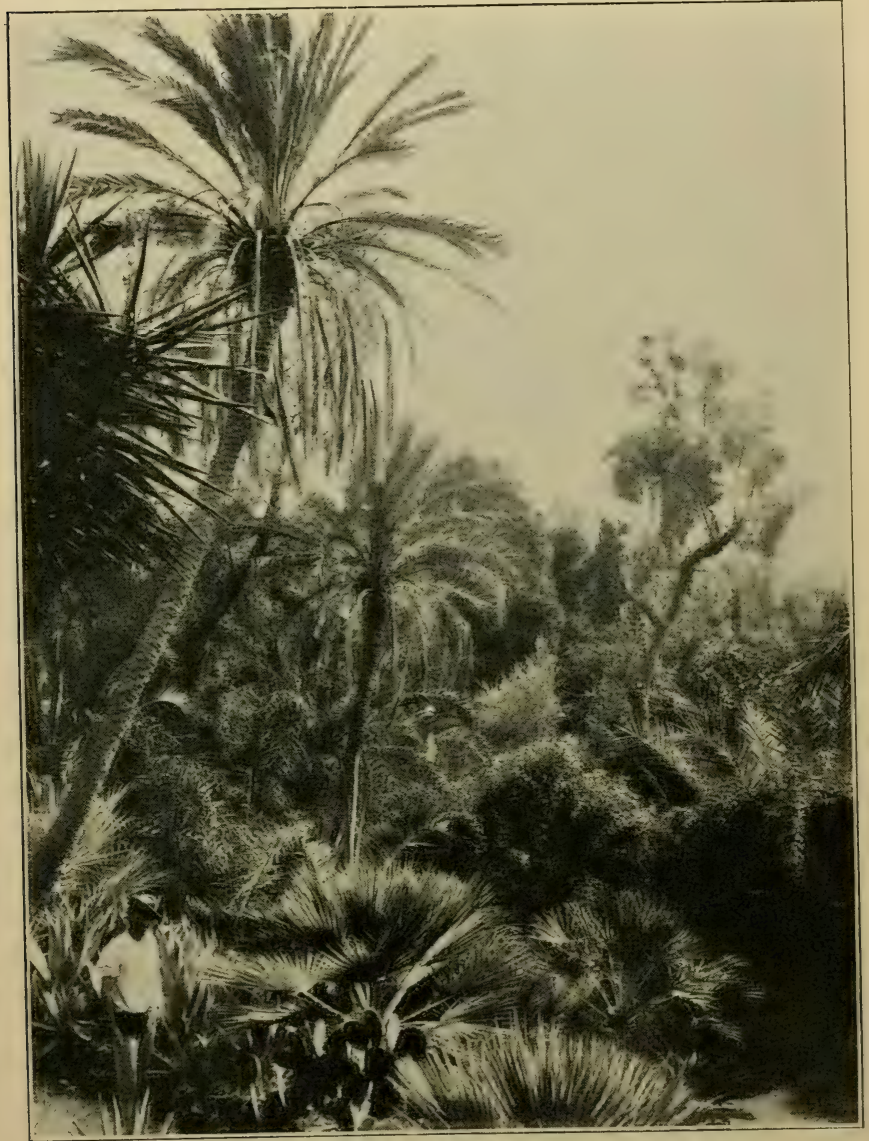

Phœnix dactylifera.

Frane. Dattier.

Prov. Parmié. 
$-142-$

Rochers maritimes; souvent cultivé - Flnuril nn juin.

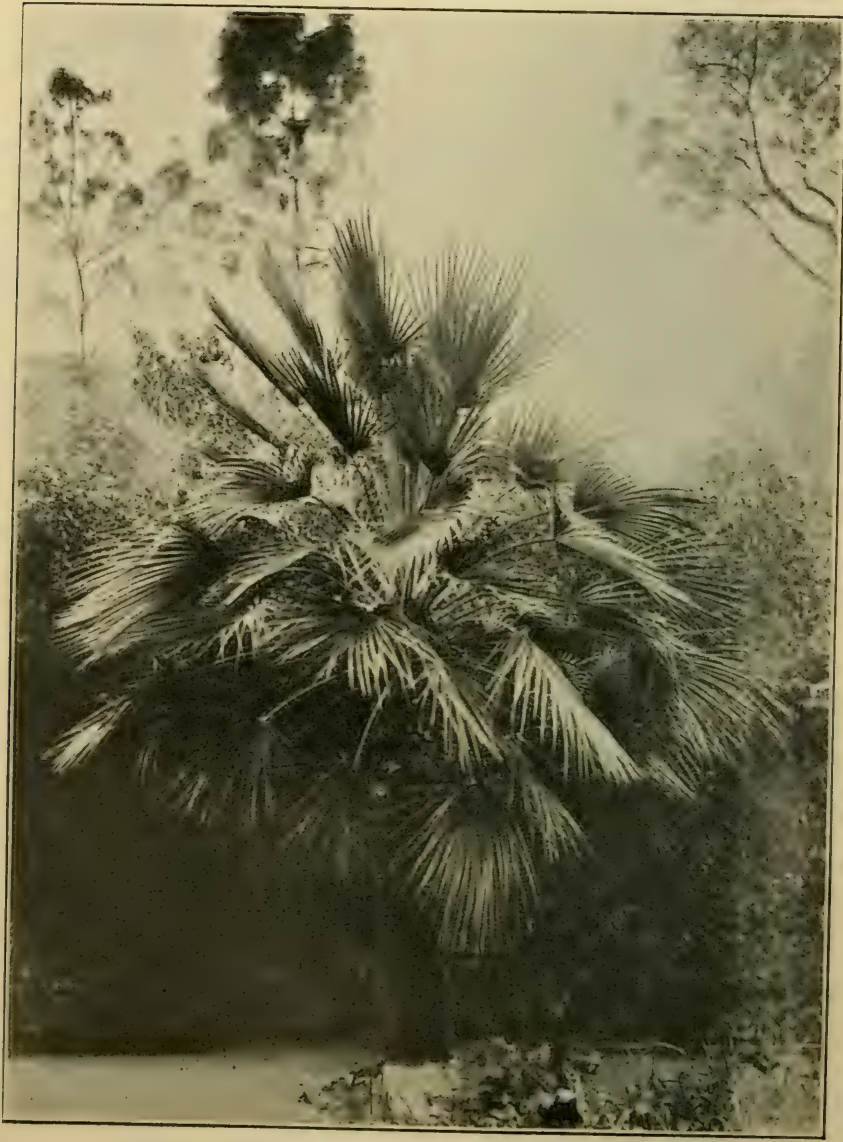

Chamaerops humilis. Frans. Palmier nain. Prov. Parmić. 


\section{CHAMAEROPS HUMILIS.}

Ital. : Pulmizio; Espagn. : Palmito; Allem. : Zwergpalme.

Palmier nain, de pelite taille, dont le tronc atteint rarement 3-4 mètres de hauteur : tronc revêtu par les fibres des graines foliaires; feuilles d'un vert sombre, coriaces. Fleurs d'un vert clair, jaunâtre; fruits ellipsoïdes, de la grosseur et de l'aspecl des jujubes, à pulpe peu abondante, jaune, douceâtre.

C'est actuellement le seul représentant indig̀ne en Europe de la vaste famille des palmiers, tandis qu'à l'époque tertiaire de nombreuses espèces de palmiers gigantesques peuplaient les forêts du centre et même du Nord de l'Europe. Le Chamaerops humilis atteint sa limite septentrionale dans le littoral, où il semble condamné à l'extinction. On en trouvait à l'état spontané très peu d'exemplaires sur les rochers entre Monaco et Mont-Alban où, selon les explorations plus récentes, faites par le $\mathrm{D}^{\mathrm{r}}$ Mader, il a déjà disparu : il réapparaît,plus en abondance, sur les côtes d'Espagne et dans l'Italie méridionale, ainsi que dans les grandes îles de la Méditerranée.

Dans les jardins on en cultive plusieurs variélés : depuis peu il est très souvent remplacé par une espèce voisine, le Chamaerops excelsa du Japon, qui offre autant de résistance, croît plus rapidement et devient plus haut. Le $C h$. excelsa porte des fruits plus petits, sphériques, d'un noir bleuâtre, semblables à des grains de raisin, en grappe très fournie.

Les feuilles du $c h$. humilis sont employées à faire de petits balais, et à la confection de chapeaux de paille à bon marché. 


\section{PRITCHARDIA FILIFERA.}

Ce beau palmier, indigène de la Californie, n'a èté introduit dans nos cultures que depuis une quarantaine d'années; mais il est devenu l'un des palmiers les plus recherchés et les plus répandus dans les jardins du Midi. Il le doit à son port majestueux, à son tronc cylindrique, renflé à la base, et à ses feuilles en éventail, très grandes, très décoratives, qui atteignent souvent 3 mètres de longueur. Les bords des feuilles vertes, luisantes, sont ornés de longs filaments blanes, bouclés; les pétioles munis d'épines raides, crochues, d'un beau jaune. Le tronc, qui croît très rapidement, peut arriver à la hauteur de 10 à 12 mètres.

Le Pritchardia filifera en plein air et sans aucun abri résiste très bien à des froids de $7-8$ degrés audessous de zéro, et ne souffre pas beaucoup des vents du Nord: on le plante souvent dans les promenades, les arenues, ou isolément sur les pelouses des parcs. Jusqu'ici, on ne l'a vu fleurir en Europe que rarement; il se multiplie au moyen de graines venues du pays d'origine. 
$-143-$

Cultivé; originaire de la Californie.

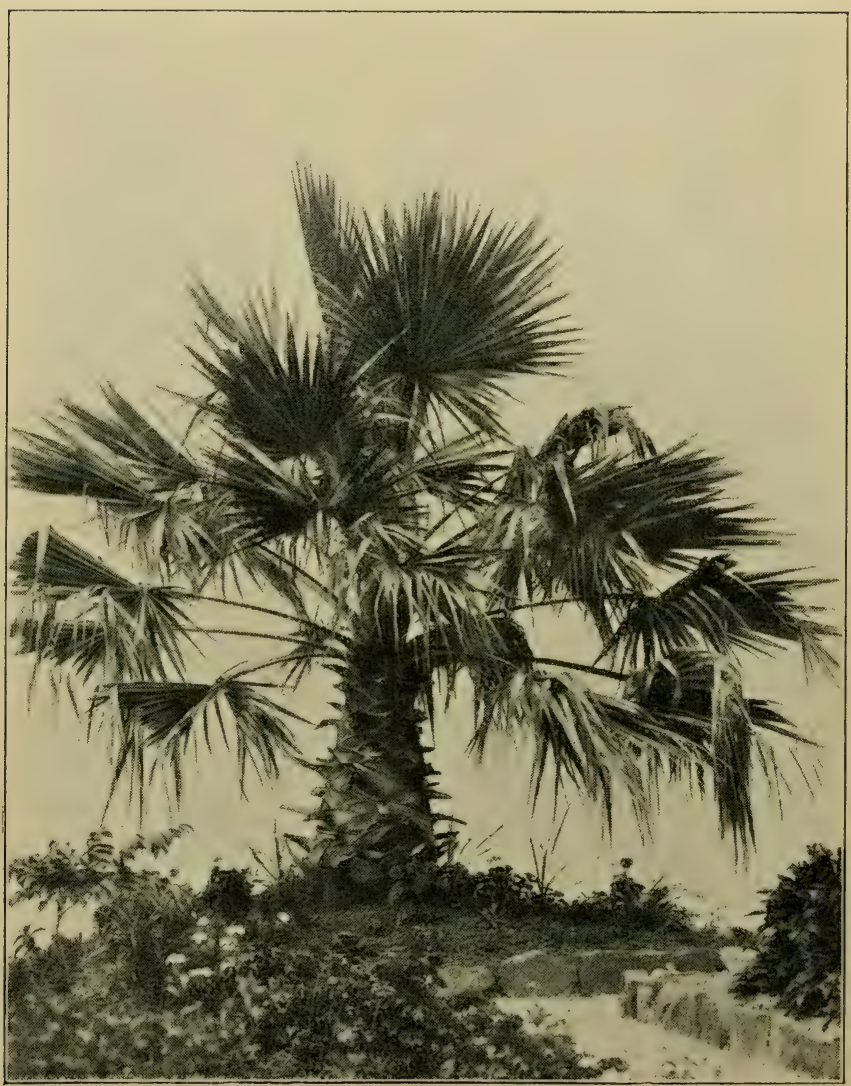

Pritchardia filifera.

- Palmiers. - 


$$
-144-
$$

Cultivé; originaire de l'Asie Mineure.

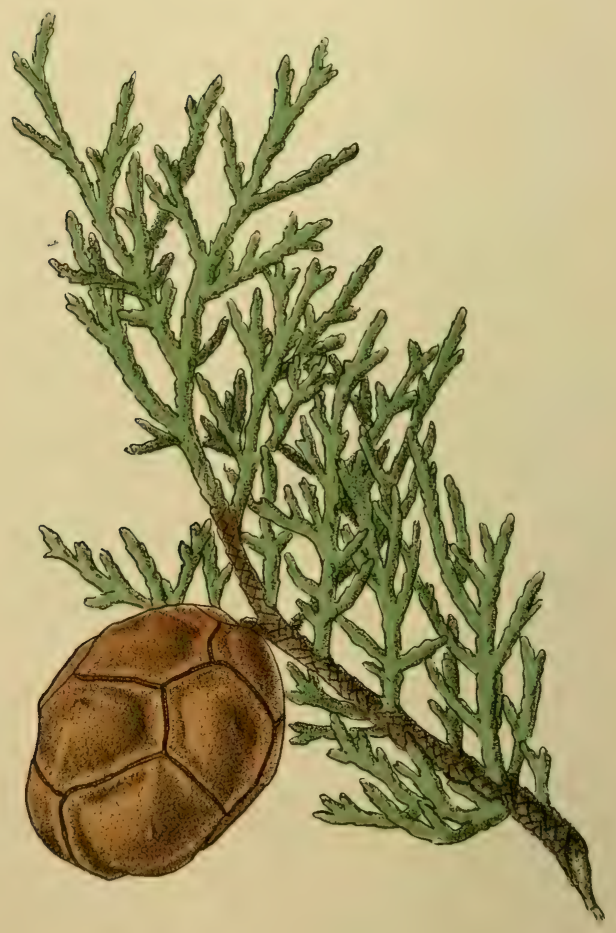

\section{Cupressus sempervirens.}

Frang. Cyprès commun.

Prov. Ouciprès. 


\section{CUPRESSUS SEMPERVIRENS.}

Ital. : Cipresu: Ligur. : Sipressu; Espagn. : Ciprès comun: Allem. : Cypresse.

Si le Pinus Pinea a été comparé à un parasol ouvert, le cyprès peut l'ètre à un parapluie fermé : il a un port très caractéristique, avec son tronc dressé, raide, jusqu'à 2əٌ mètres de hauteur, et ses branches également dressées, appliquées sur le fût comme celles du peuplier d'Italie. Ce n'est pas là cependant le port normal de la plante. On voit parfois des Cyprès cultivés auxquels les jardiniers ont donné le nom de Cupressus horizontalis, à tronc droit, mais à branches horizontales, étalées, de manière que cet arbre a plutôt le port d'un sapin. Celle-ci est la forme normale, spontanée, du Cupressus sempervirens: le cyprès commun, que tout le monde connaît, n'est qu'une variété à branches dressées - varietas pyramidata „, comme nous en connaissons pour le chêne, le robinier faux-acacia et beaucoup d'autres arbres.

Le Cupressus sempervirens est indigène en Orient, et introduit dans le Midi d'Europe depuis l'antiquité : on le cultive souvent pour former des avenues, pour marquer les limites des propriétés rurales, ou aussi pour former des brise-vents. Son bois est très dur, rougeâtre, et répand quand on le brûle un parfum très agréable. 



\section{$-146-$}

\section{TABLE DES NOMS ALLEMANDS}

DES ESPĖCES FIGURÉES

\begin{tabular}{|c|c|c|c|}
\hline & - & & Pages. \\
\hline 1ducin & & . & \\
\hline & - 102 & rnstrauch & \\
\hline$\cdots$ & $2,3,4$ & Idistel. . & \\
\hline & . 132 & er. . . & . \\
\hline & 50 & , gelbes & \\
\hline & 71 & e... & \\
\hline t. & . & ic. . & \\
\hline & & II. & \\
\hline & & ünsel. & \\
\hline & & & \\
\hline holder & . 10 & $n$. & \\
\hline & & $\therefore$ & \\
\hline & 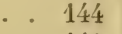 & & 10 \\
\hline$\cdots$ & 14 & Gamander . & \\
\hline & &... & \\
\hline 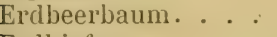 & 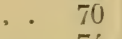 & & 2 \\
\hline & 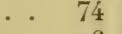 & arin. . & \\
\hline ider & & & \\
\hline ilde & 70 & & \\
\hline & · 130 & & 116 \\
\hline er. & & & \\
\hline & & & \\
\hline$\cdots$ & & iose. . & \\
\hline $\begin{array}{l}n, \mathrm{imm} \\
\therefore\end{array}$ & & relblume. & \\
\hline & 96 & Irz. . & . 117 \\
\hline & 11 & el . & \\
\hline . & & . . & \\
\hline & & 2 & \\
\hline
\end{tabular}




\section{TABLE DES NOMS ANGLAIS}

DES ESPĖGES FIGURÉES

\begin{tabular}{|c|c|c|c|}
\hline & Pages. & 5 Dea & Pages. \\
\hline wer. & $\begin{array}{l}2,3,4 \\
. \quad 68\end{array}$ & Maidenhair-Fern & $\begin{array}{r}34 \\
: \quad 130\end{array}$ \\
\hline ue gum-tree & 136 & Milk-wort. & 21 \\
\hline op.... & 23 & Musk Bugle. . & 79 \\
\hline & 12 & Myrtle & 44 \\
\hline assidony. & 82 & Navel-wort . . & 46 \\
\hline strose & 13 & $\mathrm{Ol}$ & 75 \\
\hline Fumitory & 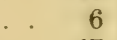 & & 72 \\
\hline ov & 17 & & . 101 \\
\hline arigold. . & 58 & $\mathrm{er}$ & 33 \\
\hline & . 116 & te. & 43 \\
\hline & 141 & & . 137 \\
\hline sh. & 5 & aurel. & . 138 \\
\hline rrose & 42 & 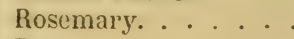 & 80 \\
\hline ider & 82 & & 20 \\
\hline & 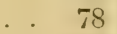 & a. & 66 \\
\hline & 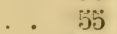 & & 10 \\
\hline ire & 129 & Se & 52 \\
\hline & , & purcl. & 45 \\
\hline & 98 & Tree & 70 \\
\hline ckle & 51 & Sweet Alis & 11 \\
\hline & 112 & - Orange. & . 132 \\
\hline & 3 & & 47 \\
\hline 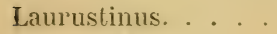 & 50 & Cistrose. & 14 \\
\hline & 114 & & 48 \\
\hline on tree & 133 & Yellow Snap-Dragon. & 86 \\
\hline
\end{tabular}

\section{TABLE DES NOMS ESPAGNOLS}

DES ESPÈGES FIGURÉES

Pages.

Abrojos. . . . . . 23

Adelfa ....... 75

Ajo de culebra
Pages. Algaravia...... 84 Algarobbo. ..... 34 Aloch. ....... 77 
Pages.

Alsina . . . . . . 98

Altabaca . . . . כ็6

Anémona..... 2, 3, 4

Angelota ...... 33

Arañas .

Arbol del amor. . . . 31

Alboser. . . . . . 70

Arros de l'ardat. . . . 47

Babols .

Baladre.

Brasera.

Bruch

Campanetas.

Caña comun

Candilles .

Cantueso .

Cap d'ase.

Capellans .

Caps blanchs.

Carclillos

Carclo Abadejo

- borriquero .

- Maria

- yesquero.

Carrasea

Carrascas de San Juan .

Cebollada.

Cenclia .

Cevadilla

Ciprés comun.

Clavell

Cohombrillo Amargo

Collejon.

Conejetes.

Corona de Rey

Coscoja.

Cosconilla.

Cospi.

Cuxa-Barba.

Datilero.

Dinada.

Durillo .

Embarrachacabras.
5

7

73

64

71

68

129

125

82

82

66

92

87

60

144

17

45
Encina comun.

Pages.

Esparrago. .

98

Estena. .

105

- negra.

13

14

Farigola.

78

Floravia..

69

Gallarets .

6

Gallocresta.. . . . . 83

Garrofer bort.

31

Ginesta pequeña... . 36

Giradol.

87

Giralda.

58

Granado.

43

Hediondo.

33

Herba blanca.

11

- de llagas.

1

65

Jaguarzo .

14

Jarablanca.

13

Lechera.

21

Lentisco.

29

Limonero.

133

Madreselva ..... 51

Madroño .

70

Manzanilla yezguera.. 63

Mata .

Matapan. . . . . 20

Matarubia.

99

Murta. .

44

Naranjo.

132

Olivarda....... . 56

Olivera.

72

Olivilla.

28

Ombligo de Venus. . . 46

Palmito.

142

Pan d'Audel.. . . . . 47

Pápolas.

Pinillo oloroso.... . 79

Pino Carrasco..... 102

Pino pinonero .... 101

Punxa-Claus ..... 23

Rabanisas blancas. . . 9

Rabiacana 
Pages.

Retama blanca .... 91

- de dor . . . . 35

- espinosa ... 40

- macho .... $33 ̈$

Roja ....... 48

Roldòn . . . . . 26

Romani...... 80

Romero. . . . . . 80

Rucla. . . . . . . . 20̉

Salado blanco. . . . 94

Salgada vera..... 94

Sanzgatillo .... : . 77

Senet bort . . . . . 38
Pages.

Taparera...... 12

Tomillo...... 78

Tomillo blanco... . 81

Torvisco...... . 97

Traylillos. . . . . . 120

Urce........ 71

Yerba cabruna .... 33

79

81

74

Zamarilla...... 81

Zamon ....... 109

Zarzaparilla de España . 104

\section{TABLE DES NONS ITALIEAS \& LIGURIENS}

\section{DES ESPĖCES FIGURÉES}

Les noms italiens sont en italique.

Abragoun Pages.

Acciüssola . . . . 59

Agaïso ....... 100

Aggiu de biscia. . . . 113

Agnocasto . . . . . 77

Agru . . . . . . 104

Alaterno ...... . 27

Albero di Giuda . . . 31

Albero del pepe. . . . 134

Alga ........ . 124

Alloro . . . . . 138

Aloë ........ 140

Anebolo...... 2, 3, 4

Anemone . . . . 2, 3, 4

Arancio dolce. . . . 132

Arastre. . . . . 40

Armun. ...... 70

Asfodelo ...... 109

Asfodile
Pages.

Asparago pungente. . 10כ̈ Batticristi ..... 54 Baxadonne ..... 116

Baxaprei . . . . . 57

Bazarigò sarvaigo. . . 96

Belladonna . . . . 75

Bocca de gallina. . . . 123

Bocca di leone . . . . 86

Boessaï. . . . . . 67

Brügo ....... 71

Brustiaire ..... 114

Bucche de Liùn. ... 86

Bunomo ..... 61

Canna ...... 129

Canna ...... 129

Capelvenere. . . . 130

Capperi....... 12

Capletti. . . . . . 46

Capuvenere. . . . 130 . 
Pages.

Carubbo ..... 34

Catucciu . . . . . 68

Cavolassi .

Chigoemau marin.

Cipresso

45

Corbezzolo

Crous de Malta.

Cucumero marino .

Curiola.

Curnà

Dattao

Dattero.

Ditamo.

Elce

Embriaghi

Erba cavallina

Erba de musc.

Erba risetta.

Erba Ruta

Erba Spaa

Erica.

Erxu .

Eucalitto

Farfuia.

Ferugola

Fico d'India

Figo d'India

Fisteccu sarvaegu.

Frassinella

Fumoterra.

Gaggiolo .

Galio

144

70

23

45

90

50

141

141

24

98

26

33

79

47

25

117

71

98

136

33

78

137

137

29

24

6

116

Galletti

Ganoefani de S. Piero.

12 วั

Garofano a mazzetti.

Giacinto

Giasintu

Ginepro

112

100

Ginestra

Guaglio.

12ว

Iride .

117

Lauro Tino.

50

Leandro
Legabosco .

Pages.

Lentisco.

51

Lerca.

29

Limone.

38

Limuin.

133

. . 133

Madreselva..... 1

Mancamogli. . . . . 64

Margrita sarvaja . . . อ อั8

Mazzu . . . . . . 3 3 כ̆

Meï-graniè . . . . . 43

Melagrano..... 43

Merxia...... 14

Nirto. . . . . 44

Mortora . . . . . 44

Murtareize . . . . 26

Murtin . . . . . . 44

Nasca. . . . . . 56

Nigella. ....... 5

Nuxea . . . . . . 24

Ombellico di Venere. . 46

Orfoeggiu ..... 138

Oxeletti che se spegian . 121

Palmizio .

142

Parma .

141

Pin gianco . . . . 102

- da pignoï. . . . . . 101

Pino d'Aleppo. . . . . 102

- da pigne ..... 101

Poligala...... 21

Porache ....... 111

Portugà . . . . . . 132

Pougliot . . . . . 81

Puligala ...... 21

Reusa ....... 42

Rattalaegua. . . . . 59

Règaggi . . . . . 104

Robbia selvatica. . . . 48

Romanin ...... 80

Rosa sempreverde. . . 42

Rosmarino ..... 80

Rozza. . . . . . 48

Rua......... 20

73 Salsapariglia nostrana . 104 
Pages.

Scannabecco .... 40

Sciù d'angiu.. . . . 118

Scursoea ...... 90

Siga.......... 104

Sipressina de montagna. 122

Sipressu....... 144

Smuzzighe...... 13

Sparagu sarvaegu. . . 105

Steccadò ...... 82

Strie....... 5

Svariglio . . . . . 89

Taggiaïnetta.. . . . 62

Tipani....... 12

Tazzetta....... 118
Pages.

Terracrepola ..... 59

Timo....... 78

Tümao....... 78

Tùmaro cagao..... 92

Tremeixe. . . . . 77

Uiva...... 72

Ulivo. ...... 72

Varego....... 97

Vedovelle....... 52

Viàldue. . . . . . 51

Viàrbora ...... 1

Viduette ...... 52

Violaciocca marina . . . 10

Zenestra....... 36

\section{TABLE DES NOMS PROVENGAUX}

\section{DES ESPĖCES FIGURÉES}

Pages.

Acacia....... 133

- rougeo..... 31

Agalancié...... 42

Aiet fer. . . . . . 113

Alapèda. . . . . . . 109

Alimonio estellado... . 3

- flammo. .. 4

- rougeo

Aloues.. . . . . 140

Aouba de mar..... 124

Arangié....... 132

Arboûs . . . . . . 70

Argieras fer. . . . . 40

Arièje... . . . . $10 t$

Augo. . . . . . . 124

Avalse. . . . . . . 99

Avaus

99

Baguié .

138

Bayoun.

114
Pages.

Bioto....... 118

Bouis blanc. ..... 94

Bouleto....... 55

Bragaloù . . . . . 114

Brugas fer ...... 91

Brugas mascle .... T1

Brus ....... 71

Cabrcireto ..... 33

Cabridoula . . . . 33

Cade acadrié . . . . 100

Cade endourmi . . . 103

Cade mourvis. . . . 103

Calmolea . . . . . 28

Cano....... 129

Canta-perdris . . . . 97

Capilero . . . . 130

Capillerà . . . . 130

Cardoum . . . . . 57

Cardousse. . . . . 67

Carinet. . . . . . 46 
Pages.

Pages.

Carolicí. . . . . . 3t

Carolino . . . . . 38

Caulechoun. . . . . . 7

Cinerero ....... 53

Coucarèta. . . . . 46

Coueta de lapin. . . . 127

Cougoumasso. . . . . 45

Councoumbre d'aze. . . 45

Cournihet fer . . . . 16

Coustelino . . . . . 59

Coutèla........ 117

Coutelassa ..... 116

Couten. . . . . 116

Crenihet fer...... 15

Crisantèmo . . . . . 58

Darboussié . . . . 70

Dictan blanc . . . . 24

Dragoun ....... 114

Embriago. . . . . 116

Entreradis . . . . . 1

Eouze ........ 98

Erba daou lagui. . . . 44

Erbo blanco ..... 11

— di masco.... . 56

- dòu la...... . 21

- dou pardoun .. 41

- dou tai .... 83

Escabiouso . . . . . 52

Esclario . . . . 104

Escudet. . . . . . . 46

Euve . . . . . . 98

Faióu fer. . . . . . 87

Farigoulo. . . . . 78

Fatamot ...... 50

Favélou. . . . . . 50

Figo de Barbario . . . . 137

Frigoula . . . . . 78

Gantelet . . . . 68

Garou . . . . . . . 97

Garoulia ...... 99

Garus

99

Gidouflada . . . . 17

Ginesto.

Ginesto fèro .... 36

Ginouflié de cinq fueio . $\quad 17$

Gloujaù.

117

Gouranié fer . . . 10

Grando maougo. . . 18

Gros Rasinet ..... 47

Grosso Rulo. . . . . 25

Jacinto . . . . . 112

Jaisso fèro . . ... 30

Keirelet. . . . . . 82

Lampourdié. . . . . 69

Lanchousclo grosso . . $\$ 88$

Lapinou . . . . . 86

Laurié roso. . . . . 75

Lebourino . . . . . 123

Limoùn. . . . . . . 133

Limounié. . . . . . 133

Lin fer. . . . . . 19

Lis de mal. . . .. . 119

Maco-muou. . . . 64

Maourèta . . . . . 87

Messugo blanco. . . 13

Messugo négro . . . . 14

Mingranié ..... 43

Miougranié. . . . . 43

Mloujès . . . . . . 14

Mourelo ...... . 87

Mournankin ... . 32

Mlourvis ....... 103

Moustardo fèro . . . . 8

Muga. . . . . . . 14

Mugan ........ 13

Muguè ........ 112

Muguet. . . . . . 118

Nasco. . . . . . . 56

Nerto. . . . . . . 44

Nertas . . . . . . 26

Nielo bardudo .... . 5

Ouciprès ....... 144

Oulivié....... 72

Ousèio fèro. . . . . 20

Pan blan. ...... 7

35 | Pantacousta...... 51 
Pages.

Parmié.... 1ł1, 142

Pébriana . . . . 78

Pebrié ....... 77

Ped de poulo . . . . 33

Pèis de nouvé. . . . . 67

Petelin. . . . . . . 29

Pin blanc. . . . . 102

-pignoun. .... 101

Pissoto........ . 76

Plantage . . . . . . 93

Pôta . . . . . . . 78

Pourraco . . . . . 109

Prudhôme . . . . . 83

Rairestèu. . . . . . 48

Rama-counil . . . . 105

Ramocounièu. . . . 105

Rampan ...... 138

Rastelet . . . . . 48

Rédou . . . . . . 26

Réjistel. . . . . . 48

Repelin.... . . . 29

Réstincle. . . . . . $2 !$

Rin-vierge . . . . . 104

Rivouarto
Roudoun. . . . . 26

Roudous...... 26

Roumaniou. .... 80

Rouqueto blanco . . . 9

Rousié fer ..... 42

Rouvet....... 91

Salièje...... 104

Saougras...... 31

Saouvo maire. . . . . 51

Séné....... . 92

Tapénié ...... 12

Té....... 39

- de mountagno. . . 22

- di collo..... . 74

Terra-Greppia . . . . 59

Toulipan... 107, 108

Trauco-pèiro . . . . 23

Trintanèta . . . . 97

Tréu estella. . . . . 37

Turbith blane. . . . 92

Ubriago....... 6

Vulnerairo .... 39

Yeuse ...... 98

\section{TABLE DES NOMS FRANGAIS \& LATINS}

DES FAMILLES ET DES ESPÈCES FIGURĖES OU CITÉES

Les noms des familles sont imprimés en égyptienne, les noms latins en italique, les noms français en romain.

\author{
Pages \\ ou planches.
}

Acacia à longues feuilles 135 Acacia longifolia. . . . 133 Adiantum Capillus-Veneris 130 Agave americana. . . 140 Agave d'Amérique . . 140 Ail blanc-de-lait.
Pages ou planches. Ail rose. . . . . . 113 Ajuga Chamaepitys. . . 79 Ajuga Iva . . . . . 79 Allium neapolitanum. 111, 113 Allium roseum ..... 113 Alysson maritime. 
Pages

ou planches.

Alyssum maritimum. . . 11

Amaryllidées. . 118, 140

Ambrosiacées

69

Anacardiacées .

$13 \dot{4}$

Andropogon citratus.

128

hirlus

128

- Ischaemim

128

Nardus . .

- Schoenanthus

Anemone coronaria.

128

128

- pavonina.

- stellata.

Anémone étoilée . des fleuristes.

\section{- cil de paon.}

Anthyllis Barba Jovis.

Anthyllis Barbe de Jupiter Antirrhinum latifolium . Aphyllanthes monspeliensis.

Apocynées .

\section{Aracées}

Arbousier-fraisier.

Arbre de Judée.

39

86

Arbutus Unedo.

114

75

125

70

31

70

Arisarum vulgare. . . 125

Arroche de mer.

94

Arundo Donax

Asparaginées.

Asparagus aculifolius.

Asphodèle blanc

Asperge sauvage. .

Asphodelus albus.

Asteriscus aquaticus.

$$
\text { - maritimus.. }
$$

Astérolicépinoux

spinosus

Atriplex Halimus .

Barbon hérissé .

Barlia longibracteala.

Bois-gentil .

129

104

105

109

103

109

60

60

60

60

94

128

120

Borraginées
Pages

ou planches.

Bourdaine...... 27

Bragalou de Montpellier. 114

Bruyère en arbre. . . . 71

Bryonia. . . . . . 45

Bugle musquée. . . . 79

Gactées. . . . . 137

Calycotome spinosa. . . 40

Camélée à trois coques. 28

Campanula Medium. . . 68

Campanulacées... . 68

Canne de Provence . . 129

Capillaire. . . . . 130

Capparidées ..... 12

Capparis spinosa.... 12

Câprier....... 12

Caprifoliacées..... 50

Capuchon. . . . . 125

Cardus Candollei. . . . 57

Carillon. . . . . . . 68

Caroubier. . . . . . 34

Carthamus tinctorius. . 58

Caryophyllées ... 15, 17

Cèdre piquant. . . . 100

Centaurea aspera. . . 64

- Calcitrapa. 23, 64

- pectinata... $6 \dot{4}$

. phrygia.... 64

- solstitialis... 64

Centaurée rude.... 64

Ceralonia Siliqua. . . 34

Cercis Siliquastrum. . 31

Gésalpiniacées..... 34

Chamaerops excelsa. . 142

humilis. . 142

Chardon de Sainte-Baume. 57

Chêne à Cochenilles. . . 99

- au Kermès. . . . 99

des Garrigues. . . 99

-liège. . . . . 998

vert. . . . . 98

Yeuse..... 98

76 Chénopodiacées.... 94 


\section{Pages \\ ou planches.}

Cheveux de Vénus. . 5, 130 Chèvrefeuille entrelacé . 5้1

Chrysanthème de Mycon.

Chrysanthemum Myconis.

segetum .

Cinóraire.

Cineraria maritima.

Cistacées.

Ciste cotonneux.

- de Montpellier.

Cistus albidus.

- crelicus.

- ladaniferus. . 13.

- laurifolius.. . 13,

- longifolius.

- salviifolius.

- monspeliensis.

Citronnier..

Citrus Aurantium.

\section{Limonum.}

Clemalis Flammula.

$$
\text { - Vitalbr.. }
$$

Clématite flammèle.

Cneorum tricoccum .

Composées.

Conifères.

Convolvulacées.....

Convolvulus althaeoides.

$\begin{array}{ll}\text { - } & \text { crvensis.. } \\ \text { - } & \text { cantabrica. } \\ \text { - } & \text { linealus.. } \\ \text { - } & \text { sepium. . } \\ \text { - } & \text { siculus. . } \\ \text { - } & \text { iricolor. . }\end{array}$

Coriaria myrtifolia.

Coriariacées.

Coris monspeliensis

Coris de Montpellier.

Coronilla Emems.

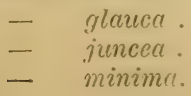

58

58

58

53

53

13

13

14

13

14

14

14

13

13

14

133

132

133

53

144

90

90

90

90

90

90

90

90

26

26

74

74

38

38

38

38
Pages

ou planches.

Coronilla varia. . . 38

Corroyère à feuilles de Myrthe ...... 26

Crassulacées . . . 46

Cresson Alénois. . . . 7

Croix de Malte. . . . . 23

Croton des teinturiers. . 87

Crozophora tinctoria . . 87

Grucifères . . . . 7

Cucurbitacées .... 45

Cupressus horizontalis. . 144

- sempervirens. 144

Cupulifères.

98

Cypéracées.

126

Cyprès commun. . . . 144

Cytise à trois fleurs. . . 32

Cylisus Laburnum. . . . 32

- triflorus. . . . 32

Daphne Gnidium . . . 97

- Laureola. . . 97

- Mezereum. . . 97

Dattier. . . . . . 141

Dianthus Carthusianorum 17

Caryophyllus. .

17

- liburnicus.

17

17

Dictammes albus .... 24

Diotis candidissima. . . 66

Diotis cotonneux . . . . 66

Diplotaxis erucoides. . . 9

Dipsacacées . . . . . 52

Drosophyllum lusitanicum 15

Ecbalium Elaterium. . 45

Echinops Ritro .

55

55

Epine jaune . . . . . 67

Erica arborea. . . . . 71

- scoparia.... 71

Ericacées..... . 70

Erigeron canadense . . 7

Eucalyptus Globulus. . . 136

Euphorbe en arbres. . 89 
Pages

ou planches.

Euphorbe des vallons . . 88

Euphorbia Characias .

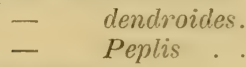

Euphorbiacées .

Fausse Roquette

Faux Baguenaudier.

Faux poivrier.

Ficoüde.

Ficoïdées.

Figuier de Barbarie. .

Flambe.

Fougères.

Fraxinelle blanche

Fumaria capreolata.

Fumariacées

Fumeterre grimpante.

Gainier.

Galactite cotomneuse

Galactites tomentosa.

Garance sauvage.

$$
\text { - voyageuse. }
$$

Garou

Gattiliel

Genêt cendré .

d'Espagne

Genévrier Cade .

$$
\text { de Phónicie. }
$$

Genista genuensis .

$$
\text { - vilosa. }
$$

Germandrée blanche

Gesse clymène .

Giclef.

89

89

49

$8 \%$

ดั4

5่́

48

48

97

57

36

35

100

103

36

36

ง1

30

45

Giroflée blanche de Nice.

- commune. dentée.

Gladiolus communis.

116

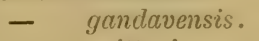

- psiltacinus.

116

$$
\text { segeium. }
$$

Glaieul des moissons
116

92
Pages ou planches.

Globularia cordifolia . . 92 - vulgaris.

92

Globulariées

Graminées .

127

Grand roseau.

129

Gremil violet .

76

Grenadier.

Helichrysum Stoechas.

43

Helléborine à languette .

82

Herbe au bitume.

123

33

Hyacinthus orientalis . . 112

Hyoséride rayonnante. . 62

Hyoseris radiata. . . . 62

Hypéricacées. . . . . 22

Hypericum Androsæmum 22

c)

- Ascyron.

calycinum.

22

22

22

Inula viscosa . . . 15, 16

Inule visqueuse. . . . . 56

Iridées.

116

Iris d'Allemagne . . . 117

Iris florentina.

117

- germanica.

117

- pallens.

117

Jacinthe

112

Jacinthe des jardinier's . 110

Jacinthe d'Orient. . . 112

Juniperus Oxycedrus . . 100

103

103

78

Labiées

Sabina.

Lagurus ovatus.

127

Lampourde épineuse . . 69

Lathyrus Clymenum.

Laurier d'Apollon.

30

Lauriel'rose

138

Laurier sauce.

$7 \check{8}$

Laurier-Tin.

138

Laurinées

50

Lan!r?!s nobilis 


\section{Pages \\ ou planches.}

Lavande des Stœchades .

82

Lavandula latifolia .

$$
\text { Spica. }
$$

- Stochas.

Lavatera maritima .

$$
\text { - punctata. }
$$

Lavatère maritime

\section{Légumineuses Mimo-} sées

Lentisque sauvage

Lepidium Draba

82

82

82

18

18

18

18

133

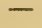

latifolium

Liliacées . sativum

Lilium bulbiferum

- croceum

Lin raide.

Pomponium.

Linacées.

Linum campanulatum.

$$
\text { - catharlicum. }
$$

Lis Mathiole.

strictum.

- turban

Liseron épineux

fausse Guimauve

Lithospermum purpureocoeruleum.

Lonicera implexa

Luzerne marine.

\section{Malvacées}

Matthiola incana

$$
\text { sinuala }
$$

Medicago marina.

Mesembrianthemum acinaciforme.

Mesembrianthemum edule

florum

76

$$
\text { - nodi- }
$$

Pages ou planches.

Millepertuis verticillé . . 22 Minette dorée des plages. 41 Momordique . . . . 45 Moricandia arvensis. . 8 Moricandie des champs . 8 Muflier jaune. . . . 86 Myrtacées . . . 43, 136 Myrthe. . ....... 44 Myrtus communis. . . 44 Naïadées . . . . . 124 Narcisse à bouquets. . . 118 Narcissus aurcus . . . 118

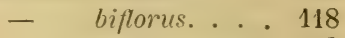

- papyraceus. 118

- poeticus. . 118 - Pseudo - Narcissus

118

Tazะella. . 118

Nerium odorum.

\section{- Oleander.}

Nerprun alaterne.

75

Nigella damascena

- saliva

Nigelle die Damas.

Nombril de Vénus

Odontitès jaune.

46

Odontiles lutea.

84

OEillet commun.

84$$
\text { - de Croatie. . . } 17
$$

- de poète. . . 17
- dles Chartreux . . 17

Olea europæa. .... 72

Oléacées . . . . . 72

Olivier....... 72

Ombellifères . . . 49

Ophrys Bertolonii. . . . 121

Ophrys de Bertoloni . . 121

Opuntia Ficus indica . . 137

Oranger ...... 132

Orchidées . . . . 120

Orchisàlongues branches 120

Orchis papilionacea . 
Pages

ou planches.

Orlaya marilima

49

Orlaya maritime

Ornithogale de Narbonne 110 Ornithogalum divergens.

- $\quad \begin{array}{r}\text { narbonense } \\ \text { - }\end{array}$

Orpin élevé.

Osyris alba.

110

110

110

110

110

Osyris blanc

91

Oxalide penchée.

Oxalidées.

Oxalis cernua.

Palmier nain.

Palmiers .

142

Pancratium maritimum.

141

Papilionacées. $30,32,35$

Passerage Drave

63

Phagnalon saxatile.

sordidum, 63 ,

Tenorei.

Philaria à feuilles étroites

Phoenix dactylifera... . 141

Phylliraea angustifolia.

$$
\text { latifolia. }
$$

medir.

Picrile commune.

Picridium vulgare.

Pin d'Alep. .

65

63

- d'Italie.

- de Jérusalem. .

- parasol.

- pignon.

Pinus cembra.

- halepensis

- maritima

- Pinaster.

- pinea.

- sylvestris.

-- uncinata.

Prstacia Lenliscus.

\section{3}

73

73

วั9

59

102

101

102

101

101

101

102

102

102

101

102

102

29
Pages

ou planches.

Pistachier...... 30

Pistolet de dames. . . 45

Pittospore de Chine. . . 131

Pittosporées . : . . . 131

Pittosporum crassifolium 131

Mahi... 131

- $\quad$ Tobira $\quad 131$

- undulatum. 131

Plantaginées . . . . 9 95

Plantago arenaria . . . 950

- Bellardi... 900

- Psyllium... 95

Plantain poilu... . . . 90

Pluie d'or'...... . 32

Plumbaginées.... . . 93

Polygala grêle . . . . 21

Polygala amara..... 21

- grandiflora. . 21

- myrtifolia... 21

- nicacensis. . 21

- Senega.... 21

Polygalacées..... 21

Posidonia Caulinii.. . . 124

Posidonia de Caulini . . 124

Primulacées . . . . 74

Pritchardia filifera. . 143

Psoralea bituminosa. . . 33

Punica Granatum . . . 43

Quercus coccifera. . . 99

- Ilex. . . . 98

- Suber. . . . 98

Queue de lièvre. . . . . 127

Renonculacées . . . 1

Rhamnacées ..... 27

Rhamnus Alaternus. . 27

- cathartica... 27

- Frangula. . . 27

Romarin officinal. . . 80

Rosa sempervirens... . 42

Rosacées...... 42

Roseau à quenouille. . . 129

Rosier toujours vert. . . 42 


\section{Pages ou planches.}

Rosmarinus offeinalis. . 80 Rubia peregrina..... 48 - tinclorum. .

Rubiacées.

Rue à grandes bractées. Ruta bracteosa.

Rutacées. 2.า. 132

Safran bàtarcl. Sain-bois .

Salsepareille d'Europe. Salsola Kali.

Salvia glutinosa.

- horminoides.

- Horminum.

- officinalis.

- pralensis.

\section{Santalacées.} Sclarea.

Sauge faux-Hormin . Scabieuse maritime.

Scabiosa atropurpurea. maritima.

Schinus Molle.

Schoenus nigricans. Scilla bifolia

- hyacinthoides

\section{- italica.}

\section{- maritima}

Scille d'Italie. Scolymus hispanicus Scrofulaire voyageuse. Scrophularia aquatica. canina. lucida. nodose

Scrofularinées . peregrina.

Sedum acre.

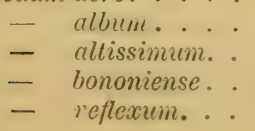

134

126

115

110

115

$11 j$ 115

$6 \pi$

8.3

83

รอั

S5

85

Sอั

S4

$4 \pi$

47
Pages ou planches.

- sexangulare. . 47 Séné bâtard ..... 33 - des Provençaux. . $\quad 92$ Serapias Lingua. . . 123 Silénacées . . . . . 16 Silene ilalica . . . . . 13 - noctiflora ... 16 - nocturna. . . . 16 - sericer. . . . . 16 Silène d'Italie. . . . . 10 ô - soyeuse . . . 16 Simarubées . . . . 28 Smilax aspera ... . 10ú Sophoracées . . . . 31 Sorghum Caffrorum . . 128 - saccharatum. 128 Spartium junceum . . . $3 ̈$ Statice pubcscens . . . . 93 Stenactis bellidiflora . . 7 Térébinthacées. . . . 99 Teucrium Bolrys. . . 81 - Marum .. 81 - montanum. . 81 - Polium ... 81

Théligonacées . . . 96 Théligone étalé. . . . 96 Theligonum Cynocrambe $\quad 96$ Thérébinthier. . . . 30 Thym ...... . . 78 Thyméléacées . . . . 9T Thymus vulgaris . . . . 78 Trèfle étoilé . . . . . 37 Tribulus terrestris . . . 23 Trifolium angustifolium. 37 - stellatum... 37 Tue-chèvres .... . 40 Tulipa Clusiana ... 108 - maleolens... 107 - Oculus solis... 107 - praceox.... 107 Tulipe de l'Ecluse. . . 108 - prícoce... 107 


\section{$-160$}

\section{Pages \\ ou planches.}

Turbith blanc.... . 92

Umbilicus pendulinus. . 46

Urospermum Dulechampsii 61

Verbénacées . . . . 77

picroides.
Pages

ou planches.

Viburmum Tims. 50

Violette de Marie . . 68

Filcx Agrus-caslu: . . 77

Ianthium spinosum. . . 69

61 Zostera marina. ... . 124

50 Zygophyllacées ... 23 


\section{TABLE GÉNÉRALE}

Préf.ce. . . . . . . . . . . . . . . . v Notices explicalives des planches . . . . . . . 1 à 144

Table des noms allemands des espèces figurées. . 146

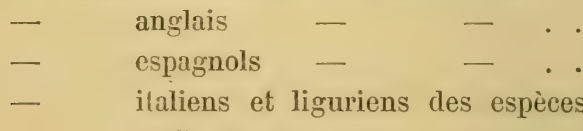

figurées. . . . . . . . . 149

- provençaux des espèces figurées . $\quad 131$

- français et latins des familles et des espèces figurées ou citées . $\quad 103$

Table générale . . . . . . . . . . . . 161

Paris. - J. Mersch, imp., 4 bis, avenue de Chàtillon. Paris. - Chromotypographie Draeger.

Paris. - Photogravure A. Barret. 


\section{Atlas}

\section{des
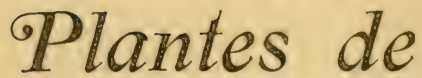 \\ France}

UTILES, NUISIBLES ET ORNENIENTALES

4OO PLANCHES COLORIÉES

REPRÉSENTANT 450 PLANTES COMMUNES

avec de nombreuses figures de détail

\section{ET UN TEXTE EXPLICATIF DE LEURS PROPRIÉTÉS ET USAGES}

EN MÉdECINE, AGRICULTURE, HORTICULTURE

DANS L'INDUSTRIE, L'ÉCoNOMIE DOMESTIQUE, ETC.

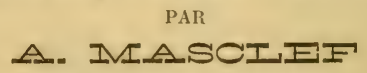

Lauréat de l'Institut.

Un volume de texte de 368 pages gr. in- $8^{\circ}$, broché, et 400 planches renfermées dans deux cartons, dos toile. . . . Prix : $60 \mathrm{fr}$. Le même, cartonné toile pleine, les planches montées sur onglets. .............. - $70 \mathrm{fr}$

Le même avec reliure demi chagrin, très soignée, les planches montées sur onglets en papier parcheminé. - $80 \mathrm{fr}$.

Les 400 planches de cet ouvrage représentent avec leurs couleurs et en grandeur naturelle 450 plantes de France communes et très répandues.

Ces planches sont imprimées en 20 à 25 teintes inaltérables et mesurent $16 \times 23$ centimètres.

L'auteur a fait en sorte que les plantes soient en même temps prises parmi celles qui sont les plus intéressantes en médecine, agriculture, horticulture, dans l'industrie, les arts, l'alimentation et l'économie domestique, par leur's usages et applications utiles, leurs propriétés nuisibles et vênéneuses, ou comme plantes ornementales et décoratives. Quand il s'est agi des propriétés médicinales, on a évité de se servir de certains termes qui souvent empéchent de mettre les ouvrages analogues entre les mains de tout le monde.

Il est représenté et décrit avec les noms scienlifiques latins et français, et les noms vulgaires:

88 plantes alimentaires de l'homme, 179 médicinales, 182 fourragères, etc. Des tables trís détaillées rendent les recherches faciles.

Mes ouvrages de même format ne font jamais double emploi entre eux.

Le prix de l'Allus Masclef, prix inconnu jusqu'alors pour des publications de ce genre, s'explique par l'étendue et le format de l'ouvrage, mais surtout par l'exécution sans rivale des planches coloriées. 


\section{Atlas des Champignons COMESTIBLES ET VÉNÉNEUX 80 planches coloriées}

Representant 191 champignons communs en France, avec leur description le moyen de reconnaitre les bonnes et les mauvaises espèces et de nombreuses recettes culinaires

\section{Par L. DUFOUR}

Docteur ès-sciences.

Un volume in- $8^{\circ}$ dans un carton......... Prix : $15 \mathrm{fr}$. Le même, relié dlemi-chagrin, texte et planches montés sur onglets

Les livres sur les champignons sont nombreux. Mais il manquait un ouvrage avec un texte court, simple et clair, et surtout de bonnes et nombreuses figures coloriées, destiné à vulgariser l'étude de ces intéressants végétaux. C'est là le but de cet Atlas, dont le prix, comme tous ceux du même genre édités à la Librairie des Sciences naturelles, a été établi de façon à permettre aux petites bourses de se le procurer.

L'A tlas des champignons figure et donne la deseription de 95 espèces comestibles et de 96 espèces suspectes ou vénéneuses.

Les planches sont tirées avec le plus grand soin en 15 à 18 couleurs ou teintes et mesurent 16 sur 23 centimètres.

\section{Atlas des Algues Marines} les plus répandues des côtes de France

\section{PLANCHES TIRÉES EN COULEUR}

Représentant 110 espèces d'Algues faciles à récolter, avec leur description et les moyens de les préparer et de les conserver

\section{Par Paul HARIOT}

Lauréat de l'Institut.

Planches et texte renfermés dans un joli carton, orní d'une vue des côtes de Bretagne. . . . . . . Prix: $12 \mathrm{fr}$. Le mème, relié en demi-chagrin, texte et planches montés sur onglets. $-18 \mathrm{fr}$.

Ouvrage élémentaire destiné aux personnes qui se rendent aux bains de mer et qui, après avoir réuni en jolis albums les belles plantes marines. trouvées dans la mer ou que les vagues rejettent sur les cótes, désirent aussi en connaître le nom. 


\section{Traité}

\section{des Arbres et Arbrisseaux}

FORESTIERS, INDUSTRIELS ET D'ORNEMENT

Cultivés ou exploités en Europe et plus particulièrement en France

DONNANT LA DESCRIPTION BT L'OTILISATION D'BNVIRON 2400 ESPĖCES ET 2000 VARIÉtÉS

\section{Par P. MOUILLEFERT}

Professeur de sylviculture à l'École nationale d'Agriculture de Grignon.

Un volume de texte de 1403 pages, grand in-8 broché en deux tomes, et 190 planches dont 40 colorićes, renfermées dans un carton dos toile....... Prix : $70 \mathrm{fr}$.

Le même, reliure demi-chagrin, très soignée, les planches montées sur onglets en papier parcheminé.... - $85 \mathrm{fr}$.

Seul ouvrage moderne français sur ce sujet; scientifique et pratique à la fois, il est indispensable aux pépiniéristes, aux forestiers, aux propriétaires de grands parcs et à tous les amateurs désireux de connaittre nos espèces ligneuses, leur culture et leurs emplois.

La valeur de ce livre est constituée par le texte. Le sujet a été agrémenté par l'addition de 144 planches noires donnant le port des arbres et 40 planches coloriées représentant, avec des figures de détail, de beaux types d'espèces répandues mais rarement figurées.

La Flore et la Végétation de la France avec une carte de la distribution des végétaux en France par Cri. Flahault, Professeur ì l'Université de Montpellier.

Forme l'introduction de la Flore descriptive et illustrée de la France par l'abbé H. Coste et ne peut être obtenu séparément. (Voir pages 12-13). 


\section{$-5-$}

\section{Dictionnaire}

\section{d'Horticulture ILLUSTRE}

de 909 figures dans le texte, dont 403 en couleur et 6 plans coloriés hors texte

\section{Par D. BOIS}

Assistant au Muséum d'Histoire naturelle

en collaboration avec de nombreux spécialistes.

\section{Préface par Maxime CORNU}

Professeur au Muséum

Deux volumes grand in-8 $8^{\circ}$ de 1228 pages, brochés . . Prix : $40 \mathrm{fr}$. Le même, relié en deux volumes, toile pleine, avec fers

spéciaux

Le mème, relié en un volume, demi-chagrin .... - $45 \mathrm{fr}$.

Le Dictionnaire d'Horticulture, ouvrage pratique et entièrement original, s'adresse aussi bien aux jardiniers qu'aux amateurs et gens du monde n'ayant que peu ou pas de connaissances horticoles.

Les plantes de plein air et de serres, les arbres fruitiers ou d'ornement, les légumes sont traités avec tous les développements qu'ils comportent.

Plus de 25 spécialistes autorisés traitent, chacun en ce qui le concerne, les opérations culturales, la greffe et la taille des arbres, le chauffage des serres, les questions d'engrais, l'outillage horticole, les maladies des plantes, les insectes et autres animaux nuisibles ou utiles au jardin. Chaque auteur signe ses articles.

Les figures, dont près de moitié en couleur dans le texte mème, ont été choisies de préférence parmi celles qui ne se trouvent pas dans mes divers Atlas. 


\section{$-6-$ \\ Tlanuel}

\section{de Géographie Botanique Par le Dr OSCAR DRUDE}

Directeur du Jardin Royal Botanique de Dresde, Membre de la Société Botanique de France Traduit par Georges POIRAULT et revu et augmenté par l'Auteur

Un fort rolume de 5วכ0 pages grand in- $8^{\circ}$, accompagné dle 4 cartes en coulcur, cartonné, toile pleine ........ Prix : $18 \mathrm{fr}$.

Ce livre est un résumé de l'état présent de nos connaissances en géograpłice botanique, résumé largement tracé, susceptible, par conséquent, d'intéresser bien des lecteurs que rebuteraient des ouvrages plus détaillés. De nombreuses indications bibliographiques permettent de remonter aux sources et d'étudier les questions particulières. L'auteur a ajouté de nombreux compléments donnant ainsi à la traduction une valeur nouvelle.

\section{CAtlas des Plantes}

\section{MÉDICINALES ET VÉNÉNEUSES DE FRANCE}

\section{PLANCHES COLORIÉES}

\section{Extraites de a l'ATLAS DES PLANTES DE FRANCE ,}

Avec un texte nouveau indiquant les propriétés médicinales de plus de lö0 plantes, leur mode d'emploi, leurs doses, etc.

Par H. ROUSSEAU, Docteur en médecine, et A. MASCLEF, Lauréat de l'Institut Un vol. grand in- $8^{\circ}$ de 128 pages et 137 planches colo-

riées, le tout monté sur onglets, cart. toile pleine. Prix : $25 \mathrm{fr}$. * Le texte seul, broché. ........... - 2 fr. 50

Nous avons cxtrait de l'Atlas des Plantes de France toutes les plantes médicinales, en y ajoutant un texte nouveau qui explique le mode d'emploi et les doses de ces plantes, indications qui ne pouvaient trouver place dans le texte de M. Masclef.

Texte et planches sont classés par ordre alphabétique, d'après les noms francais. Le texte est complété par des descriptions de quelques plantes intéressant la pharmacie et qui, dans l'ouvrage principal, n'ont pu être figurées.

Une table donnant la.classification des plantes d'après leurs propriétés médicinales termine l'ouvrage. 
TABLEAU DES PRIMCIPAUX CHAMPIGNOHS COMESTIBLES \& VENENEUX

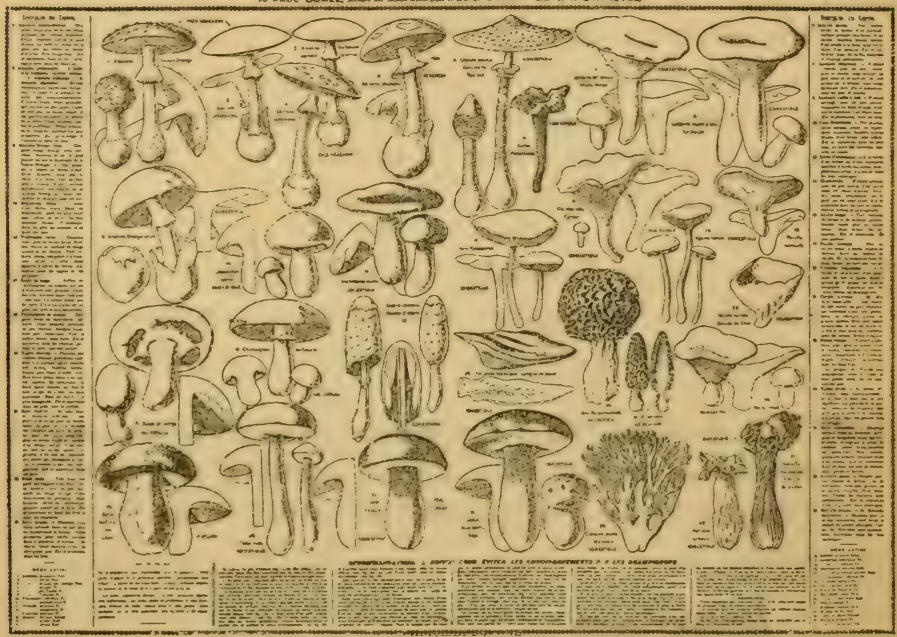

\section{Tableau (colorié)}

des

\section{Principaux Champignons Comestibles et Vénéneux Par Paul DUMÉE}

Membre des Sociétés mycologique et botanique de France, Pharmacien.

Ce tableau, imprimé en 8 couleurs, est d'une scrupuleuse exactitude et préviendra bien des accidents dus autant à l'ignorance qu'a l'imprudence. Il cst surtout destiné à étre fixé au mur. Les personnes désireuses de le mettre en poche peuvent se le procurer plié, renfermé dans un cartonnage souple.

Prix rlu Tahleau, mesurant $50 \times 6 i^{\mathrm{cm}}$ à plat.

$1 \mathrm{fr}$. " net. expédié par la poste au lour d'un rouleau. 1 fr. $20-$ plié, dans un cartonnage souple. . . 1 fr. $35-$ le même, expédié par la poste . . . 1 fr. 45 -

Les dimensions réelles du Tableau sont environ 55 fois celles de la réduction figurée ci-dessus. 
LLOYD (J.). - Flore de l'Ouest de la France (Charente-Infér.,

Deux-Sèvres, Vendée, Loire-Infér., Morbihan, Finistère, Côtesdu-Nord, Ille-et-Vilaine). $4^{e}$ édition augmentée des plantes de la Gironde, des Landes, et du littoral des Basses-Pyrénées, par J. Foucaud. Un volume in-18 de 326 pages, broché. Occasion (au lieu de 7 fr., franco) . . . . . 5 fr.

GAUTIER (G.). - Catalogue raisonné de la flore des Pyrénées-Orientales. Introduction par Ch. Flamault. Un volume in-8 $8^{\circ}$ de 591 pages, broché.

BATTANDIER ET TRABUT. - Flore de l'Algérie contenant la description de toutes les plantes signalées jusqu'à ce jour comme spontanées en Algérie, et Catalogue des plantes du Maroc.

Premiere partie :

Tome I. - Dicotylédones. Un fort vol. gr. in- $8^{\circ}$ de 875 pages. 20 fr. Tome II. - Monocotylédones. Un vol. gr. in-80 de 2006 pages. . $\quad 7$ fr.

\section{Deuxième partie :}

Fascicule I. - Catalogue des Lichens de l'Algérie, par C. Flager. Catalogue des Algues du Maroc, de l'Algérie et de la Tunisie, par F. Debray. Catalogue des Diatomacées du Maroc, de l'Algérie et de la Tunisie, par P. Petr. Un rol. gr. in- $8^{\circ}$ de 281 pages . . 7 fr.

- Atlas de la Flore d'Algérie. - Iconographie avec diagnoses d'espèces nouvelles, inédites ou critiques de la Flore Atlantique; Phanérogames et Cryptogames acrogènes.

Fasc. I. - Grand in- $8^{\circ}, 16$ pages, 11 planches . . . . . 4 fr'. Fasc. II. - Grand in- $8^{\circ}, 17$ pages, 12 planches. . . . . . 6 fr. 


\section{INDEX GENERUM PHANRROGAMORUM}

LSQUE AD FINEM 1887 PROMULGATORUM IN BENTHAMI ET HOOKEBI “ GENERA PLANTARUM »

FUNDATUS CUM NUMERO SPECIERUM SYXONYMS ET AERA GEOGRAPHICA

Par Th. DURAND

Directeur du Jardin Botanique de l'État à Bruxelles.

Un fort volume grand in-80 de 722 pages. . . . . . . . $25 \mathrm{fr}$.

Seul ouvrage d'ensemble, d'un format réduit, sur la flore ru globe; indis. pensable pour le classement d'un herbier.

\section{PLANTAE EUROPEAE}

ENUMERATIO SYSTEMATCA ET SYNoNyMICA PLANTARUM PHANEROGAMICARUM

IN ELROPA SPONTE CRESCENTIUM VEL IERE INQUILIXARUM

\section{Par le $\mathrm{D}^{\mathrm{r}} \mathrm{K}$. RICHTER}

Yol. I. Gymnospermes et Ionocotylédlones, gr. in-8 $8^{\circ}, 378$ p. 12 fr. 50 Vol. II. Fasc. 1 et 2. Dicotylédones, gr. in $-8^{\circ}, 320$ p. . . . 12 fr. 50

Formera \&́ volumes; $M$. Richter étant décédé, les volumes II à IV seront publiés par M. le $D^{\mathrm{r}}$ M. Gürke. Les Plantæ Europeæ, remarquables par leur impression claire et de bonnes tables, donnent, outre des indications bibliographiques pour toutes les espèces et tous les synonymes, la distribution géographique de chacune.

C'est actuellement le seul ouvrage d'ensemble pour la Flore d'Europe.

JADIN (F.). - Du siège des principes médicamenteux dans les végétaux. Étude histochimique, 1894, gr. in-8, 154 p. (Complément de tous les traités de Pharmacologie). 4 fr.

HUSYOT (T.). - Le dessin d'histoire naturelle sur papier, pierre lithographique, bois et divers papiers pour photogravures, avec figures dans le texte, spécimens de papiers, lithographies et gravures, adresses et prix de fournisseurs et de graveurs. Un volume in-8 $8^{\circ}$ de 80 pages et 6 planches noires. . . $2 \mathrm{fr} .50$

\section{Utile ì tous les naturulistes.}

Librairie Paul Klincksieck. Rue Corneille, 3, Paris. 


\section{Catalogue systématique des}

\section{Zoocécidies \\ de l'Europe}

et du bassin méditerranéen

G. DARBOUX

Maitre de Conférences de Zoologie

à l'Université de Lyon.
PAR

C. HOUARD

Préparateur de Botanique à l'Université de Paris.

Un fort volume de $\$ 60$ pages gr. in- $\varsigma^{\circ}$ avec $\$ 63$ figures dans le texte. Prix ................. $30 \mathrm{fr}$.

Les Desmidiées

\section{de France}

\section{Par J. GOMERE}

Pharmacien de $1^{\text {ro }}$ classe

Membre de la Société Botanique de France

Un rolume grand in- $8^{\circ}$ de 224 pages, avec 16 planches colorićes.

Prix ................ . $20 \mathrm{fr}$.

\section{INDEX BRYOLOGICUS}

ÉNUMÉRATION DES MOUSSES CONNUES JUSQU'A CE JOUR AVEC LEUR SYNONYME ET LEUR DISTRIBUTION GÉOGRAPHIQUE

\section{Par E.-G. PARIS}

Un fort volume de 1400 pages grand in-So broché. . . . . . 55 fr.

L'ouvrage est entièrement rédigé en latin et par ordre alphabitique. Un prospectus détaillé sera envoyé sur demande. 
PATOUILLARD (N.). - Les Hyménomycètes d'Europe. Anatomie générale et classification des champignons supérieurs. Un vol. in- $8^{\circ}$ de 166 p. avec 128 fig. sur 4 pl. Prix : 6 franes. Ouvrage s'adressant aux amateurs possédant un microscope grice auquel on arrive plus surrement à une délermination exacte des espéces.

COSTANTIN (J.). - Les Mucédinées simples. Histoire, classification, culture et rôle des champignons inférieurs dans les maladies des végétaux et des animaux. Un volume in- $8^{\circ}$ de 210 pages avec 190 figures. . . . . . . Prix : 6 francs.

Étude d'ensemble sur les moisissures. L'emploi du microscope est intispensable.

LAPLANCHE (M.-C. de). - Dictionnaire iconographique des Champignons supérieurs (Hyménomycètes) qui croissent en Europe, Algérie et Tunisie, suivi des tableaux de concordance (pour les Iyménomycètes) de Batsch, Bulliard, Kirombholz, Letellier, Paulet, Persoon, Scheffer, Sowerby, etc. Un volume in-12 de 542 pages. . . Prix : 10 franes.

Basé sur la classification de Fries, complétée par les auteurs modernes, ce ouvrage donne par ordre alphabétique l'indication précise des planches et figures des ouvrages oí toutes les espéces ont été reprèsentées.

L'auteur y a ajouté, sous forme de tableaux, la clef des noms des espèces figurées dans les iconographies les plus importantes, antérieures à Fries.

GRAMONT DE LESPARRE (A. de). Étude sur la reproduction sexuée de quelques Champignons supérieurs. 1902. gr. in- $8^{\circ}, 80$ pages, avec 16 figures dans le texte et 3 planches coloriées . . . . . . . . . . Prix : 5 francs. Plus de la moilie de l'ourraye est consacrée aux Truffes. HÉRIBAUD (J.). - Les Diatomées d'Auvergne. 1883, gr. in-8, 250 pages, 2 planches. . . . . . . . Prix : 12 francs.

Ouvrage couronné par l'Académie des siciences.

- Les Diatomées fossiles d'Auvergne, 1902, gr. in- $\AA^{\circ}$, 79 pages, avec 2 planches représentant environ 40 espèces nouvelles. . . . . . . . . . . Prix : 5 francs. 


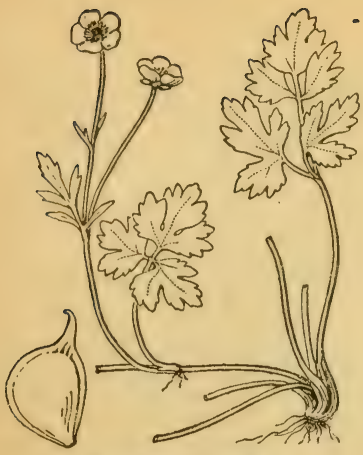

Ranunculus repens

En sov

\section{IL A PARU $\{$ Le vo \\ Flore descrip \\ de la}

\section{de la Corse et des}

Par l'Abbi

Membre honoraire de la

Cet ouvrage, absolument nouveau comme fonds et comme fo profession et simples amateurs. Ces dernier's y trouveront un vocabul simples que clairs. En dehors des noms latins des espèces, l'auteur ina ou usages. Mais ce qui constitue le principal charme de la Flore CO description - des 4000 espèces de nos plantes indigènes. Ces figure. toutes originales et spécialement dessinées pour la Flore COSTE.

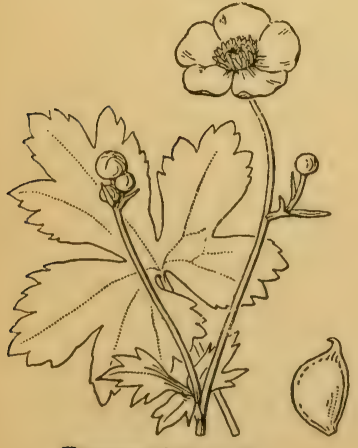

Ranunculus acris
Cet ouvrage paraîtra en fascicules de 1 formeront un volume. L'époque d'appari à l'avance, mais des dispositions ont achevée en 1904.

Le prix des trois volk

Jusqu'à ce que la publication soit tern m'envoyant le montant d'avance et en un

à $\mathbf{5 0}$ francs jusqu'à l', à $\mathbf{5 5}$

Demander un $p$ Aucun fascicule n'e La souscription 
1, complet.

II, fasc. $1,2,3$.

\section{e et illustrée}

\section{zance}

atrées limitrophes GOSTE

Botanique de France.

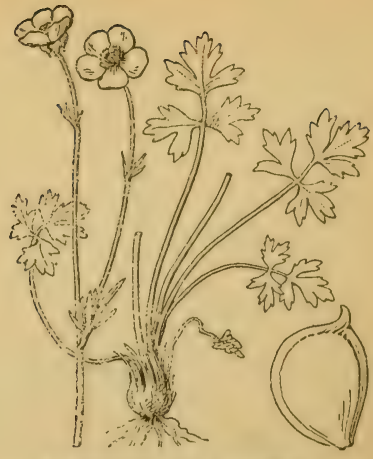

Ranunculus bulbosus

s'adresse à tous ceux qui s’intéressent aux plantes : botanistes de llustré de 450 figures et de nombreux tableaux analytiques aussi les noms francais, quand il en existe, et succinctement les propriétés ce sont les figures - toutes placées en marge en regard de leur blables ì celles dont nous donnons ici quatre reproductions, sont

60 pages gr. in- $8^{\circ}$, dont trois ou quatre e chaque fascicule ne peut être fixée prises pour que la publication soit

\section{est de 60 francs.}

ce prix est réduit pour les personnes avec leur souscription :

ement $d u$ volume II.

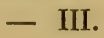

tus détaillé.

endu séparément. obligatoire.

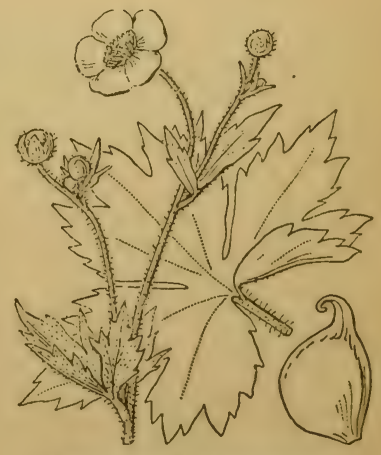

Ranunculus lanuginosus 
HÉRIBAUD (J.). - Les Muscinées d'Auvergne. 1899, gr. in- $8^{\circ}, 344$ pages . . . . . . Prix : 15 francs.

OLIVIER (II.). - Flore analytique et dichotomique des Lichens de l'Orne et des départements circonvoisins. 2 parties avec supplément. 1892 , in- $8^{\circ}, 344$ pages, 2 planches n. et col............ Prix : 12 francs.

Les renseignements pour la récolte, préparation et conservation des Lichens donnent à ce livre un intérêt plus général.

- Exposé systématique et description des Lichens de l'Ouest et du Nord-Ouest de la France (Normandie, Bretagne, Anjou, Maine, Vendée).

Vol. I, 1897, grand in- $8^{\circ}$, xxxiv-3̈3̈ pages . Prix : 10 fr. " "Supplément 1900, grand in- $8^{\circ}$, 32 pages . . . - $2 \mathrm{fr}$. " Vol. II, fasc. I, 1900, grand in- $8^{\circ}, 86$ pages. . . . - 2 fr. 50 " $\quad$ II, 19C1, grand in- $8^{\circ}, 90$ pages . . . 2 fr. 50 " $\quad$ III, 1902, grand in- $8^{\circ}, 97$ pages . . . - 2 fr. 50

LUGET (E.). - Les Insectes nuisibles aux Rosiers sauvages et cultivés en France. - Descriptions et mœurs. Dégâts. Moyens de destruction. 2 édition revue et augmentée. 1900, in-8 $8^{\circ}, 390$ p. 13 pl. noires . . . . Prix : 7 francs.

COSSilanN. - Catalogue illustré des Coquilles fossiles de l'Eocène des environs de Paris, faisant suite aux travaux paléontologiques de Desmares. 1896, 3 parties avec supplément et $\mathbf{2}$ appendices. En tout 7 fascicules, grand in- $8^{\circ}$, de $\mathbf{1 3 8 2}$ pages avec 46 planches . . . . Prix : 75 franes.

Cet ouvrage énumère toutes les espèces décrites par Deshayes et toutes celles découvertes depuis. Une table générale facilite les recherches.

Librairie Paul Kinncrsieck. Rue Corneille, 3, Paris. 
BOULAY (N.). - Études sur la distribution géographique des Mousses en France, au point de vue des principes et des faits. 1877, gr. in-8n, 239 p. . . . Prix : 3 franes.

- Muscinées de la France. I. Mousses. 1884, gr. in-8, clxxiv-624 p. . . . . . . . Prix : 15 francs. Le tome II (Hejpatiques) paraitra vers maı 1903. On peut s'inscrire dès maintenant pour le recevoir.

- Flore pliocène du Mont-Dore (Puy-de-Dôme). 1892, grand in $-4^{\circ}, 113$ pages, 10 planches arec de nombreuses figures dans le texte . . . . . . Prix : 15 francs.

- Muscinées (Mousses, Sphaigrnes, Ilépaliques) de l'Est de la France. 1872. gr. in- $8^{\circ}$, xII-880 pages. Prix : 10 francs.

-- Flore fossile de Gergovie (Puy-de-Dòme). 1899. gr. in-8 ${ }^{\circ}$, 83 pages, 10. planches. . . . . . Prix : 6 fr. 50

HUSNOT (T.). - Hepaticologia Gallica. Flore analytique et descriptive des IIépatiques de France et de Belgique. 1873̈-81. in-8 $8^{\circ}, 102$ p. $13 \mathrm{pl}$. . . . . . Prix : 10 fr. 50

- Flore analytique et descriptive des Mousses du Nord-Ouest de la France (env. de Paris, Normandie, Bretagne, Anjou, Maine), $2^{\circ}$ éd., contenant un traité élémentaire de Bryologie avec 10 échantillons et 84 figures. 1882, in-8, 173 p. 4 pl. . . . . . Prix : 5 franes.

Sphagnologia Europæa. Descriptions et figures des Sphaignes de l'Europe. 1882, gr. in-8", 16 p. 4 planches.

Prix : 3 franes.

- Muscologia Gallica. Descriptions et figures des Mousses de France et des contrées voisines. 2 rol. 1884-94, gr. in-8 ${ }^{\circ}$, 470 p. 125 planches.

Prix : 50 francs. 
HUSNOT (T.). - Descriptions, figures et usages des Graminées spontanées et cultivées de France, Belgique, Iles britanniques, Suisse. 1896-99, in-4 ${ }^{\circ}, 100 \mathrm{p}$. 33 pl. représ. 350 espèces. . . . . . . Prix : 25 francs.

BROGARD (E.). - Manuel de Taxidermie ou l'art d'empailler les oiseaux. 1889, in-8 $8^{\circ} 47$ pages et 2 grands tableaux contenant les figures des diverses opérations préparatoires pour le montage des pièces et 22 phototypies représentant les phases de la levée de la peau et du montage prises sur nature.

Prix : 3 francs.

LEPRIEUR (C. E.). - Chasse aux Coléoptères. Formation. entretien et conservation des collections de Coléoptères. 1887, gr. in-8 ${ }^{\circ}, 64$ pages.

Prix : 2 francs.

FAUCONNET (L.). - Faune analytique des Coléoptères de France, avec 2 suppléments. 1892, gr. in- $8^{\circ}, 536$ p. 15 fr. 50

- Genera des Coléoptères de France. 1894, grand in-8 ${ }^{\circ}$, 84 pages.

Prix : 5 franes.

- Notions élémentaires d'anatomie externe des Coléoptères et vocabulaire de tous les termes employés en entomologie pour l'étude spéciale de ces insectes. Conseils sur leur chasse, leur préparation et la formation d'une collection. 1897-98, in-8 $8^{\circ}, 40$ pages. . . Prix : 2 francs.

BRUYANT ET EUSÉBio. - Faune de l'Auvergne. Monographie des Carabides et des Cicindélides, 1902, gr. in-8, 260 pages et 11 planches, comprenant 390 figures. . Prix : $12 \mathrm{fr}$. 
 \\ Bibliothèque de Poche du Naturaliste}

La BIBLIOTHĖQUE DE POGHE DU NATURALISTE, inaugurée en mai 1894 par l'Atlas des Plantes des champs, des prairies et des bois, s'est rapidement fait une place à part parmi tant d'ouvrages destinés à vulgariser les connaissances en histoire naturelle.

Le plan adopté pour ces volumes peut se résumer ainsi :

$1^{\circ}$ Emploi de grandes figures coloriées, représentant les sujets les plus répandus que tout le monde peut rencontrer;

$2^{\circ}$ Format très portatif (celui de ce catalogue);

$3^{\circ}$ Texte intéressant, mis à la portée de tout le monde par l'emploi de termes simples, non savants ;

$4^{\circ}$ Disposition de ce texte en regard des planches;

$5^{\circ}$ Exécution très soignée;

$6^{\circ}$ Prix très réduits.

Les volumes de la Bibliothèque de Poche renferment en tout :

1310 planches coloriées et

124 - noires, représentant :

1041 espèces de plantes

1091 - d'animaux.

Il n'existe nulle part ailleur's une collection analogue offrant pour une somme aussi modique une pareille profusion de planches coloriées.

Voir pages 18 et suivantes les tilres des volumes publiés. La collection sera augmentée annuellement d'un ou deux volumes concus dans le même esprit. 


\section{BIBLIOTHEQUUE DE POCHE DU NATURALISTE}

Ces volumes se vendent cartonnés toile pleine, souple, coins arrondis, tranche rouge; ils n'existent pas brochés.

I. Atlas de poche des Plantes des champs, des prairies et des bois, à l'usage des promeneurs et des excursionnistes. Série I, $4^{\mathrm{e}}$ Édition. 128 planches coloriées et 23 planches noires représentant 181 plantes ou arbres communs en France avec 162 pages de texte par R. SIÉLAIN. Cartonné. . . . . Prix : $6 \mathrm{fr} .50$ Chaque planche indique l'endroit ou se trouve la plante, son époque de foraison, ses noms habituels, français, latin et celui de la famille. Les plantes sont classées par ordre de floraison.

V. Atlas de poche des Plantes des champs, des prajries et des bois, à l'usage des promeneurs et des excursionnistes. Série II. $2^{\mathrm{e}}$ Édition. 128 planches coloriées et 23 planches noires représentant 154 plantes ou arbres communs en France avec 162 pages de texte par R. SIÉLAIN. Cartonné. . Prix : $6 \mathrm{fr} .50$ Quoique indépendant du premier volume, il lui fait suite et le complète.

Les plantes figurées dans les deux volumes ne représentent que des espèces de pays peu accidentés. La Série II renferme un certain nombre d'espèces du littoral.

\section{Atlas de poche des Plantes des champs, des prairies} et des bois, à l'usage des promeneurs et des excursionnistes. Série III. 128 planches coloriées représentant 129 plantes communes en France avec 154 pages de texte par R. SIÉLAIN. Cartonné. . Prix : 6 fr. 50

La Série III, parue fin avril 1899, contient une Table générale des 3 séries. On y trouve des renseignements pour la formation d'un herbier.

Ce volume contient encore des espèces répandues partout, pouvant intéresser le promeneur et l'excursionniste. Il n'y a aucun double emploi dans les 3 séries; l'une complèle l'autre. Au total, 389 espéces herbacies et 75 espèces ligneuses sont représentées dans les 3 volumes.

Puur les plantes des monlagnes, voir Flore coloriée, par CORREVON.

Ces ouvrages n'exigent aucune connaissance en botanique. 


\section{BIBLIOTHĖQUE DE POCHE DU NATURALISTE}

II. Flore coloriée de poche à l'usage du touriste dans les montagnes de la Suisse, de la Savoie, du Dauphiné, des Pyrénées, de l'Auvergne, des Cévennes, du Jura et des Vosges. 2 Édition améliorée. 144 planches coloriées représentant 181 plantes, avec un texte donnant la description de 480 espèces non figurées, par H. CORREVON, Directeur du Jardin alpin d'acclimatation à Genève. Cart. . Prix : 6 fr. 50

Chaque planche indique l'endroit, la nature du terrain et l'altitude auxquels se trouve la plante, ses noms habituels français et latin, allemand ct anglais et le nom de la famille. Cet ouvrage convient pour tous les pays de montagne.

\section{Petit Atlas de poche des Champignons de France} les plus répandus, comestibles ou vénéneux. $2^{\text {e }} \dot{E} d i$ tion. 36 planches coloriées représentant 37 espèces presqu'en grandeur naturelle, accompagnées d'un texte explicatif comprenant des recettes culinaires, par Paul DUMÉE, Membre des Sociétés mycologique et botanique de France, Pharmacien. Cartonné. Prix : $4 \mathrm{fr}$.

Chaque planche indique l'endroit et l'époque auxquels on peut récolter le champignon, ses noms habituels français et latin, ses dimensions et s'il est comestible ou vénéneux. Dans le texte, l'auteur s'applique à bien faire ressortir les caractìres saillants à observer pour éviter toute confusion.

" En fait de champignons, mieux vaut en connaitre peu, mais bien, que beaucoup et mal., 


\section{BIBLIOTHÉQUE DE POCHE DU NATURALISTE}

IV. Atlas de poche des Insectes de France utiles ou nuisibles, précédé d'une étude d'ensemble sur les insectes. 2 édition, 72 planches coloriées représentant 322 insectes, avec 160 pages de texte, par E. DONGÉ. Cartonné .

Prix : 6 fr. 50

Chaque planche indique les endroits oi se trouvent ces insectes, ainsi que leurs noms habituels français et latin.

VII. Atlas de poche des Oiseaux de France, Suisse et Belgique, utiles ou nuisibles, par le Baron L. D'HAMONVILLE. Série I. 72 planches coloriées et 4 planches noires représentant 70 oiseaux, 28 œufs et 4 nids, avec 160 pages de texte. Cart. Prix : 6 fr. 50

Chaque planche contient un oiseau, représenté en entier avec son œuf s'il est typique, et indique si l'oiseau est sédentaire ou migrateur, utile, nuisible ou indifférent, ses noms habituels français, populaires et latin, ainsi que celui de la famille.

IX. Atlas de poche des Oiseaux de France, Suisse et Belgique, suivi d'un catalogue descriptif complet de tous les oiseaux de ces pays, par le Baron L. D'HAMONVILLE. Série II. 72 planches coloriées et 16 planches noires représentant 85 oiseaux, 20 oufs et 4 poussins, avec 164 pages de texte. Cartonné ......... Prix : 6 fr. 50

Les 2 séries réunies contiennent 155 oiseaux, 48 aufs, 4 poussins et 4 nids. Il n'y a aucune répétition. 


\section{BIBLIOTHĖQUE DE POCHE DU NATURALISTE}

VI. Atlas de poche des Coquilles des côtes de France communes, pittoresques ou comestibles, par Pн. DAUtzenberG, suivi d'un appendice sur les Crustacés, Oursins, etc., les plus communs des plages. 64 planches coloriées et 8 planches noires renfermant 233 espèces, avec 160 pages de texte. Cartonné . . . . . . . Prix : 6 fr. 50

VIII. Atlas de poche des Papillons de France, Suisse et Belgique, les plus répandus, avec description de leurs chenilles et chrysalides et étude d'ensemble sur les papillons, par le $\mathrm{D}^{\mathrm{r}}$ PaUl GIROD. 72 planches coloriées représentant 285 papillons, avec 180 pages de texte. Cartonné. . . . . . . . . Prix : 6 fr. 50

XI. Atlas de poche des Poissons d'eau douce de France, Suisse romande et Belgique les plus répandus, suivi d'un appendice sur les Tritons, Tortues, Crustacés, Mollusques, etc., les plus communs de nos cours d'eau et étangs. 64 planches coloriées et 8 planches noires représentant 64 poissons et 30 autres animaux, avec 160 pages de texte par C. RAVERET-WATTEL, Vice-Président de la Société d'Acclimatation, Directeur de l'Établissement de Pisciculture du Nid de Verdier. Cartonné . Prix : 6 fr. 50 


\section{BIBLIOTHĖUE DE POCHE DU NATURALISTE}

XII. Atlas de poche des Plantes utiles des Pays chauds les plus importantes pour le commerce, par P. DE JANVILLE. 63 planches coloriées et 37 planches noires représentant 78 espèces et 21 vues d'ensemble, de culture ou de régétation, avec 180 pag'es de texte. Cartonné . .

Prix : 6 fr. 50

Cacao, Café, Thé, Épices, Huiles, Parfums, Textiles, Caoutchouc, Gommes, Bois, etc.

Intéresse le commerçant, les élèves des écoles commerciales et... tout consommateur.

XIII. Flore coloriẻe de poche du Littoral méditerranéen de Gênes à Barcelone, y compris la Corse, par le $\mathrm{D}^{\mathrm{r}}$ O. PENZIG, Professeur à l'Université de Gênes. 139 planches coloriées et らૅ planches noires représentant 144 plantes communes sur le Littoral, avec 170 pages de texte. Cartonné. . Prix : 6 fr. 50 
BIBLIOTHẼQUE DE POCHE DU NATURALISTE

XIV. Atlas de Poche des Fleurs de Jardins les plus faciles à cultiver, par Paul IIARIOT. 128 planches coloriées, représentant 137 plantes communes avec 190 pages de texte. Cartonné . . . . Prix : 6 fr. 50

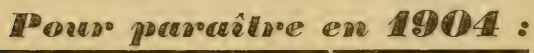

XV. Atlas de poche des Arbustes et Arbrisseaux les plus faciles à cultiver, par Paul HARIOT. 128 planches coloriées. Cartonné . . . . . Prix : 6 fr. 50 Fera suite au précédent.

\section{Atlas colorié}

des

Plantes médicinales

\section{indigènes}

144 PLANGHES EN GOULEUR REPRÉSENTANT 148 ESPÈCES

AVEG TEXTE

donnant les propriétés et emplois en médecine populaire de 364 plantes

\section{Par Paul HARIOT}

Pharmacien de $1^{\text {ro }}$ classe, Ex-Interne des Ilôpitaux de Paris.

Un fort volume in-12 de $x-291$ pages, aree 14t planches coloriées et 4 figures noires, relié toile pleine. . . . . Prix : 6 fr. 50 


\section{Table des Matières par noms d'Auteurs}

Battandier et

Trabut ... 8

Bois. ..... . 5

Boulay . . . 1 10

Brocard. . . . 16

Bruyant. . . . 16

Comère .... 10

Correvon . . . 19

Cossmann. . . 14

Costantin . . . 11

Coste ... 12.13

Darboux. . . . 10

Dautzenberg. . . 21

Dongé. .... 20

Drude. . . . . 6

Dufour .... 3 Laplanche. . . 11

Leprieur. . . . . 16

Lloyd. . . . . 8

Lucet. . . . . 14

Masclef . . . . 2.6

Mouillefert. . . 4

Olivier .... 14

Paris . . . . 10

Patouillard . . 11

Penzig . . . . 22

Poirault. . . . . 6

Hariot. . . . 3.23

Héribaud . . 11.14

Houard . . . . 10

Husnot . . 9.15.16

Jadin . . . . . 9

Raveret-Wattel . 21

Richter. . . . 9

Rousseau .... 6

Siélain .... 18

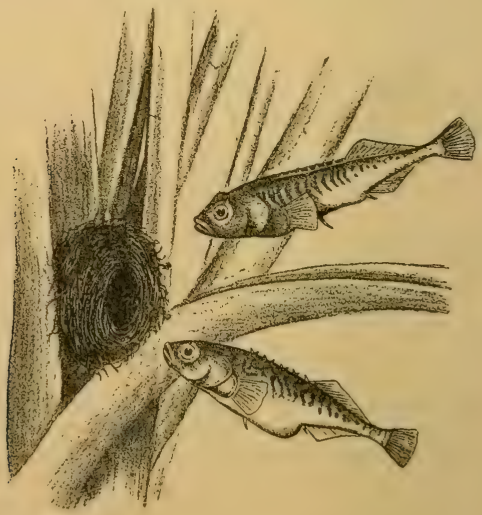

paris. - J. Mersch, imp., 4 bis, Av. de Châtillon. 


Penzig, O./Flore coloriee de poche du li

|| || || || || || || || || || ||| || ||

(I)

35185001103413 


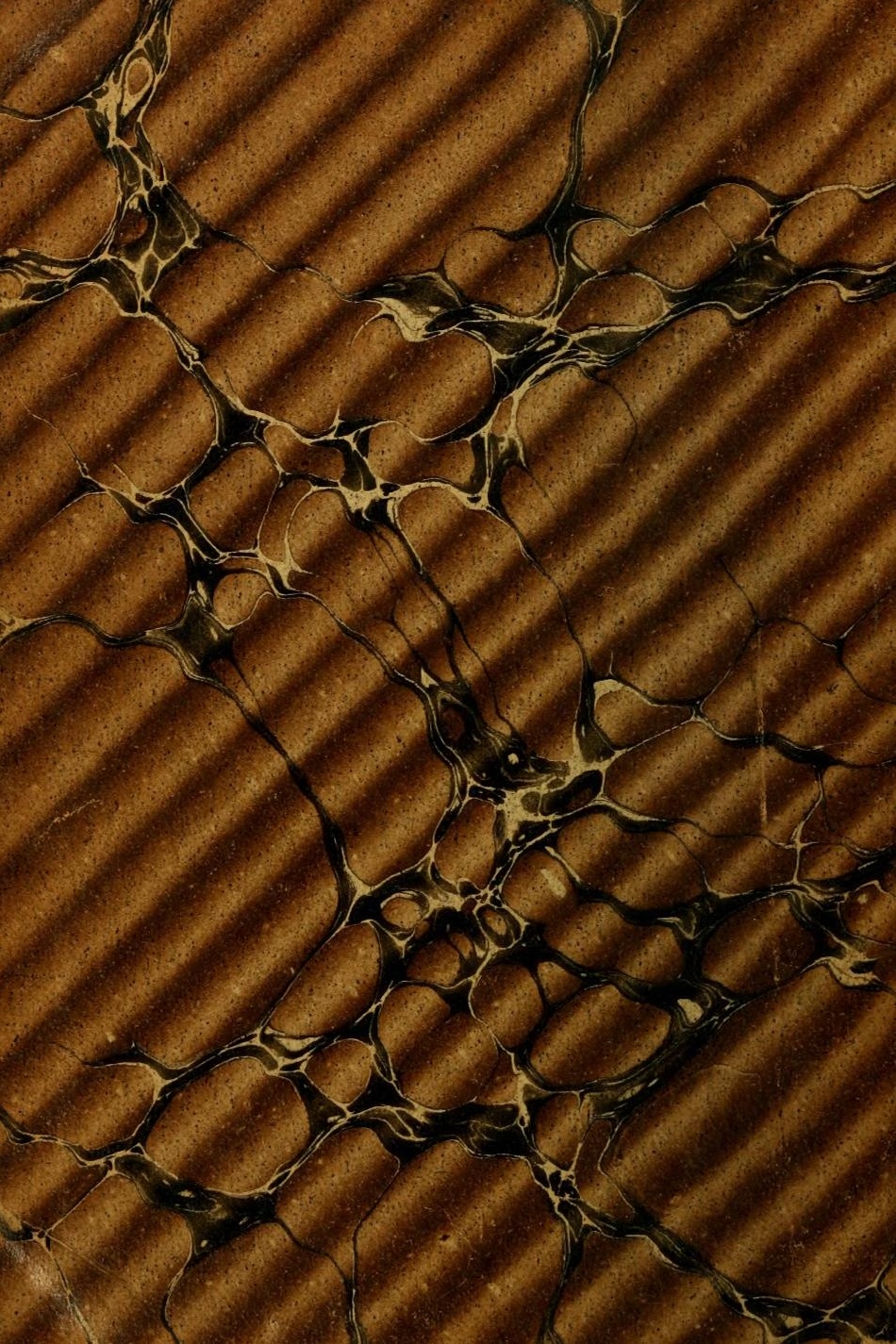




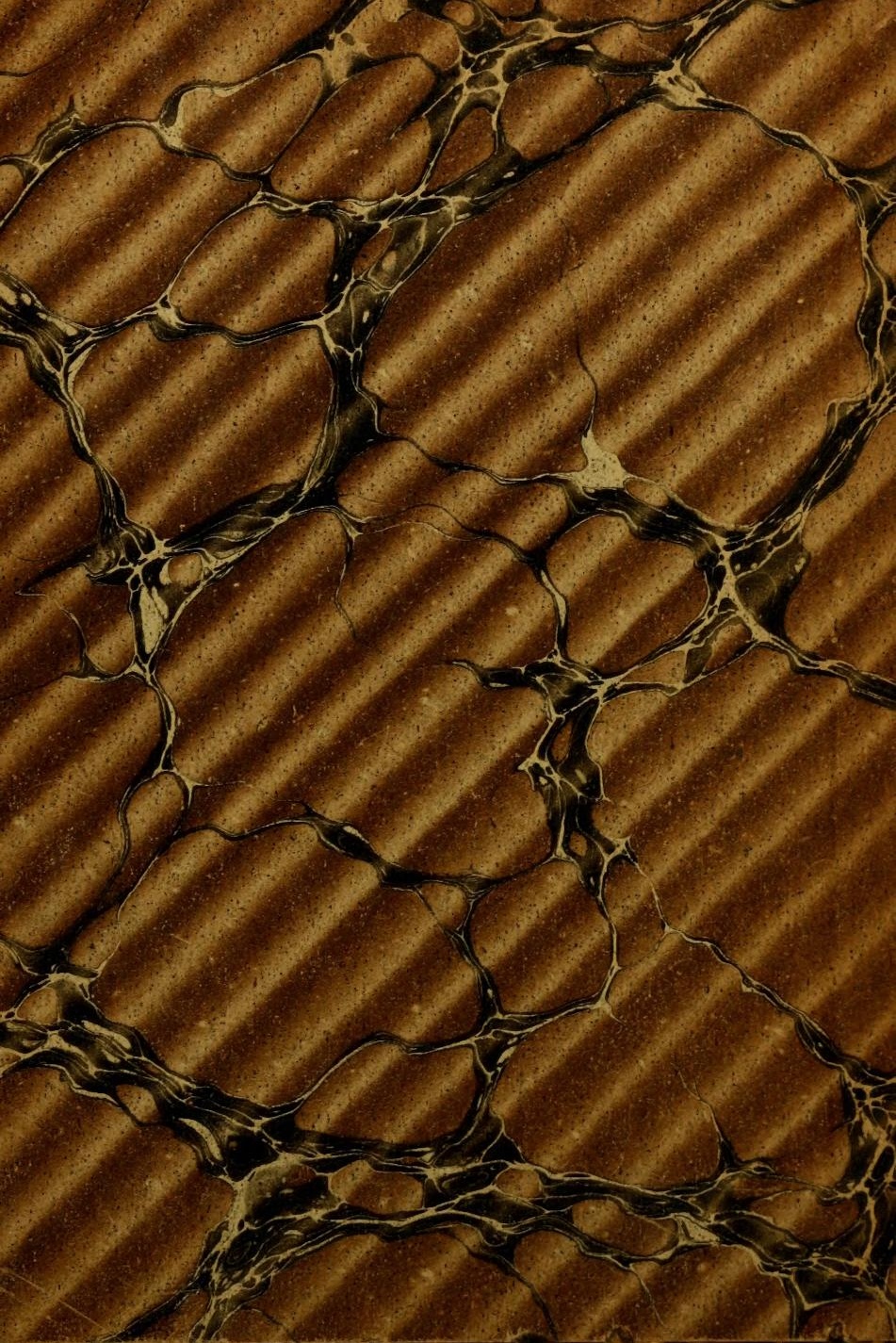


